\title{
Detection and analysis of deck cracks in a long span empirically designed bridge deck through embedded sensory systems
}

\author{
Mourad Y. Riad \\ West Virginia University
}

Follow this and additional works at: https://researchrepository.wvu.edu/etd

\section{Recommended Citation}

Riad, Mourad Y., "Detection and analysis of deck cracks in a long span empirically designed bridge deck through embedded sensory systems" (2006). Graduate Theses, Dissertations, and Problem Reports.

2735.

https://researchrepository.wvu.edu/etd/2735

This Dissertation is protected by copyright and/or related rights. It has been brought to you by the The Research Repository @ WVU with permission from the rights-holder(s). You are free to use this Dissertation in any way that is permitted by the copyright and related rights legislation that applies to your use. For other uses you must obtain permission from the rights-holder(s) directly, unless additional rights are indicated by a Creative Commons license in the record and/ or on the work itself. This Dissertation has been accepted for inclusion in WVU Graduate Theses, Dissertations, and Problem Reports collection by an authorized administrator of The Research Repository @ WVU.

For more information, please contact researchrepository@mail.wvu.edu. 


\title{
DETECTION AND ANALYSIS OF DECK CRACKS IN A \\ LONG SPAN EMPIRICALLY DESIGNED BRIDGE DECK THROUGH EMBEDDED SENSORY SYSTEMS
}

\author{
Mourad Y. Riad
}

\author{
Dissertation submitted to the \\ College of Engineering and Mineral Resources \\ at \\ West Virginia University \\ in Partial fulfillment of the requirements \\ for the degree of
}

Doctor of Philosophy

in

Civil Engineering

\author{
Samir N. Shoukry, Ph.D., Chair \\ David Martinelli, Ph.D. \\ Gergis William, Ph.D. \\ Ken Means, Ph.D. \\ Jacky Prucz, Ph.D.
Department of Civil and Environmental Engineering
Morgantown, West Virginia
2006

keywords: Instrumentation, Long-term bridge monitoring, bridge deck cracks, finite element modeling, steel-deck composite action, bridge dynamic analysis, material testing 


\begin{abstract}
DETECTION AND ANALYSIS OF DECK CRACKS IN A LONG SPAN

EMPIRICALLY DESIGNED BRIDGE DECK THROUGH EMBEDDED SENSORY SYSTEMS
\end{abstract}

\title{
Mourad Y. Riad
}

Bridge decks exhibit premature longitudinal and transverse cracks leading to dramatic decrease in their service lives. Because of safety concerns, state highway agencies are overburdened by conducting annual visual inspections to detect signs of distresses in bridge elements and to provide continuous records of the conditions of such bridges. Those inspections are time consuming, and have multiple limitations which often yield controversial outputs. In this study, an instrumentation based system is designed and implemented on the Star City Bridge near Morgantown WV, to provide more sophisticated, and accurate methods to assess the structural performance of bridge elements, and hence provide a rational method of making decisions about the condition of such bridges. The instrumentation system consists of an array of more than 750 sensors that provide continuous records of the triaxial state of strains in the concrete deck, thermal map along the deck, opening of expansion joints at the bridge ends, steel girders bending moments and shearing stresses, axial forces in the bracing members and angle of inclination of the abutments. The traffic spectrum crossing the bridge is measured via a weigh-in-motion system installed at one bridge approach and a weather station is installed at the bridge proximity. An innovative approach for deck crack detection and monitoring is established and analytical evaluation of slip strains in the deck system is presented. The study involves detailed 3D finite element modeling of the multiple phases of construction, and reasons of concrete deck cracks are explained through analysis of the dynamic properties of the superstructure. Analysis of continuous time histories along 2 years showed that bridge decks are subjected to a variety of temperature gradients across the deck system that are not accounted for in design procedures. 


\section{ACKNOWLEDGEMENTS}

I would like to express my sincere gratitude and appreciation to my research advisor Dr. Samir N. Shoukry for providing guidance and support through the entire course of this work. His help, encouragement, and meticulous efforts were unlimited and indispensable for accomplishing this study.

Sincere appreciation is also extended to Dr. David Martinelli, Dr. Gergis William, Dr. Ken Means and Dr. Jacky Prucz, for serving on my examining committee. Special thanks are extended to my colleagues and friends for their help during the course of installing the instrumentation system.

My deepest and most affectionate feelings are expressed to my parents for their love, care, support, encouragement and prayers throughout all my efforts.

The author gratefully acknowledges the financial support from the West Virginia Division of Highways that allowed this research work to materialize. 


\section{TABLE OF CONTENTS}

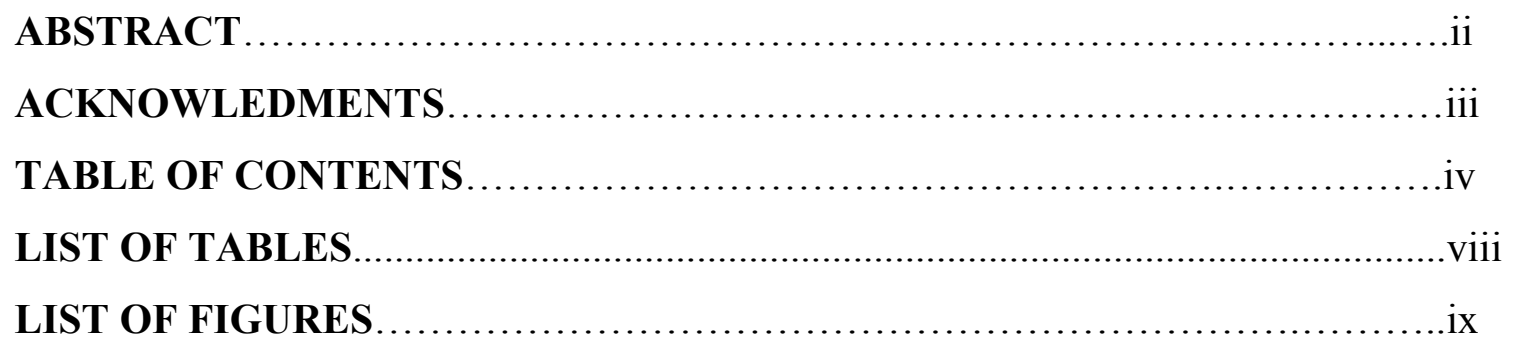

CHAPTER ONE

INTRODUCTION

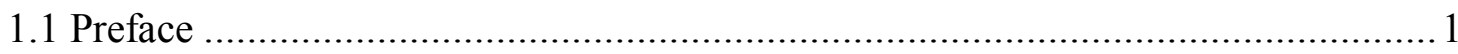

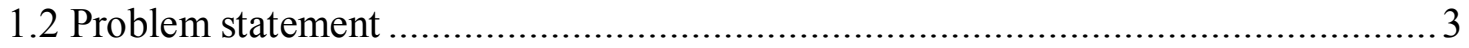

1.3 Incentive of Instrumentation based Bridge Health Monitoring ............................. 4

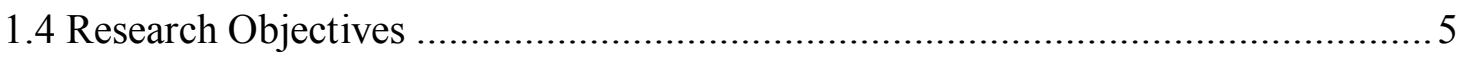

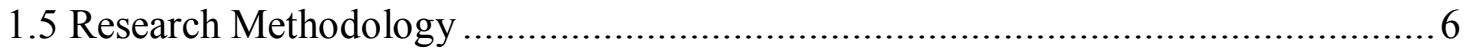

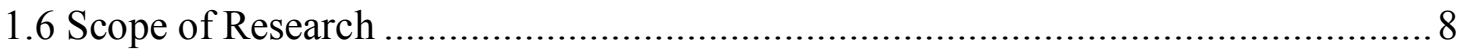

\section{CHAPTER TWO LITERATURE REVIEW}

2.1 Literature review on bridge instrumentation for Long-term monitoring ................ 10

2.2 Literature Review on Bridge Health Monitoring using Measurements of Modal

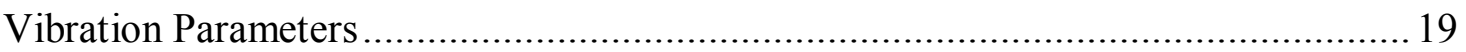

2.3 Review on Empirical Bridge deck design.........................................................23

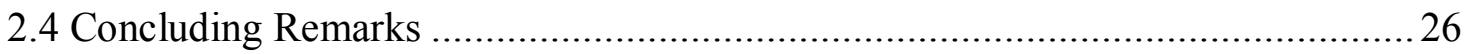

\section{CHAPTER THREE DESCRIPTION OF STAR CITY BRIDGE}

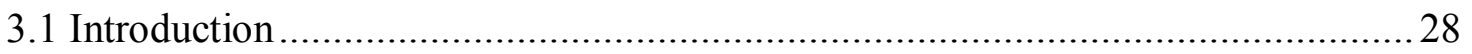

3.2 Reinforced Concrete Deck ............................................................................... 30

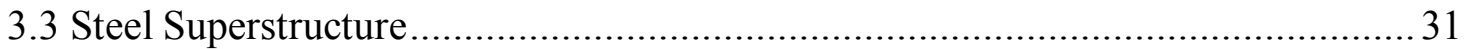

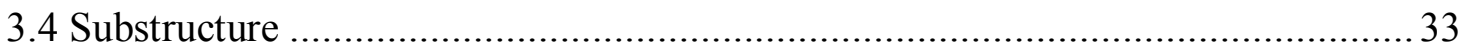

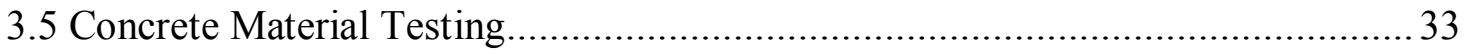

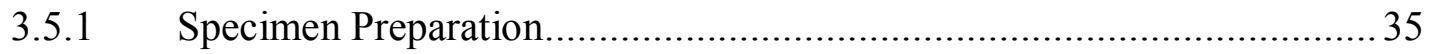




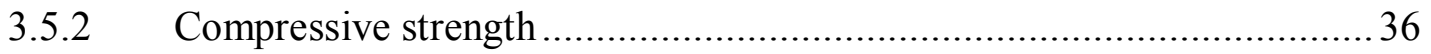

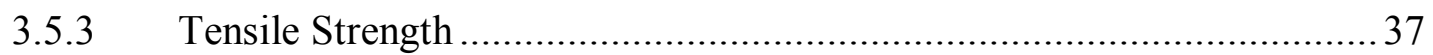

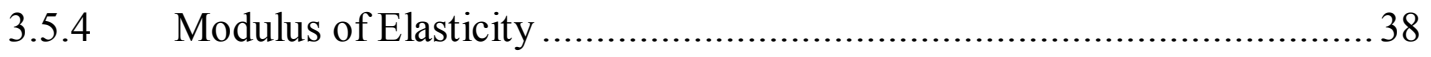

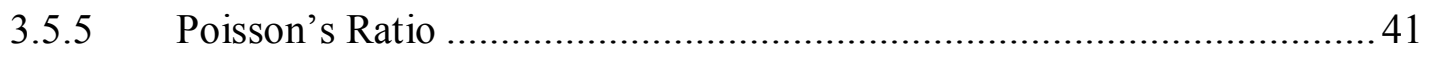

3.5.6 Coefficient of Thermal Expansion ....................................................... 42

3.5.7 Analysis of Concrete Material Properties ……….................................. 43

\section{CHAPTER FOUR INSTRUMENTATION SYSTEM}

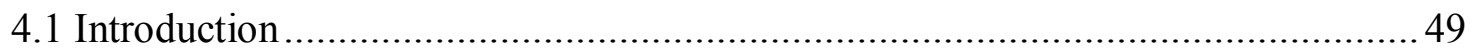

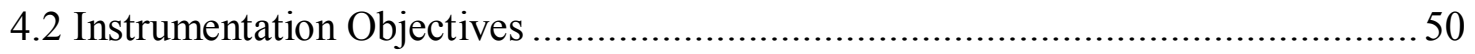

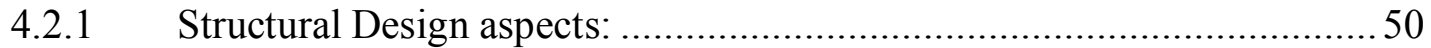

4.2.2 Enhance Bridge Maintenance Strategies ............................................. 50

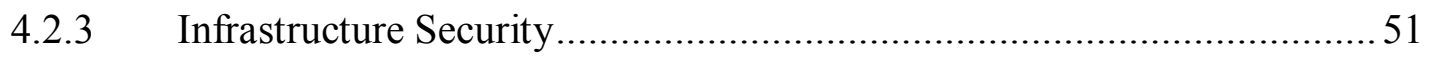

4.2.4 Forensic Studies of Reasons for Structural Deterioration .........................51

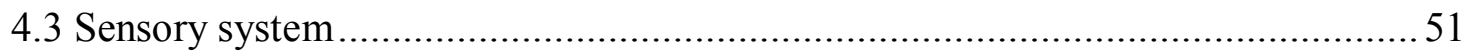

4.3.1 Measurement of Response Parameters................................................52

4.3.2 Measurements of Loading Parameters ................................................... 67

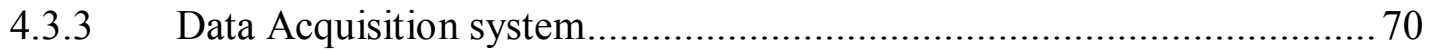

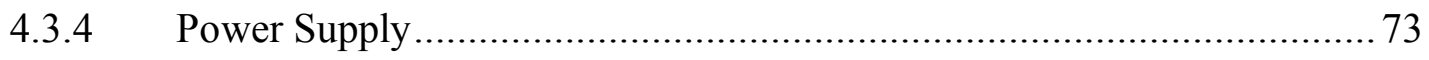

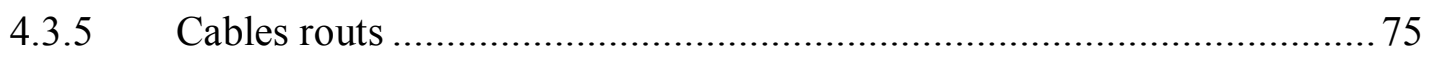

4.3.6 Challenges during Sensors Mounting ..................................................... 77

\section{CHAPTER FIVE GINITE ELEMENT MODELING}

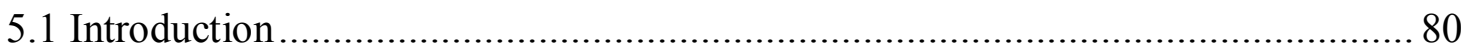

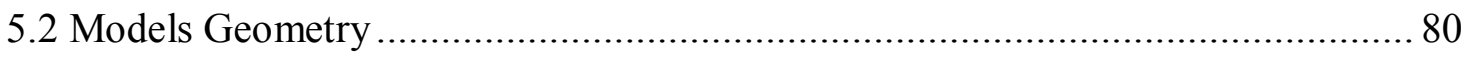

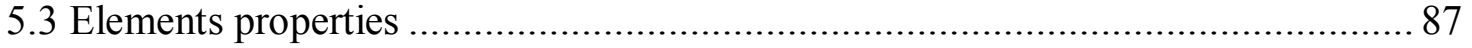

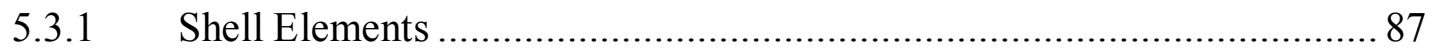

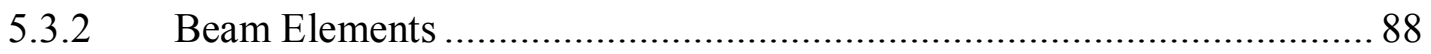




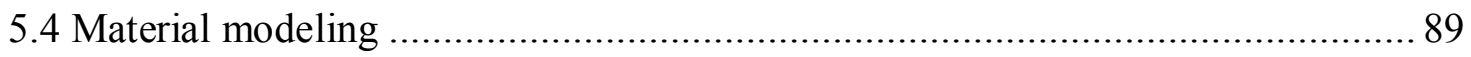

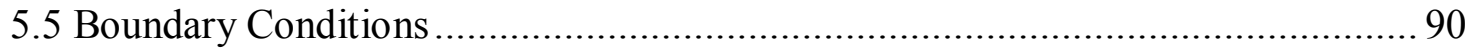

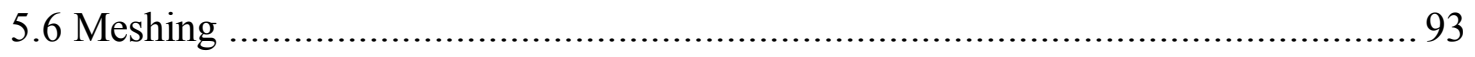

5.6.1 Meshing of Shell Elements ........................................................ 93

5.6.2 Meshing of Beam Elements............................................................... 94

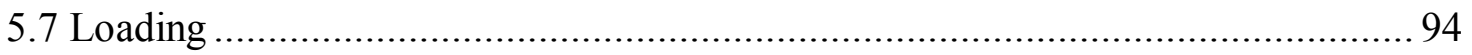

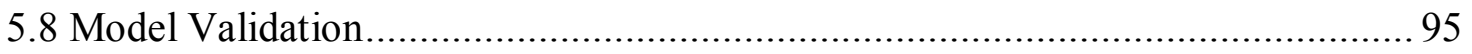

5.8.1 Validation through Theoretically Calculated Displacements.................. 96

5.8.2 Validation through Strain Measurements.......................................... 97

5.9 Evaluation of Mesh Quality...............................................99

\section{CHAPTER SIX MONITORING AND ANALYSIS OF CONCRETE DECK CRACKS}

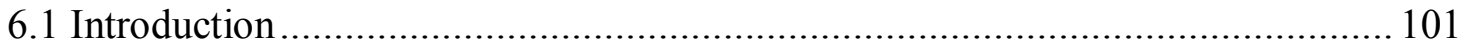

6.2 Analysis of Steel/Concrete Composite Action............................................... 101

6.3 Instrumentation Based Crack Detection and Monitoring Techniques ................ 109

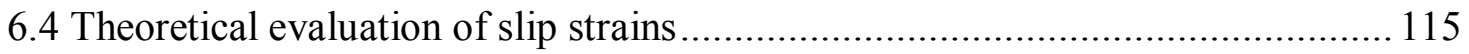

6.4.1 Identification of Thermal Loading Configurations on WV Bridge decks

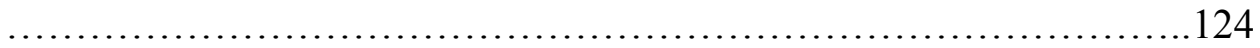

6.4.2 Calculations of Maximum Slip Strains is Concrete Bridge Deck .......... 126 6.5 Analysis of Cracks Initiation through Frequency Spectrum Analysis of Bridge

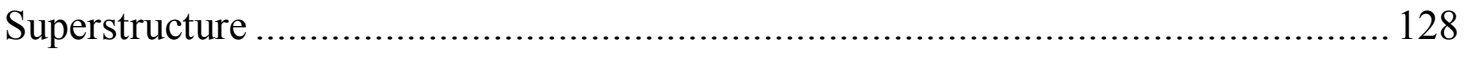

6.6 Structural Health of the Bridge Superstructure after Deck Cracks .................... 137

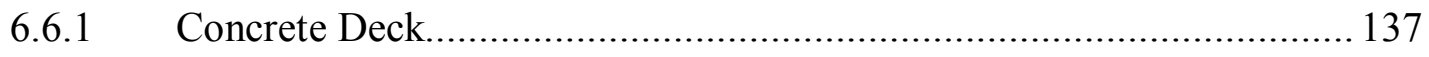

\section{CHAPTER SEVEN CONCLUSIONS}

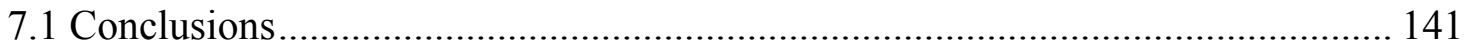

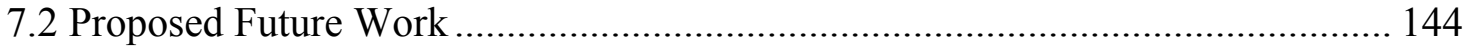




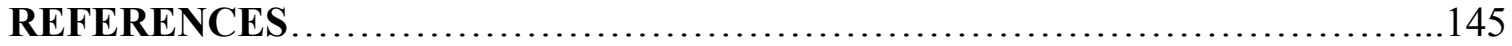

APPENDIX .............................................................. 158 


\section{LIST OF TABLES}

Table 3.1 Tests Plan for Measurements of Concrete Properties..................................... 34

Table 3.2 Average Compressive Strength of Concrete Material [MPa (PSI)] ................ 37

Table 3.3 Average Tensile Strength of Concrete Material [MPa (PSI)] ........................ 38

Table 3.4 Average Modulus of Elasticity of Concrete [MPa (PSI x $\left.10^{6}\right)$ ] .................... 41

Table 3. 5 Average Poisson's Ratio of Concrete .................................................... 42

Table 3.6 Average Coefficient of Thermal Expansion ................................................ 43

Table 3.7 Values of Hyperbolic Function Parameters for Concrete Strength ................. 44

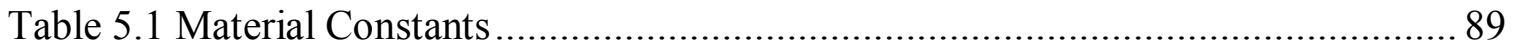

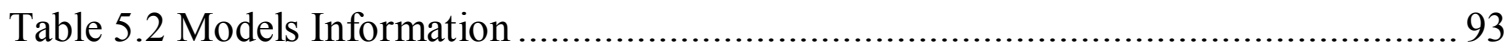

Table 5.3 Comparison of FEM and Theoretical Girder Displacements......................... 97

Table 6.1 Temperature Ranges for Bridge Design According to AASHTO ................. 125

Table 6.2 Maximum Positive Temperature Gradient in Bridge Superstructure............ 126

Table 6.3 Maximum Negative Temperature Gradient in Bridge Superstructure ........... 126

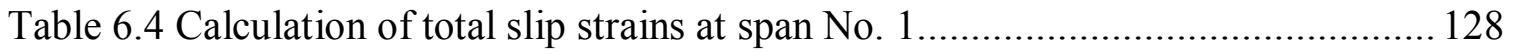

Table 6.5 FE Modal Analysis of Steel Superstructure of Phase II ............................. 134

Table 6.6 FE Modal Analysis of Full Bridge Superstructure .................................... 136 


\section{LIST OF FIGURES}

Figure 2.1 Load-Deflection Curves for Partially Restrained Slabs (Park, 1964) ............24

Figure 2.2 Deck Reinforcement Required for Interior Slab and Girder Bridge (Fang et al.,

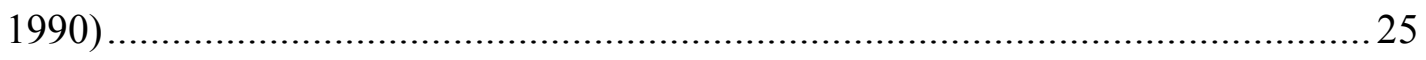

Figure 3.1 Star City Bridge Open to Traffic................................................................2 29

Figure 3.2 Deck Cross Section Showing Sequence of Construction ............................ 29

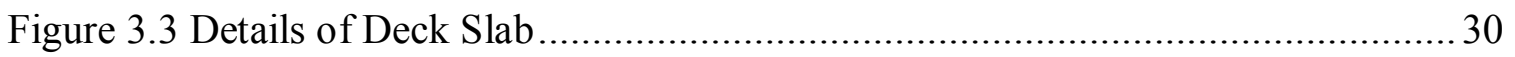

Figure 3.4 Sequence of Concrete Deck Pour............................................................. 31

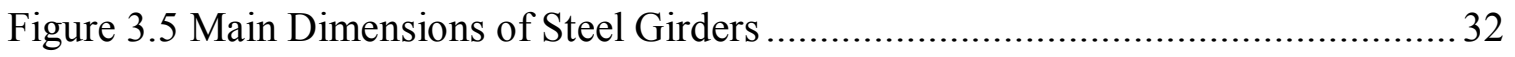

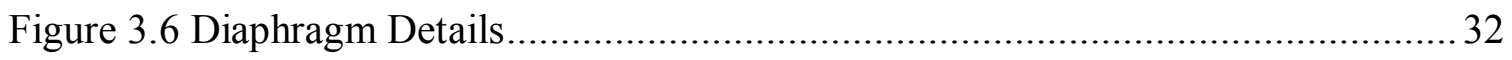

Figure 3.7 Erection Operations of Steel Girders...................................................... 33

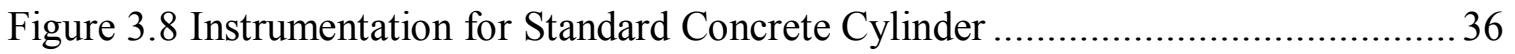

Figure 3.9 Testing of Compressive Strength of Concrete ........................................ 37

Figure 3.10 Test Setup for Measurements of Modulus of Elasticity .............................39

Figure 3.11 Schematic Diagram of Setup for Measurements of Modulus of Elasticity ... 40

Figure 3.12 Measurements of Coefficient of Thermal Expansion................................ 43

Figure 3.13 Concrete Compressive Strength for Pour No. 1 ...................................... 45

Figure 3.14 Concrete Compressive Strength for Pour No. 2 ..................................... 45

Figure 3.15 Concrete Compressive Strength for Pour No. 3 ..................................... 46

Figure 3.16 Thermal Blankets Covering Deck Pour No. 1 ......................................... 47

Figure 3.17 Comparison between Measured and Predicted Concrete Properties ............. 48

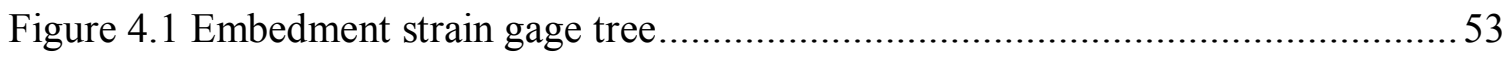

Figure 4.2 Location of Embedment Sensors in Bridge Cross Section ..........................54

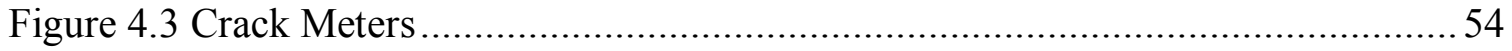

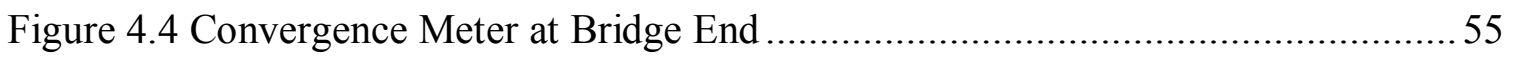

Figure 4.5 Bonding Operations of Strain Gages on Steel Superstructure ......................56

Figure 4.6 Location of Maximum Stresses along Bridge Length..................................58

Figure 4.7 Measurement of Steel Girders Bending Moments .....................................58

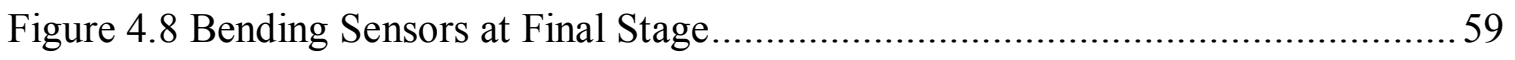

Figure 4.9 Schematic Drawing of Bending and Shear Sensors on G6 at Pier 3 .............. 60 


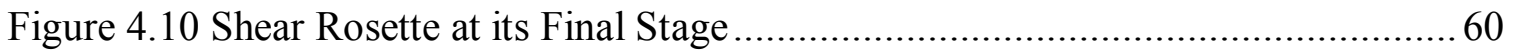

Figure 4.11 Strain Gage Bonded to a Diaphragm Diagonal Member................................ 61

Figure 4.12 Locations of Strain Measurements on Steel Superstructure ......................... 62

Figure 4.13 Inclinometers and Wireless Data Transmission Devices............................... 64

Figure 4.14 Position of Inclinometer on Girder Lower Flange ……………………....... 65

Figure 4.15 Position of Inclinometers along Girder No. 5 ...........................................6

Figure 4.16 Dynamic Strain Measurements in Concrete Deck ...................................... 66

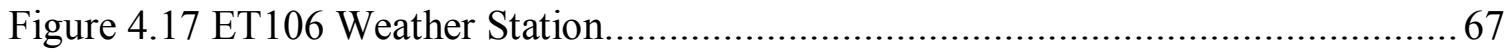

Figure 4.18 Weigh In Motion System at the Bride Entrance .........................................69

Figure 4.19 Sequence of Placing the WIM System at the Bride Entrance.......................69

Figure 4.20 Wiring of Gages to Multiplexers Boards .................................................. 71

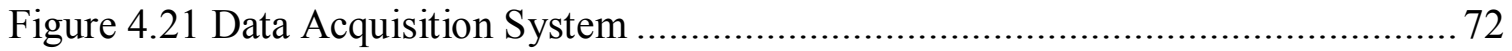

Figure 4.22 Data Acquisition Moisture Protection .................................................... 73

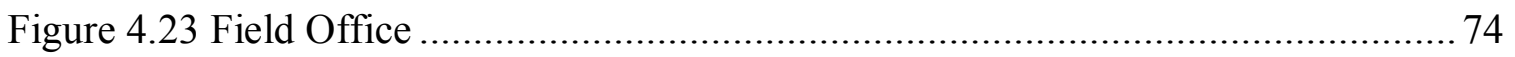

Figure 4.24 Mounting of Solar Panels at Location of Dataloggers ............................... 74

Figure 4.25 Three Dimensional CAD Bridge Model.................................................... 76

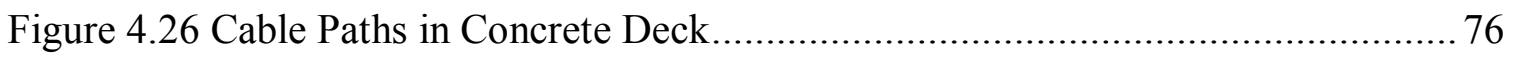

Figure 4.27 Accessibility of Sensor Location by use of Man-lift................................... 78

Figure 4.28 Mounting Strain gages on Steel Girders of Mid-span 2 …......................... 78

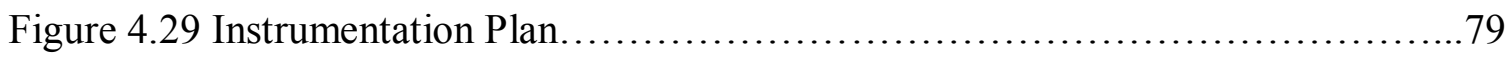

Figure 5.1 A- Steel Girder Details from Abutment 1 to Pier 1 1...................................... 82

Figure 5.2 Steel Girder Details from Pier 1 to Mid-span 2 ......................................... 83

Figure 5.3 Steel Girder Details from Mid-span 2 to Pier 2 .......................................... 84

Figure 5.4 Steel Girder Details from Pier 2 to Pier 3 …………………..................... 85

Figure 5.5 Steel Girder Details from Pier 3 to Abutment 2.......................................... 86

Figure 5.6 Steel Superstructure of Full Bridge Model................................................... 87

Figure 5.7 Four-Node Shell Element for Thin and Thick Shells.................................... 88

Figure 5.8 Geometry Definition of Beam Elements ……............................................... 88

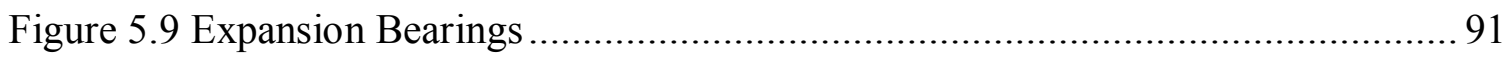

Figure 5.10 Fixed Bearings at Pier 2 …………………....................................... 92 
Figure 5.11 Bottom view of Full FE Model Showing Supports Degrees of Freedoms .... 92

Figure 5.12 Loading of Concrete Deck Weight on FEM ......................................... 95

Figure 5.13 Deformation of Steel Girders due to Placement of Concrete Deck ............. 96

Figure 5.14 Comparison of Strains in Steel girders at Span 1 (Pour No. 1) ....................98

Figure 5.15 Comparison of Strains in Steel Girders at Span 2 (Pour No. 2).................. 98

Figure 5.16 Comparison of Strains in Steel Girders at Span 4 (Pour No. 1).............99

Figure 6.1 Bending Strain Distribution of Full Composite Section............................. 104

Figure 6.2 Comparison of Concrete Strain Magnitudes at Day 5 .............................. 107

Figure 6.3 Comparison of Concrete Strain Magnitudes at Day 11 ............................. 108

Figure 6.4 Ratio of Theoretical Concrete Strains to Measured Data .......................... 109

Figure 6.5 Strain Variations in rebar and concrete in Span 2 over Girder 6 ................ 111

Figure 6.6 Instrumentation used for Crack Detection in Concrete Deck ..................... 111

Figure 6.7 Crack Initiation and Growth on Span No. 1 over Girder 6........................ 112

Figure 6.8 Correlation Coefficient bet. Concrete and Rebar Strains at Pier 2 .............. 114

Figure 6.9 Difference in Concrete and Rebar Strain values at Top of Pier 2 ............... 115

Figure 6.10 Free Body Force Diagram of a Deck Segment (Nie et al., 2004)............. 116

Figure 6.11 Superstructure Deformation Due to Maximum Positive Temperature Gradient

Figure 6.12 Superstructure Deformation Due to Maximum Negative Temperature Gradient 127

Figure 6.13 Mode Shapes No. 1 to No. 6 of Steel Superstructure of Phase II 132

Figure 6.14 Mode Shapes No. 7 to No. 10 of Steel Superstructure of Phase II 133

Figure 6.15 Mode Shape No. 14 of Steel Superstructure of Phase II 134

Figure 6.16 Mode Shape Corresponding to $1^{\text {st }}$ Natural Frequency of Full Bridge Superstructure 136

Figure 6.17 Mode Shape Corresponding to $2^{\text {nd }}$ Natural Frequency of Full Bridge Superstructure 137

Figure 6.18 Stresses in Concrete Perp. to Traffic on Top of Mid-span 4, Girder 6........ 139

Figure 6.19 Stress in Traffic Direction on Top of Mid-span 4, Girder 6 ...................... 140

Figure 6.20 Stresses in Steel Reinforcement at Mid-Span 4 .................................. 140 


\section{CHAPTER 1}

\section{INTRODUCTION}

\subsection{Preface}

The American Society of Civil Engineers report card (ASCE, 2005) assessing the nation's infrastructure indicates no improvement since receiving a collective D+ in 2001. In the category of bridges, the report card assigned a grade $\mathrm{C}$ to America's bridges. $27 \%$ of the nation's bridges are rated as structurally deficient or functionally obsolete. A bridge is classified structurally deficient when its deteriorated components lead to its closure or make it restricted to lightweight traffic. A functionally obsolete bridge has older design features and can not accommodate current heavyweight traffic volumes. Recommendations for future policies emphasizes that simply building new bridges is not a solution to comply with the increased demand in highway capacity, but rather change in the current transportation behavior by making use of latest technologies. The recommendations insisted on allocating adequate funding for research and development of civil engineering innovations that offer cost-effective solutions to infrastructure needs. Among major barriers to improve the bridges' conditions are inadequate or inconsistent data that indicate in-service performance, condition, and capacity of existing ones (Lenett et al., 2001). Lenett further suggested that the serviceability states of a given classification of structures are adversely influenced by the lack of information about the fundamental deterioration and damage mechanisms.

In an effort to improve the cost efficiency and effectiveness of maintenance strategies, the Intermodal Transportation Efficiency Act (ITEA) in 1991 mandated implementation of bridge management systems (BMSs) by all state departments of transportations (DOTs). The program aims to improve the overall condition of an agency's network of bridges by determining the optimal time for an agency to execute improvement actions on a bridge, given the funds available (Edward Czepiel) . 
The improvement in acquiring reliable data for monitoring bridge performance went through an evolutionary process that involved engineers, bridge owners as well as legislators. The National Bridge Inspection Program (NBIP) was established since 1968 in response to the collapse of the "Silver Bride" between Point Pleasant, WV, and Gallipolis, OH, in 1967 (FHWA, 1991) . The information contained in the NBIP was used to establish repair fund strategies by the Federal Highway Act of 1970 through the Special Bridge Replacement Program (SBRP). This program used the NBIP data to classify bridges on major highways as non-deficient, structurally deficient or obsolete thus being eligible for replacement funds. Realizing the importance of bridge assessment data provided by bridge inspectors and its major impact on replacement decisions, the Federal Highway Administration (FHWA) set a Coding Guide that outlined inspection procedures and those specific elements on each bridge to be inspected. Refinements and revisions were later made to the Code in 1972, 1979 and 1988. The NBIP was later replaced by the Highway Bridge Replacement and Rehabilitation Program (HBRRP) that provided funding for rehabilitation as well as replacement of bridges on all public roads. The Intermodal Surface Transportation Efficiency Act of 1991 expanded the HBRRP to mandate every state DOT to implement management systems for maintenance planning recognizing that preventive maintenance acts are most effective in minimizing problems before they occur. Two major generic BMS projects adapted from cost models have been developed nationwide, Pontis(1993) and BRIDGIT(1993). Those generic models use bridge data provided by inspections at an element level as a quantitative measure of deterioration. Deterioration is modeled through Markovian (1993) process and cost models are used to examine trade-offs between options.

Meanwhile, a national effort is being conducted to develop remote sensing systems that would allow more sophisticated and accurate methods to assess the structural performance of bridge elements and hence provide a rational method of making decisions about the bridges' condition. This effort is focused on collecting objective data that originate from a sound scientific approach and indicate the structural condition of bridge elements relying on quantitative measurements. 


\subsection{Problem statement}

Design theories and analytical models are based on simplified assumptions and idealizations that may or may not indicate the actual behavior of operating structures. Empirical methods are based on observations and/or analysis of laboratory scaled specimens or other simulating tools such as finite element models. Such methods are usually used to study and analyze structural response due to isolated loading parameters, while simulating combined loading configurations that real structures are subjected to is often a tedious task. For example it is hard to simulate static and dynamic loading configurations while subjecting a full-scale structure to specific temperature and moisture variations. Moreover, the principal of superposition may not be adequate in most cases due to response non-linearity. Therefore researchers as well as practitioners realized the importance of studying the behavior of structures and their response to actual loading configurations through instrumentation based long-term monitoring programs.

For the case of bridge decks, monitoring efforts through sensory systems were conducted for the purpose of identifying anomalies such as formation of cracks in the reinforced concrete slab. Two main challenges lie in this aspect. The first is that the exact locations of such cracks are not known; therefore it is hard to predict the exact sensor locations where cracks can be monitored. The second is that the real causes of such cracks are still not understood; therefore it is hard to predict the exact time of crack initiation and propagation, or relate that to loading patterns.

Through all BMS programs, it is clear that all results and decisions will be as good as the information that is input into the system. Nowadays, inspections of existing bridges are being conducted routinely and inspection histories are being kept in each bridge's record (AASHTO, 1994) . Through the course of those inspections, the physical and functional condition of a bridge as well as analysis of overload permit applications are determined. While those inspections are essential to establish priorities for repair and rehabilitation actions, visual inspection of bridges have multiple limitations. Critical evaluation of traditional biannual visual inspections has found that this approach is not sufficiently reliable to detect deteriorations that allow timely repair actions (Moore et al., 
2001) . Inherent from their nature, visual inspections are often found highly variable. Inspectors have to rely on their experience and exercise personal judgment with limited testing opportunities to identify and classify signs of deteriorations. Visual inspections are time consuming and represent a financial overburden that State highway agencies are overtaking. Most importantly, visual inspections are unable to detect invisible damage or distress (Chase, 2003) .

This task represents an overburden on highway agencies and more efficient tools for monitoring needs are required. Such monitoring tools have to use minimally intrusive techniques and effective schemes to offer more adequate, less expensive and more frequent monitoring data.

\subsection{Incentive of Instrumentation based Bridge Health Monitoring}

Both researchers and practitioners are motivated to find means of quantifying changes in condition of performance of bridge elements using non-destructive techniques without trading off accuracy and reliability. Advancement in measurement techniques, sensory systems and communications offered a great tool to implement non-destructive strategies that would allow not only monitoring existing structures but also evaluate retrofit details and various construction techniques. Strategies of monitoring bridge performance using instrumentation systems were categorized by (Aktan, 1996) :

- Bridge health monitoring through measurements of changes in the global geometry or local responses of an existing bridge under service conditions. This is achieved by intermittent measurements of variables through application of a proper instrumentation system.

- Monitoring bridge response for measuring absolute local and global responses since construction.

- Diagnostic testing of an existing bridge by measuring incremental global or local changes due to static or dynamic loads. 
- Monitoring an existing bridge by identifying global or local responses through intermittent measurements in the long term with the objective to capture incremental variations in each event.

(Lenett et al., 2001) summarized the goals pursued through application of instrumentation based systems in any of the above categories:

- Identification of deterioration mechanisms that influence long term bridge health for the purpose of mitigating those defects.

- Provide sound basis for design of structural repairs.

- Explore effects of new methods of construction on the stress distribution in bridge elements.

- Provide objective data that indicates the current condition of a bridge or the change in that condition due to an overloading event or application of a retrofit.

- Provide data about various loading configurations.

- Verify design methods.

- Investigate unknowns in terms of loading and response behavior.

- Setting more rational methods for maintenance strategies and management techniques.

\subsection{Research Objectives}

This study focuses on evaluating the superstructure response of an empirically designed bridge deck to real life loading conditions including both dynamic axle loads and long term changes due to environmental exposure. This research work aims at integrating an instrumentation based system in the new Star City Bridge within its construction phases for the purpose of monitoring the long term response parameters of various bridge elements. The objectives can be summarized within the following categories:

- Design and implement an instrumentation based system to provide more sophisticated data and better methods of bridge monitoring than visual inspections to identify signs of distresses, hence respond timely to bridge maintenance needs. 
- Design an instrumentation-based method for identifying crack initiation and propagation in reinforced concrete deck slab.

- Study the behavior and response of a light-weight designed deck to loading configurations in an effort to understand the reasons that contribute to the formation of cracks in such bridge decks.

- Identifying actual stresses that occur in critical bridge elements due to real life loads and climatic changes, especially after deck cracks occur. This will serve to verify the effect of cracks on the overall bridge performance.

- Identify thermal loading configurations on the bridge deck through long-term monitoring, in an effort to improve the design load specifications with accurate data.

- Provide continuous data records that can offer better understanding of the behavior of various bridge elements, thus can be used to enhance the performance of future bridges to make them more efficient.

\subsection{Research Methodology}

The objectives stated above are achieved by accomplishing multiple tasks including:

- Perform an objective review within the technical literature on instrumentation and data acquisition systems that can be implemented to secure data for a combined long term and real time monitoring of bridge superstructures.

- Design and development of a sensory system for remote monitoring of critical bridge elements response to various loading configurations. The capacity of the sensory system includes measurements of both loading parameters as well as 
response parameters. The loading parameters address both dynamic configurations due to traffic axle loads as well as long term static loading due to environmental exposure and cyclic changes in air temperature and moisture.

- Examine design calculation sheets of the empirically designed Star City Bridge superstructure and identify locations of critical stresses at various structural members. Examination of the calculation sheets will determine the locations of sensors, their sensitivity and measuring range.

- Installation of the sensory system on the Star City Bridge in order to acquire data in a timely manner reflecting the actual response of bridge elements as loading is applied since construction phases. The sensory system is installed while the bridge is still under construction for two reasons:

1 - Provide measurements of the concrete deck static weight.

2- Allow embedment of sensors in the concrete deck.

- Collect continuous records of data for long time durations (at least 12 months) in order to provide time histories and database of both loading and response parameters.

- Verify recorded measurements using numerical techniques and/or theoretical modeling whenever possible and determine accuracy of collected data.

- Post process measurement time histories in order to extract required data for analysis.

- Combine theoretical analysis and instrumentation based methods to conduct an indepth study to design an innovative method that reveals formation of hidden cracks in concrete deck. 


\subsection{Scope of Research}

The nature of the work tasks in this research program involves multiple engineering disciplines including structural engineering, transportation, electro-mechanical engineering, and instrumentation, which adds value to the outcome results. Through the course of this work, various research frontiers are faced which widened the scope of this program as summarized herein:

- This work puts into perspective a detailed instrumentation system that is developed for the purpose of long-term bridge health monitoring that allows more frequent, less expensive and more sophisticated bridge safety inspections. The instrumentation system demonstrates a rational method for making decisions about the condition of a bridge member while being minimally intrusive, and allows remote monitoring through phone line communications.

- Databases of time-histories of engineering measurements are built through the course of data collection. The database includes measurements of:

1. Three dimensional strains and stresses in concrete deck at locations of maximum positive and negative bending moments.

2. Strains in longitudinal and transverse deck steel reinforcement at locations of maximum positive and negative bending moments.

3. Thermal mapping along concrete bridge deck and at supporting steel girders.

4. Overall expansion and contraction of bridge ends relative to abutments at the location of expansion joint.

5. Crack opening and closure in concrete deck.

6. Shearing strains and stresses at location of maximum shearing stresses on the steel girders.

7. Bending strains at steel girders at locations of maximum positive and negative bending moments.

8. Out-of-plane strains of steel girder webs.

9. Inclination of steel girders at multiple locations along the length. 
10. Strains and forces at diaphragm members.

11. Angle of inclination of supports including piers and abutment of end span.

12. Dynamic strains in concrete deck at location of wheel paths.

13. Weather data through a weather station

14. Axle load spectrum of traffic crossing the driving lane of the bridge.

- A weigh-in-motion (WIM) system is developed and installed at the bridge approach using piezoelectric sensing devices, loop detectors and an in-house built data acquisition system. The WIM system proved to be cost efficient and reliable to acquire traffic data that enables providing a traffic load spectrum and classification of vehicles approaching the bridge.

- Through data analysis, a new concrete crack detection technique is developed. This technique is based on measurements of strain time histories and successfully indicated time of occurrence of cracks and their development. Such techniques are most useful for State DOT personnel and bridge agencies to check the status of the concrete material in bridge decks constructed using stay in place (SIP) forms where the deck bottom is inaccessible.

- Composite action in steel/concrete is verified and means of measurement of this action is developed and values are quantified.

- The work combines analytical modeling using Three Dimensional Finite Element Modeling (3DFEM) of the superstructure and field testing for analyzing both static and dynamic characteristics of the bridge superstructure.

- Analytical calculations of slip strain between steel reinforcement and superstructure due to maximum temperature gradient on bridge deck. 


\section{CHAPTER 2}

\section{LITERATURE REVIEW}

\subsection{Literature review on bridge instrumentation for Long-term monitoring}

The last two decades showed an increasing interest in developing health monitoring systems for civil infrastructures (Xia et al., 2005) and (Fujino and Abe, 2003). Structural health monitoring (SHM) of a bridge can be described as the continuous recording of the loading environment as well as measurement of critical response parameters of the bridge components. Although a number of challenges face the effective application of SHM strategies on large infrastructure systems, there is enough evidence that various state agencies and bridge owners are getting more motivated recently for new ideas on instrumented bridge monitoring concepts. SHM has been used for evaluating performance of structures, identify symptoms of operational incidents, anomalies due to deterioration and damage, and for checking the structural health during or after an extreme loading event (Aktan et al, 2000). A complete SHM design is reported by (Catbas et al., 2004) to have the following architecture:

1. Identification of performance and health metrics

2. Sensors and data acquisition networks

3. Data fusion, analysis and information management

4. Real time data interfaces for manual, semi and/or fully automated data evaluation

5. Decision making

6. Metrics of success

The International Association for Structural Control (IASC) jointly with the ASCE SHM Task Group developed a benchmark SHM problem to improve the effectiveness of detection and damage assessment of structures (Johnson et al., 2000) . Because there is no off-shelf type bridge monitoring system available, researchers have to assemble 
suitable components that would satisfy their monitoring objectives. In all reviewed instrumentation based long-term bridge monitoring systems, the common approach is to integrate existing technologies in the most cost-effective, efficient and reliable design.

A sensory system was installed on a 3 spans semi-composite steel stringer bridge near Cincinnati, Ohio (Lenett at al., 2001) for the purpose of long-term monitoring and structural analysis of the bridge elements since construction. Special interest was drawn to monitor this bridge because of its relatively unusual span geometry that featured an end span to middle span ratio of (0.45). The bridge also incorporates both continuous and integral construction. This work includes measurements of strains, temperatures, inclinations, and soil pressure in the foundations and substructure. The superstructure including steel beams and crossframes were instrumented with strain gages and temperature sensors. The instrumentation system involves a total number of 238 sensors in the superstructure where 58 were removed and 116 sensors in the substructure. The steel beams were monitored during critical shop fabrication procedures and through subsequent construction events. Instrumentation of this bridge started with the bridge construction in 1995 and modal impact and diagnostic truckload testing were performed before opening to traffic in 1997. Atmospheric effects were collected at the site via a weather station, and recording of response data were conducted through the first year of bridge service life. Fabrication and erection stresses were found to range in the steel superstructure from $20.68 \mathrm{MPa}$ (3 ksi) to $103.42 \mathrm{MPa}(15 \mathrm{ksi})$. The authors found significant local stresses that are not considered in design methods and attributed their cause to structural details such as in the integral abutments and welded connections for crossframes and bearing plates. Shrinkage stresses were measured to be near or higher than the cracking threshold for the used concrete material (Class S). The authors drew an important conclusion from this effort that environmental stresses were not explicitly considered in the bridge design, yet those stresses exceeded by far any stress caused by any recorded truck traffic.

The SR-33 Lehigh River Bridge is instrumented with an array of sensors through a research project to investigate the effects of temperature, shrinkage, creep, and live load 
behavior (Connor R.J. et al., 2002) The bridge consists of 4 spans of continuous weathering steel truss that is composite with the reinforced concrete deck. Because of this unique structural characteristic the bridge was instrumented within its construction phases in May 2001 and field monitoring is expected till 2005. The instrumentation program includes measurement of strains and temperatures both on the steel superstructure and in the concrete deck. Vibrating wire strain gages are used at 59 locations in the first and second span and at the location of one pier. Uniaxial wire resistant strain gages are used to measure dynamic response in the steel stringers and rebars. Based on data records, the authors concluded that the overall behavior of the truss under live load was as expected and no unusual behavior was observed. The Authors added that stresses during construction were found in reasonable agreement with those calculated in design.

The Pereria-Dos Quebradas viaduct in Colombia is instrumented with more than 300 transducers for real time health monitoring (Thomson et al., 2001). The authors indicated the importance of this Viaduct to represent the most important civil infrastructure built recently in Colombia. Being completed in 1997, this $615 \mathrm{~m} \mathrm{(2017 \textrm {ft } )}$ long bridge was the world's twentieth longest cable stayed bridge. The bridge consists of steel girders and joints and a post-tensioned concrete slab with 72 cables connected from two principal piers. The instrumentation system includes accelerometers, displacement transducers, inclinometers, temperature sensors, and macropar sensors. All signals are transmitted to a monitoring station located nearby the bridge. The system is designed to measure slow varying phenomena due to temperature changes, foundation settlements and concrete relaxation. Records every six hours include measurements of local strains in piers and deck slab as well as pier rotation. Fast Varying phenomena due to traffic, wind, and seismic activities are recorded in terms of axial and transverse accelerations in the cables as well as longitudinal, transverse and vertical accelerations of the deck and piers. The level of corrosion in the steel reinforcement in the piers and deck slab are recorded manually every 6 months. Weather data are recorded through a weather station. Despite the large investment in the sensory system (\$ 1.5 million) an inventory of the viaduct instrumentation and data acquisition found that many of the transducers were incorrectly 
installed and wired, many transducers have been damaged and the system was under review for operation in 2002.

The Akashi Kaiko Bridge in Japan is the world longest suspension bridge. Because of its remarkable length, new methods of design for aerodynamics and seismic stability were implemented. A set of instruments and a system network provide monitoring data that are used to verify assumptions and design constants. The data are also analyzed for structural maintenance purposes as well as traffic management and control in case of an earthquake or typhoon. The scope of monitoring includes measurements of response parameters and loading effects. Response parameters refer to displacements, accelerations, stresses, strains and forces in the bridge members and cables. Loading effects include those due to wind, earthquake, temperature and the combined highways and railways live loads. (Sumitro et al., 2001) indicate that field measurements of displacements and vibration amplitudes recorded during the 1998 typhoon have confirmed simulation results obtained in a wind tunnel test.

The Bridge No. 4048.2S017 crossing Boone River on Highway 17 in central Iowa was chosen to investigate the effectiveness and stability of a bolt loosening retrofit designed to eliminate web fatigue cracking. The bridge consists of 3 spans and features five main plate girders with an integral concrete deck. An on-site remote monitoring system was installed to collect continuous measurements of strains, displacements, and temperature. Data were collected remotely when a significant loading was present. The instrumentation systems included 4 thermocouples, 2 gradient strain gages installed on 2 web gaps, 5 weldable strain gages distributed on the diaphragm members and one girder, and 4 direct current displacement transducers installed at one stiffener connection. Data collection is triggered by a threshold value of $20 \mu \varepsilon$ at the flange bottom, which drives the system to save 8 seconds of data before and after the event. Data analysis for 4 months indicated a substantial reduction in strains at the web gap following the implementation of the retrofit, which confirmed its effectiveness (Wipf et al., 2003) . 
About 30 fiber optic sensors were embedded in the concrete deck of the Moesa railway bridge near Bellinzona in southern Switzerland for monitoring its deformation during concrete setting and shrinkage as well as during the bridge sliding phase (Inaudi et al., 1997) . The bridge comprises composite steel and concrete deck supported on 3 spans of $30 \mathrm{~m}$ (98.4 ft) each. The bridge replaces an older one and was cast in place and then slide laterally at its location using hydraulic jacks. The fiber optic sensors had an active length ranging from 2 to 4 meters and were mounted to the steel reinforcement in the longitudinal direction. Measurements were conducted after concreting and during bridge sliding. Results showed that bending values were too small to produce cracks and confirmation that no damage occurred to the bride while pushing was concluded.

The feasibility for using Global Positioning systems (GPS) and other sensors to remotely monitor structural health condition on operational bridges was investigated by (Meng et al., 2004) . The system targets to measure the natural frequencies of vibrations and integrates a number of GPS devices and triaxial accelerometers to detect both high and low frequencies of bridges. The Wilford Bridge over the River Trent in Nottingham, UK was used as a test bed for this study. The bridge is a suspension footbridge structure spanning $68 \mathrm{~m}(223 \mathrm{ft})$ and consists of a steel deck covered a wooden floor. A comparison of the first natural frequency of vibrations detected by the system and that computed from a Finite Element Model of the bridge indicated a close match. However, the authors indicated that noise problems in the field data needed to be addresses and more refinements were needed to get a better match for the second natural frequency.

In 1996, the Versoix Bridge located near the city of Versoix, Switzerland was instrumented with about 100 fiber optic deformation sensors in order to monitor longterm performance of the bridge with special attention to the interaction of the old bridge and a new extension that introduced a security lane in both directions (Vurpillot et al., 1997) . The Versoix Bridge is a classical concrete bridge consisting of two pre-stressed concrete beams supporting a concrete deck with two overhangs. Monitoring of the bridge included measurements of average strains in concrete, analysis of average curvature, detection of torsion and distribution of horizontal and vertical displacements. Seven years 
of data collection concluded that the structure was perfectly monolithic and no delamination was detected.

A system of weldable strain gages and inclinometers were used to instrument the Michigan Street Bridge in Strugeon Bay, Wisconsin for remote monitoring the health of fracture critical components of the bridge. This 65 years old rolling bascule bridge consists of thirteen spans of a total length of $430 \mathrm{~m}$ (1413 ft) of a combination of steelconcrete girders and steel trusses. A system of 16 strain gages were welded in two patterns at locations of the most badly deteriorated track plates for initial testing at closing cycle (Prine and Fish, 1996) . Inclinometers in orthogonal pairs were installed on the main piers to monitor inclinations during those tests. A total of 6 sensors (4 strain gages and 2 inclinometers) at 2 locations were kept for continuous data recording. Analysis of one year of data demonstrated that the damage continued to progress and cracks continued propagation at the location of the strain gages.

As AASHTO is adopting the Load and Resistance Factor Design (AASHTO, 1998 and 1996) ', specifications for implementation by state DOTs, the need for verifying various theoretical approaches and design methods undertaken by the specifications emerged. The Doremus Avenue Bridge, located in Newark, NJ, is New Jersey's initial LRFD design and was the subject of an instrumentation and modeling based study that aimed at evaluating the analytical behavior of the bridge (Nassif et al., 2002) . One of the studies' objectives was also to identify the instrumentation procedure(s) and equipments to be used in future field testing and monitoring programs. An array of sensors was installed on the new bridge at locations based on a finite element modeling study. One drilled shafts and 2 piers were instrumented with triaxial geophones at various depths for monitoring the bridge response to dynamic loads and for a comparison with numerical models. The proposed permanent Bridge Structural Testing System consists of mounting 96 Vibrating Wire Strain Gages as well as 30 Vibrating Wire Thermo-Couples within the deck slab and 6 demountable strain gage transducers on the steel superstructure. Dynamic measurements are proposed to be conducted using a set of accelerometers mounted on the lower flanges of the steel girders while performing 
dynamic live load tests. A weigh in motion system is proposed to be placed on driving lanes for collection on live load data.

In order to detect wire breaks within strands or cables in the Bronx-Whitestone Bridge in New York City, a SoundPrint system developed by Pure Technologies was installed in 2000. The bridge is one of the longest suspension bridges in the US with a main span of $700 \mathrm{~m}$ (2296 ft). The system consists of an array or 51 acoustic sensors that continuously measure the energy or dynamic response generated when tensioned steel wires fail. The sensors are mounted on each of its 2 main cables and are connected to the SoundPrint data acquisition (DAQ) and management system that is placed inside the bridge anchorage. Data are transmitted from the DAQ to the Pure Technologies data processing center in Calgary, Canada through a local internet connection where it is being analyzed. Pure Technologies reported that the system has achieved an operation efficiency of $98 \%$ (PureTechnologies, 2005) .

(Masri et al., 2004) developed a multithreaded design based software which acquires data from multiple channels, monitor, condition and distribute the data in real time through the internet to various remote locations. The system was implemented on the Vincent Thomas Bridge in San Pedro, Ca. The bridge features a cable suspended deck with a main span of $545 \mathrm{~m}$ (1788 ft) in length and connects Los Angeles with its harbor. The study used 26 accelerometers that were installed on the bridge in 1980 as an upgrade to its seismic study project and is maintained through the California Strong Motion Instrumentation Program. The Authors demonstrated the ability of the system to identify the bridge modal properties such as natural frequencies and damping ratios from a recent earthquake that automatically triggered the system's recording capabilities.

The California Department of Transportation conducted a study to evaluate the feasibility of using a GPS based system for monitoring the performance of its long span bridges and land slides (Loren, 2003) . The approach of the study was that GPS technology can provide real-time monitoring of displacements that could be correlated to the amount of damage in the structure. The system was implemented on the Vincent 
Thomas Bridge in Los Angeles Harbor, the San Francisco Bay Bridge, and the Golden Gate Bridge in San Francisco. The system utilizes a combination of high precision realtime kinematic GPS (RTK-GPS) and wireless communication technology. The study showed that networking RTK-GPS is a good tool for detecting differential displacements that can indicate movements after a destructive event such as an earthquake.

(Fang and Kim, 2001) Instrumented 2 bridges in Orange county Ca., for longterm structural performance monitoring. The selected bridges were the Jamboree Road Crossing and the West Street on Ramp, both are typical 3 spans concrete pre-stressed post-tensioned box-girder bridges. The monitoring system comprised a set of triaxial thervo-accelerometers that were placed on the bottom flange of the girder, strain gages and rebar gages that were embedded in the concrete beams, and linear variable displacement transducers (LVDTs) that measured relative displacements between the girder and support as well as soil pressure sensor at the abutment. Data collection included 82 sets (10 minutes each) during day time. Preliminary vibration data were analyzed to obtain dynamic properties of the bridges including modal parameters such as natural frequencies and mode shapes, and those were compared to finite element modeling predictions while long term analysis and being performed.

(Rizkalla et al., 2000) used an array of fiber optic and temperature sensors to instrument 3 bridges in Canada after being repaired with Fiber Reinforced Polymer (FRP) composites. The monitoring system uses 63 fiber-optic Bragg Grating (FBG) sensors to monitor strains in FRP bars in the girders, 22 electric-based temperature sensors for temperature compensation, and 26 wire-resistance strain gages for comparison with the FBG measurements. The authors concluded that temperature induced effects were far greater than those induced by traffic loads.

The Commodore Barry Bridge which spans the Delaware River between Chester, Pennsylvania and Bridgeport, New Jersey is instrumented with a system that carries over 100 channels for SHM purposes. The Bridge features the longest cantilever trussed bridge worldwide. (Catbas et al., 1999) review information technologies associated with 
this instrumentation system which includes slow speed sensors to monitor slow responses as well as high speed sensors in addition to a camera that records traffic patterns. All sensors are wired to a data acquisition station that comprises both slow speed and high speed data acquisition systems. Data are being stored in two data-bases; one is internet based and the other one processes data locally and makes them downloadable from the internet.

In 2003, (Shoukry et al., 2005) , instrumented the Evansville Bridge in West Virginia for the purpose of conducting a study on early age cracks in bridge decks. The Evansville Bridge is a 3 spans composite steel/concrete deck with a total length of $45.7 \mathrm{~m}$ $(150 \mathrm{ft})$. The instrumentation system consists of 232 sensors of various natures that allow continuous remote monitoring of deck behavior and response to loading conditions since placement of the concrete deck. Measurements include parameters such as tri-axial strains in the concrete deck, relative expansion and contraction of spans, inclinations and strains in steel girders, temperature mapping in the deck, strains in steel rebars, and crack initiation and propagation. Analysis of long-term monitoring response of about 1.5 years of data yielded development of many crack detection techniques for concrete decks and illustrated main factors that contribute to early age bridge cracking. Among those factors, the authors illustrated the effect of thermal and shrinkage stresses that developed in the deck because of the constraining effects of the stay-in-place forms and shear studs, as well as non-uniform curing of the concrete along the deck that result from in-plane temperature variations along the deck. The authors also indicated that the sensory system employed in this study can be used to assess the integrity of the bridge superstructure in sustaining traffic and environmental loads. Specific to integral abutment bridges, the study illustrated a poor composite action between steel girders and concrete deck in early age, and the constraining effect of integral abutment to expansion and contraction of the bridge superstructure. 


\subsection{Literature Review on Bridge Health Monitoring using Measurements of Modal Vibration Parameters}

Identification of modal vibration parameters such as natural frequencies and mode shapes of structural systems can be achieved experimentally through various instrumentation based studies. Instrumentation for this purpose has long been available (Vierck, 1979) and had advanced considerably in the last three decades. As damage occurs in structural systems, their performance is adversely affected, so as their mechanical properties. Based on this concept, damage identification can be achieved by a comparison of vibration characteristics of structural elements between two different states. One represents the initial and often undamaged state and the second represents the deteriorated state after damage. The basis of most damage detection methods is that damage will alter the measured dynamic response of the system that is dependant on mass, stiffness and energy dissipation properties of the system (Sohn et al., 2003) . Depending on the nature of damage, i.e. cracks, rust, plastic deformation, etc... deterioration can occur in different rates. Damage can occur in incremental accumulation such as in the case of fatigue cracking or can occur as a result of discrete events such as overloading events or after an earthquake. For example, (Fisher, 1984) indicated that brittle fracture due to fatigue cracking was one of the most common causes of failure in steel bridge components. Therefore, periodic evaluation of the structural performance both over long time scales as well as after a damaging event is always necessary.

One major challenge that faces applications of damage identification using vibration analyses of infrastructures is that environmental variations including temperature and moisture changes affect the dynamic response of such structures and can not be overlooked. (Sohn et al., 2001) indicated that the measured natural frequency of the Alamosa Canyon Bridge in New Mexico varied by 5\% during a 24 hours test period. Another study conducted by (Farrar et al., 1994) identified the fundamental natural frequencies on I-40 Bridge over the Rio Grande in New Mexico to go against intuitive expectations as 4 levels of deteriorations were purposely inflicted on the beams. In this study, Farrar attributed the variation in dynamic properties of the bridge to temperature effects. Another limitation discussed by (Friswell and Penny, 1997) was the inability to 
locate damage considering the global nature of the modal parameter opposed to the local nature of the damage. Similar concerns were also discussed by (Aktan et al., 1999) were the authors suggested that both local and global approaches to SHM needed to be investigated simultaneously. (Garibaldi et al., 1999) stated another shortcoming for SHM using vibration measurements which is related to accessibility limitations on bridges and large structures for placing sensors. Most under-decks are inaccessible and it is definitely impractical to close bridges for periodical monitoring and data collection.

SHM process attempts to monitor measurements information from dynamic input and response of structures and identify the onset of damage by regression analysis. (Farrar and Doebling, 1999) suggested a statistical pattern recognition paradigm in four parts; (1) Operational Evaluation, (2) Data Acquisition, Fusion, and Cleansing, (3) Feature Extraction and Information Condensation, and (4) Statistical Model Development for Feature Discrimination. (Sohn et al., 2001) provide a comprehensive review of latest technologies and methods for identification of damage through techniques that examine changes in measured dynamic response in structures and mechanical systems. In their review, Sohn et al. stated that many researchers have noted the need to use vibrations induced by ambient environmental or operating loads for assessment of the structural integrity of large infrastructures opposed to dependence on artificial excitation mechanisms. However, the structural system in the case of bridges is harder to analyze, since the natural frequency of the system does not remain constant but oscillates in a range with respect to the location of moving vehicles (Li et al., 2002) . This approach was followed by (Nagayama et al., 2005) to identify modal properties of the Hakucho Bridge in Japan, utilizing ambient vibration measurements. The following section presents a summary of studies involving periodically sampled dynamic response measurements from an array of sensors to determine the state of health in bridges.

(Cioara and Alampalli, 2000) conducted a study on 3 bridges in New York State between 1993 and 1995 to estimate modal parameters from excitations that are provided from normal traffic. In order to remove the free response components from the forced response the authors used a variant of the random decrement technique and modal 
parameters were estimated from the free decay time series. A concluding remark was that environmental conditions such as temperature and humidity play a major role in variations in modal parameters.

(Rohrman et al., 1999) conducted a 3 years experimental study on the Westend Highway Bridge in Berlin to provide a mathematical formula that describes the change in bridge frequency due to thermal effects. The bridge is $243 \mathrm{~m}$ (797 ft) long and consists of 8 spans of pre-stressed concrete box girders. The authors concluded that the bridge reactions on the footings as well as material properties change with temperature if the bridge free expansion and contraction is obstructed. The authors also suggested a linear relationship between the measured natural frequencies and temperature. Regression analysis of measurements indicated a change is the first 12 first natural frequencies amounting $0.75 \times 10^{-2}$ to $4.3 \times 10^{-2} \mathrm{~Hz}$ every $1^{\circ} \mathrm{C}$.

(Lau et al., 1999) studied the effect of wind on structural health monitoring of three bridges in Hong Kong; the Tsing Ma, Kap Shui Mun, and Tin kau Bridges. The authors used a sensory system consisting of 756 sensors to measure wind velocity, temperature, accelerations, strains, displacements, and weight of vehicles. Installed video cameras allowed monitoring of traffic flow. The system allows calculating the natural frequencies, mode shapes, and modal damping ratios for the suspending cables to calculate their tension. The authors concluded that the bridges were over designed.

A study by (Ren et al., 2004) was conducted on the John A. Roebling Suspension Bridge over the Ohio River between Covington, Kentucky and Cincinnati, Ohio. This investigation aims to determine the live load response and safety margins of the bridges' main cables. The bridge was completed in 1867, and consist on a $321.9 \mathrm{~m}$ (1056 ft) main suspended span that carries two-lanes steel grid roadway and sidewalks cantilevered from the trusses. The suspension bridge system consists of two sets of suspension cables that are restrained by massive masonry anchorages. Dynamic parameter characteristics were acquired through ambient vibration test data using 14 accelerometers that were placed at the beam joints in the lower chord of the stiffening 
truss in orientations that allowed capturing vertical as well as transverse accelerations. The natural frequencies resulting from 3 tests were used to update a Finite Element Model which was used to define the bridge load carrying capacity. The authors concluded that the cables safety factor were still greater than 2 assuming $40 \%$ reduction of the primary and secondary cables cross sectional area.

The Maysville cable-stayed Bridge connecting Maysville, Kentucky and Aberdeen, Ohio over the Ohio River was subject to an investigation to analyze its dynamic characteristics and to establish a finite element model as a baseline in its structural analysis and monitoring studies (Harik et al., 2005) . The bridge has a total length of $640 \mathrm{~m}(2100 \mathrm{ft})$, carries 2 traffic lanes and 2 shoulders and was open to traffic in 2001. The cable-stayed superstructure consists of precast and post-tensioned concrete deck sections supported by 2 main steel plate girders with floor beams. Suspension cables are anchored to 2 main concrete towers. On-site dynamic testing provided acceleration data from 3 tests conducted in 2001 through ambient vibrations. Triaxial accelerometers were used in 80 locations on the deck and provided time-history data as loaded trucks excited the bridge. The modal characteristics of the bridge were extracted from the peak picking of the average normalized power spectral densities in frequency domain. The test results were used to calibrate a finite element model that reflects the as-built initial structural condition of the bridge. The authors report that a good agreement was observed between the frequency results of the calibrated finite element model and those from the field tests. It was also cited that good match for higher modes was not expected using output-only filed measurements.

(Cunha et al., 2001) conducted a study on the Vasco Da Gama Cable-stayed Bridge crossing the Tagus River in Portugal. The bridge has a central span of $420 \mathrm{~m}$ $(1378 \mathrm{ft})$ long that crosses the main navigation channel and consists of two main lateral prestressed girders connected by a slab and transverse steel I-Beams. The bridge is suspended by two plans of 48 stays connected to each of the two concrete towers. An experimental study was conducted to identify the most relevant modal parameters from the aerodynamic and seismic point of view. The experimental program consisted of 
preliminary measurements of acceleration levels, ambient vibration test to identify global natural frequencies and mode shapes using 58 measurement stations on the deck and towers, response measurements due to heavy truck load excitation, free vibration test, and dynamic measurements of stay cables. The instrumentation system combined between independent triaxial accelerographs synchronized and laser interferometry for noncontact dynamic measurements of stay cables. Results of natural frequencies and mode shapes from the tests showed good correlation with analytical predictions from a finite element model developed at design stage.

\subsection{Review on Empirical Bridge deck design}

The $16^{\text {th }}$ edition of the (AASHTO, 1996) guide provided standard specifications for design of concrete slabs following the flexural method. The factor of safety from decks designed following the working stress design method was found to be at least 10 . However, extensive research work proved that slabs did not resist concentrated wheel loads primarily by flexural action as traditionally believed. The new (AASHTO LRFD, 2004) design guide provides a new concept for design of bridge decks based on findings from nonlinear finite element analysis of reinforced concrete deck behavior by (Fang, 1985) , (Holowka et al., 1980) , (Hewitt and De V Batchelor, 1975) , and (Fang et al., 1990) . The concept is based on an internal arching effect that the slabs sustain due to a complex internal membrane stress behavior which develops once cracking occurs at locations of positive moments. This action results from lateral confinement provided by the surrounding concrete slabs, rigid appurtenances and supporting components, creating an internal compressive dome (Sozen and Siess, 1963) . In this case, failure modes occur due to punching shear rather than flexural stresses. The phenomenon of membrane action in concrete elements was investigated since early ages of concrete construction (Cope and Clark, 1984). Extensive interest in this phenomenon attracted researchers when (Ockleston, 1995) conducted experimental studies on abandoned concrete floors and found enhancement in their ultimate strength to reach double that expected from the yield line theory. (Park, 1964) demonstrated the effect of membrane action through an experimental and analytical investigation and suggested that the maximum compressive 
moment is reached at deflections amounting $1 / 2$ the effective depth of the slab. Park added that beyond this deflection, compressive membrane action diminishes rapidly and flexural action takes over the slab response. Figure 2.1 illustrates development of the membrane action according to Park.

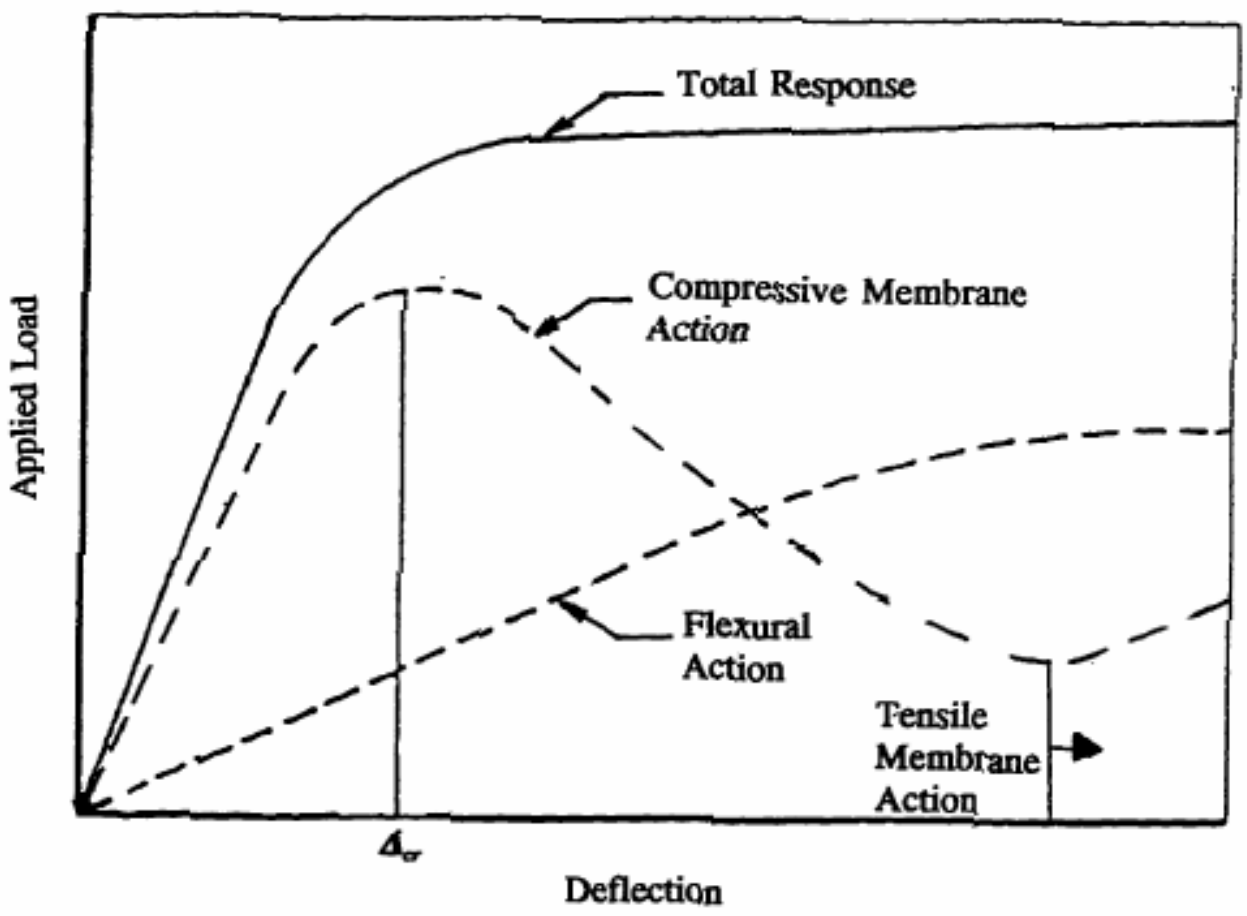

Figure 2.1 Load-Deflection Curves for Partially Restrained Slabs (Park, 1964)

The (AASHTO LRFD, 2004) design specifications suggests 3 methods of analysis for slab-on-beam bridge decks; The approximate elastic method described in Article 4.6.2.1, the refined method specified in Article 4.6.3.2, and the empirical design method specified in Article 9.7.2. The elastic method of analysis is based on subdividing the deck into strips perpendicular to the supporting components and considering the extreme positive moment in any deck panel to apply on all positive moment regions. Similarly, the extreme negative moment over any support would apply to all negative moment regions. The refined method follows a finite element analysis approach which is time consuming and difficult to validate, therefore this method should only be used for special structures (Staff-BridgeSight software, 1999) . The empirical design method is a no analysis method where the reinforcements is prescribed for a given slab cross section. 
Based on physical tests and analytical investigations, the guide states that the most important parameter concerning the resistance of concrete slabs to wheel loads was the ratio between the effective length and the design depth of the slab. Therefore, provisions for empirical deck designs indicated limits to this ratio not to exceed 18 and not to be smaller than 6 . The design guide indicated a minimum slab core depth of 10.16 $\mathrm{cm}$ (4.0 in) and a minimum slab depth of $17.78 \mathrm{~cm}$ (7 in), excluding a sacrificial wearing surface. The empirical design method requires four layers of isotropic reinforcements that provide both local flexural resistance and global confinement necessary to develop arching effects. The minimum amount of reinforcement is $0.27 \mathrm{in}^{2} / \mathrm{ft}$ of steel for each bottom layer and $0.18 \mathrm{in}^{2} / \mathrm{ft}$ of steel for each top layer. The specified steel to gross area are requirements to provide better crack control in the positive moment area, and to prevent spalling of the deck due to bar corrosions. The provisions in the new design guide do not include cantilevered overhanging slabs (Hays et al., 1989) .

Comparing the reinforcement requirements in the empirical design method to that in the traditional flexural method indicates that a reduction up to $50 \%$ in the main steel reinforcement can be realized using the empirical method. Figure 2.2 shows a comparison of steel reinforcement required in both methods as sited by (Fang et al., 1990).

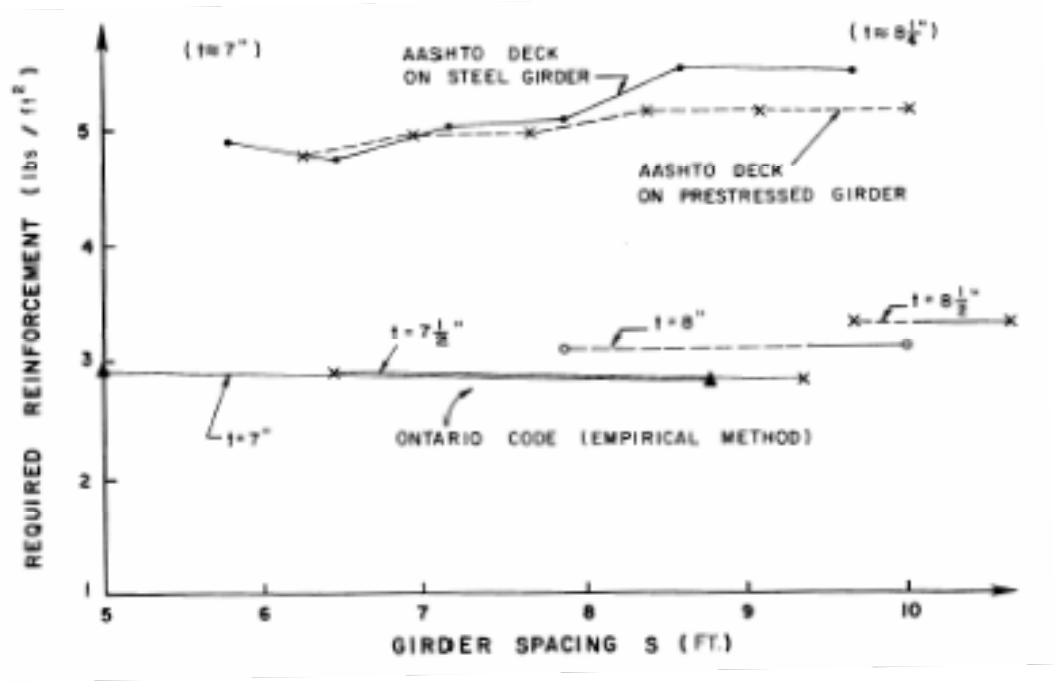

Figure 2.2 Deck Reinforcement Required for Interior Slab and Girder Bridge (Fang et al., 1990) 


\subsection{Concluding Remarks}

A review of the literature is conducted to identify the state of the art in instrumentation systems for remote monitoring and analysis of bridge decks. The review focused on identifying techniques that proved successful in securing valuable data for long term monitoring of bridge structures as well as instrumentation methods that identified bridge deck behavior from dynamic measurements. Design methods for concrete bridge decks suggested by the AASHTO LRFD bridge design guide are briefly reviewed. The following remarks can be drawn from this review:

- Advanced technologies in instrumentation, measurement systems and communications attracted structural engineers and researchers for remote monitoring of bridge systems during the last 2 decades.

- Although a number of challenges face the effective application of structural health monitoring strategies, various measurement systems demonstrated to be useful for identifying key-performance parameters through long term monitoring programs of bridge decks.

- SHM programs based on continuous measurements has been used for evaluating performance of structures, identify symptoms of operational incidents, anomalies due to deterioration and damage, and for checking the structural health during or after an extreme loading event.

- There is no off-shelf type bridge monitoring system available, therefore researchers have to assemble suitable components that would satisfy their monitoring objectives by integrating existing technologies in the most costeffective, efficient and reliable design.

- Dynamic properties of large structures are sensitive to environment variations, therefore damage identification using vibration analysis of infrastructures could 
lead to misleading results if effects of temperature, and moisture changes are overlooked.

- Both local and global approaches for Structural Health Monitoring strategies are needed to be investigated simultaneously in order to provide a set of indices that can adequately assess the condition of a structure and diagnose any signs of deterioration.

- There is more interest to use ambient environmental or operating loads for assessment of the structural integrity of large infrastructures opposed to dependence on artificial excitation mechanisms.

- Due to accessibility limitations, it is preferable to install instrumentation systems while the structure is being under construction, provided that the system is rugged to sustain hazards from construction operations.

- The empirical deck design method specified by the AASHTO LRFD bridge design guide is newly adopted and no long term data are available to verify the performance of such decks in operational environment. 


\section{CHAPTER 3}

\section{DESCRIPTION OF STAR CITY BRIDGE}

\subsection{Introduction}

The new Star City Bridge is replacing a two lane steel bridge that became a bottleneck for traffic in the Area of Star City, Morgantown, WV and their surroundings. In 2001 Buchart-Horn Inc. was recognized for this design achievement in the category of large bridges. The design of the new Star City Bridge captured First Place honors for the Engineering Excellence Award at West Virginia Department of Transportation Division of Highways. The deck is analyzed following the latest design methods for light weight bridge decks which offer a remarkable amount of flexibility despite its long span.

The bridge measures 306 meters $(1004 \mathrm{ft})$ in total length and consists of 5 traffic lanes that cross the Monongahela River over 4 spans to connect Star City and Morgantown (WV) to I-79. Figure 3.1 is a view of the bridge after completion of construction work and open to traffic.

The bridge design is governed by the West Virginia Department of Transportation, Division on Highways Standard Specification for Road and Bridges, Adopted in 2000, and its supplemental specifications. The design follows the (AASHTO LRFD, 1998) Bridge Design Specifications. Construction followed a sequence of 2 major stages. Stage one consisted of casting the substructure and superstructure for northbound portion of the bridge while maintaining traffic on the existing old bridge. Stages two consisted of the substructure and superstructure of the southbound portion of the bridge. A closure pour linked the two phases and formed the median curb. Figure 3.2 illustrates a cross section of the deck and shows both construction stages. The bridge has a $102^{\circ}$ skew angle with its centerline. 


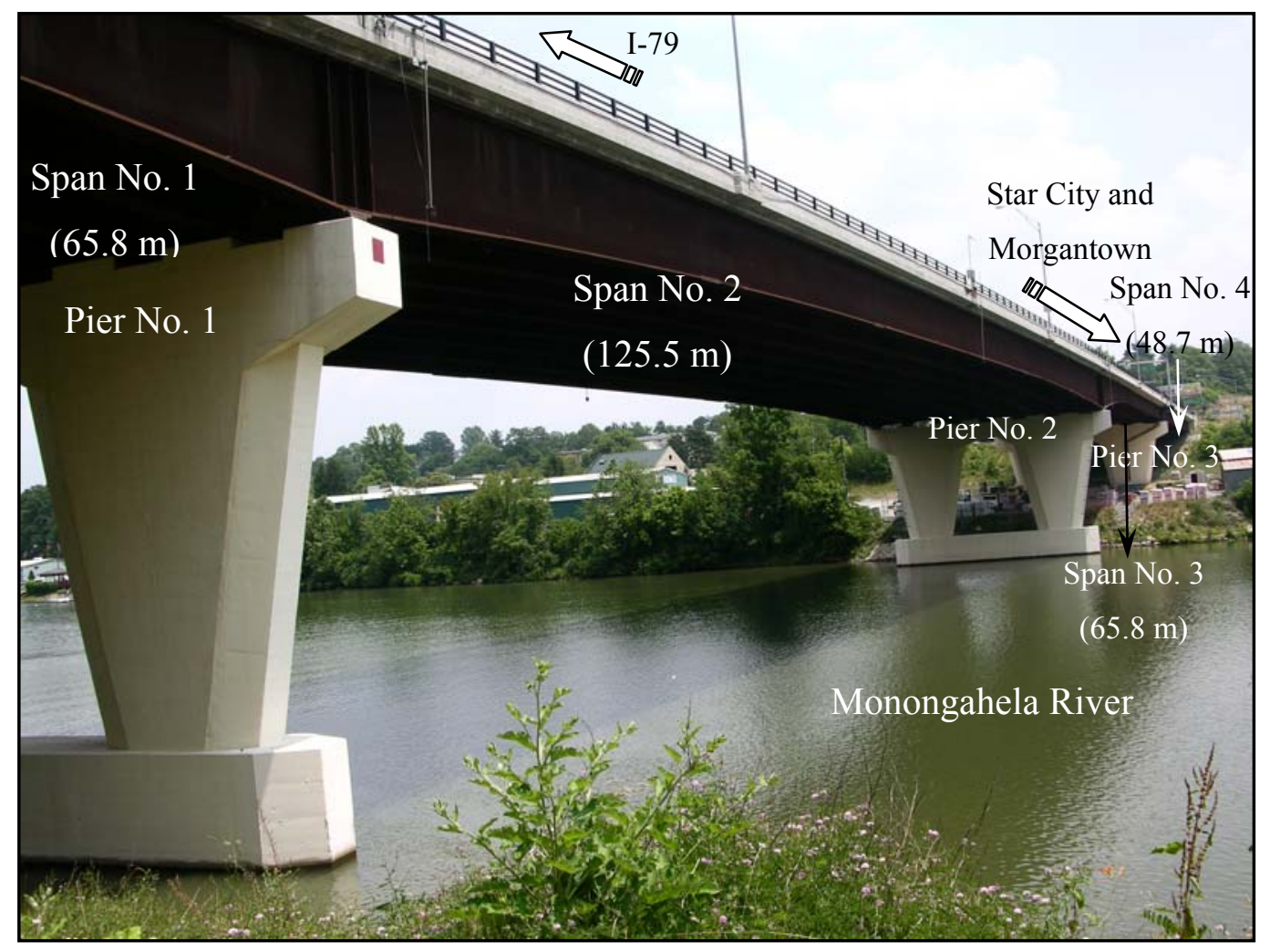

Figure 3.1 Star City Bridge Open to Traffic

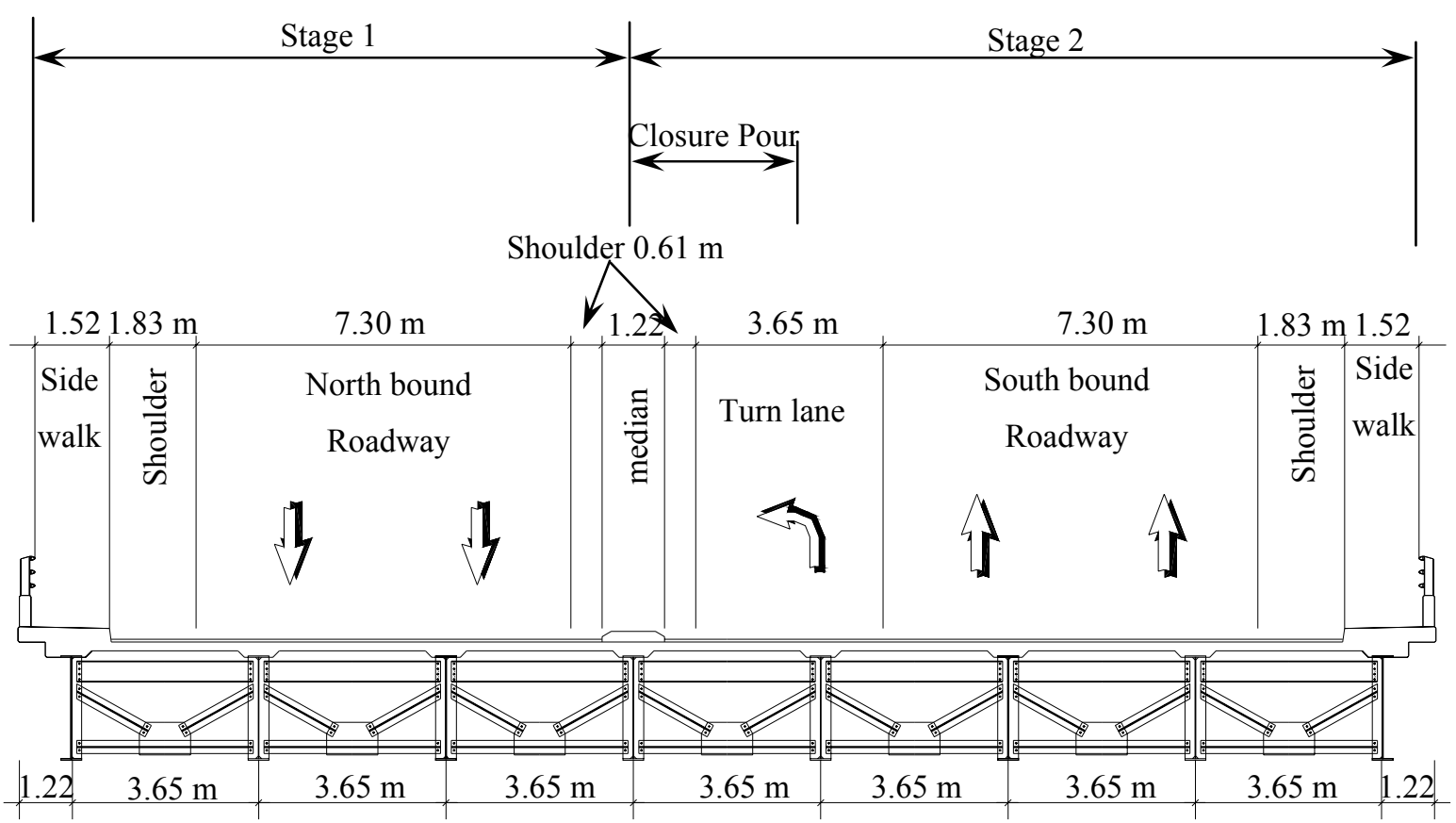

Figure 3.2 Deck Cross Section Showing Sequence of Construction 


\subsection{Reinforced Concrete Deck}

The concrete deck consists of a reinforced concrete slab $16.5 \mathrm{~cm}$ thick (6.5 in), overlaid by a $5 \mathrm{~cm}$ ( 2 in) layer of Latex Modified Concrete (LMC). The concrete deck is supported by steel girders spaced at 3.65 meters $(12 \mathrm{ft})$. Design specifications indicate use of concrete Class $\mathrm{K}$ with water reducing and retarding admixtures. Epoxy coated rebars in accordance with AASHTO M31, Grade 60 (AASHTO M31, 1996) are used as steel reinforcement. A minimum concrete cover of $2.54 \mathrm{~cm}(1 \mathrm{in})$ is specified for both top and bottom steel reinforcing mats. Figure 3.3 shows a detailed cross section of the concrete deck slab. Stay is place forms have been used in casting the deck.

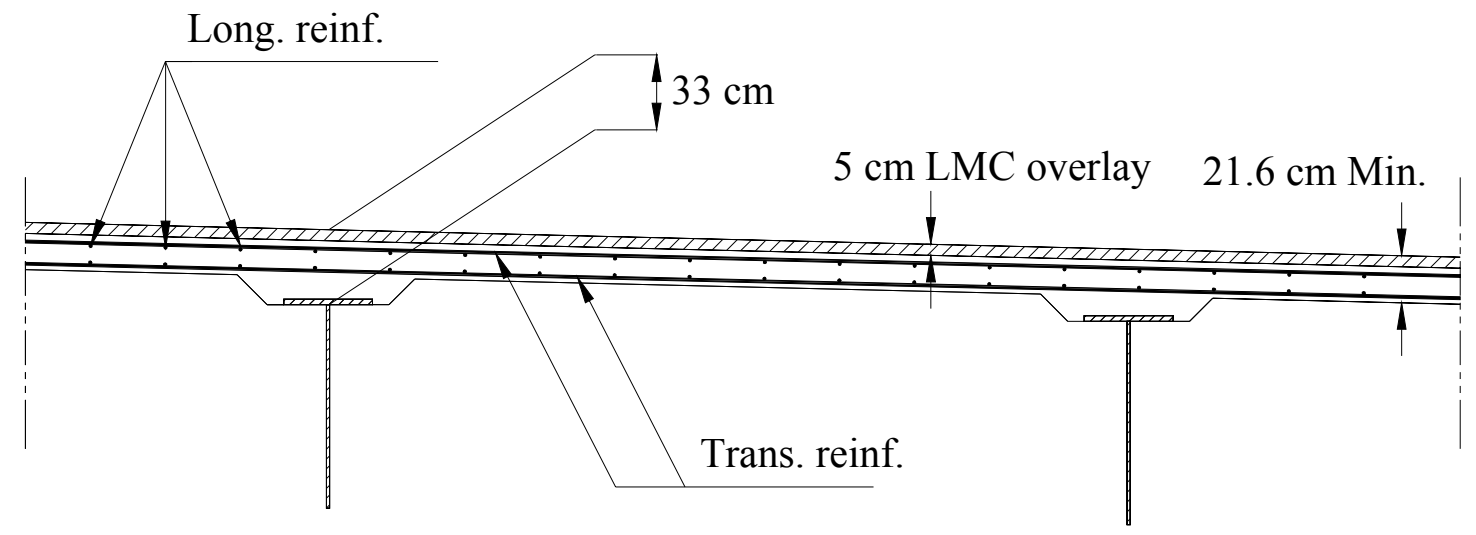

Figure 3.3 Details of Deck Slab

The concrete deck corresponding to each stage was planned to be poured in a sequence of 4 periods. Figure 3.4 illustrates the pouring sequence of the concrete deck as planned in the bridge construction sheets. While pouring phase two, periods 6 and 7 were combined together to overcome delays due to cold weather conditions. A modular expansion joint is placed at each end of the bridge designed to allow expansion and contraction up to $30 \mathrm{~cm}$ (12 in). 


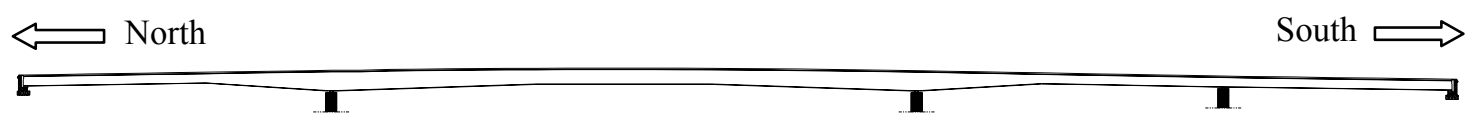

\section{ELEV.}

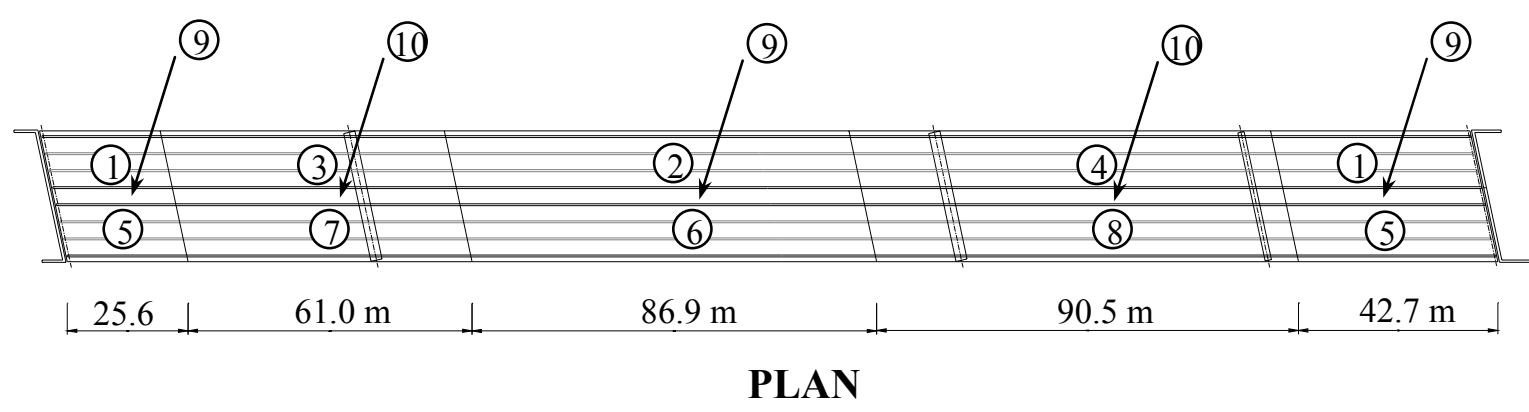

Figure 3.4 Sequence of Concrete Deck Pour

\subsection{Steel Superstructure}

8 identical continuous steel girders with variable inertia support the concrete deck. The girders web varies in height from 1.98 meters $(6.5 \mathrm{ft})$ to 3.96 meters $(13 \mathrm{ft})$ according to the location along the bridge length. All structural steel components are from weathering steel material. Grade $50 \mathrm{~W}$ steel is specified for the portion of girders at mid-spans and at locations of both abutments and Pier 3, while grade HPS70W is specified at locations of Pier 1 and Pier 2. Tension flanges, webs and splice plates are designed to meet AASHTO requirements of Grade 50-T2 in areas where grade 50W steel is used and the AASHTO requirements of Grade 70-T2 where grade HPS70W steel is used. Fabricated sections of the steel members were stored at the project site till assembly as continuous girders by field bolted splices. No field welding or cutting was permitted on the site. The overall dimensions of the steel girders are shown in Figure 3.5. 


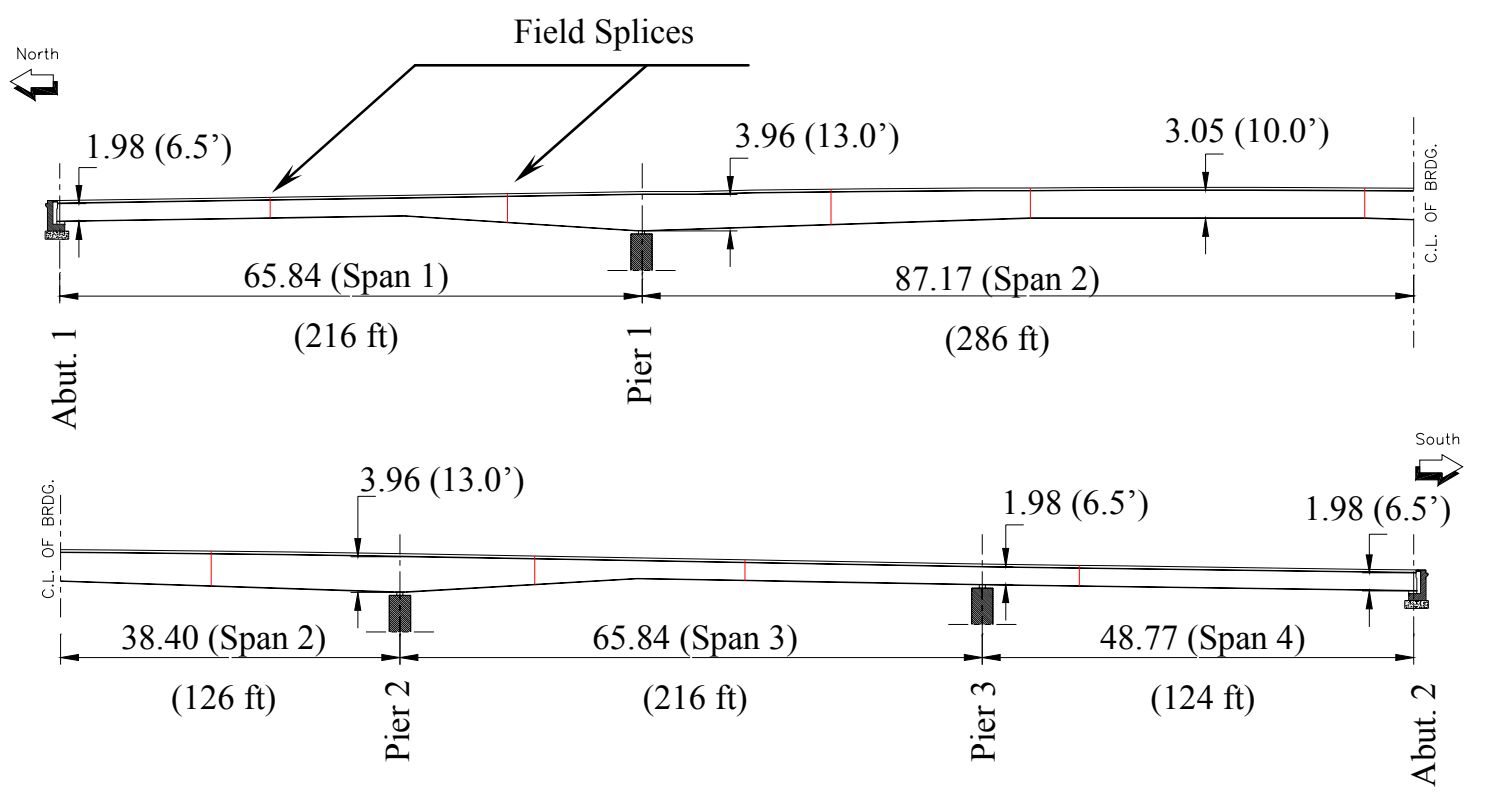

Figure 3.5 Main Dimensions of Steel Girders

The bracing system consists of steel diaphragms as shown in Figure 3.6, spaced at intervals of $8.23 \mathrm{~m} \mathrm{(27} \mathrm{ft)} \mathrm{at} \mathrm{Span} 1$ and Span 3, $8.38 \mathrm{~m}(27.5 \mathrm{ft})$ at Span 2, and $8.15 \mathrm{~m}$ $(26 \% / 4 \mathrm{ft})$ at Span 4 . The superstructure rests on reinforced elastomeric bearings that transfer the deck load to the abutments and piers. Figure 3.7 illustrates erection operations of steel girders

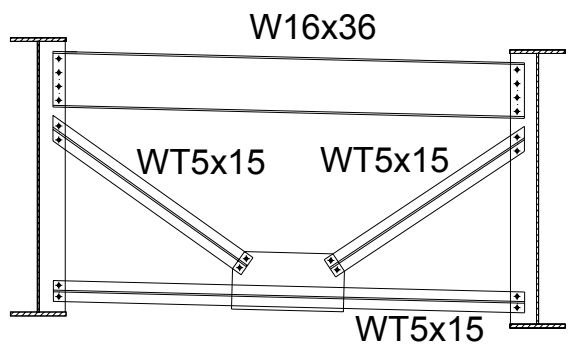

Typical End Diaphragm

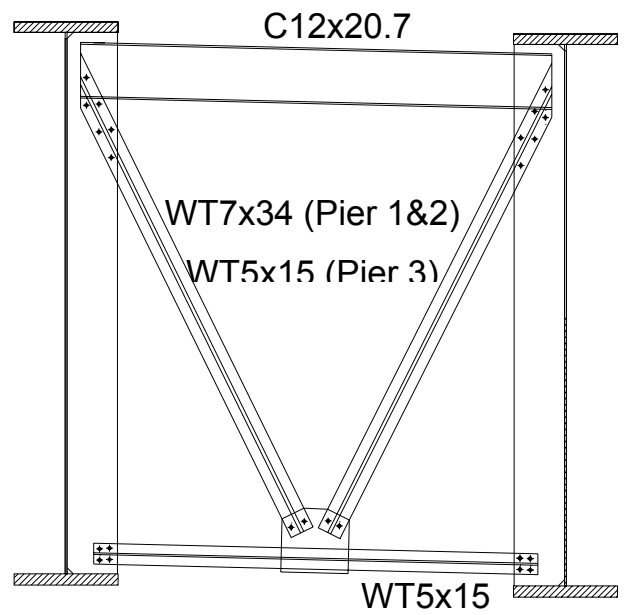

Typical Intermediate and Pier Dianhragms

Figure 3.6 Diaphragm Details 


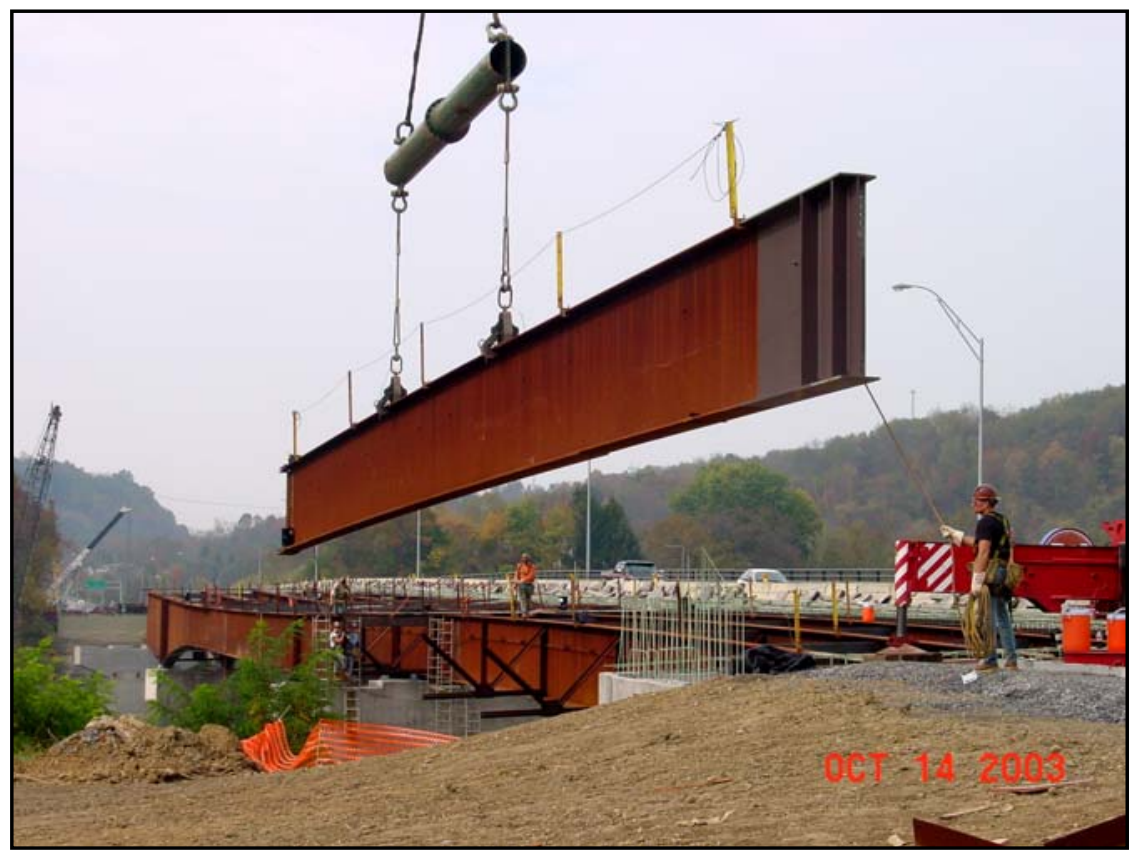

Figure 3.7 Erection Operations of Steel Girders.

\subsection{Substructure}

The substructure consists of 2 abutments, wingwalls and 3 Piers. All but Abutment No.1 are supported by deep foundation consisting of piles and caps, while Abutment No.1 is resting on shallow foundations. The actual vertical clearance above normal water level measures $16.76 \mathrm{~m}(55 \mathrm{ft})$.

\subsection{Concrete Material Testing}

In order to be able to analyze any structural system, mechanical properties of the materials used need to be evaluated. Despite the fact that concrete appears as a simple material, it is very complex in its nature and determining its characteristics requires extensive testing planning. The mechanical properties of the concrete material used to cast the concrete deck are evaluated according to an experimental program based on testing standard concrete specimens. This testing program is set to evaluate the development of mechanical concrete properties with age starting from day 3 till 60 days after casting. Experiments focus on evaluating mechanical properties such as 
compressive strength $\left(\mathrm{f}_{\mathrm{c}}{ }_{\mathrm{c}}\right)$, tensile strength $\left(\mathrm{f}_{\mathrm{s}}\right)$, Modulus of Elasticity $\left(\mathrm{E}_{\mathrm{c}}\right)$, Poisson's Ratio (r), and Coefficient of thermal expansion and contraction $\left(\alpha_{c}\right)$. Table 3.1 gives an overview of the performed tests and number of specimens along with their respective age.

Table 3.1 Tests Plan for Measurements of Concrete Properties

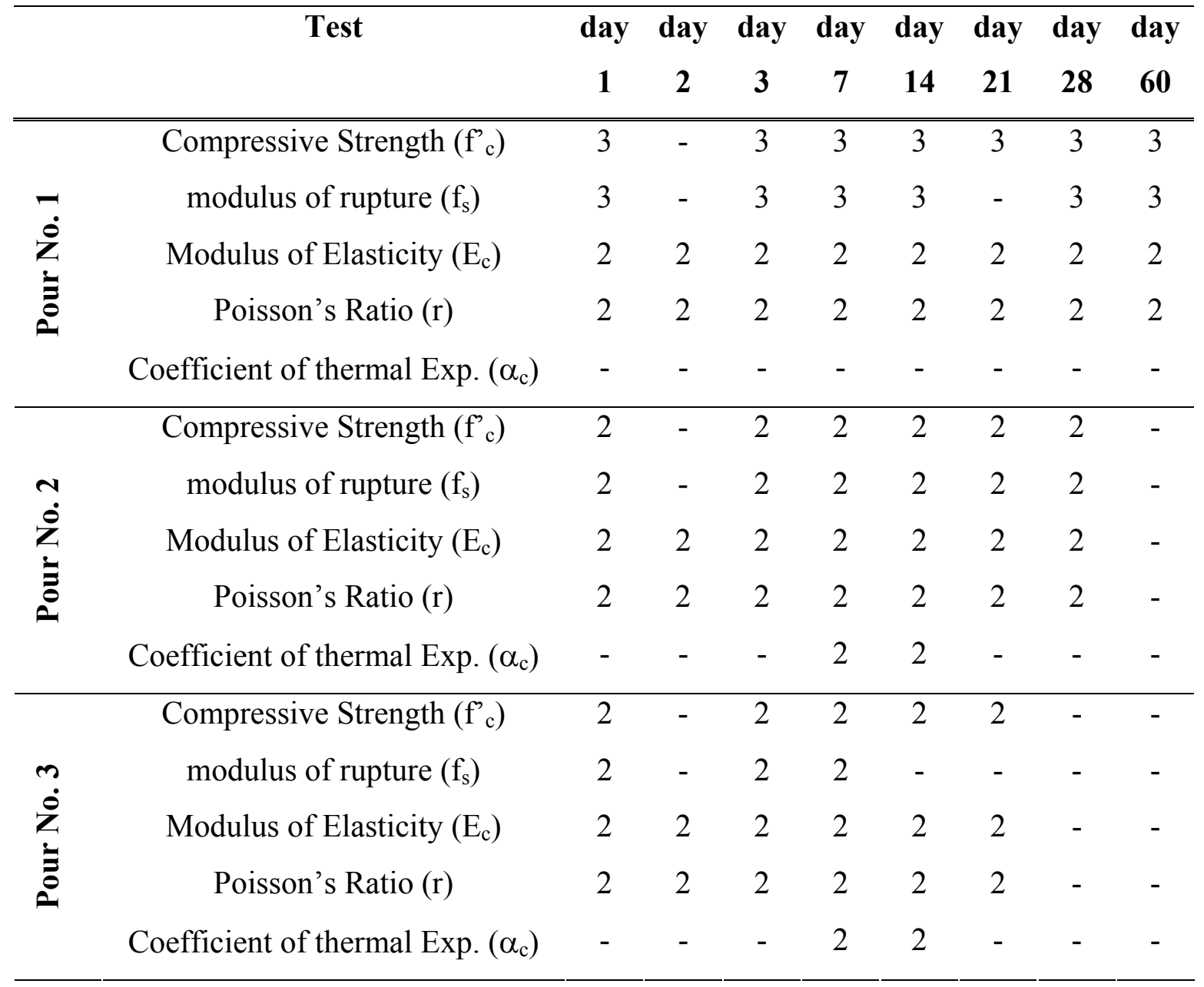

A total of 85 standard concrete cylinders were prepared through the course of the 3 pours of the deck at phase 2. Among those, 6 were instrumented with embedment strain gages; 2 at each pour. 43 specimens were tested to determine the compressive strength at various ages. 36 specimens were tested to determine the tensile strength at various ages. For each pour, 2 instrumented cylinders served to plot stress-strain relations to evaluate the concrete elastic properties. The instrumented cylinders were also used to plot longitudinal 
versus lateral strains to determine Poisson's ratio and to evaluate the concrete thermal characteristics at various ages.

\subsubsection{Specimen Preparation}

Standard concrete cylinders (6" x 12") were prepared and cured according to ASTM C192/C192M-02 (ASTM, 2002) . PVC cylindrical molds were used for casting concrete cylinders after being greased from the inside surface. Specimens were cast at the site location and were covered in plastic sheets in place till initial setting time. Concerns of cold weather conditions at the site mandated transferring the concrete specimens to the laboratory as soon as possible. Once the concrete material gained initial strength (8-12 hours) they were removed to the laboratory for curing. Molds were removed after 24 hours of casting and cylinders were moist cured by immersion in saturated water till the moment of testing. A submerged water pump circulated the water in the curing tank continuously and temperature was controlled at $25^{\circ} \mathrm{C}$ using a tank-heater.

Six instrumented cylinders were prepared for non-destructive testing. Instrumentation for each specimen consisted of 2 embedment Vibrating Wire (VW) strain gages model 4202 manufactured by Geokon (Geokon, 1996). Each strain gage incorporate a thermistor type YSI 44005 that provides actual temperature at the surrounding concrete medium and is used to make temperature compensation to the strain gage reading. The strain gage has a gage length of $51 \mathrm{~mm}$ ( $2 \mathrm{in}$ ) which is suitable for embedment in the concrete cylinder without affecting its characteristics. All sensor components are made of stainless steel and the gage is fully waterproof. Figure 3.8 illustrate an instrumented mold prior casting concrete. The two embedment strain gages are fixed together in an orthogonal configuration at their center (non-moving element). A thread is initially used to tie the two strain gages outside the mold and secure them in a cross shape with a $90^{\circ}$ angle. The two gages are then fixed with epoxy at their center. This arrangement is then placed at the mold center using strings that are attached to the mold sides. The strain gages are secured at their location in order to provide strain data from the longitudinal as well as lateral direction as the specimen is loaded. Care is taken while arranging the strain gages in 
order not to damage the gages at any stage. The gage readings are checked before and after each step using a portable reading unit (GK 403) and the threads used to hold the gages in position do not exert any excessive stains on the gages.

\subsubsection{Compressive strength}

Concrete is essentially a compression material. It is well known that the compressive strength of concrete is much higher than its tensile strength and in many cases the tensile resistance is neglected all together in design. Therefore, measurements of compressive strength of concrete material are of main interest in any project. Testing of compressive strength was carried out according to ASTM C39/C39M-99 (ASTM, 1999) as illustrated in Figure 3.9. Results from compression tests for the three pours are listed in Table 3.2. The results are average values of tested specimens. Detailed results of all compression tests can be found in (Appendix A1-Section A1.1).

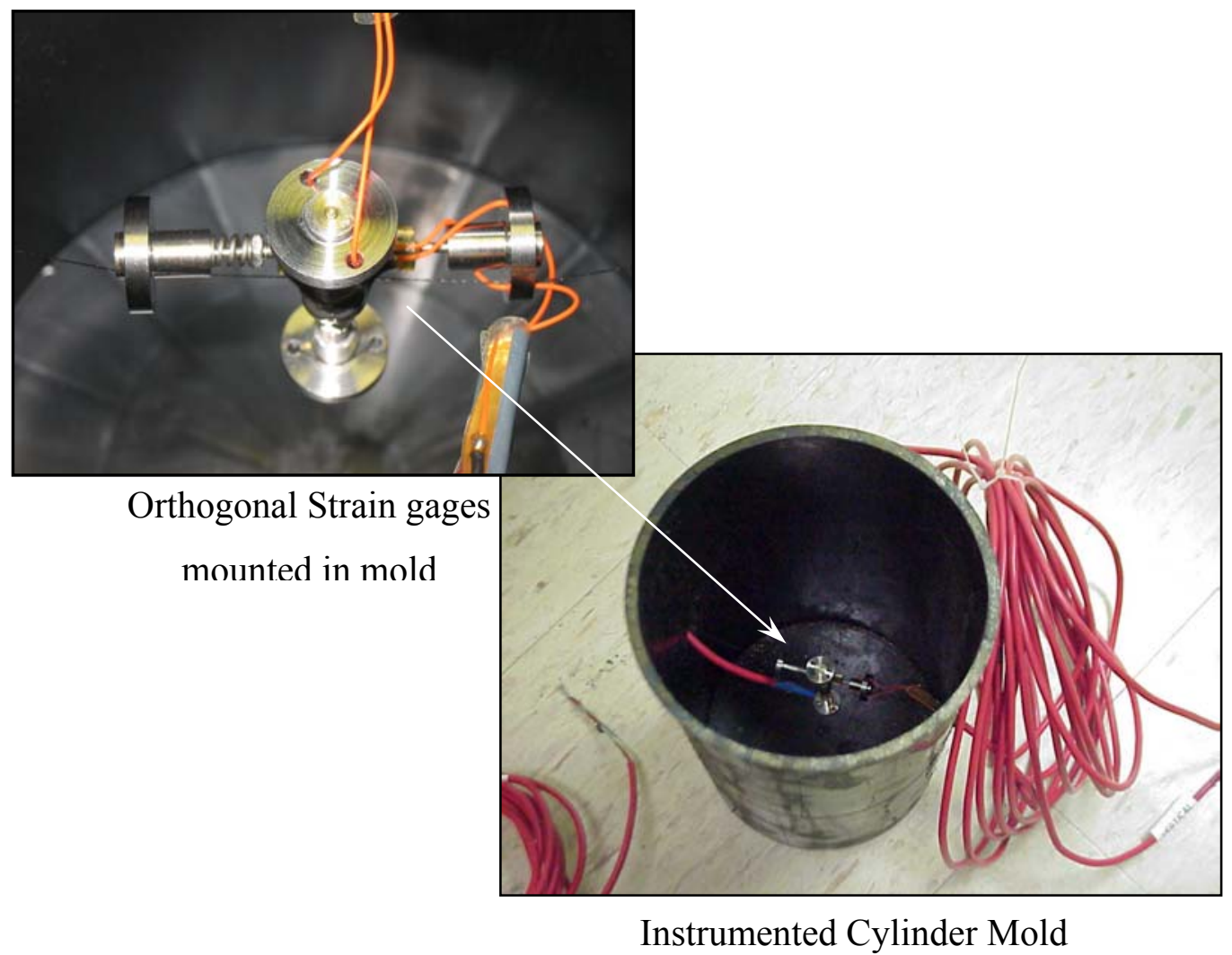

Figure 3.8 Instrumentation for Standard Concrete Cylinder 
Table 3.2 Average Compressive Strength of Concrete Material [MPa (PSI)]

\begin{tabular}{lccc}
\hline Age of Concrete & Pour No. 1 & Pour No. 2 & Pour No. 3 \\
\hline Day 1 & $12.27(1780)$ & $15.06(2184)$ & $17.74(2573)$ \\
Day 3 & $25.76(3737)$ & $21.34(3095)$ & $29.63(4297)$ \\
Day 7 & $34.13(4951)$ & $31.21(4527)$ & $30.48(4421)$ \\
Day 14 & $38.20(5541)$ & $34.32(4978)$ & $35.24(5111)$ \\
Day 21 & - & $34.75(5040)$ & $32.74(4748)$ \\
Day 28 & $40.80(5918)$ & $35.54(5155)$ & - \\
Day 60 & $47.61(6906)$ & - & - \\
\hline
\end{tabular}

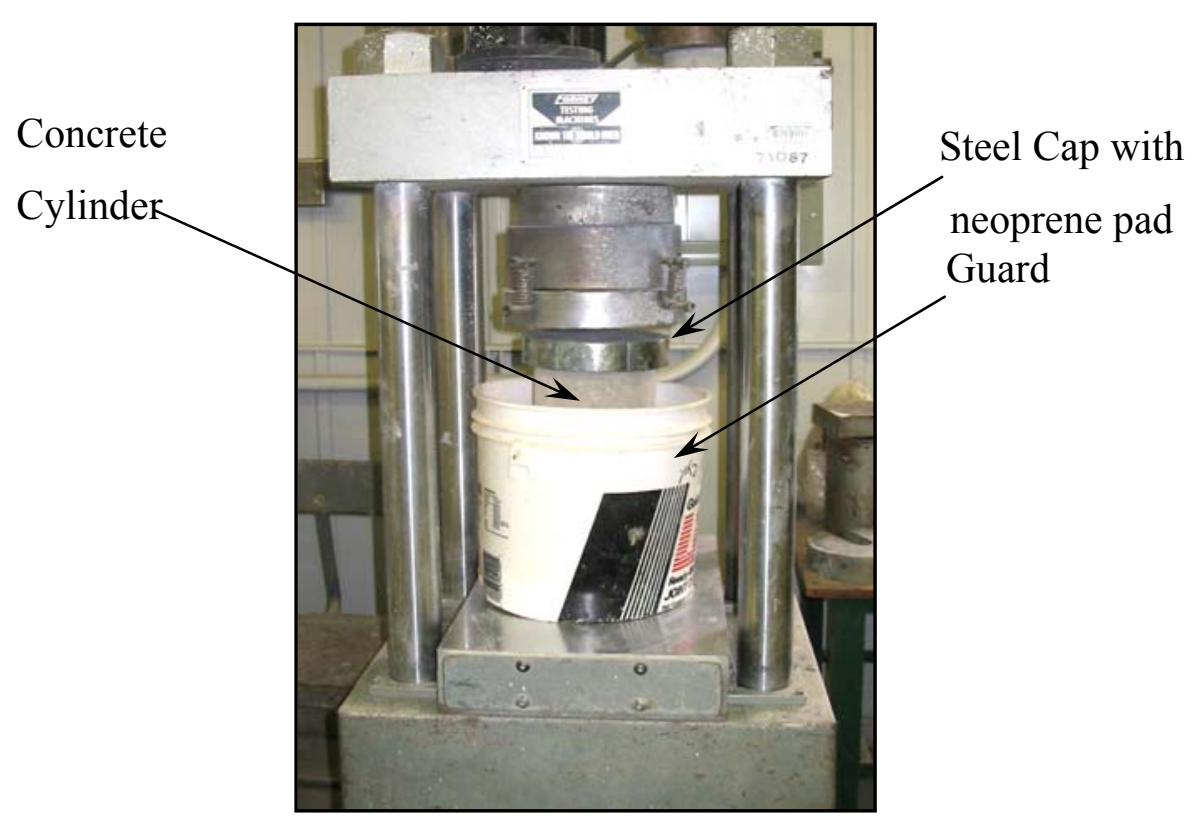

Figure 3.9 Testing of Compressive Strength of Concrete

\subsubsection{Tensile Strength}

(Carino and Lew, 1982) conducted a study on statistical analysis of experimental data of splitting tensile strength and compressive strength of normal-weight concrete. The data included published test results by (Gardner and Poon, 1976) as well as unpublished data from the National Bureau of Standards (NBS), (Lew and Reichard, 1978). In their study, Carino and Lew reported that the assumed proportionality of splitting tensile strength to the square root of compressive strength was not the most accurate relationship. Carino 
and Lew argued that the current ACI formula overestimated the splitting tensile strength for low compressive strength and underestimated that for high compressive strength. Therefore tensile strength of concrete material at various ages was determined by conducting a set of tests in the laboratory. Standard concrete cylinders were tested for splitting tensile strength according to ASTM C496/C496M-02 . A summary of the test results are listed in Table 3.3, while detailed results are given in (Appendix A1-Section A1.2).

Table 3.3 Average Tensile Strength of Concrete Material [MPa (PSI)]

\begin{tabular}{lccc}
\hline Age of Concrete & Pour No. 1 & Pour No. 2 & Pour No. 3 \\
\hline Day 1 & $1.60(233)$ & $2.14(310)$ & $2.03(249)$ \\
Day 3 & $3.11(451)$ & $2.91(422)$ & $2.23(324)$ \\
Day 7 & $3.52(511)$ & $3.27(474)$ & $3.02(438)$ \\
Day 14 & $3.45(501)$ & $3.53(512)$ & - \\
Day 21 & - & $3.43(498)$ & - \\
Day 28 & $3.85(558)$ & $4.27(620)$ & - \\
Day 60 & $3.38(491)$ & - & - \\
\hline
\end{tabular}

\subsubsection{Modulus of Elasticity}

Modulus of Elasticity, also known as Young's Modulus, is expressed as the ratio between normal stresses and corresponding strains below the proportional limit of the material. Previous studies showed that the concrete Modulus of Elasticity is directly related to its compressive strength. (Byfors, 1980) studied the early age properties of concrete material where he demonstrated that at 5 hours, the strains in compression are mainly inelastic. Byfors recorded that the concrete material at that early age behaves similar to a clay-like material. The known stress-strain relationship that characterizes the concrete material starts appearing after 15.8 hours. After this particular age, the shape of the stress-strain relationship does not change radically although its absolute quantitative magnitudes vary. The modulus of elasticity of the three deck pours was evaluated at ages ranging from 24 hours till 60 days after concrete casting. Test procedures followed 
specifications of ASTM C469-94e1 for determining the static Modulus of Elasticity of Concrete in compression. The Instrumented cylinders were used for this purpose where compressive stresses are provided through a loading frame, and corresponding strains are collected from the embedment strain gages. For every particular age of concrete, two tests were performed on two different cylinders and the value of the modulus of elasticity refers to their average.

The test setup is illustrated in Figure 3.10 and a schematic diagram illustrates the setup main components in Figure 3.11.

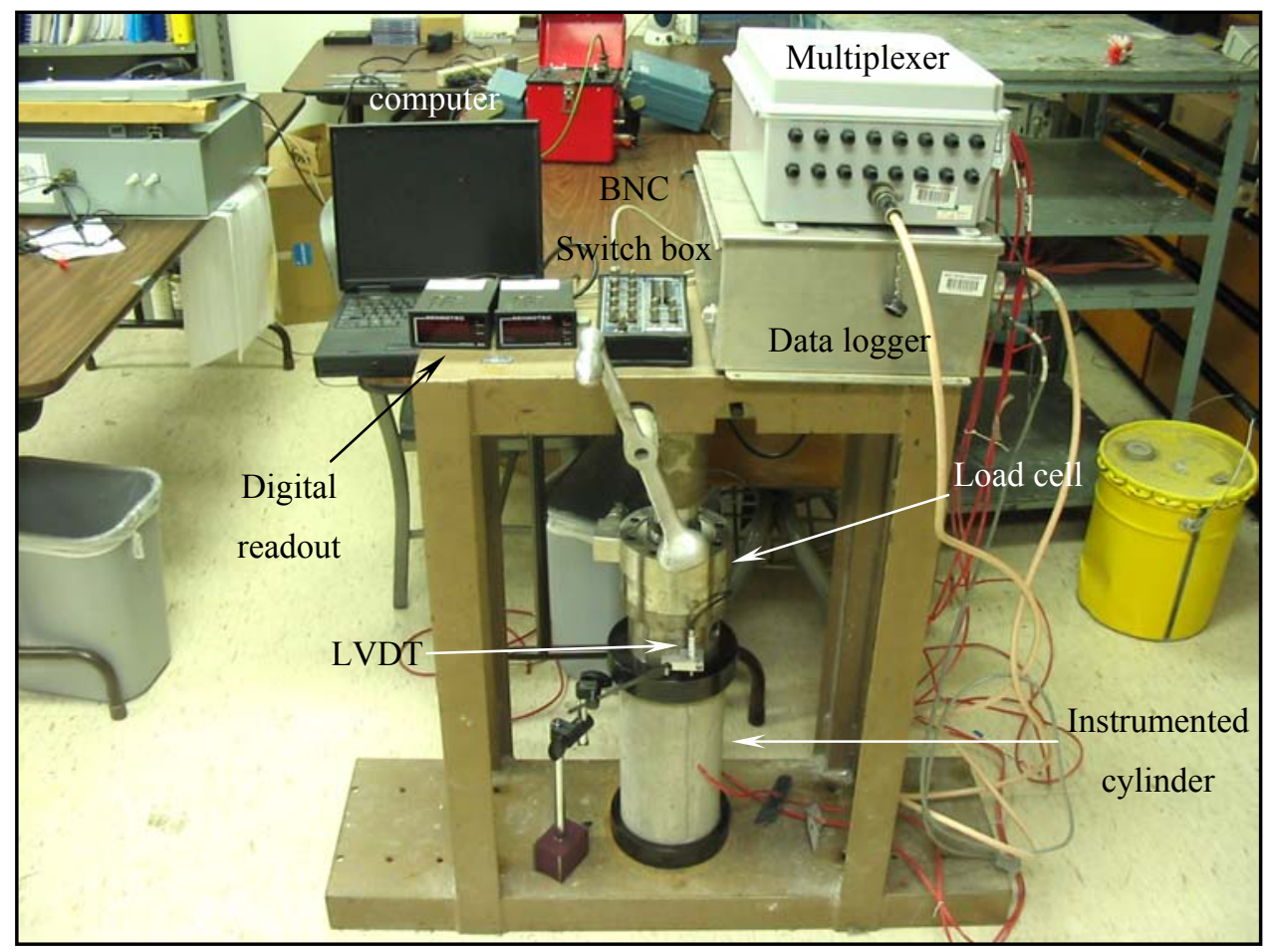

Figure 3.10 Test Setup for Measurements of Modulus of Elasticity 


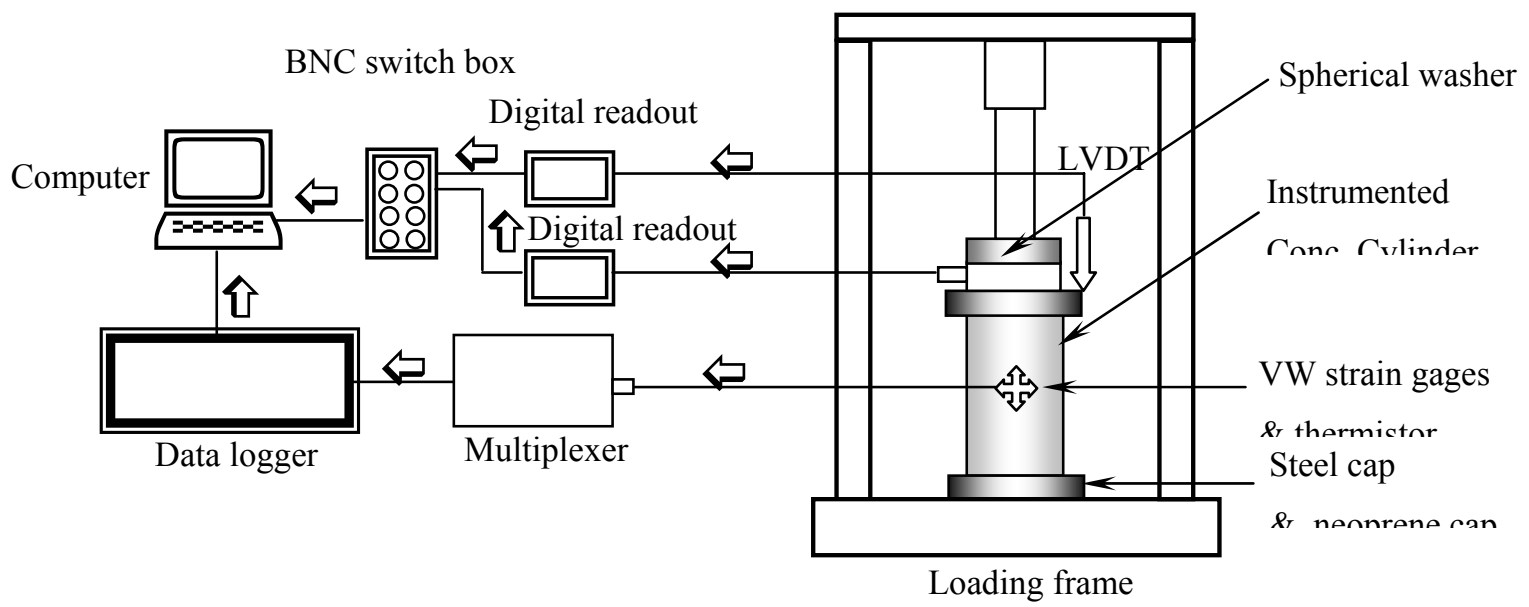

Figure 3.11 Schematic Diagram of Setup for Measurements of Modulus of Elasticity The setup main components are:

- Instrumented concrete cylinder for measuring compressive stress and corresponding strains. The cylinder is loaded using standard steel caps and neoprene pads to insure a uniform stress across the cylinder top and bottom surfaces. A spherical washer is used to apply an axial load on the specimen.

- Load cell model (41/0573-01) from Sensotec with capacity $222 \mathrm{KN}$ (50,000 lbs) for recording the applied load.

- LVDT model 060-3590 from Sensotec with 0.2 inches range for monitoring rate of deformation.

- Signal conditioner and digital indicator (Sensotec model GM) as readout units for load cells and LVDT.

- BNC switch box from National Instruments.

- Multiplexer model 8032 from Geokon.

- Data Logger model 8020 Micro-10 from Geokon for recording of strains and temperature data from vibrating wire sensors.

- Computer equipped with Labview software for recording of loading data as well as online monitoring of loading and displacement rates, and Multilogger software for controlling the data logger. 
Table 3.4 illustrates the average Modulus of Elasticity of concrete material for each pour recorded along ages varying from day 1 to day 60. Detailed results of the testing procedures can be found in (Appendix A1-Section A1.3).

Table 3.4 Average Modulus of Elasticity of Concrete [MPa (PSI x 106 )]

\begin{tabular}{lllllll}
\hline Age of Concrete & \multicolumn{2}{c}{ Pour No. 1 } & \multicolumn{2}{c}{ Pour No. 2 } & \multicolumn{2}{c}{ Pour No. 3 } \\
\hline \hline Day 1 & 36453.27 & $(5.287)$ & 23924.81 & $(3.470)$ & 23062.96 & $(3.345)$ \\
Day 2 & 34408.28 & $(4.991)$ & 27820.34 & $(4.035)$ & 26855.08 & $(3.895)$ \\
Day 3 & 36299.86 & $(5.265)$ & 29130.35 & $(4.225)$ & 28475.35 & $(4.130)$ \\
Day 7 & 38473.43 & $(5.580)$ & 31302.20 & $(4.540)$ & 29095.87 & $(4.220)$ \\
Day 14 & 38091.46 & $(5.525)$ & 34301.42 & $(4.975)$ & 33818.78 & $(4.905)$ \\
Day 21 & 39816.19 & $(5.775)$ & 32508.78 & $(4.715)$ & 32991.41 & $(4.785)$ \\
Day 28 & 40995.54 & $(5.946)$ & 41816.70 & $(6.065)$ & 23062.96 & $(3.345)$ \\
Day 60 & 35095.00 & $(5.090)$ & 23924.81 & $(3.470)$ & - & \\
\hline
\end{tabular}

\subsubsection{Poisson's Ratio}

Poisson's Ratio for concrete material is being calculated from the data collected during the Modulus of Elasticity tests according to ASTM C469-94e1. Strain measurements from the longitudinal and lateral embedment strain gages are used to provide a ratio between the axial and transversal deformation of the concrete cylinder under compression. Poisson's ratio is recorded in Table 3.5 for various concrete ages. 
Table 3. 5 Average Poisson's Ratio of Concrete

\begin{tabular}{lccc}
\hline Age of Concrete & Pour No. 1 & Pour No. 2 & Pour No. 3 \\
\hline Day 1 & 0.259 & 0.1885 & 0.206 \\
Day 3 & 0.24 & 0.2105 & 0.197 \\
Day 7 & 0.2595 & 0.202 & 0.2305 \\
Day 14 & 0.261 & 0.225 & 0.198 \\
Day 21 & 0.245 & 0.2375 & 0.2225 \\
Day 28 & 0.2495 & 0.213 & - \\
Day 60 & 0.237 & - & - \\
\hline
\end{tabular}

\subsubsection{Coefficient of Thermal Expansion}

Coefficient of thermal expansion is obtained following (CDR-C39-81) . Temperature variations of the concrete cylinders as well as corresponding strains are recorded while saturated in a water bath as shown in Figure 3.12. Tests were performed for the second and third concrete pours at day 7 and 14. At each concrete age, two instrumented cylinders were tested for a temperature rise up to $10^{\circ} \mathrm{C}$ from room temperature. The coefficient of thermal expansion was evaluated for both longitudinal as well as lateral deformations and their averages are being calculated. The test is performed on stages where the temperature is being controlled by a heater that increases the water temperature to a known value. Once the temperature reaches a steady state condition, the temperature is increased to the next level. Strain values are continuously recorded from the data acquisition system with an interval of 2 minutes. Table 3.6 lists the average coefficient of thermal expansion resulted from those tests while detailed measurements can be found in (Appendix A1-Section A1.4). 


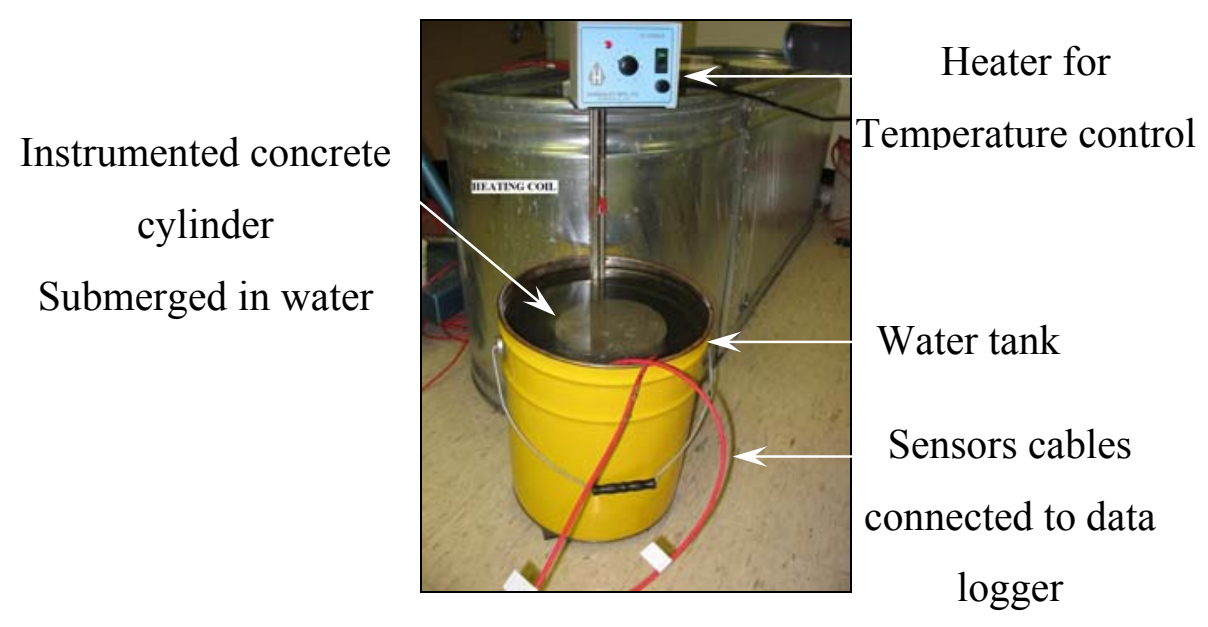

Figure 3.12 Measurements of Coefficient of Thermal Expansion

Table 3.6 Average Coefficient of Thermal Expansion

\begin{tabular}{lcc}
\hline Age of Concrete & $\begin{array}{c}\text { Pour No. 2 } \\
\left(\operatorname{strain}^{\rho} \mathrm{C}\right)\end{array}$ & $\begin{array}{c}\text { Pour No. 3 } \\
\left(\operatorname{strain}^{\rho} \mathrm{C}\right)\end{array}$ \\
\hline Day 7 & 9.82 & 9.16 \\
Day 14 & 9.46 & 8.93 \\
\hline
\end{tabular}

\subsubsection{Analysis of Concrete Material Properties}

The maturity method is a useful nondestructive technique for estimating the in-place strength of concrete material (Nawy, 1997) . A comprehensive review of this method's history can be found in (Carino and Tank, 1992). The method compensates for the combined effects of time and temperature on development of in-situ concrete strength. The method is described in ASTM C1074-98 where the maturity index is expressed in terms of a temperature-time factor and equivalent age established from recorded temperature history of the field concrete. The strength of the field concrete is estimated using the calculated maturity index and strength-maturity relationship developed from the laboratory tests.

Te strength-maturity relationship is expressed in Equation 3.1.

$$
S=S_{u}\left[\frac{k\left(t-t_{o}\right)}{1+k\left(t-t_{o}\right)}\right]
$$


Where:

$$
\begin{array}{lll}
\mathrm{S} & = & \text { average compressive strength at age }(\mathrm{t}) \\
\mathrm{T} & = & \text { test age } \\
\mathrm{S}_{\mathrm{u}} & = & \text { limit strength } \\
\mathrm{t}_{\mathrm{o}} & = & \text { age when strength development is assumed to begin (zero days) } \\
\mathrm{k} & = & \text { rate constant }
\end{array}
$$

In order to determine the values for $\mathrm{S}_{\mathrm{u}}$ and $\mathrm{k}$ for each pour, the hyperbolic function in equation 3.1 is fitted to the experimental data set as shown in figure 3.12 to Figure 3.14 . The function parameters are listed in Table 3.7.

Table 3.7 Values of Hyperbolic Function Parameters for Concrete Strength

\begin{tabular}{lccc}
\hline Parameter & Pour No. 1 & Pour No. 2 & Pour No. 3 \\
\hline \hline $\mathrm{K}$ & 0.3 & 0.65 & 0.8 \\
$\mathrm{~S}_{\mathrm{u}}$ & 7100 & 5500 & 5500 \\
\hline
\end{tabular}

The equivalent age $\left(t_{\mathrm{e}}\right)$ is computed from Equation 3.2.

$$
t_{e}=\Sigma e^{-Q\left(\frac{1}{T_{a}}-\frac{1}{T_{s}}\right)} \Delta t \quad \text { Equation (3.2) }
$$

Where:

$$
\begin{array}{lll}
\mathrm{t}_{\mathrm{e}} & = & \text { equivalent age at a specific temperature } \mathrm{T}_{\mathrm{s}},(\text { days }) \\
\Delta \mathrm{t} & = & \text { time interval, (days) } \\
\mathrm{T}_{\mathrm{a}} & = & \text { average concrete temperature during time interval, }(\mathrm{K}) . \\
\mathrm{T}_{\mathrm{s}} & = & \text { specific temperature, }(293 \mathrm{~K}) . \\
\mathrm{Q} & = & \text { activation energy divided by gas constant }(5000 \mathrm{~K})
\end{array}
$$

the compressive strength at the site $(\mathrm{S})$ at various ages can be predicted by substituting the equivalent age of concrete of each pour and its corresponding $\mathrm{K}$ and $\mathrm{S}_{\mathrm{u}}$ values into the strength maturity relationship (equation 3.1). Figure 3.13 to Figure 3.15 illustrate a comparison between laboratory test results and calculated compressive strength of each pour using the maturity method. 


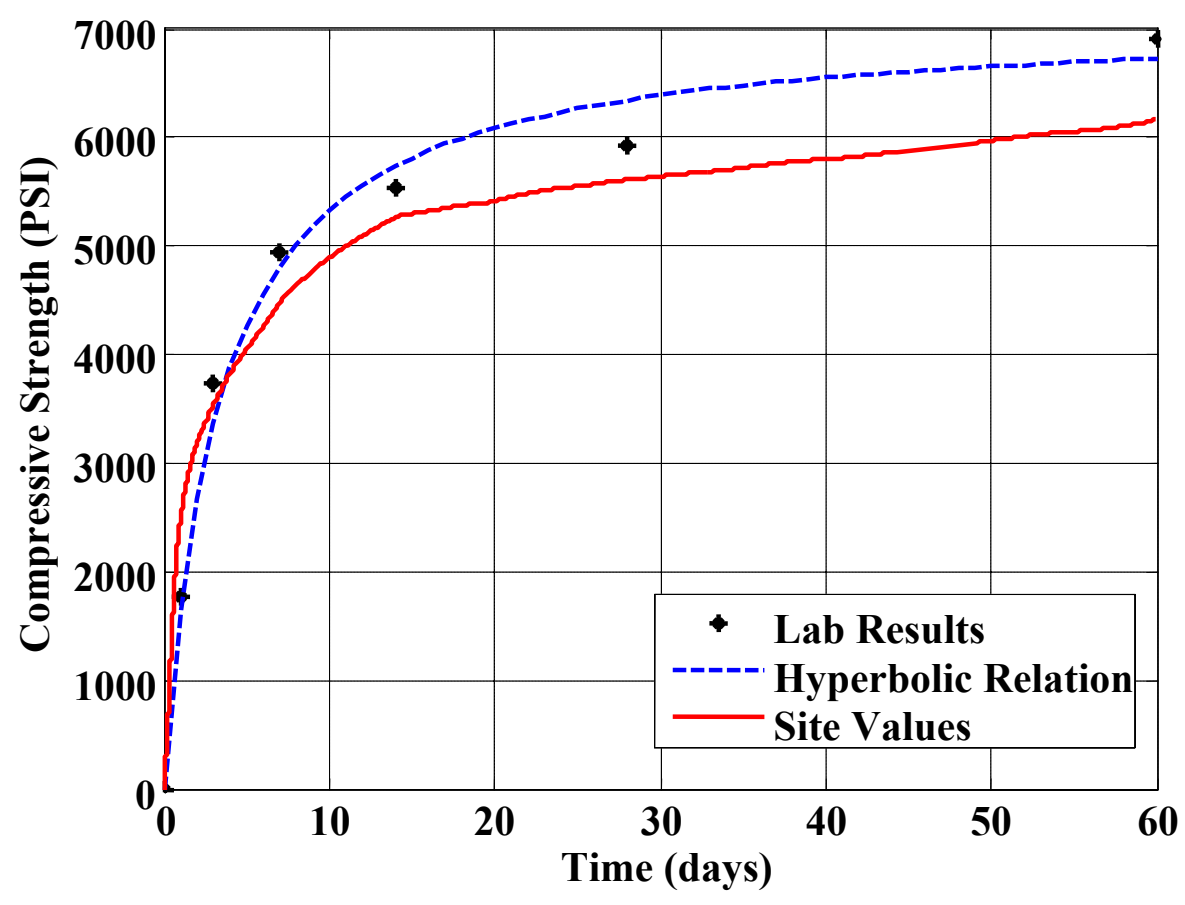

Figure 3.13 Concrete Compressive Strength for Pour No. 1

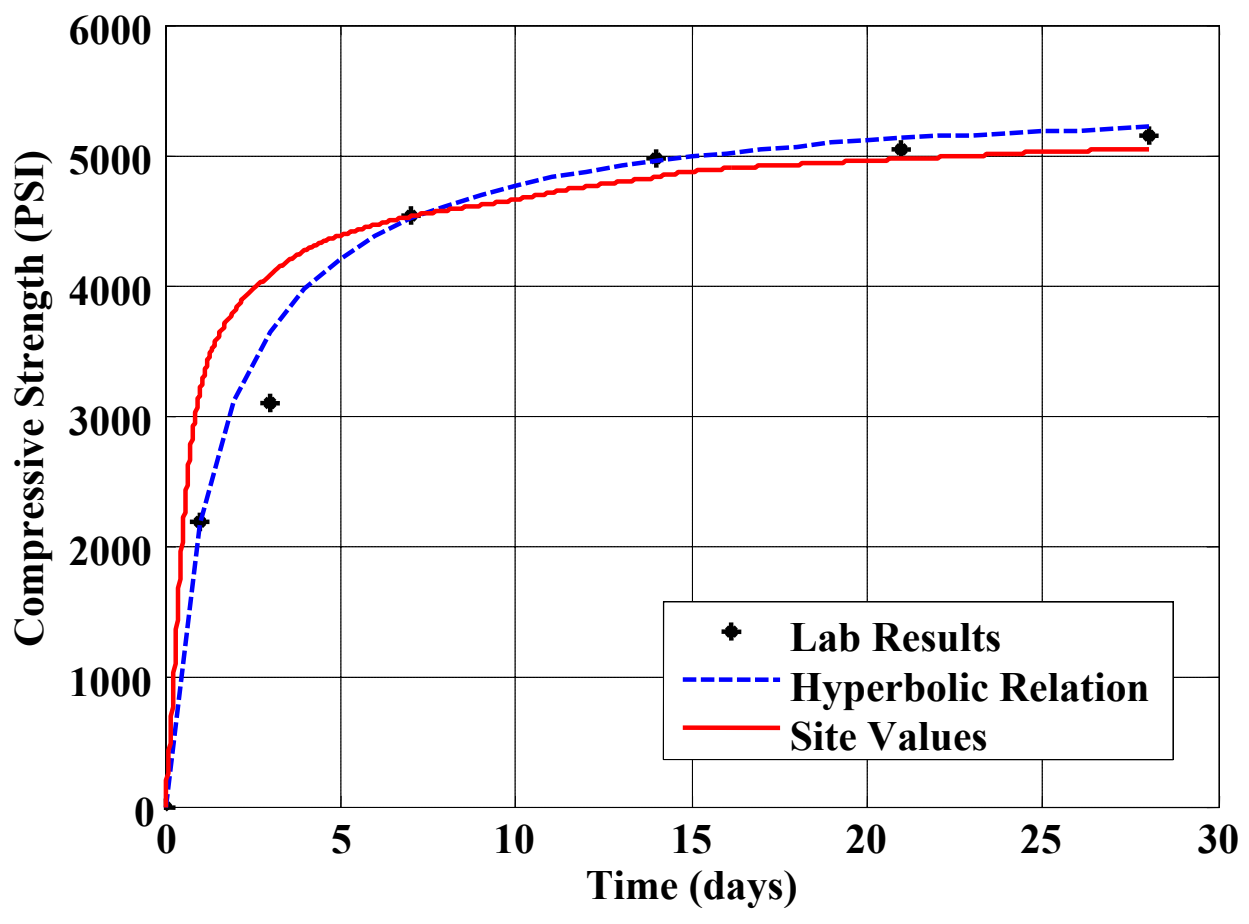

Figure 3.14 Concrete Compressive Strength for Pour No. 2 


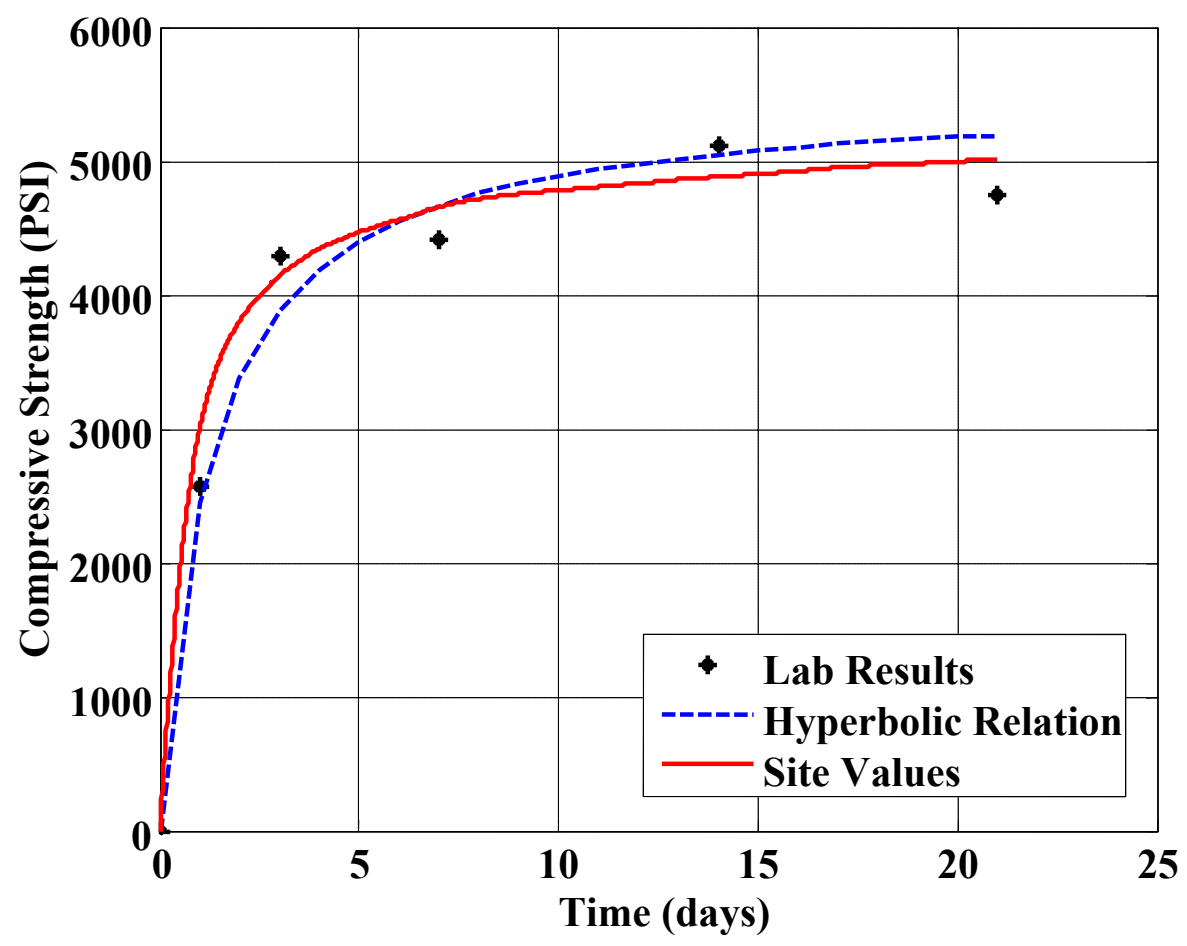

Figure 3.15 Concrete Compressive Strength for Pour No. 3

Although the values of average in-situ compressive strength of concrete material approaches those measured from laboratory tests for pour No. 2 and No. 3, those field values predicted for pour No. 1 are relatively smaller compared to their corresponding laboratory results. The decrease in strength magnitude observed by the maturity method is attributed to the decrease in ambient temperature after pouring the first sequence. This particular pour took place in late December of 2003. Because of the cold weather conditions, the concrete temperature was sustained above $10^{\circ} \mathrm{C}\left(50^{\circ} \mathrm{F}\right)$ for the first 14 days by using thermal blankets and running warm water as illustrated in Figure 3.16. After this period, the blankets were removed and the concrete temperature dropped to a range between $-12^{\circ} \mathrm{C}\left(10.4^{\circ} \mathrm{F}\right)$ during the night and $+4^{\circ} \mathrm{C}\left(39.2^{\circ} \mathrm{F}\right)$ during the day. 


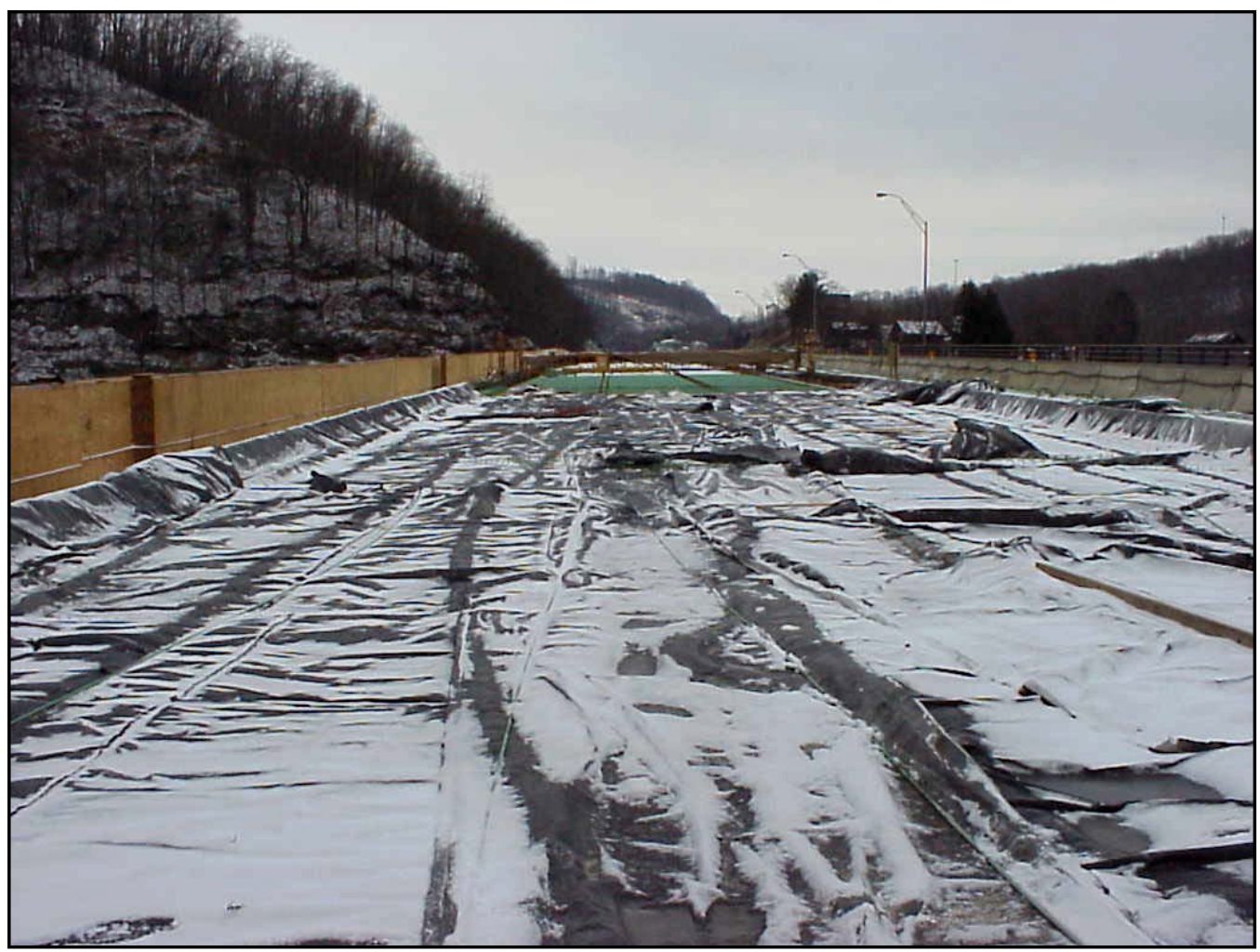

Figure 3.16 Thermal Blankets Covering Deck Pour No. 1

Values of modulus of elasticity and split tensile strength can be predicted from the compressive strength measurements using the empirical formulae as in equation 3.3 and equation 3.4 respectively.

$$
\begin{gathered}
E_{c}=33 w_{c}^{1.5} \sqrt{f_{c}^{\prime}} \quad \text { Equation (3.3) } \\
f_{s}=7 \sqrt{f_{c}^{\prime}} \quad \text { Equation (3.4) }
\end{gathered}
$$

Where:

$\mathrm{f}_{\mathrm{c}}$, is the compressive strength of concrete (PSI)

$\mathrm{w}_{\mathrm{c}} \quad$ is the weight of concrete (lbs)

Measurement values of modulus of elasticity and split tensile strength are compared to predicted values from Equation 3.3 and Equation 3.4 in Figure 3.17. It is evident from the comparison that the test results are quite in accordance with theoretically predicted values. 

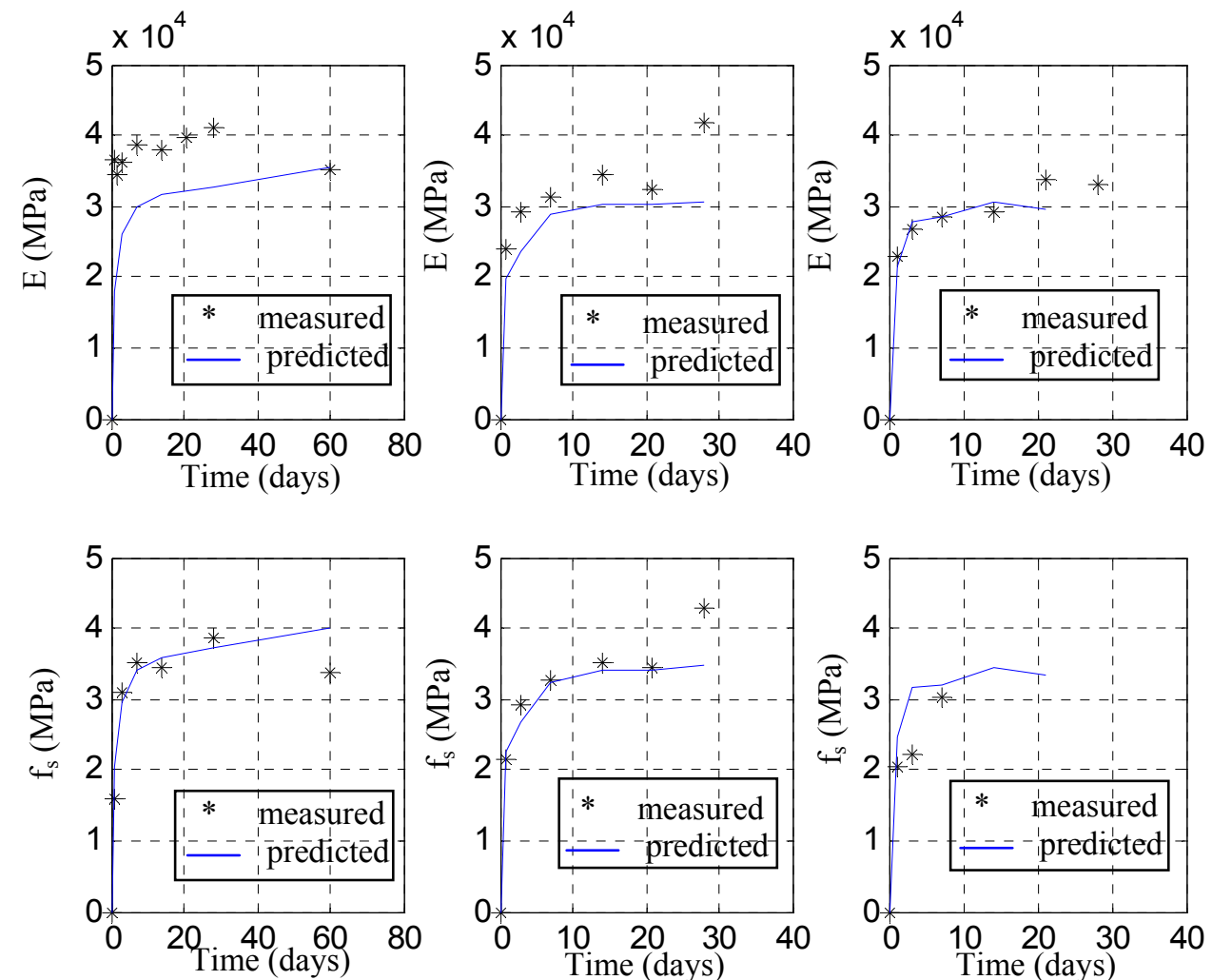

Pour No. 1

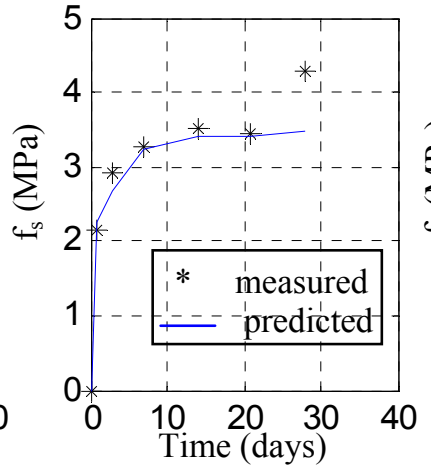

Pour No. 2

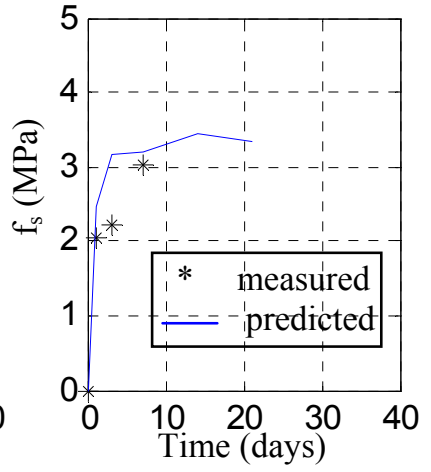

Pour No. 3

Figure 3.17 Comparison between Measured and Predicted Concrete Properties 


\section{CHAPTER 4}

\section{INSTRUMENTATION SYSTEM}

\subsection{Introduction}

The instrumentation system is designed to allow remote monitoring and to secure data records of key performance parameters directly related to bridge structural health such as relative motion, fatigue, true stress in steel super-structure members and concrete deck. This data base provides continuous time histories of the behavior of the bridge members, which combined together, give an indication of the damage profile of the structure. The sensory system is classified in 2 main categories; measurements of loading parameters and response parameters. Response parameters refer to tri-axial state of stress and strains in the concrete deck, strains and bending moments as well as shearing stresses and inclinations of the steel girders, forces at the diaphragm members, expansion and contraction of bridge ends, strains and stresses in rebars, crack formation in concrete deck and inclinations of abutments and piers. Loading parameters include long term effects such as seasonal and diurnal climatic changes, and dynamic effects such as traffic loads. The instrumentation system is economically feasible and has proven to be reliable, robust to survive multiple construction phases and durable to sustain exposure to harsh environmental conditions for years. Similar systems were used on different scales on "Smart Highways and Bridges" in West Virginia as means of ensuring the efficiency, longevity, safety and security of transportation infrastructure (Shoukry et. al 2003, 2004 and 2005). The instrumentation of Star City Bridge is also aiming to demonstrate the effectiveness and benefits that health monitoring of civil infrastructure can offer while taking it from mainly a research area into practical implementations that can be applied routinely in the future. 


\subsection{Instrumentation Objectives}

The instrumentation system of Star City Bridge allows remote sensing of the response of various bridge elements at critical locations in the superstructure. The instrumentation plans were set to provide a record of measurements in particular locations that were identified through examination of the design sheets and indicated maximum response to various loading configurations. The sensory system serves the following goals:

\subsubsection{Structural Design aspects:}

Because of the complexity of the problem, there are a lot of assumptions that have gone into bridge design. Continuous monitoring of the bridge response to the adverse effects of weather and traffic loads can provide necessary data that makes it possible to verify those assumptions. Analysis of measurements time histories can give better understanding of bridge behavior and develop more rational approaches for design than empirical methods. The loading and response time histories will be used to verify design predictions related to empirically designed decks as well as provide a more in-depth analysis of the behavior of bridge structures. Main tasks are:

- Identify the actual stresses that occur in critical bridge elements due to real life loads and climatic changes. This will serve to identify the cost effectiveness in design theories and eliminate over design applications.

- Provide continuous data histories that can offer better understanding of the behavior of various bridge elements, thus can be used to enhance the performance of future bridges to make them more efficient.

- Identify the actual locations where maximum stresses occur and device means to selectively optimize the design and strengthen those locations using high performance materials that are expensive if used on the full length of the bridge.

\subsubsection{Enhance Bridge Maintenance Strategies}

It is apparent that the ability to detect damage at early stages is critical to reduce repair costs and time duration for those repairs. By providing a more sophisticated and better 
method than visual inspections to identify signs of distresses, it will be possible to respond timely to the bridge maintenance needs. Maintenance of the bridge can be performed before the occurrence of severe deterioration. Such a rational method will enhance the way decisions are made about the condition of the bridge members and will set priorities for maintenance strategies.

\subsubsection{Infrastructure Security}

The sensory system is designed in an attempt to provide a warning signal in case of severe damage to a critical element. Similar systems may be used on bridges, tunnels, dams, pipelines, power transmission lines, to remotely monitor their condition and provide an early warning signal in case of damage due to an accident or a deliberate act of terrorism.

\subsubsection{Forensic Studies of Reasons for Structural Deterioration}

Data form both loading configurations and response parameters are collected continuously from the time of construction. It will become possible to conduct forensic analysis to identify the factors that lead to different structural deterioration signs. There are various factors that can contribute to the deterioration of bridge elements. In order to identify means to treat a distressed component, it is important to locate the main cause of such deterioration first and hence identify proper maintenance procedures.

\subsection{Sensory system}

The right selection of sensors is crucial for any successful measurement. Before selecting the sensory system installed on Star City Bridge, a variety of sensor technologies were closely examined and different sensors were tested in the laboratory for validation of their sensitivity level, stability in various environmental conditions and loading configurations, and also for verifying their response range. Examples of such sensors were fiber optic strain gages, wire resistance strain gages, and vibrating wire sensors. The design of the instrumentation system and installation schedules were thoroughly studied 
and discussed with both WVDOT officials and the contractor's engineers prior to installation of any sensor. This coordination was necessary in order to protect the sensors from the rigors of concrete placement during the course of construction and to organize the logistics of traffic and use of heavy lifting equipments within the various construction operations. All sensors used were tested in the laboratory before being shipped to the site in order to insure their proper function.

\subsubsection{Measurement of Response Parameters}

Long term response data are measured using sensors that operate following the Vibrating Wire Principal. In this technique, a wire is under tension between two end blocks. Once a deformation occurs in the surrounding medium, the end-blocks move relative to each other, which alters the resonant frequency of the attached vibrating wire. By plucking the tensioned wire, the resonant frequency can be measured using an electromagnetic coil. Strains in the medium are measured by knowing the calibration that relates the change in resonant frequency of the vibrating wire to the deformation between the end blocks. Vibrating wire gages have great advantages over more conventional electrical resistance or semi-conductor types. The reason lies mainly because of the use of a frequency rather than a voltage as the output signal; a feature that provides excellent long term stability, resistance to effects of humidity variations, and suitability for signal transmission over long cables. All long term sensors in this instrumentation system are manufactured by Geokon Inc. and operate in a temperature range between $-20^{\circ} \mathrm{C}$ to $+80^{\circ} \mathrm{C}$.

\section{Tri-axial strains in Concrete Deck}

105 embedment strain gages model VCE-4204 measure the tri-axial state of strain in the concrete deck. Those are placed in a strain tree configuration as indicated in Figure 4.1 where each tree contains 5 strain gages. Strains are measured at the locations of the top and bottom reinforcing mats in both directions; parallel to traffic and perpendicular to traffic. the "x direction" refers to the direction parallel to traffic, while "y direction" refers to the one perpendicular to traffic. The total number of strain trees is 21 . The VCE4204 is a vibrating wire embedment strain gage designed for direct placement in concrete (Geokon, 2000), and having a gage length of $10.16 \mathrm{~cm}$ (4 in), it is suitable for embedment in the Star City Bridge deck. All gages are water proof and all their 
components are made from stainless steel for corrosion protection. The sensors are placed between the deck rebars by being attached to stainless steel bars $0.635 \mathrm{~cm}(1 / 4 \mathrm{in})$ in diameter. Plastic wire ties are used to secure the stainless steel bars to the deck steel reinforcement while stainless steel clamps are used to attach the gages at their proper position on the stainless steel bars. The sensors were attached at the location of the coil in order to avoid stressing the end blocks. The strain gages Model 4204 have a nominal range of $3000 \mu \varepsilon$ and a resolution of one $\mu \varepsilon$.

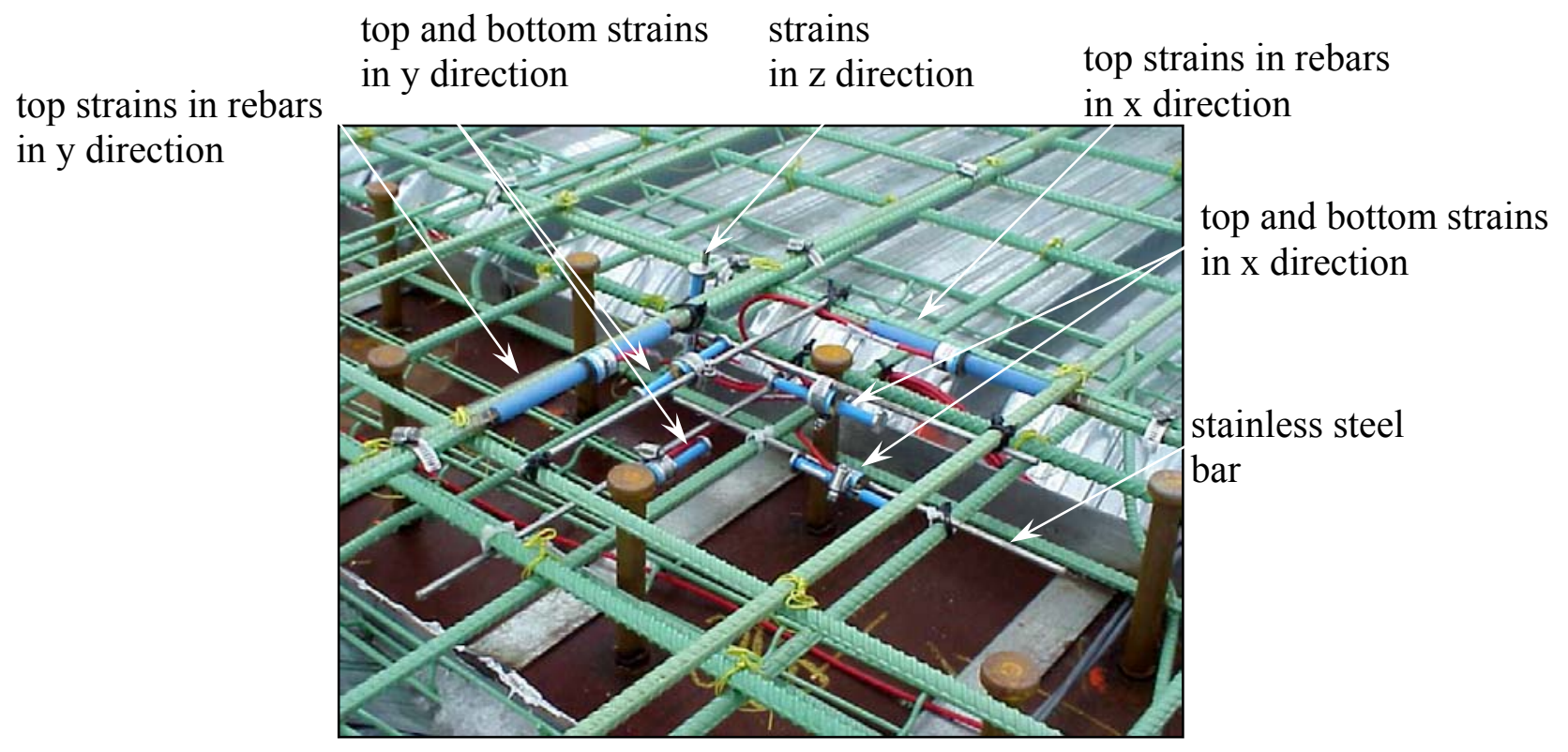

Figure 4.1 Embedment strain gage tree

\section{Strains in Concrete Deck Steel Reinforcement}

42 vibrating wire rebar strain meters model 4911 continuously record the strains in the deck steel reinforcements. The rebar strain meters, also known as sister bars are installed as components of the strain trees to measure strains in the top mat reinforcement in both $\mathrm{x}$ and y directions as indicated in Figure 4.1. The sister bars are installed by tying those to the reinforcing bars using two pairs of stainless steel clamps. Geokon manufacture the sister bars with a short length high strength steel containing the sensing element, and welded between two $59.4 \mathrm{~cm}$ (23.27 in) long sections of dented reinforcing bars No. 4 (12 mm diam.). The gage has a strain range of $2500 \mu \varepsilon$, with a resolution of $0.4 \mu \varepsilon$ (Geokon, 2000a) . 
The strain trees are positioned to collect strain data in the concrete material and steel reinforcement at locations of maximum stresses between the bridge piers and at the locations of the piers. The strain trees are embedded in the deck along Girders No. 6, 7, and 8. Figure 4.2 illustrate the locations of the strain trees with respect to the bridge cross section.

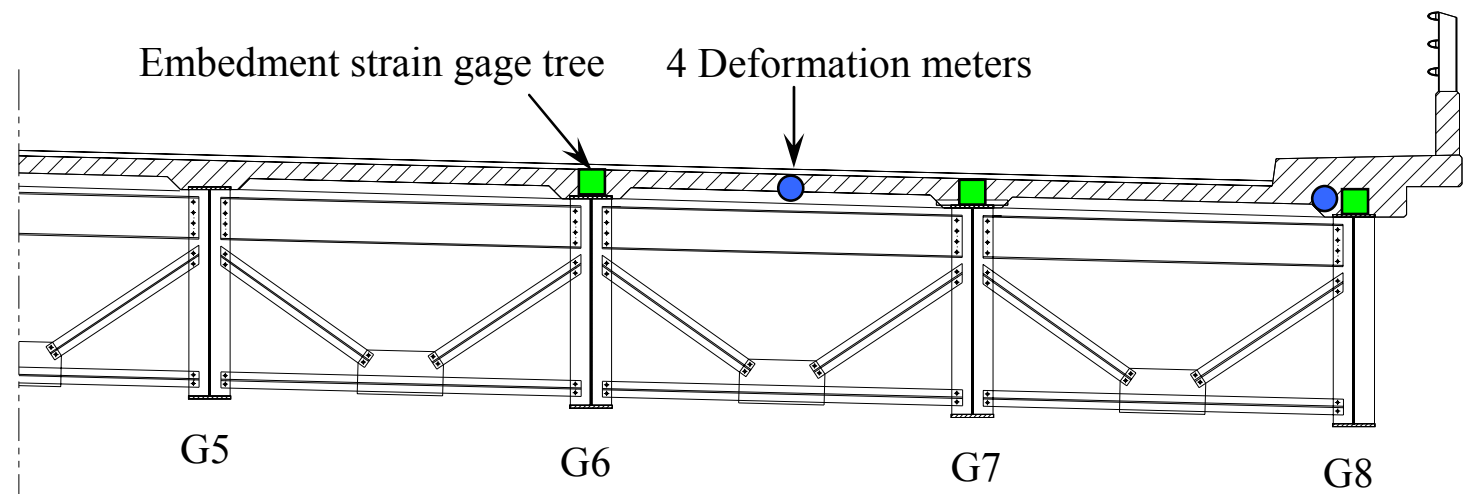

Figure 4.2 Location of Embedment Sensors in Bridge Cross Section

\section{Measurements of Cracks in Concrete Deck}

56 embedment vibrating wire crack meters model 4430 record the initiation and propagation of concrete cracks at locations of maximum stresses in the deck. Those are placed in series of 4 sensors with $2.54 \mathrm{~cm}$ (1 in) overlap as illustrated in Figure 4.3 to provide incremental deformation measurements at 14 locations along the deck.

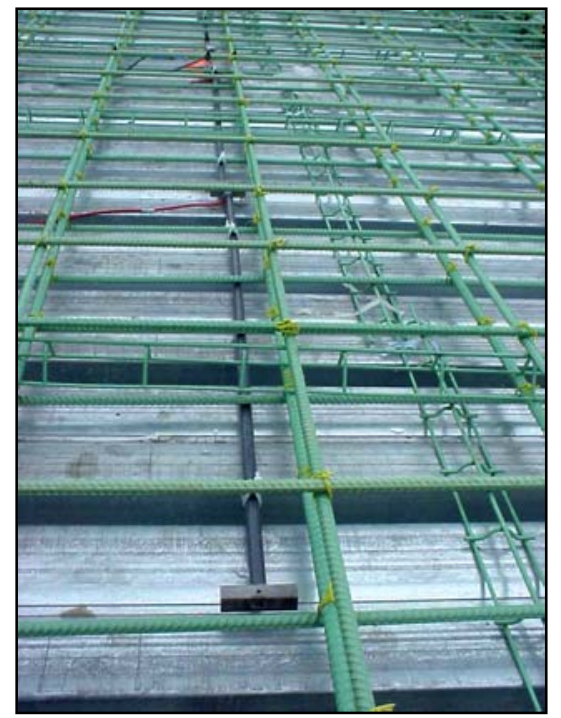

Figure 4.3 Crack Meters 
The Crack meters were specially manufactured to have a length of $122 \mathrm{~cm}(4 \mathrm{ft})$, and a diameter of $1.27 \mathrm{~cm}(1 / 2 \mathrm{in})$ to fit the $2.54 \mathrm{~cm}(1 \mathrm{in})$ bottom concrete cover. The crack meters were placed between the bottom reinforcing mat and the SIP forms to detect any cracks at the deck bottom. The sensors were secured at their locations with plastic wire ties that attached them to the bottom steel reinforcement. The extension range of the crack meters in $12.5 \mathrm{~mm}(1 / 2$ in). Figure 4.2 illustrates the location of the crack meters in the deck cross section.

\section{Overall bridge expansion and contraction}

Two vibrating wire displacement transducers model 4420 record the overall expansion and contraction of the bridge ends relative to their corresponding abutment due to seasonal and daily temperature changes. A special fixture was manufactured at West Virginia University workshops to house those 2 sensors and adopt them to be embedded in concrete as shown in Figure 4.4. As the 4420 displacement transducer is designed to measure displacements across joints, it was not intended to be embedded in concrete. Therefore the sensor was placed inside a $10 \mathrm{~cm}$ (4 in) diameter PVC tube with its anchors extended outside the tube through 2 end opening. After the concrete was placed, the tube was cut in the middle at the location of the expansion joint, to allow for the sensing gage to expand and contract freely. The sensor measures displacements up to a range of $30 \mathrm{~cm}$ $(1 \mathrm{ft})$.

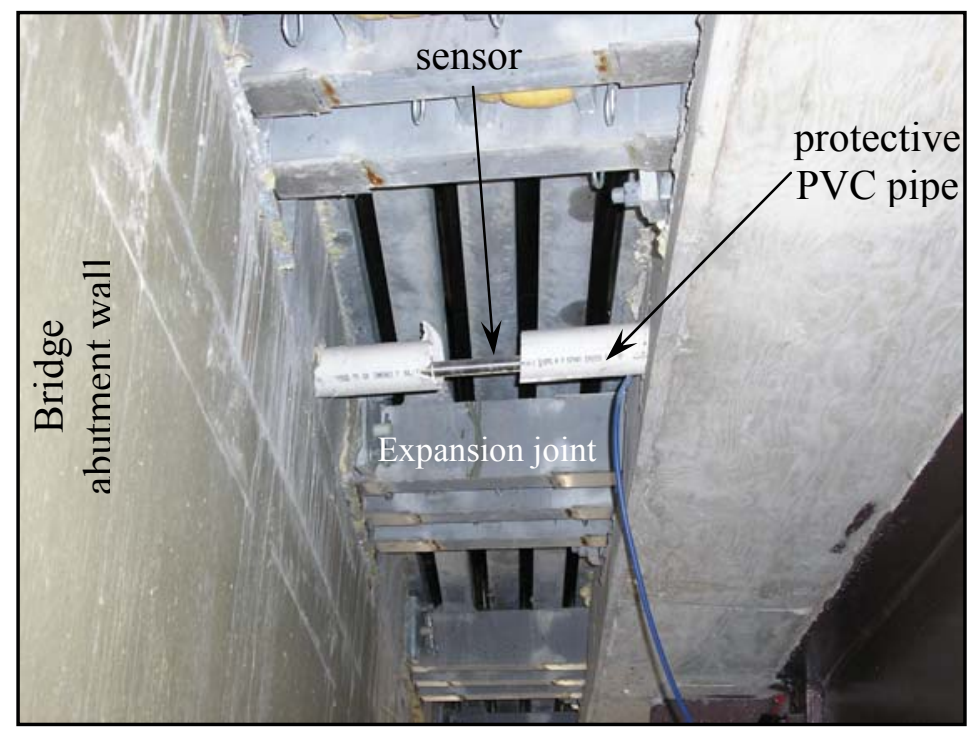

Figure 4.4 Convergence Meter at Bridge End 


\section{Straining actions in steel superstructure}

200 strain gages model VSM-4000 are installed on the steel superstructure to record both shear and bending stresses as well as straining actions in the girders and diaphragm members. The Model 4000 gages are designed primarily for arc welding to steel elements and have a gage length of $150 \mathrm{~mm}$ (6 in) with a strain range of $3000 \mu \varepsilon$ and a1 $\mu \varepsilon$ sensitivity (Geokon, 1998). Mounting those particular sensors on the steel girders represented a challenge since any type of welding was not allowed by the WVDOT due to concerns of excessive stress concentrations resulting from localized heat generation during the welding process. A special technique was adopted for bonding the selected strain gages to the steel girders and proved to be very efficient. The bonding agent (Loctite H4500) was then protected against exposure to moisture attacks. Bonding of strain gages followed a sequence as illustrated in Figure 4.5.

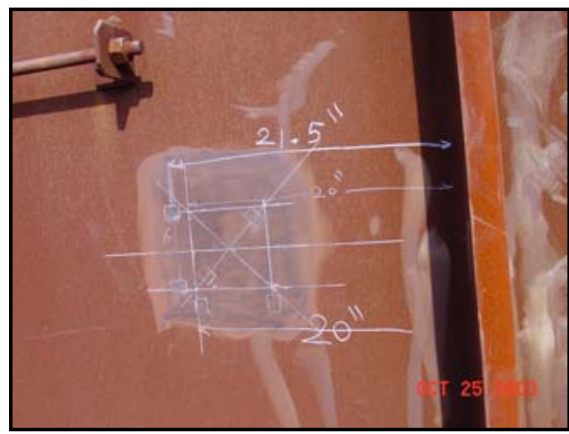

Surface preparation and measurements

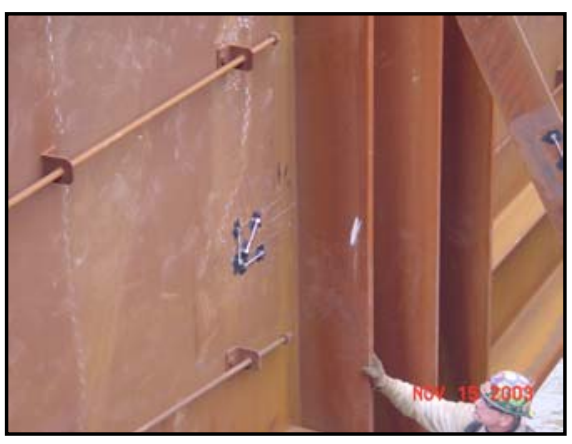

Permanent Moisture protection

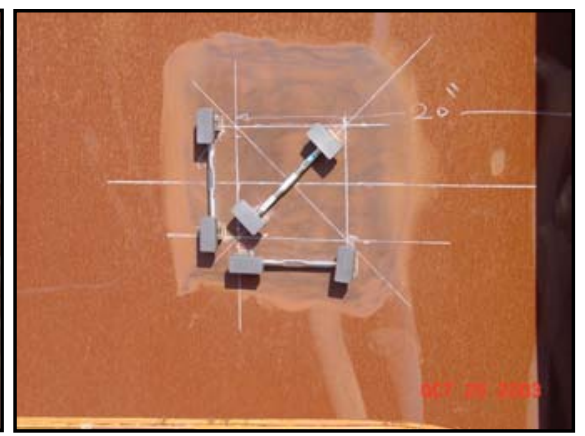

Bonding strain gages

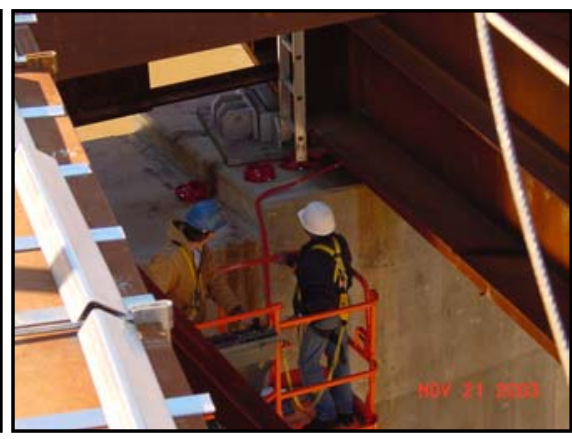

Cable mounting

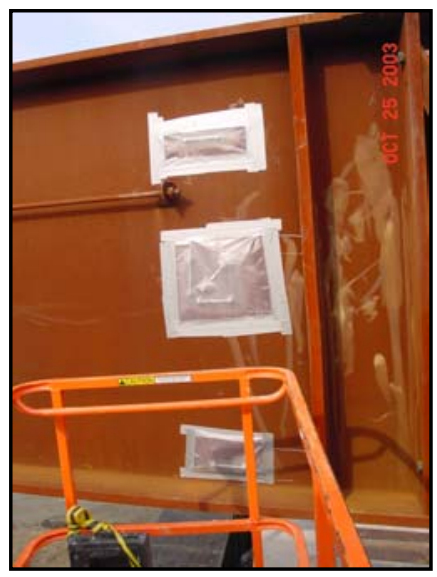

Temporary moisture protection

Figure 4.5 Bonding Operations of Strain Gages on Steel Superstructure 
The VSM-4000 gages are mounted according the following procedures:

- The surface at the back of the mounting blocks (bonding surface) is prepared by grinding before receiving the bonding agent.

- The sensor is mounted to the blocks and set aside; in the mean time the location of the sensor on the steel structure is prepared.

- The surface on the steel member is cleaned with acetone to remove all dirt and oil.

- The position of the sensor is marked on the clean surface and the exact sensor location is recorded.

- The position of the mounting blocks on the steel surface is grinded to remove all scale, debris and rust.

- Right before applying the bonding agent, the steel surface of application as well as the mounting blocks are cleaned again with acetone.

- The epoxy bonding material (Loctite H4500) is applied on the steel member and spread with a wooden application stick.

- The sensor is mounted on the surface and kept in position by a pair of magnets that were positioned on the mounting blocks.

- After the bonding agent is set (3 minutes), the bonded sensor and blocks are covered with a plastic sheet and sealed with duck tape to protect from rain or moisture.

- The location of each sensor is revisited where the coil assembly and cable are attached to the sensor, the mid-range is set, and a layer of rubber moisture sealant is spread on the exposed bonding agent for protecting against moisture.

\section{Girders Bending Moment}

The VSM-4000 gages are bonded on the girders web in a typical arrangement to measure bending moments. The locations of the sensors along the girders correspond to the locations of maximum stresses that were identified from studying the bridge design calculation sheets as illustrated in Figure 4.6. The gages are arranged in two pairs back to back on the web as shown in Figure 4.7 in order to measure both in-plane and out-of- 
plane bending moments. Bending strains are usually higher at distances away from the section neutral axis. Therefore the lower pair of gages is bonded at a distance of $10 \mathrm{~cm}$ (4 in) measured from the lower flange. The location of the top pair varied according to accessibility measures. Due to the large height of the girders, it was not possible to reach the top flange at some locations; hence the gages were bonded at distances from the top flange measuring $10 \mathrm{~cm}$ (4 in) when possible, and $38 \mathrm{~cm}$ (15 in) otherwise.. Bending moments were measured on both girders No. 6 and No. 7. Figure 4.8 is a picture of the sensors mounted on the steel girders at their final form.

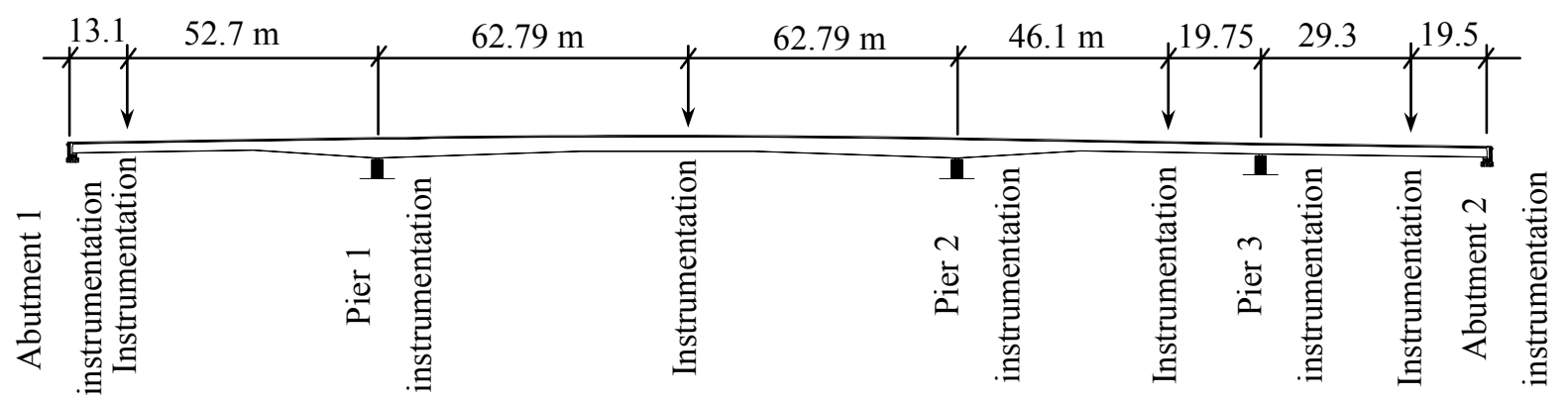

Figure 4.6 Location of Maximum Stresses along Bridge Length

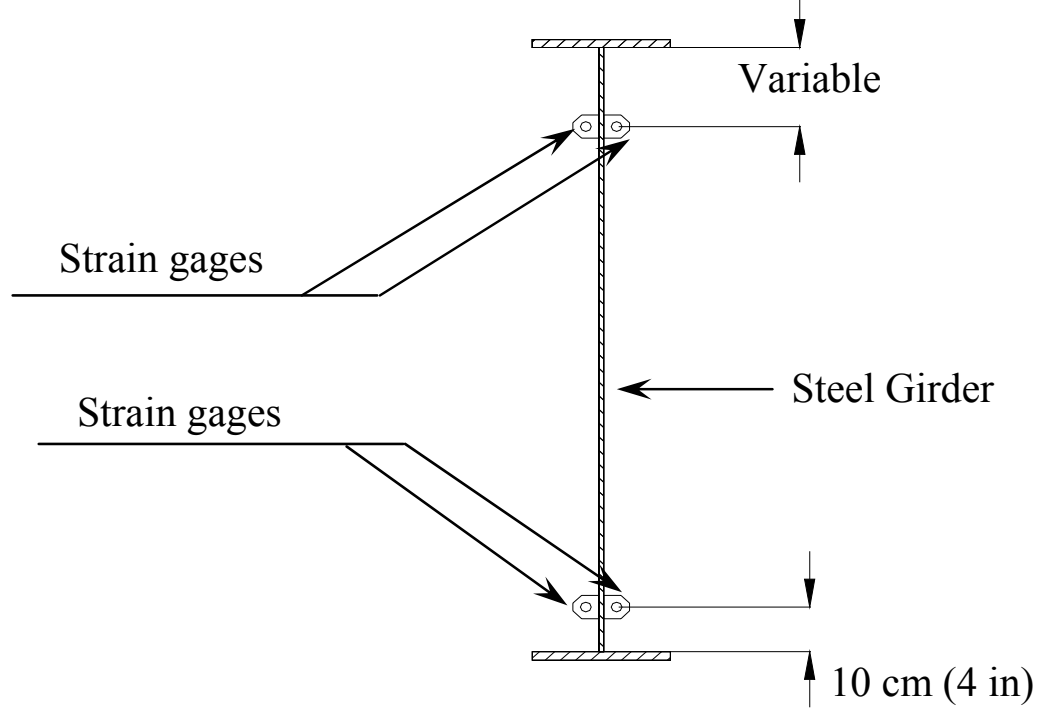

Figure 4.7 Measurement of Steel Girders Bending Moments 


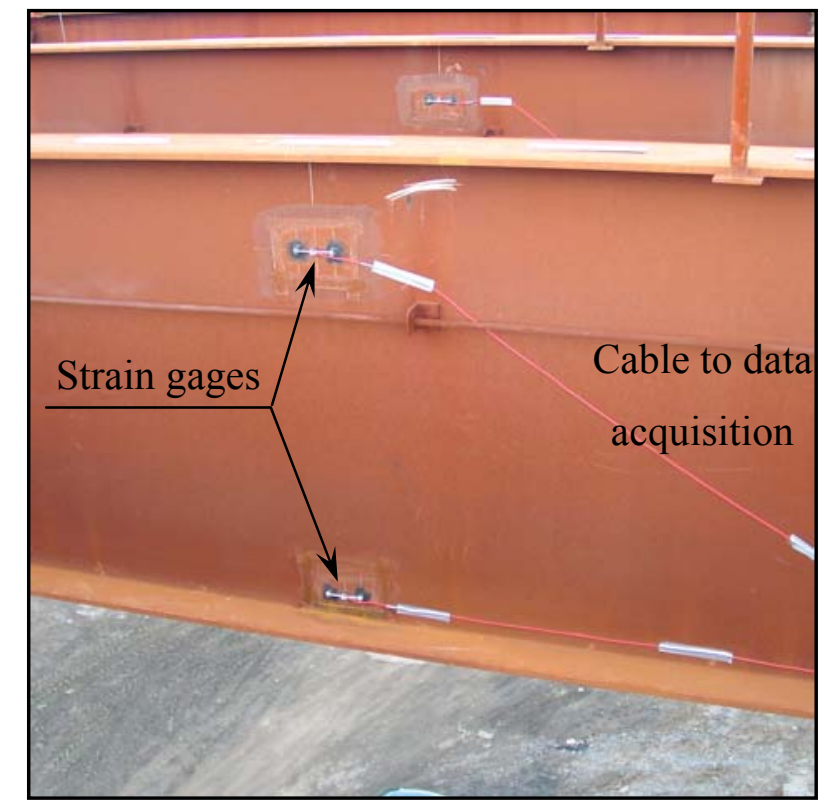

Figure 4.8 Bending Sensors at Final Stage

\section{Girders Shearing stresses}

Three VSM-4000 gages are bonded in a 45 degree strain rosette configuration at location of maximum shearing stresses on the girders supports. The strain rosette is placed at the girders' mid-height in order to measure shearing stresses at the location of maximum shear flow. Shearing stresses are measured on girders 5, 6, 7 and 8 at the location of both abutments. Shearing stresses are also measured on girders 6 and 7 on both sides of each pier. Figure 4.9 illustrate a schematic drawing showing mounting of sensors on girder No. 6 from one side of pier 3 while Figure 4.10 illustrates the typical position of a strain rosette at pier 1. 


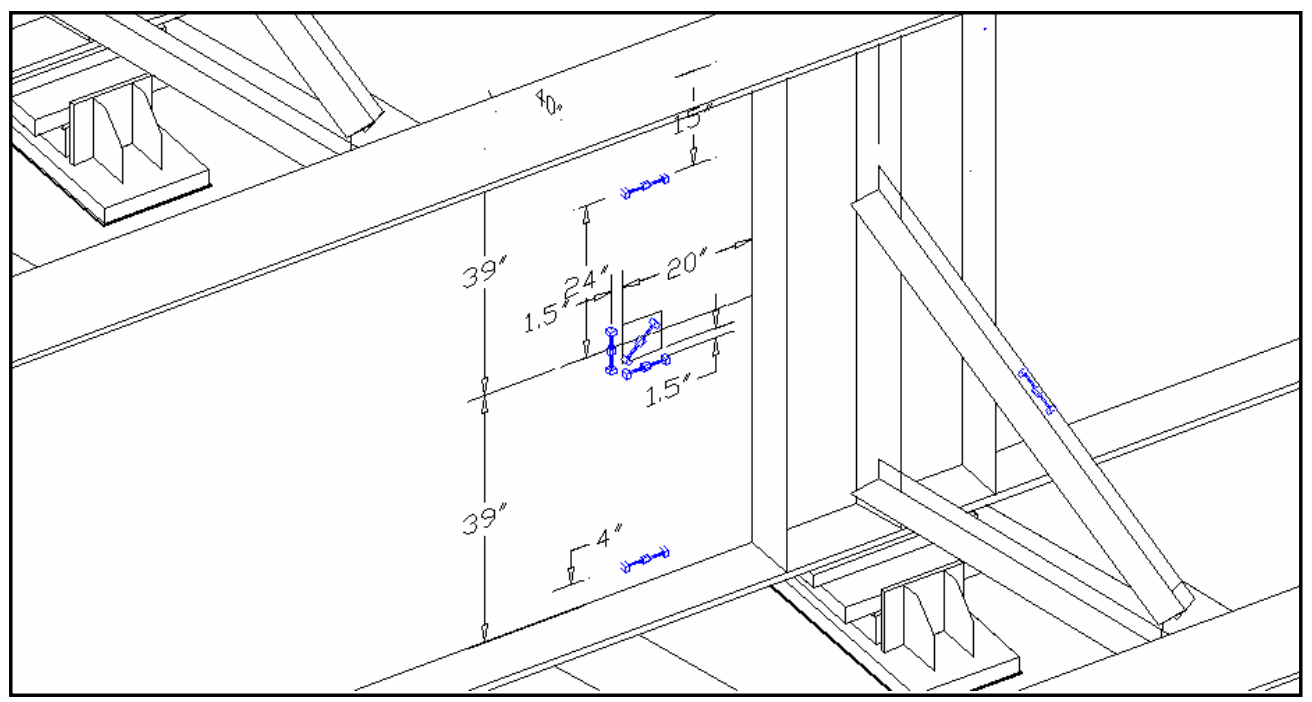

Figure 4.9 Schematic Drawing of Bending and Shear Sensors on G6 at Pier 3

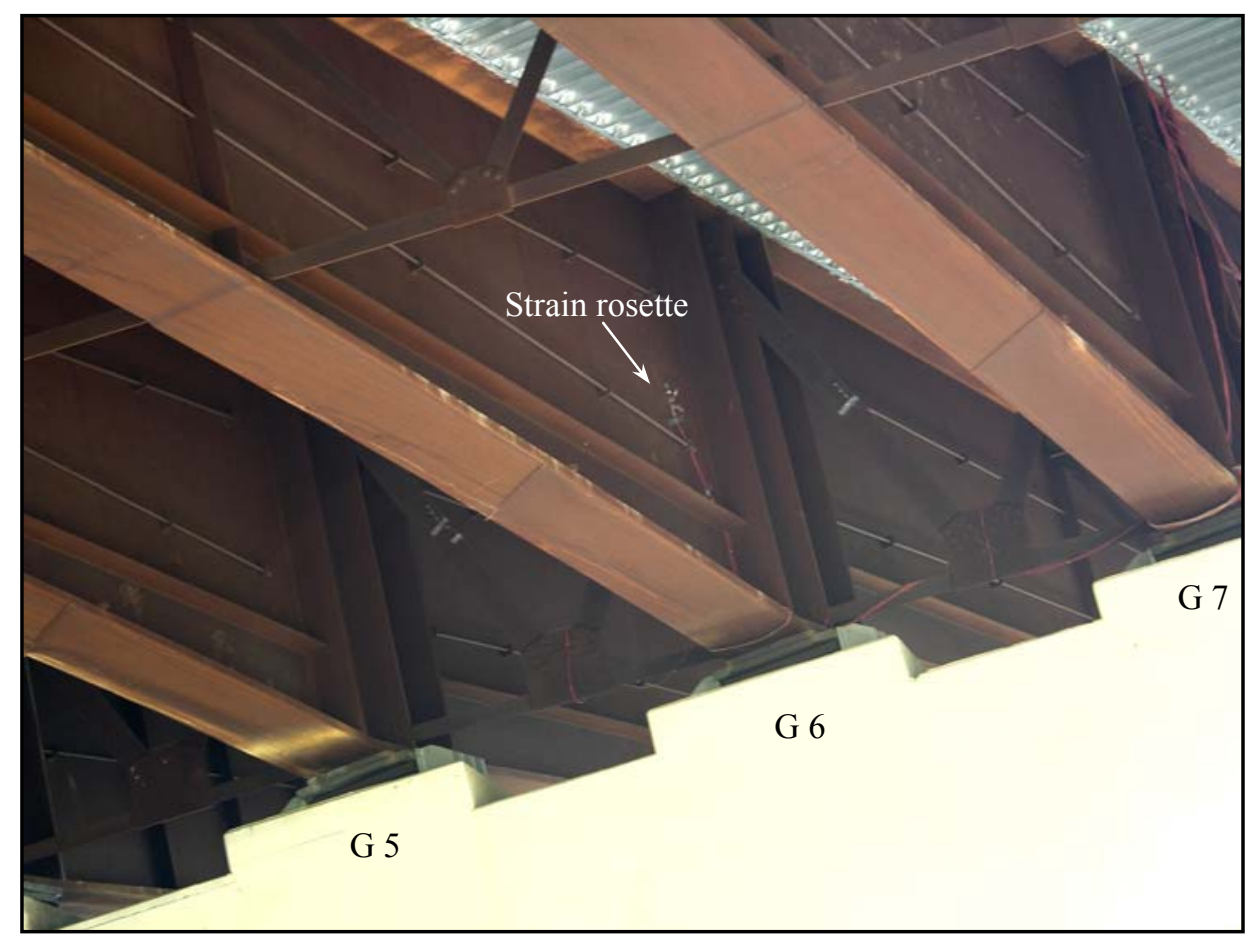

Figure 4.10 Shear Rosette at its Final Stage

\section{Forces and bending moments in diaphragm members}

Axial forces in diagonal diaphragm members as well as those for the top chord members are measured through records of strain values. Stain gages model VSM-4000 are bonded 
at designated diagonal members at the location of piers as well as at location of maximum deck stresses between supports. Each diagonal member carries one strain gage at its mid-length, which allows recording axial strain variation and could be post processed to calculate the change in axial forces in that particular member. The gage is bonded at the middle of the member flange. The top chord members carry two bonded strain gages that allow measuring both axial forces as well as bending moments. The gages are bonded at $5 \mathrm{~cm}$ ( 2 in) from the top and bottom of the web. Figure 4.11 illustrates an example of a strain gage bonded to a diagonal member while Figure 4.12 shows the locations of bonded strain gages on the steel superstructure measuring shearing stresses, bending moments, and axial forces at the locations of piers, abutments and inbetween bridge supports.

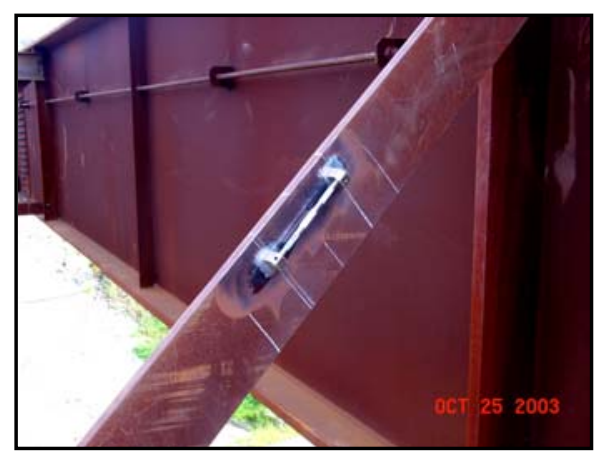

Figure 4.11 Strain Gage Bonded to a Diaphragm Diagonal Member

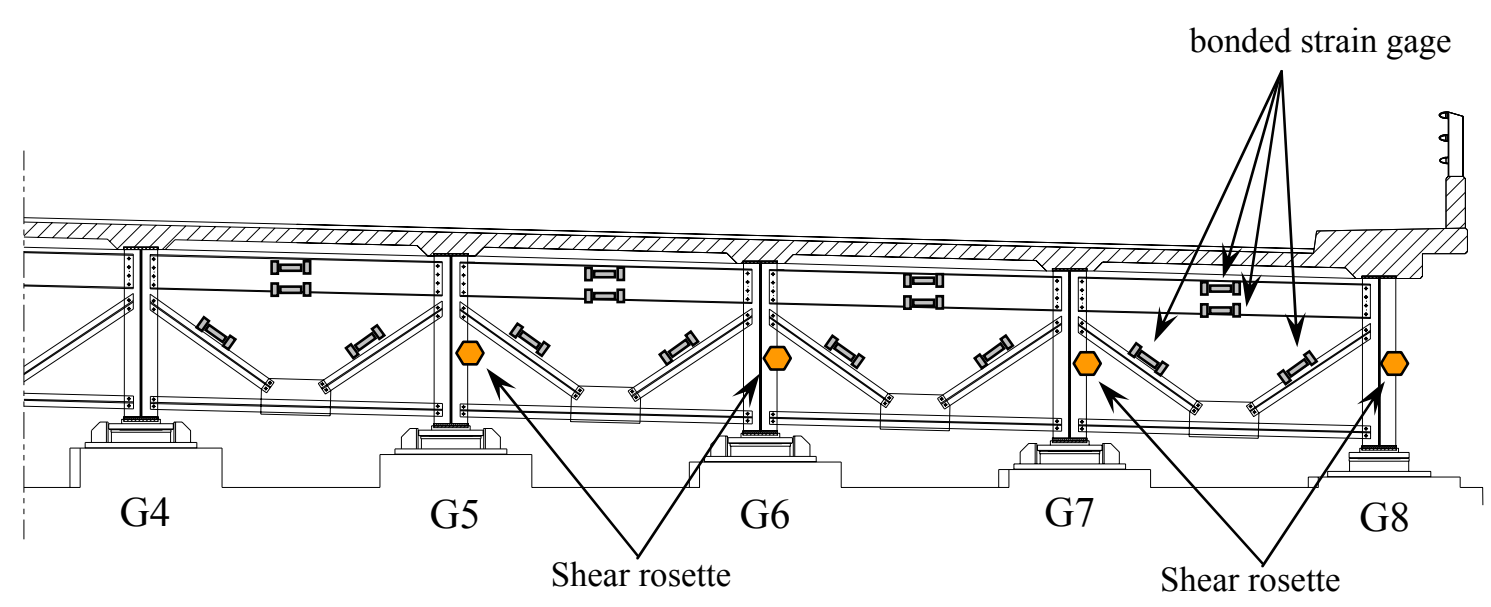

A- Instrumentation of Steel Superstructure at location of Abutments 


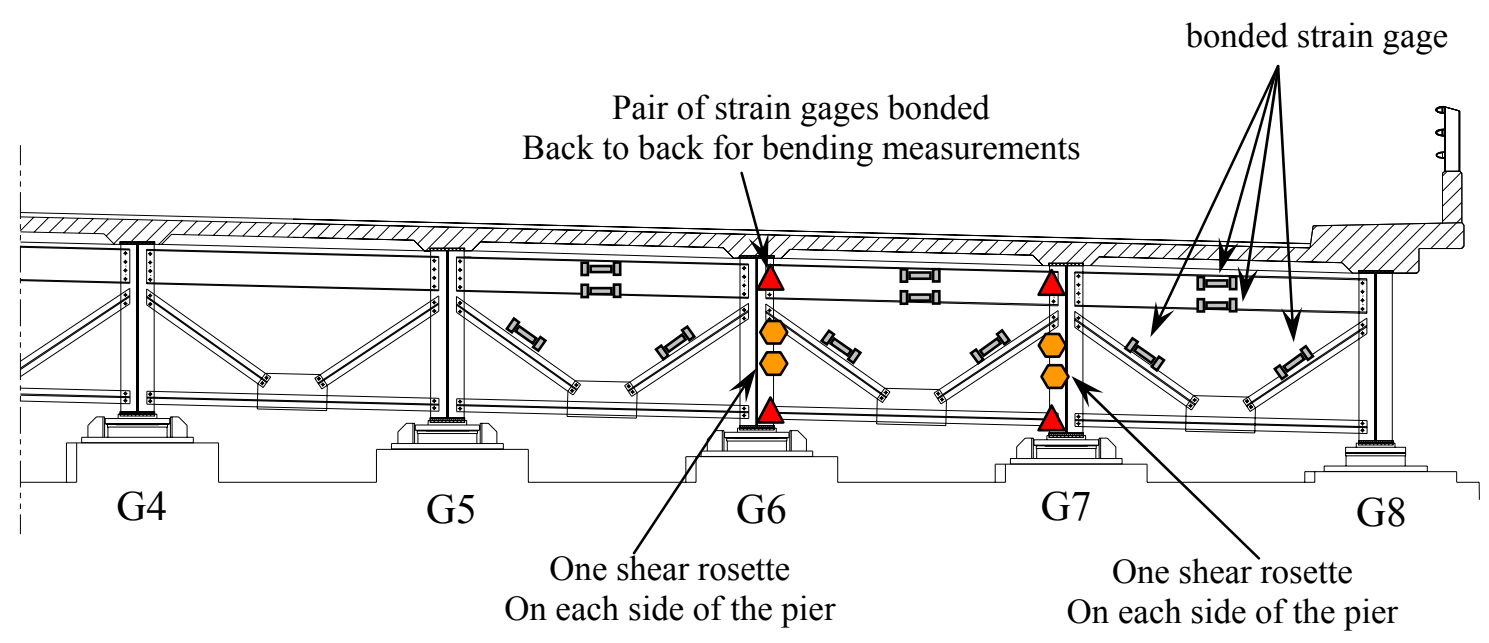

B- Instrumentation of Steel Superstructure at location of Piers

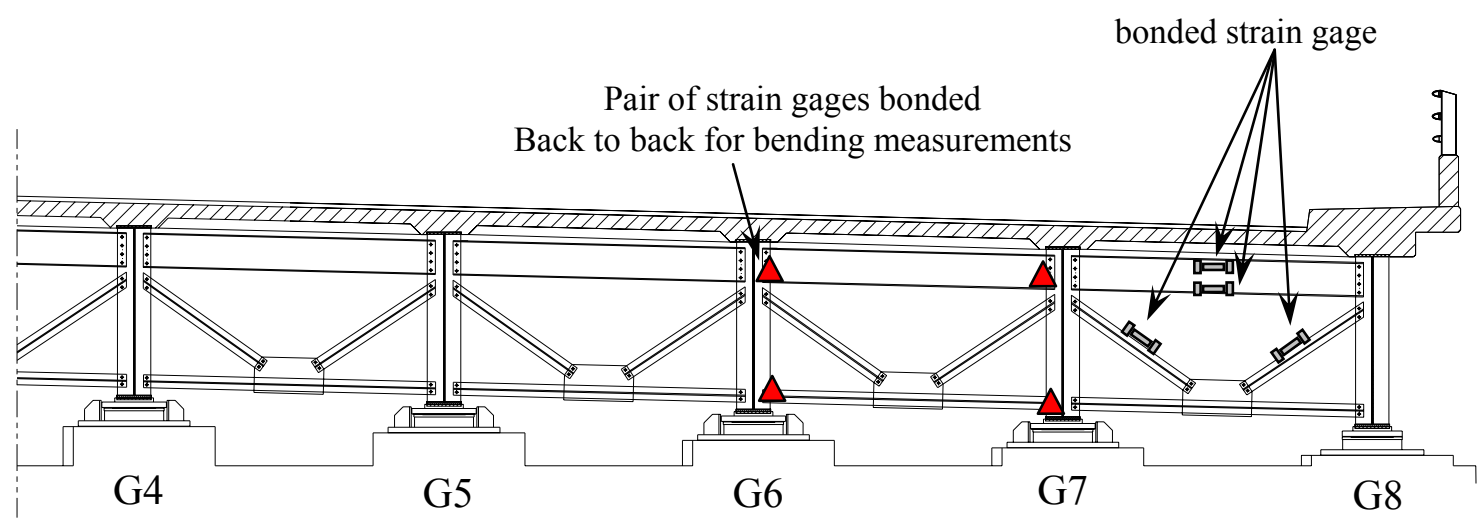

\section{C- Instrumentation of Steel Superstructure at Max. Stresses between Supports}

Figure 4.12 Locations of Strain Measurements on Steel Superstructure

\section{Temperature Measurements in Bridge Superstructure}

Each and every vibrating wire sensor incorporates a thermistor type YSI 44005 that provides continuous records of the temperature in the medium surrounding the sensor. The temperature record is needed to apply a temperature correction to the sensor reading that takes into consideration the variation between the coefficient of thermal expansion and contraction of the sensor material and that of the measured medium. There are 439 thermistors involved in this instrumentation system that provide an overall thermal map of the concrete deck temperature and record temperature data for the sensors thermal 
compensation. Temperature is recorded in the concrete deck at levels of both top and bottom reinforcing mats as well as in the deck mid-height. Temperature is also measured at the girders web at the location of the top and bottom flanges as well as at mid-length of diaphragm members. The thermistors are able to measure temperatures spanning $-50^{\circ} \mathrm{C}$ to $+150^{\circ} \mathrm{C}$.

\section{Angle of Inclination of Steel Girders}

Angles of inclination of the steel girders are continuously recorded at 4 locations as well as abutment 2 and pier 3. Inclinometers models LCI-14.5 manufactured by Jewell Instruments are used for the measurements of angles. The sensor is from the inertial type, designed for low frequency tilt sensing applications with a range of \pm 14.5 degrees. The sensor follows the servo force-balance principal where the sensing element is the flexure suspension type torquer. The servo force-balance inclinometer produces an output signal proportional to the force required to maintain the mass in an equilibrium position. The high level DC output signal is proportional to the sine of the angle of tilt with a resolution of 0.1 arcs second.

Inclinometers data are being transmitted wirelessly through an in-house built digital wireless system to the field office. Given the relatively small values of the analog data and the high level of external electrical noise, transferring those data through cables hundreds of feet away from the place of origin would be highly risky. Amplifying the signal before transmission would not solve the problem considering the risk of signal contamination with amplified noise. Therefore, the system was designed to convert the analog values produced by the inclinometers into a digitized format at the location of each inclinometer and to transmit them wirelessly. Each inclinometer sensor is connected to a transmitter box designed for minimum current consumption, which transmits the signal to one common receiver, in a peer-to-peer serial communication protocol. The digitized data are fed into an RF transceiver through a quarter wave antenna as an input. The RF transceiver runs in a license free range and conveys those data to the receiver, which converts them into a digital format with a 16 bits resolution at 200ksps suitable for 
a single board computer (SBC). Using the master-slave concept, the whole process of data collection and storage is controlled through the (SBC) being the master. Data are collected serially by the SBC and stored as an equivalent voltage value in a comma delimited, text format. Figure 4.13 include a picture of one inclinometer setup placed on abutment No. 2 and its data transmission device. Figure 4.14 illustrates one inclinometer while being positioned on the girder lower flange.

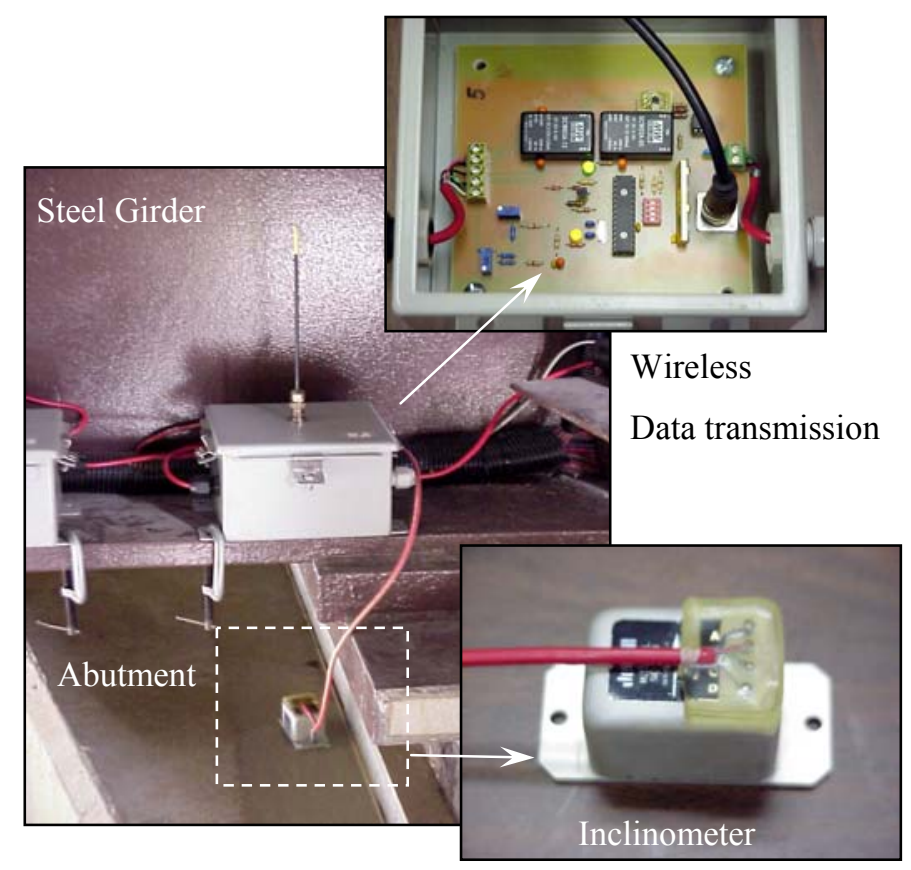

Figure 4.13 Inclinometers and Wireless Data Transmission Devices

Prior to installing the inclinometer systems on the bridge girder, extensive calibration of the sensor-transmitter subassemblies was performed in the laboratory in order to issue a set of equations that relate angles and digital output signals from the system. Since the digital value is proportional with the angle of tilt, a Sine-bar and a set of block gages were used to apply a range of known angles to each device, and the corresponding digital voltage readings were recorded. 


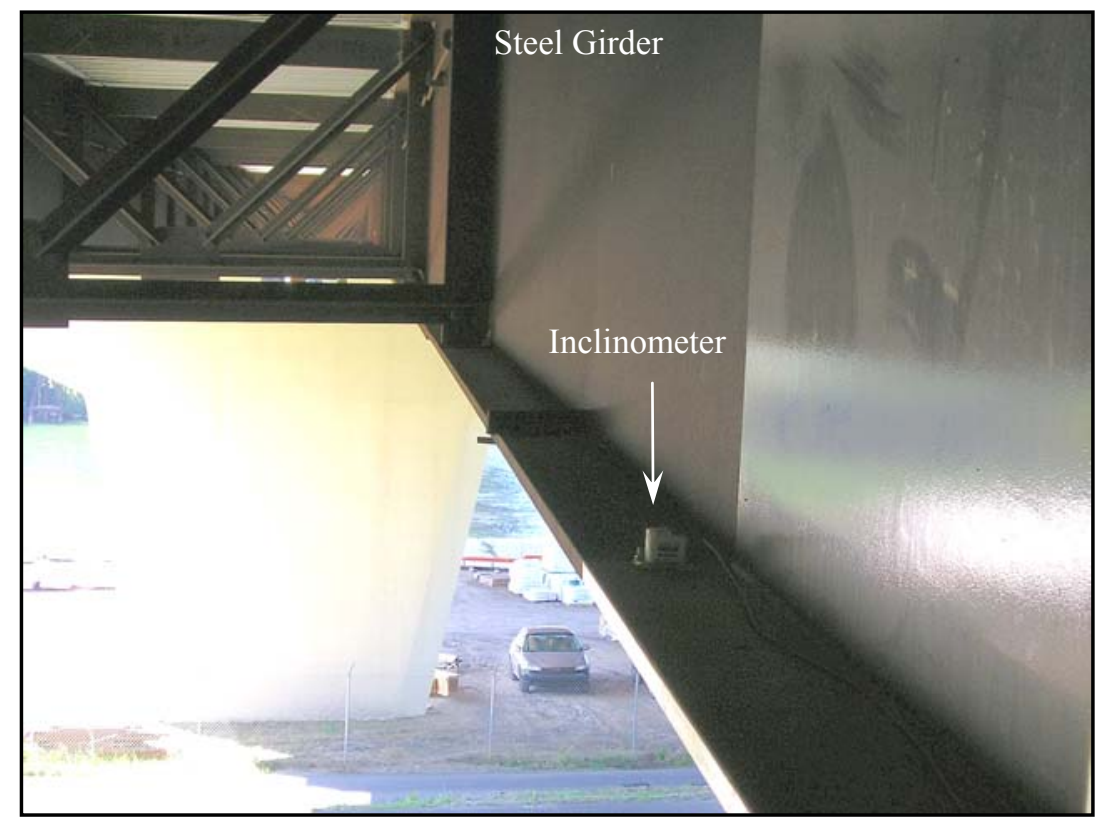

Figure 4.14 Position of Inclinometer on Girder Lower Flange

The digital voltage values from the wireless system were also compared to output voltage readings measured directly from the sensor. The calibration process yielded the following equations that convert digital signals into angles:

$$
\begin{array}{lr}
\text { Inc 1: } a=2.875 \times\left(\frac{5.012 \times D V}{32767}\right)-0.2661 & \text { Equation 4.1 } \\
\text { Inc 2: } a=2.8953 \times\left(\frac{4.988 \times D V}{32767}\right)-0.8714 & \text { Equation 4.2 } \\
\text { Inc 3: } a=2.8868 \times\left(\frac{5.004 \times D V}{32767}\right)-0.4723 & \text { Equation 4.3 } \\
\text { Inc 4: } a=2.8602 \times\left(\frac{5.017 \times D V}{32767}\right)-0.4291 & \text { Equation 4.4 }
\end{array}
$$

Where: a is the angle (deg.)

DV is the output digital value

Figure 4.15 illustrates the location of the inclinometers mounted on Girder No. 5. 


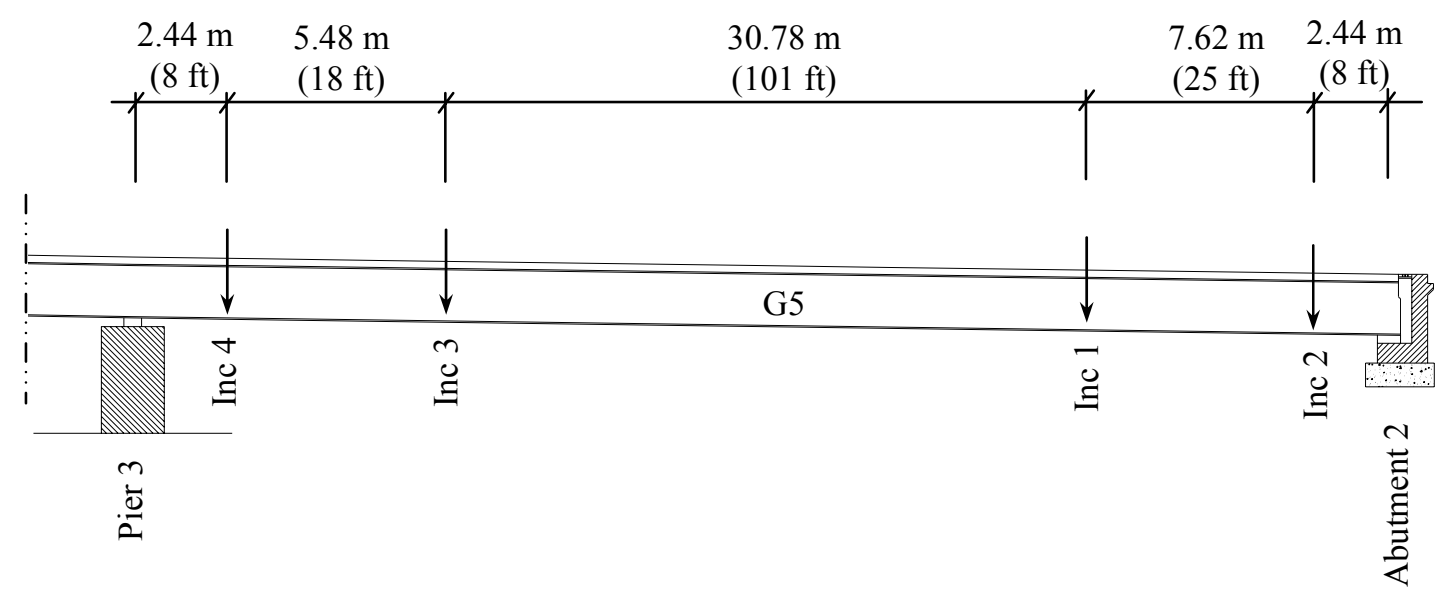

Figure 4.15 Position of Inclinometers along Girder No. 5

\section{Dynamic Strains in Concrete Deck}

14 innovative vibrating wire embedment strain gages record the dynamic stresses in 2 directions in the concrete deck along the wheel paths due to moving traffic. Those innovative sensors are unique and proved through laboratory calibration their ability to record both dynamic and static response of structures through a special data acquisition unit. The sensors proved to be stable and experience zero drift which makes them capable of retaining their reference level for years. The sensors measure strain values at the level of the top reinforcing mat. Figure 4.16 shows the location of dynamic measurements on the concrete deck and mounting of the dynamic sensors within the steel reinforcements.

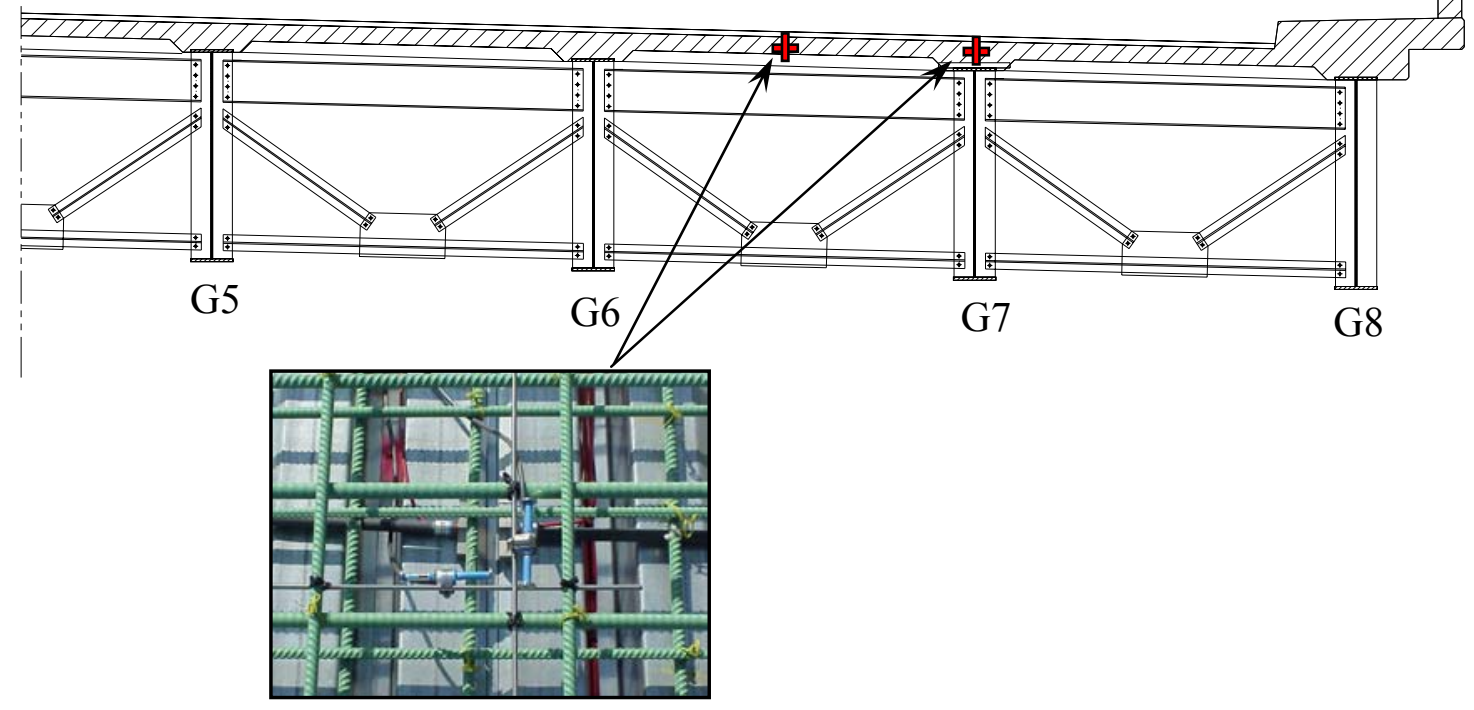

Figure 4.16 Dynamic Strain Measurements in Concrete Deck 


\subsubsection{Measurements of Loading Parameters}

Loading parameters are categorized in terms and effects into long-term and instantaneous configurations. Long-term loading include weather related variables such as changes in ambient temperature and relative humidity. Instantaneous loading refer to the effect of traffic loads, wind loads, and dynamic shocks.

\section{Measurement of Weather Data}

Diurnal and seasonal climatic changes are important parameters that contribute to the long term loading configuration. A weather station is installed at the bridge site and provides records of weather data. The weather station is Model ET106 Manufactured by Campbell Scientific Inc., and provides continuous measurements of wind speed and direction, ambient temperature, relative humidity, rain fall, and solar radiation. The weather station is illustrated in Figure 4.17. The ET106 is mounted on a $3 \mathrm{~m}(10 \mathrm{ft})$ pole which is fixed to a $1.2 \times 1.2 \times 0.6 \mathrm{~m}(4 \times 4 \times 2 \mathrm{ft})$ concrete base. The weather station is equipped with a COM210 phone modem that allows remote communication through a phone line. The "Visual Weather" software controls the station and allows performing post-processing operations on retrieved data to produce special meteorological reports. The weather station is configured to record weather data with a frequency of 15 minutes.

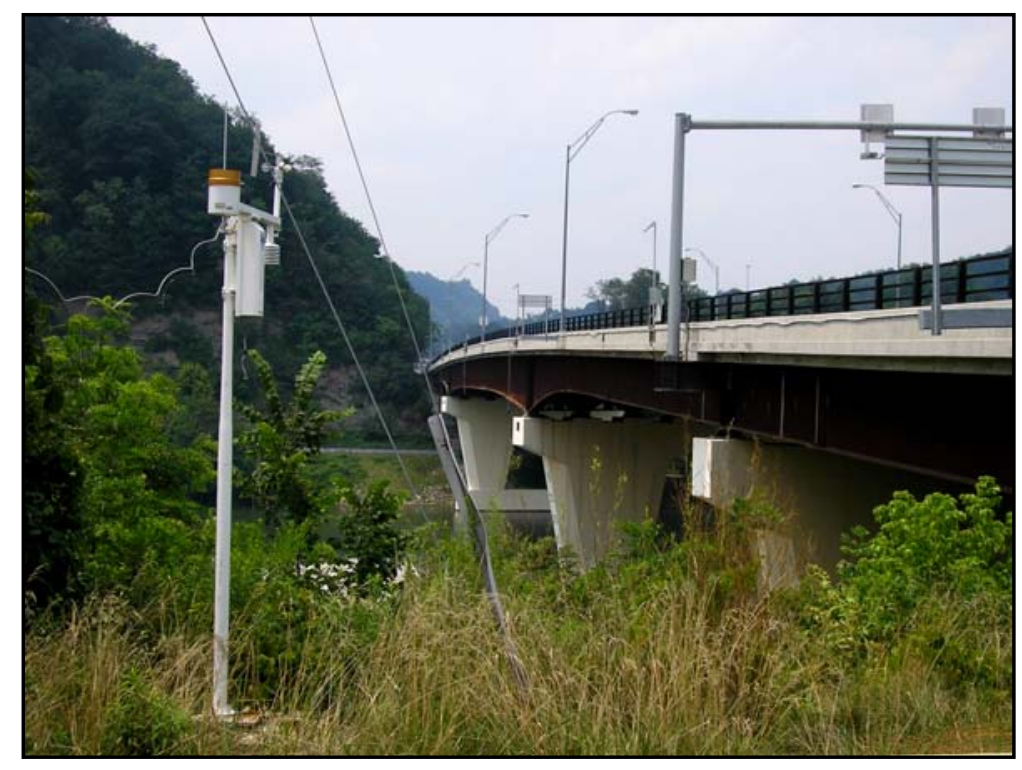

Figure 4.17 ET106 Weather Station 


\section{Measurements of traffic spectrum}

Peizo-electric sensors are the core of a weigh in motion (WIM) system that is installed at the bridge entrance and provides continuous time histories of axle loads crossing the southbound roadway. The system is designed in an attempt to create a cost effective device based on commercially available components and in-house built data acquisition system as well as in-house developed software. Data output formats and protocols for equipment calibration are developed following the guidelines of (ASTM-E-1318). The WIM system is installed on the driving lane of the southbound roadway which carries most of the traffic and is capable of providing data including wheel weight, actual speed, number of axles for each vehicle, and distance between axles, as vehicles travel at highway speeds. The WIM System uses two piezo-electric sensors type Lineas 9195E, manufactured by Kistler Instruments, along with two inductive loops and loop detectors manufactured by EMX IND. INC. As shown in Figure 4.18, conditioned signals from the sensor block are fed into an in-house built signal processing unit. A weather proof control box is fixed at the proximity of the bridge entrance and houses the signal processing unit including the following components:

- signal conditioners

- loop detectors

- $\mathrm{A} / \mathrm{D}$ converter

- on-site processor unit

- $\quad$ storage block

- power management block

- Two marine batteries that are charged through a solar panel.

Figure 4.19 illustrated the sequence of placing the WIM system at the bridge entrance. 


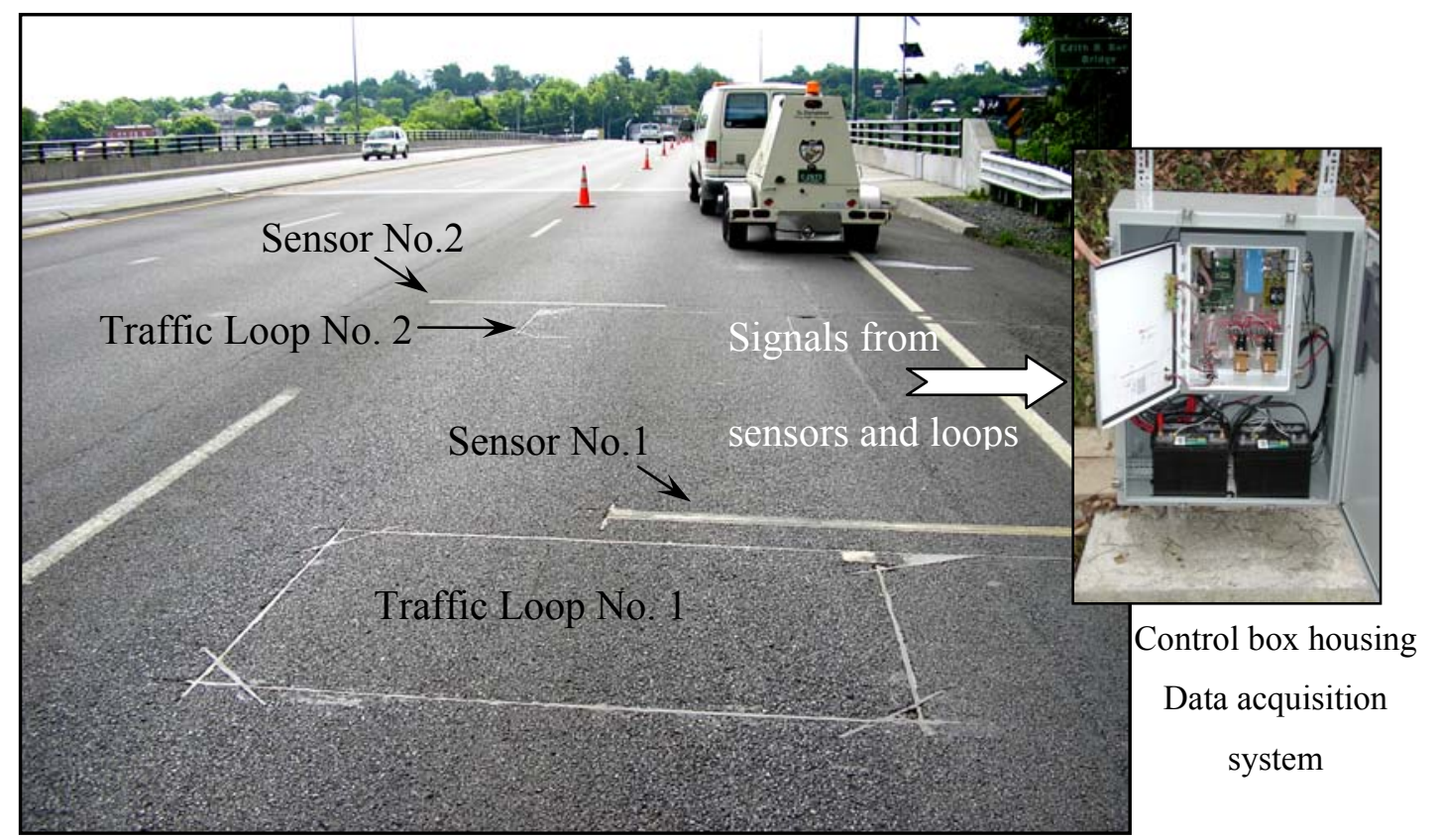

Figure 4.18 Weigh In Motion System at the Bride Entrance

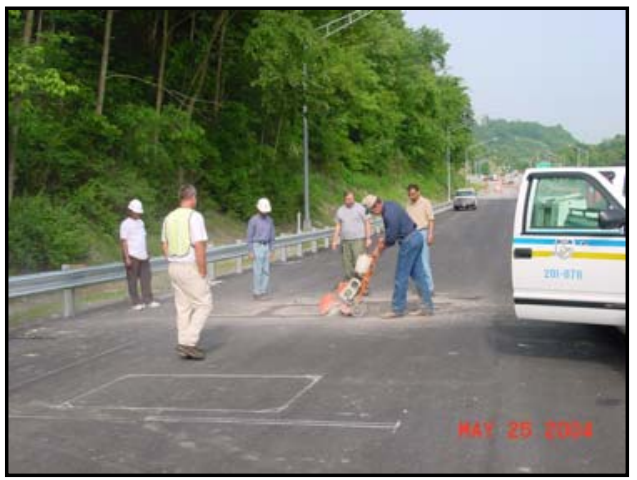

Saw-cutting at locations of sensors

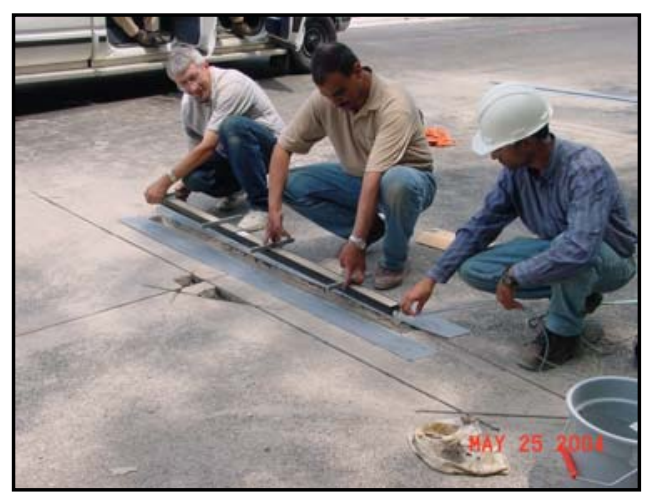

Placement of Peizo-electric sensors

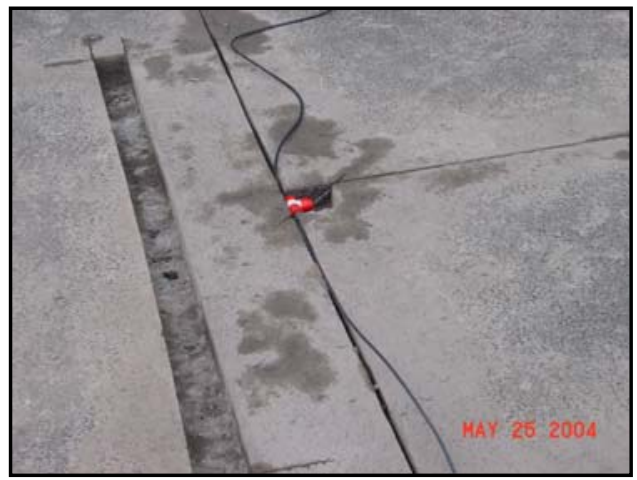

Placement of loop detectors at cleaned cuts

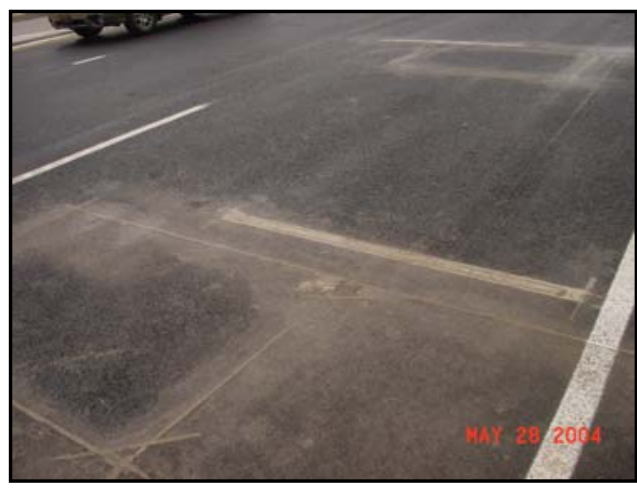

Grouting

Figure 4.19 Sequence of Placing the WIM System at the Bride Entrance 


\subsubsection{Data Acquisition system}

The long-term monitoring system uses six micro-10 data loggers model 8020 (Geokon, 2003) that are placed at different location along the bridge in a network configuration. The data loggers are housed in weather proof enclosures that are secured to the parapet wall and are accessible from the bridge side walk for maintenance purposes and/or for direct manual downloading of data. Model 8020 Micro-10 datalogger is capable of reading vibrating wire sensors, Carlson type sensors, thermistors, thermocouples, Sonic probes, TDR cables, and all voltage type devices, etc... One data logger can accommodate up to twelve single ended sensors for direct measurements, while this capacity can be expanded up to 256 channels by connecting eight multiplexers each with 32 channel capacity. The data logger electronic blocks are contained in a stainless steel enclosure for use in harsh environment and can provide resistance to moisture and humidity and protection against lightning damage. Wide temperature tolerance allows the loggers to work in a temperature range of $-23^{\circ} \mathrm{C}$ to $+50^{\circ} \mathrm{C}\left(-9.4^{\circ} \mathrm{F}\right.$ to $\left.+122^{\circ} \mathrm{F}\right)$. The standard memory storage capacity is 62000 data points, and can be expanded optionally to $1,000,000$ data points. A digital signal processing unit (DSP) is incorporated with the datalogger to eliminate effects of electrical noise and interference on vibrating wire sensors. The data logger is controlled through a Windows ${ }^{\circledR}$ based Multilogger software that can be configured to provide online monitoring, collection of data, and setting alarm limits. The data loggers were programmed to collect data from all installed sensors simultaneously according to the sequence of construction with a frequency of 20 minutes since time of construction to date.

Vibrating wire sensors are wired to 28 multiplexers model 8032 that are mounted at different locations along the full length of the bridge, each with 32 channel capacity. Each multiplexer communicates to the closest data logger through one single communication cable. Each multiplexer consists of a terminal board where sensors lead wires are connected and a multiplexer board with mechanical relays that allow switching of the gage connections. Figure 4.20 illustrates wiring of sensors into multiplexer boards. The multiplexers are configured to accommodate 16 channels of 4 conductors or 32 channels of 2 conductors through a jumper on the multiplexer board. A special fixture is 
constructed from galvanized steel angles and allowed mounting the multiplexers on the structural steel girders. The fixtures were tailored at the site to accommodate each location individually and to mount a number of 2 to 3 multiplexers as required.

All data loggers are daisy-chained together and can be accessed from the field office on a single coaxial cable through Campbell Scientific MD9 Multidrop System. Through the MD9 system, each datalogger in the network has a unique ID, therefore can be addressed individually from a single computer. The communication cable is mounted on the parapet wall and runs along the bridge in a protective PVC conduit. The data acquisition system is equipped with a COM200 phone modem that enables remote monitoring and download of data from any place on earth via a telephone line. Figure 4.21 illustrates the configuration of data acquisition and distribution of logging units. As mentioned before, the WIM system as well as the inclinometers have separate in-house built data acquisition systems.

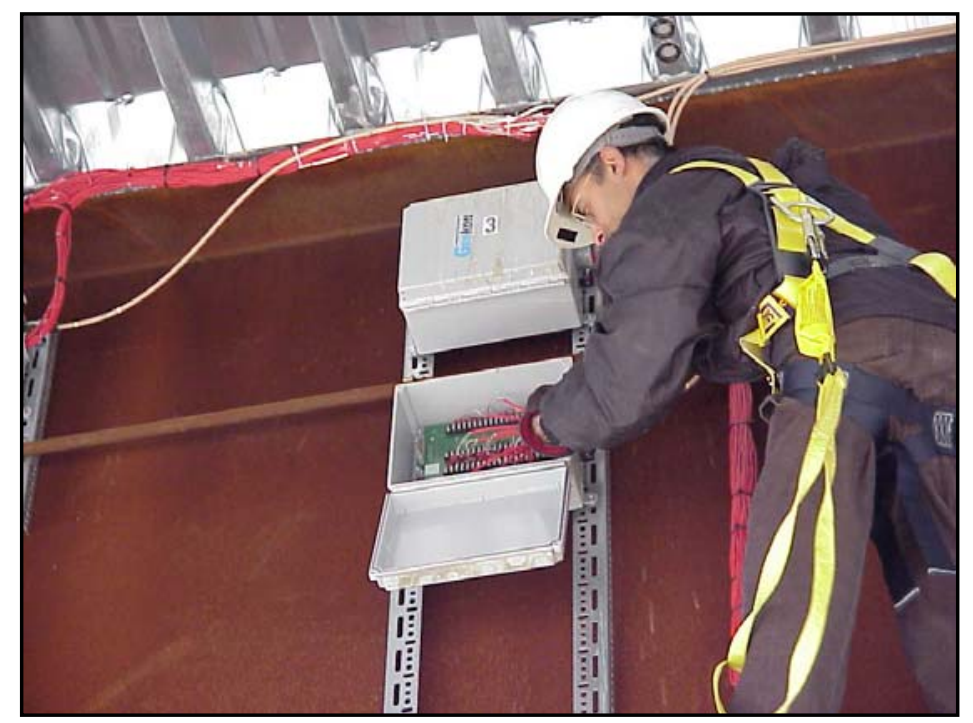

Figure 4.20 Wiring of Gages to Multiplexers Boards 


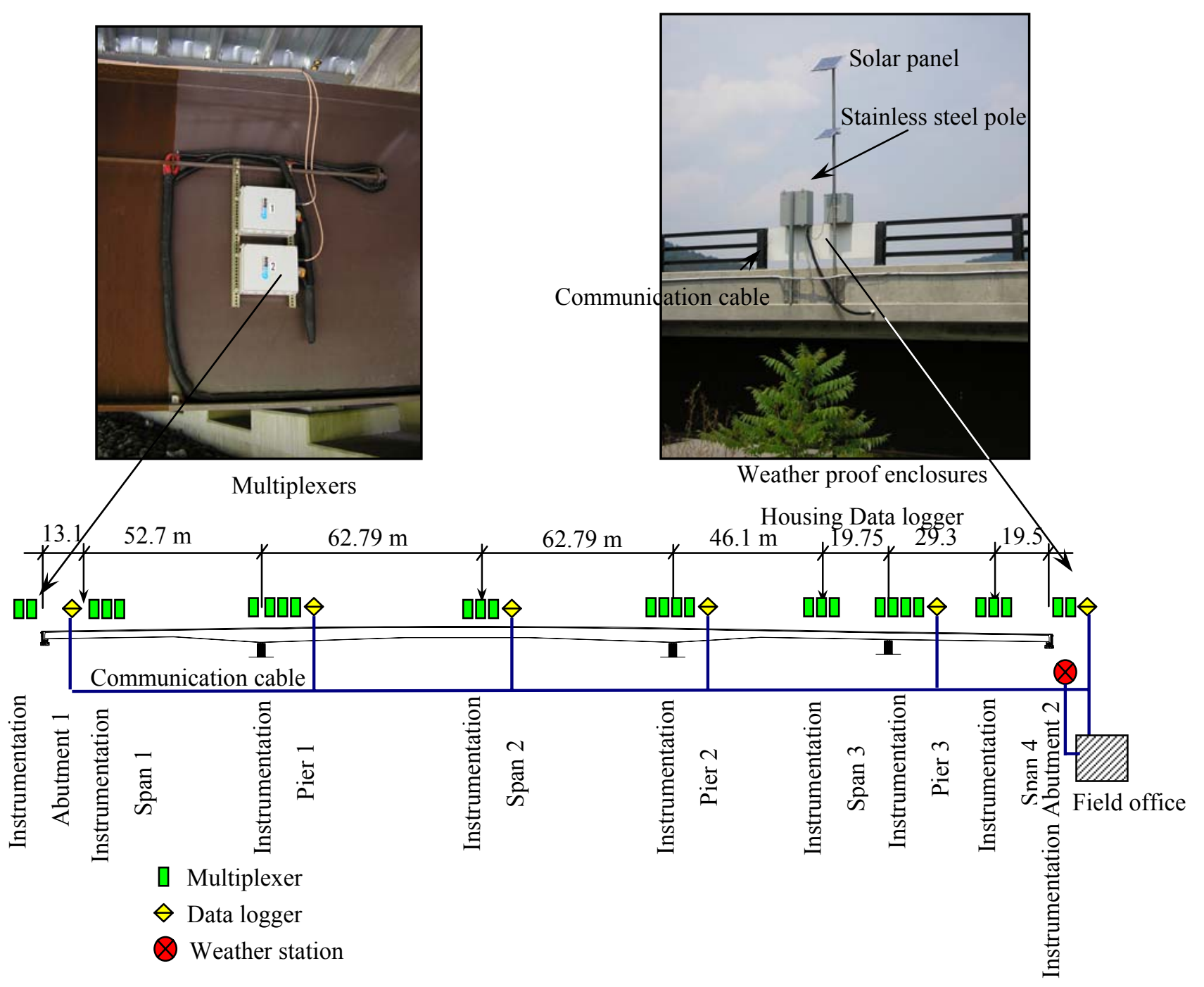

Figure 4.21 Data Acquisition System

Special care was taken to secure the data acquisition system and sensors connectors against moisture and/or chemical attacks. Once all sensors terminals are connected to the multiplexers and the system is tested, all inlets were sealed with an expanding foam substance that filled all voids between the cables once cured as illustrated in Figure 4.22. Furthermore, each multiplexer and data logger enclosure was equipped with 5 to 6 dehumidification packets (Desi Pak by SÜD-CHEMIE) to absorb any amount of moisture contained within those sealed boxes. 


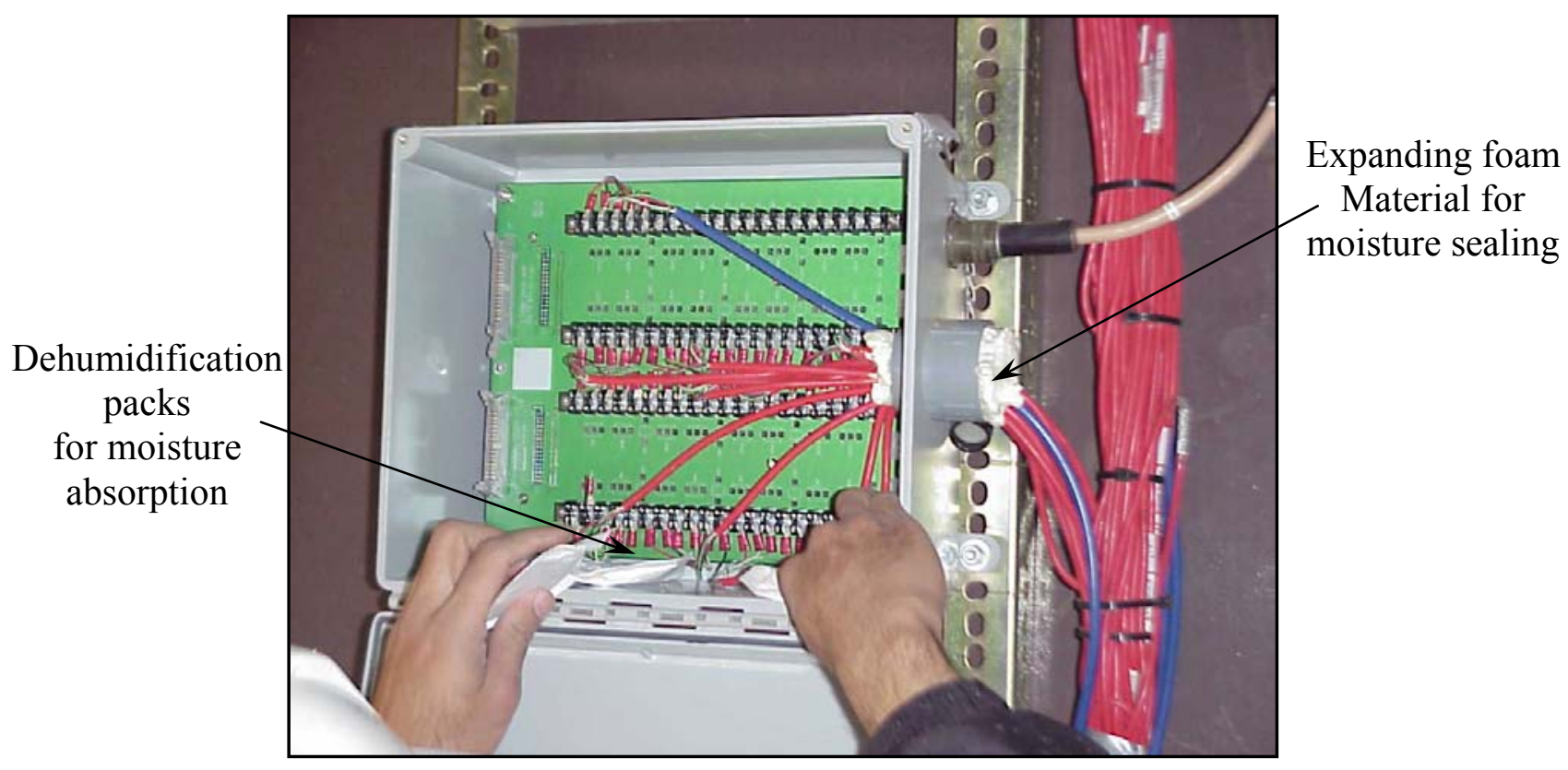

Figure 4.22 Data Acquisition Moisture Protection

The MD9 terminal is housed in a permanent field office that was erected by the bridge entrance. The field office shown in Figure 4.23 is equipped with $120 \mathrm{AC}$ power supply and a phone line, thus provides remote communication with the data acquisition system via phone. The field office consists of two rooms $3.05 \times 3.05 \mathrm{~m}^{2}\left(10 \times 13 \mathrm{ft}^{2}\right)$ where one is dedicated as a storage facility and the second houses the electronics equipments. The communication cables that connects the data acquisition network runs in a PVC conduit along the bridge parapet wall and was drawn to the filed office under ground. All instruments in the system had a common ground at the proximity of the field office.

\subsubsection{Power Supply}

All equipments, sensors, and data acquisition systems are powered through $12 \mathrm{~V}$ DC marine batteries that are continuously charged through photovoltaic solar panels. Each solar panel is mounted to a fifteen feet long stainless steel mast fixed to the bridge parapet wall at the location of the data loggers as illustrated in Figure 4.24. The marine batteries are housed in separate weather-proof enclosures in order to be isolated from the data loggers in an effort to secure the latter from any possible leakage of acid vapors. The 
MD9 terminal runs through $120 \mathrm{AC}$ power from the field office, and is internally converted into $12 \mathrm{~V} \mathrm{DC}$.

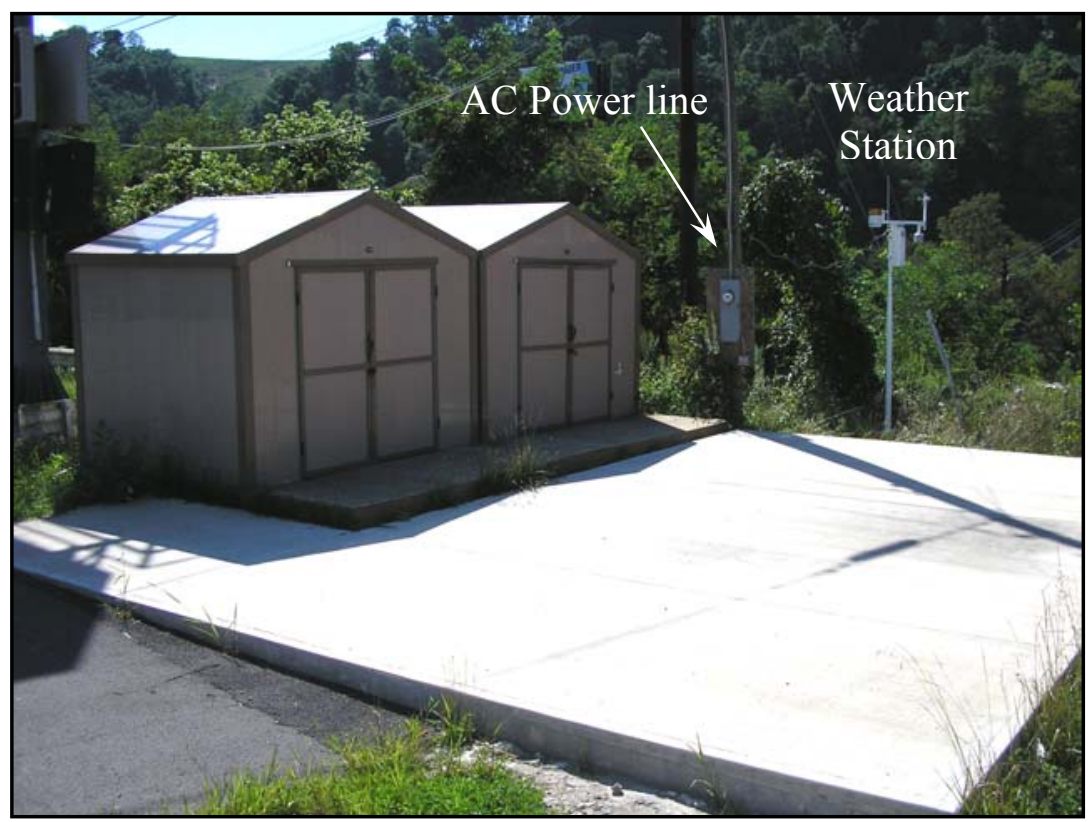

Figure 4.23 Field Office

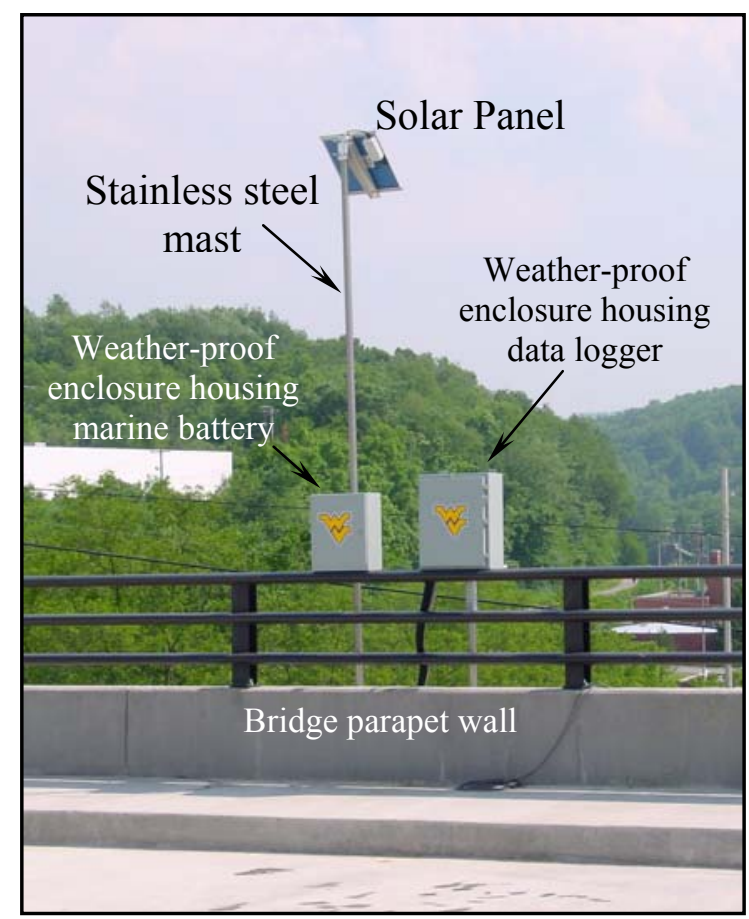

Figure 4.24 Mounting of Solar Panels at Location of Dataloggers 


\subsubsection{Cables routs}

Extensive planning was dedicated not only to selection of sensors and their corresponding locations on the bridge but also to the cable routs and their paths from the gage locations to the data acquisition system. Cable routs were planned in a fashion that would not affect the structural integrity of any of the bridges' component. For this purpose a three dimensional CAD simulation of the bridge was performed and consisted of detailed elements of the bridge as well as the instrumentation system including sensors, cables, and data acquisition enclosures. The CAD model gave a realistic insight of the shortest paths for cables and the optimum location of data acquisition units along the bridge. Figure 4.25 shows examples of the three dimensional CAD model of the bridge. All plans, sensor locations, fixtures, mounting procedures and cable routs were discussed and approved by WVDOT personnel prior to any installation. Cables coming from the embedment deck sensors ran through the non-structural corrugation of the SIP forms as shown in Figure 4.26 till a location close to the steel girders where they were dropped through a $3.8 \mathrm{~cm}$ (1.5 in) diameter opening in the forms. A rubber ring was fastened to the opening rims in the SIP form which protected the cable from tear. Once the cables were passed through, all openings were sealed with foam. Cables reaching the multiplexers were secured to the bracing steel members using plastic wire ties. 


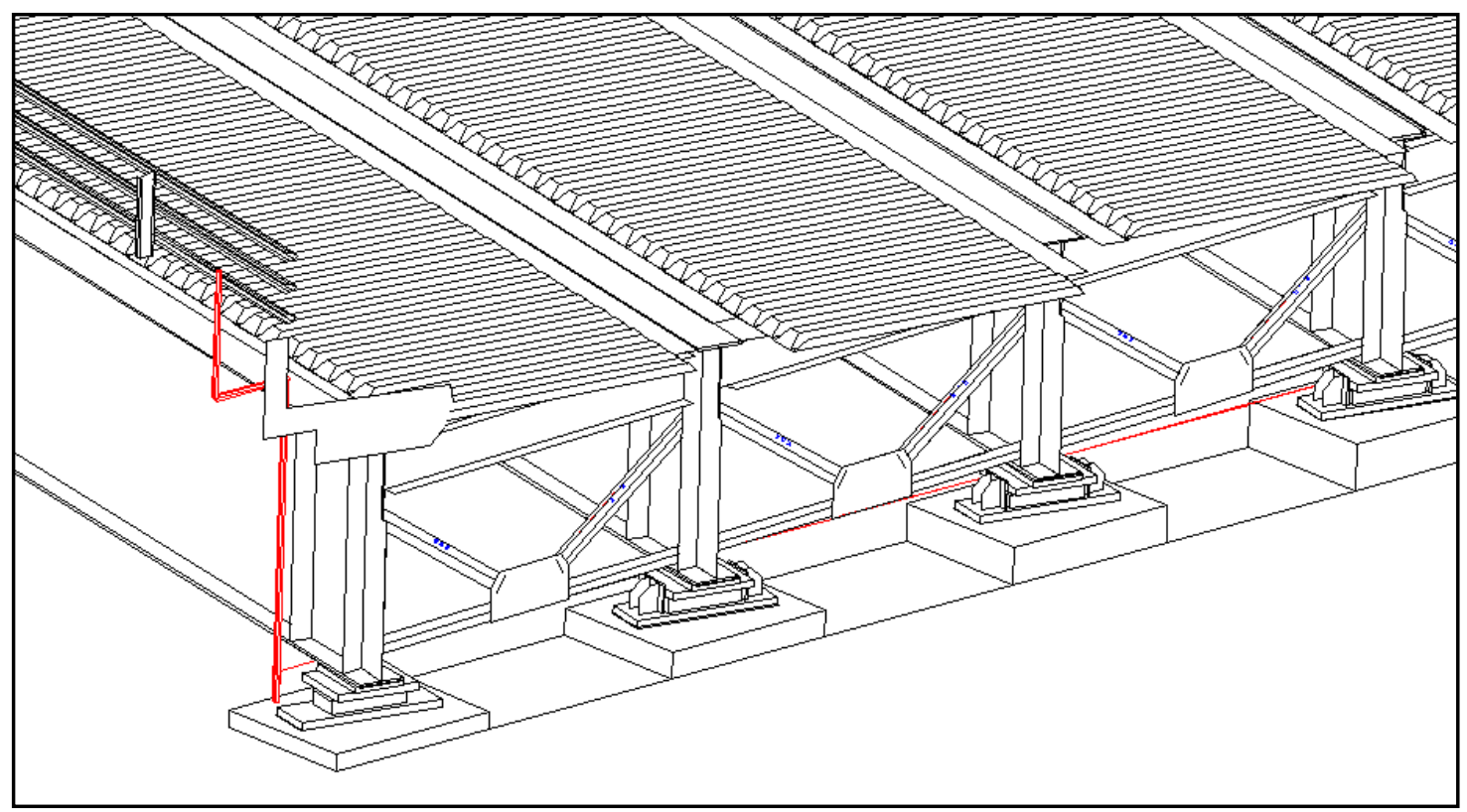

Figure 4.25 Three Dimensional CAD Bridge Model

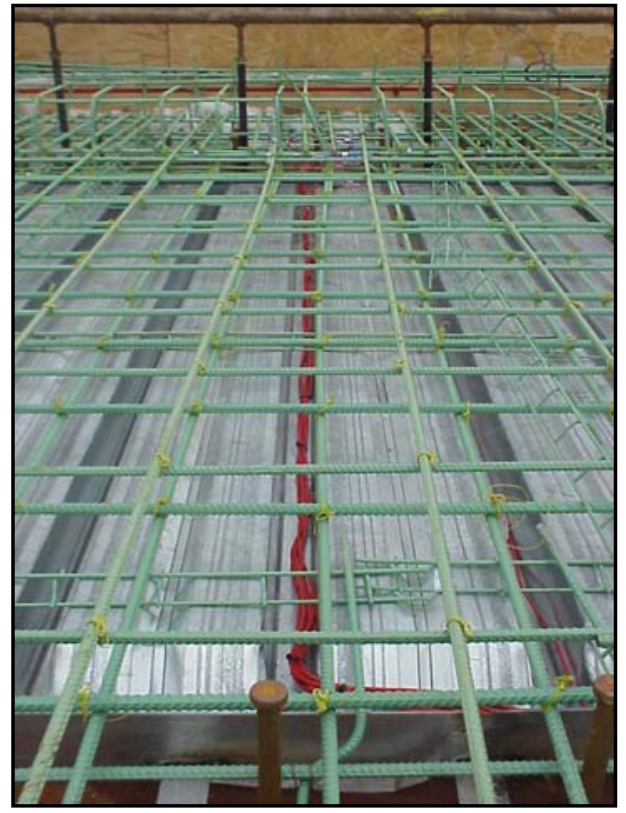

Figure 4.26 Cable Paths in Concrete Deck 


\subsubsection{Challenges during Sensors Mounting}

During the installation process many challenges were faced and had to be overcome in order to achieve this task. The installation of the instrumentation system on the steel superstructure took place during the months of November and December of 2004, where temperature drop to as low as $-10^{\circ} \mathrm{C}\left(15^{\circ} \mathrm{F}\right)$. The harsh weather conditions during installation had to be overcome since the construction schedule was very tight. Another challenge was the time duration to install all sensors. The construction was under a tremendous amount of pressure from several agencies in order to complete the construction work according to a rescheduling plan since many delays hindered the original construction schedule. For this reason, most of the instrumentation system had to be placed and functional during only 2 months. There was a substantial amount of accessibility limitation were location of sensors were not easily reached due to the large dimensions of the steel girders and the vast spans. Reaching locations on top of the ground was achieved by use of a man-lift as shown in Figure 4.27. Other locations especially at mid-spans were only reached by walking down the top or bottom flanges of the girders. Figure 4.28 shows the installation of sensors on mid-span No. 2. After installation of sensors, it was discovered that the steel structure was acting as a huge antenna that collected signals from three radio towers that belonged to a local radio station (WAJR). The collected radio waves increased the electrical noise/signal ratio to the amount where the sensor signals could not be identified. This problem was solved once the concrete deck was placed and radio waves were blocked from reaching the steel structure. Figure 4.29 illustrates all the instrumentation system including sensors and the data acquisition system mounted over the entire bridge length. 


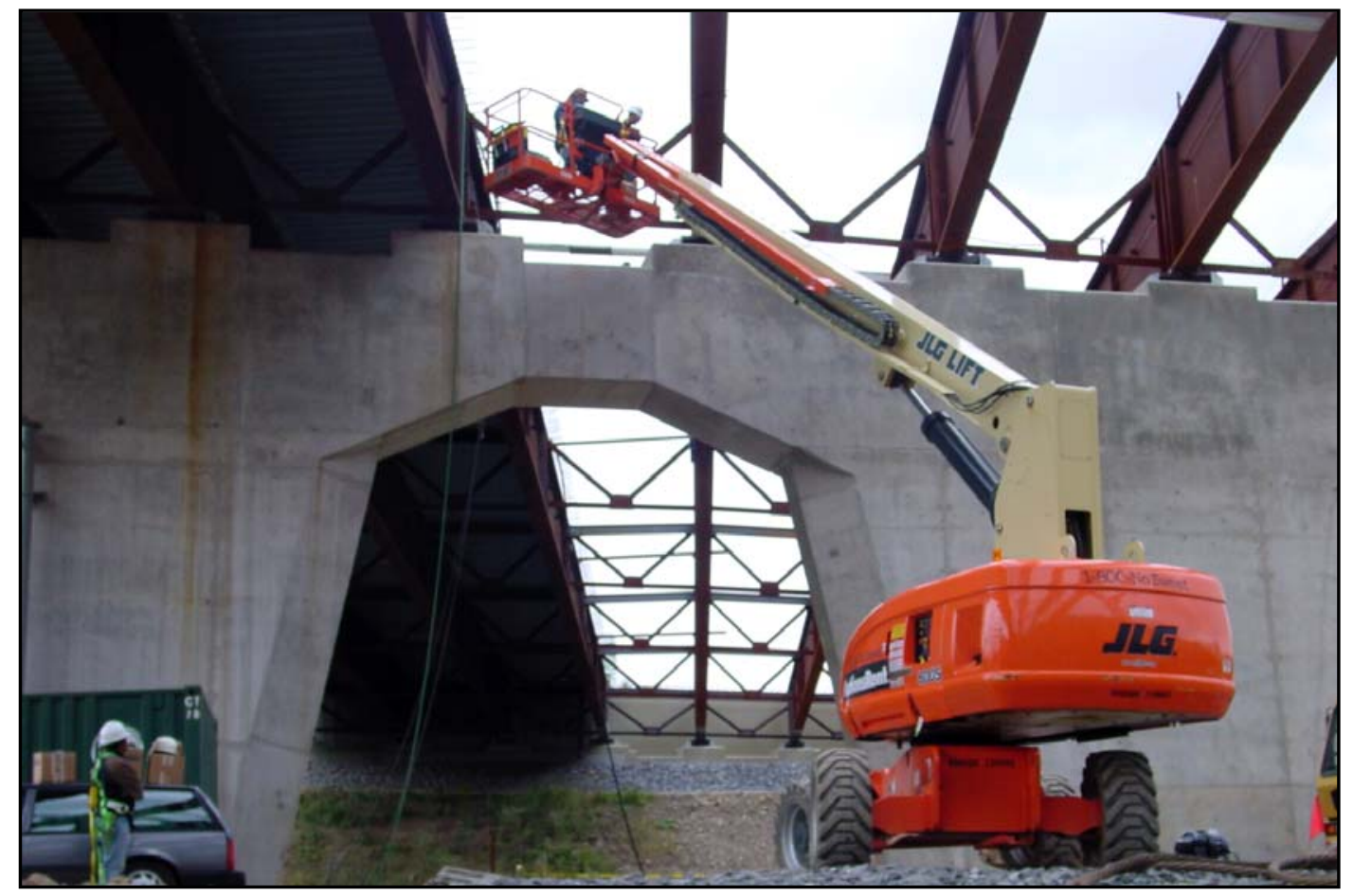

Figure 4.27 Accessibility of Sensor Location by use of Man-lift

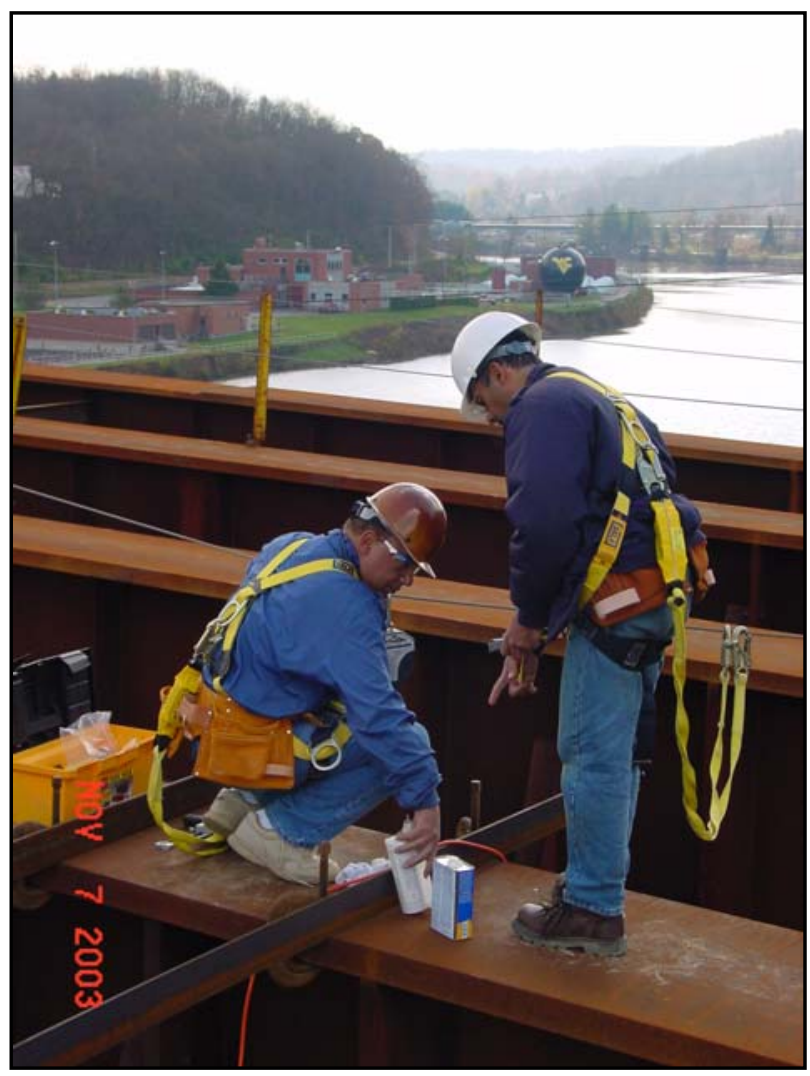

Figure 4.28 Mounting Strain gages on Steel Girders of Mid-span 2 

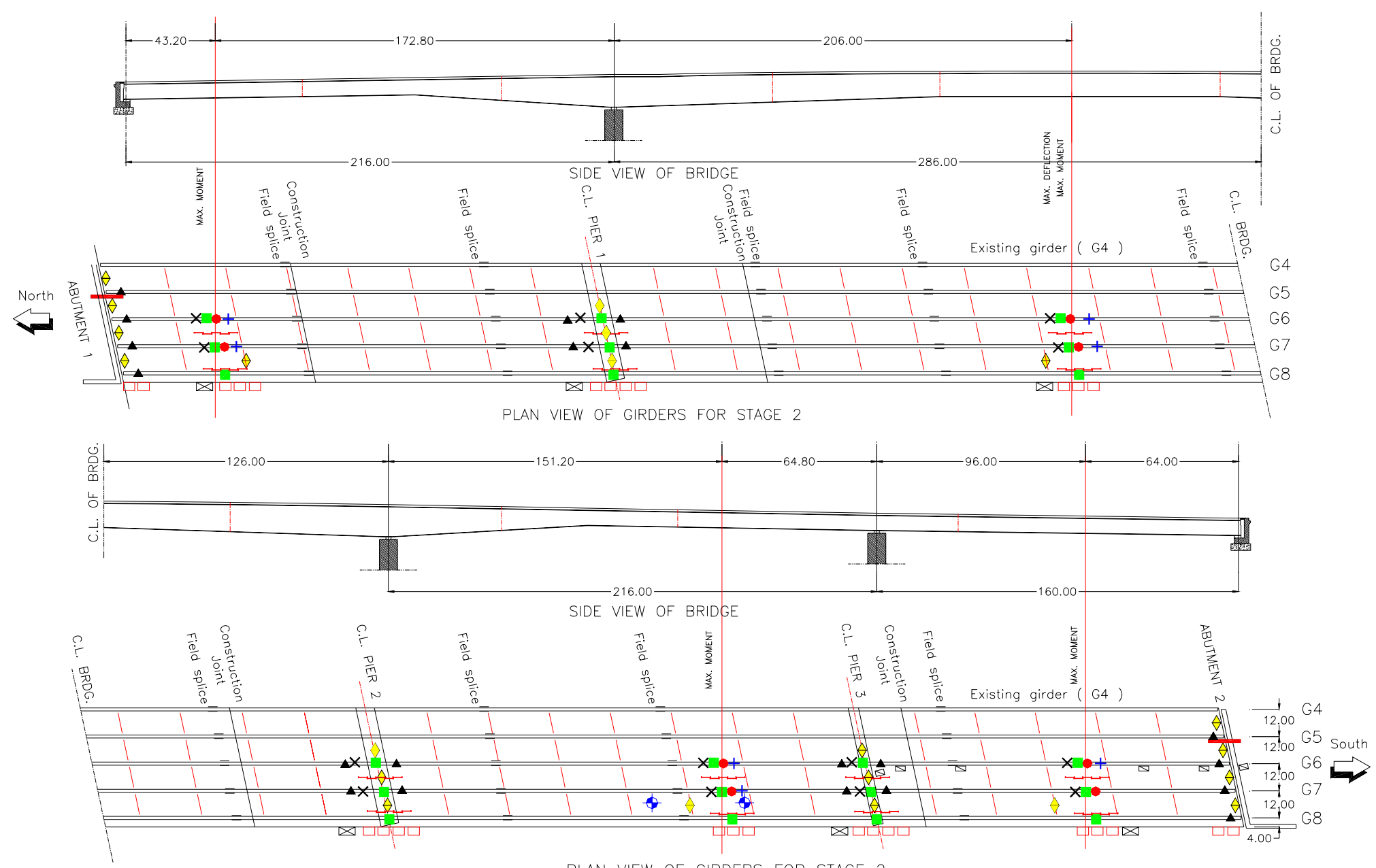

PLAN VIEW OF GIRDERS FOR STAGE 2

$\checkmark \quad$ Bracing response, 4 strain gages at 21 locations

- Shear in steel girders, 3 strain gages at 20 locations

- Torsion in steel girders, 2 strain gages at 8 locations

\section{Multiplexer}

Data logger

- Three Dimensional strain tree, 5 strain gages +2 sister bars at 21 locations

\section{Crack initiation in concrete deck, 4 Crack meters at 14 locations}

$\downarrow \quad$ Temperature gradient, Thermistor tree of 10 sensors at 2 locations

$\times \quad$ Bending of steel girders, 2 strain gages at 14 locations

$\square \quad$ Inclination of steel girders, inclinometer at 6 locations

Relative movement of bridge ends, displacement transducer at 2 locations

$+\quad$ Dynamic response in concrete, 2 Strain gages at 7 locations

Figure 4.29 Instrumentation Plan 


\section{CHAPTER 5}

\section{FINITE ELEMENT MODELING}

\subsection{Introduction}

The finite element method proved to be a powerful tool for solving complicated problems that are tedious if attempted using analytical approaches. In this study, three dimensional finite element (3DFE) modeling programs have been created in support of the measurements obtained form the instrumentation system installed on Star City Bridge. Once the models are verified those can also serve to conduct structural stress analysis studies that might be cost prohibitive if performed on a real large structure. The 3DFE study includes two models that simulate the second stage of construction as well as the entire bridge after completion. The models are performed using ADINA software (Bathe, 2004) as mesh generator and program solver while detailed geometry was generated in AutoCAD (Autodesk, 2004) and imported into ADINA. The first model consists of 4 steel girders with their full length along with the bracing system and the concrete deck. The second model consists of the entire bridge including the 8 steel girders topped with the concrete deck, and braced with diaphragms members.

\subsection{Models Geometry}

In order to provide an accurate simulation of the bridge response, the models were meticulously detailed with all geometrical properties and dimensions as indicated in construction drawing sheets including all structural members, various plate thicknesses, and vertical as well as horizontal girder stiffeners. Figure 5.1 to Figure 5.5 show details of one girders' geometry that is generated in AutoCAD and is employed for modeling both, phase 2 as well as the entire bridge superstructure. The dimensions indicated on the top and bottom of the girder refer to distances in meters and their corresponding conversions in feet between brackets. The dimensions of the top and bottom flanges are 
indicated in inches between brackets underneath the distance. The first number refers to the flange width, while the second number indicates the thickness. The web consists of steel plates with $1.43 \mathrm{~cm}(9 / 16)$ inches thickness and height varying from 1.98 to $3.96 \mathrm{~m}$ (78 to 156 in). The height at Spans 1, 3 and 4 is $1.98 \mathrm{~m}$ while measures $3.05 \mathrm{~m}(120$ ") at span 2. The web height at both Pier 1 and Pier 2 is $3.96 \mathrm{~m}$ (156") and a haunch allows the transition from the smaller dimensions. The haunch follows parabolic relations as indicated is Equations 1 and 2;

$$
\begin{array}{lr}
\text { web depth }=78+7.32378 \times 10^{-5}\left(1032-x_{1}\right)^{2} & \text { Equation 5.1 } \\
\text { web depth }=120+1.23983 \times 10^{-5}\left(1704-x_{2}\right)^{2} & \text { Equation 5.2 }
\end{array}
$$

where $x_{1}$ and $x_{2}$ are distances along girder length from the location of the pier.

Equation 1 refers to the haunch at Span 1 and 3, while Equation 2 refers to the haunch at span 2. 


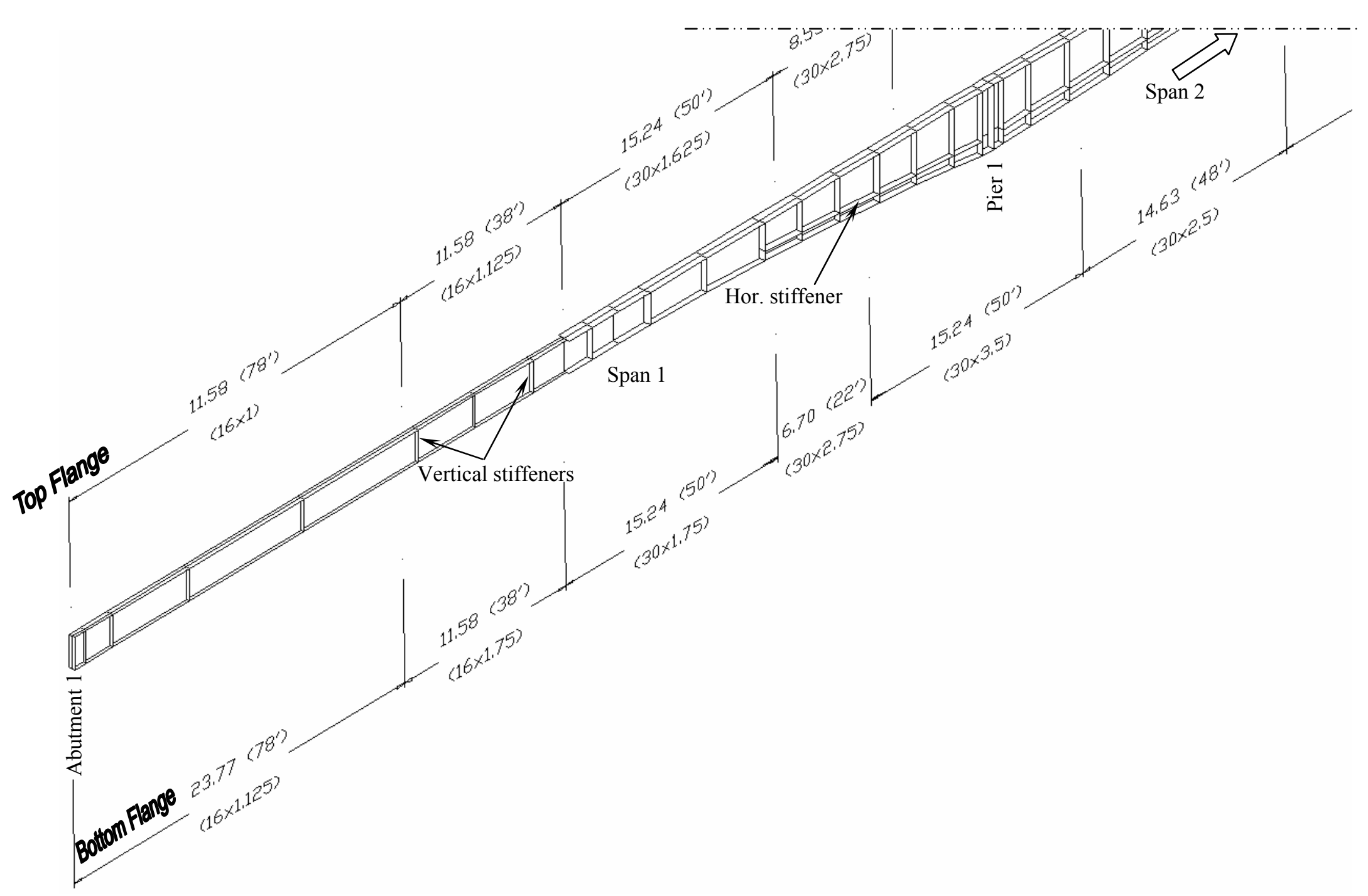

Figure 5.1 A- Steel Girder Details from Abutment 1 to Pier 1 


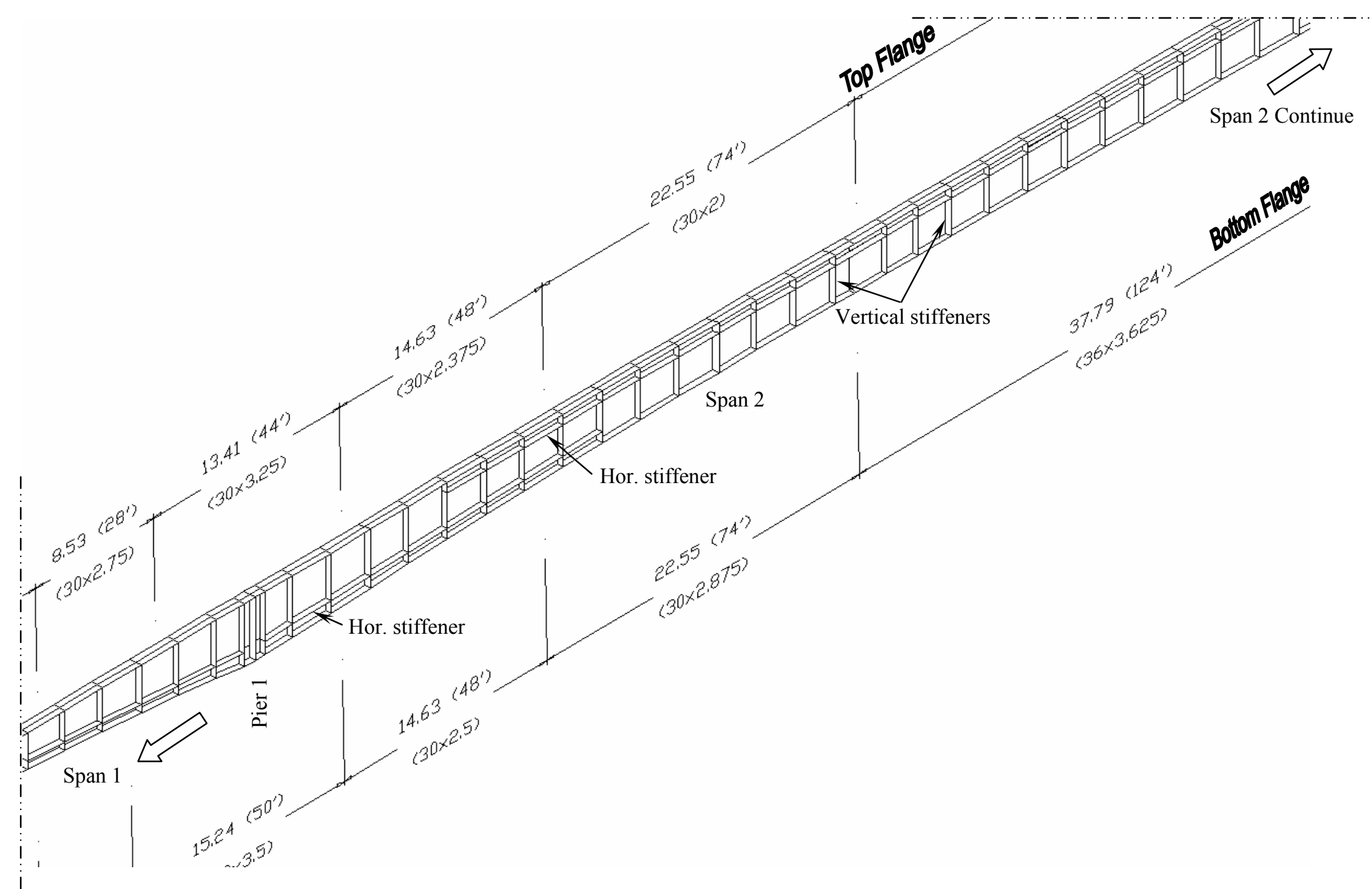

Figure 5.2 Steel Girder Details from Pier 1 to Mid-span 2 


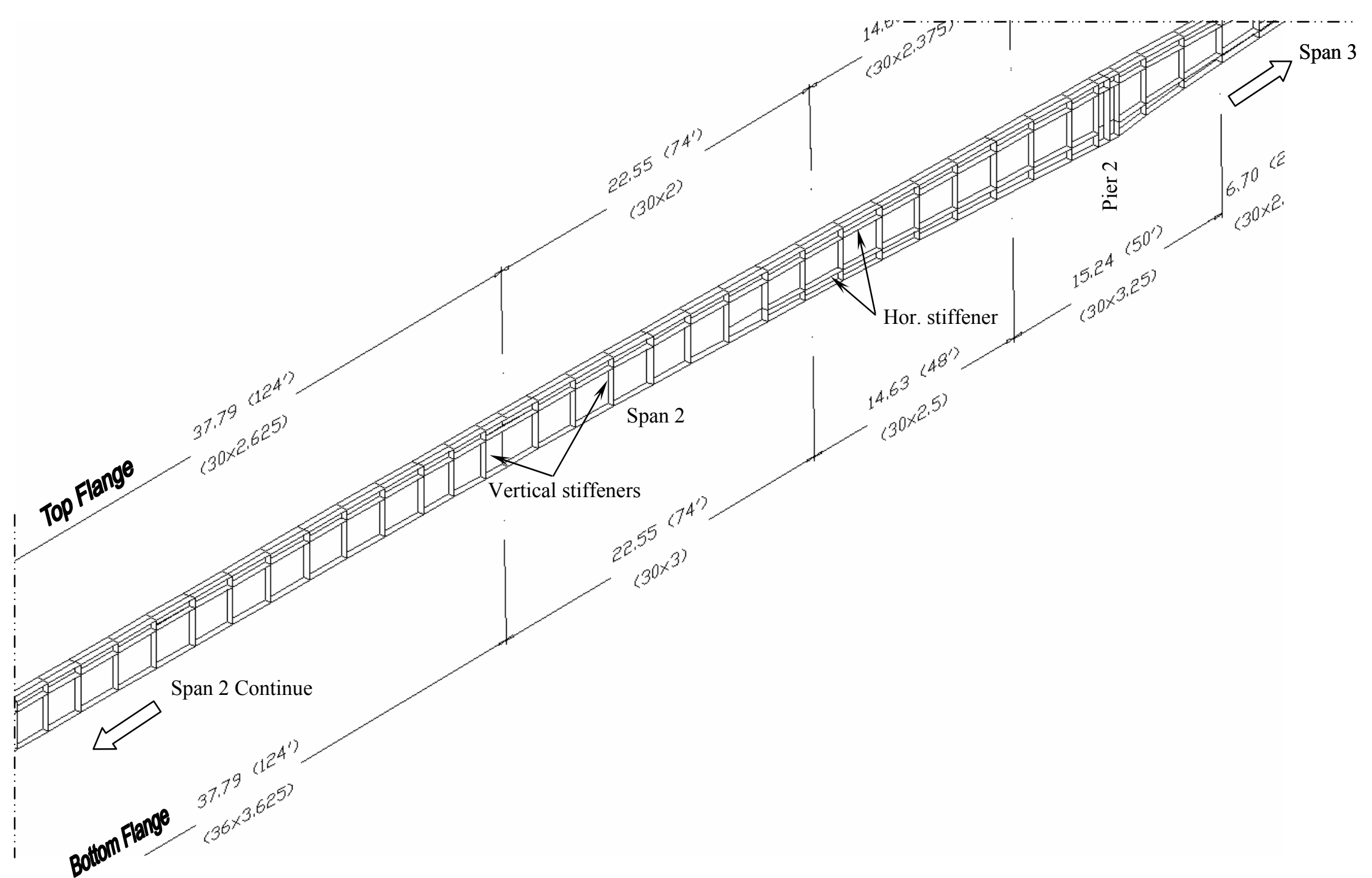

Figure 5.3 Steel Girder Details from Mid-span 2 to Pier 2 


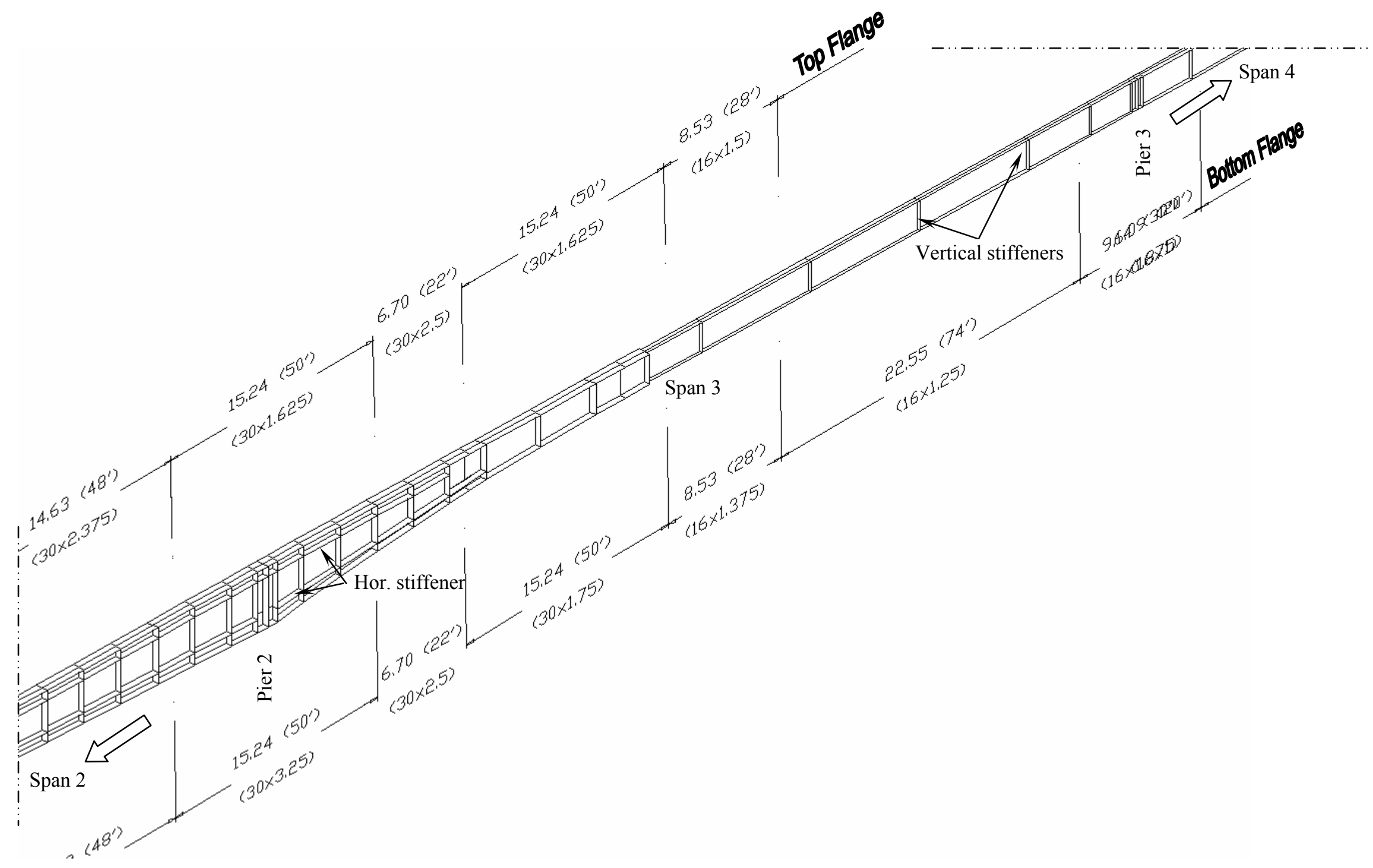

Figure 5.4 Steel Girder Details from Pier 2 to Pier 3 


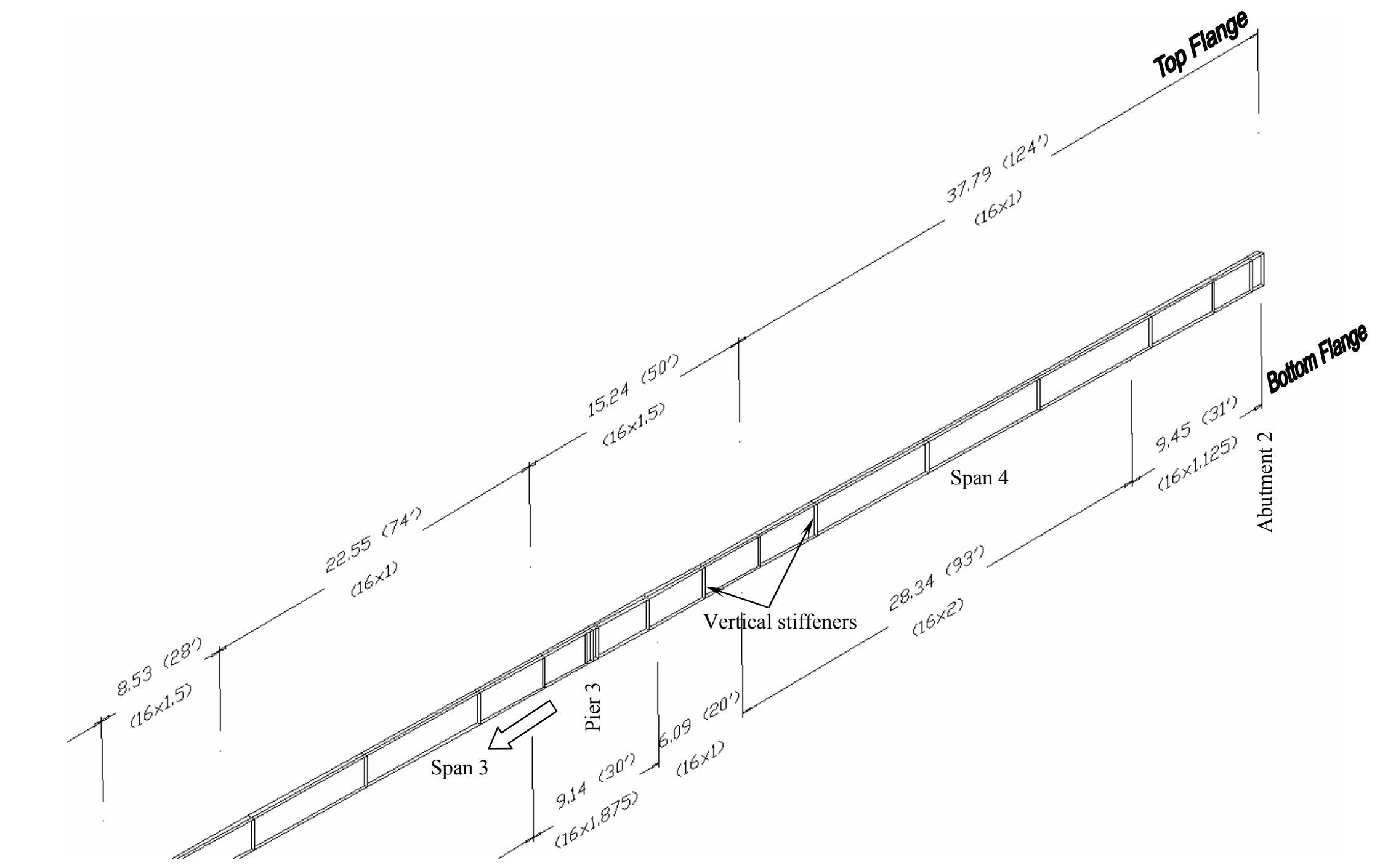

Figure 5.5 Steel Girder Details from Pier 3 to Abutment 2 


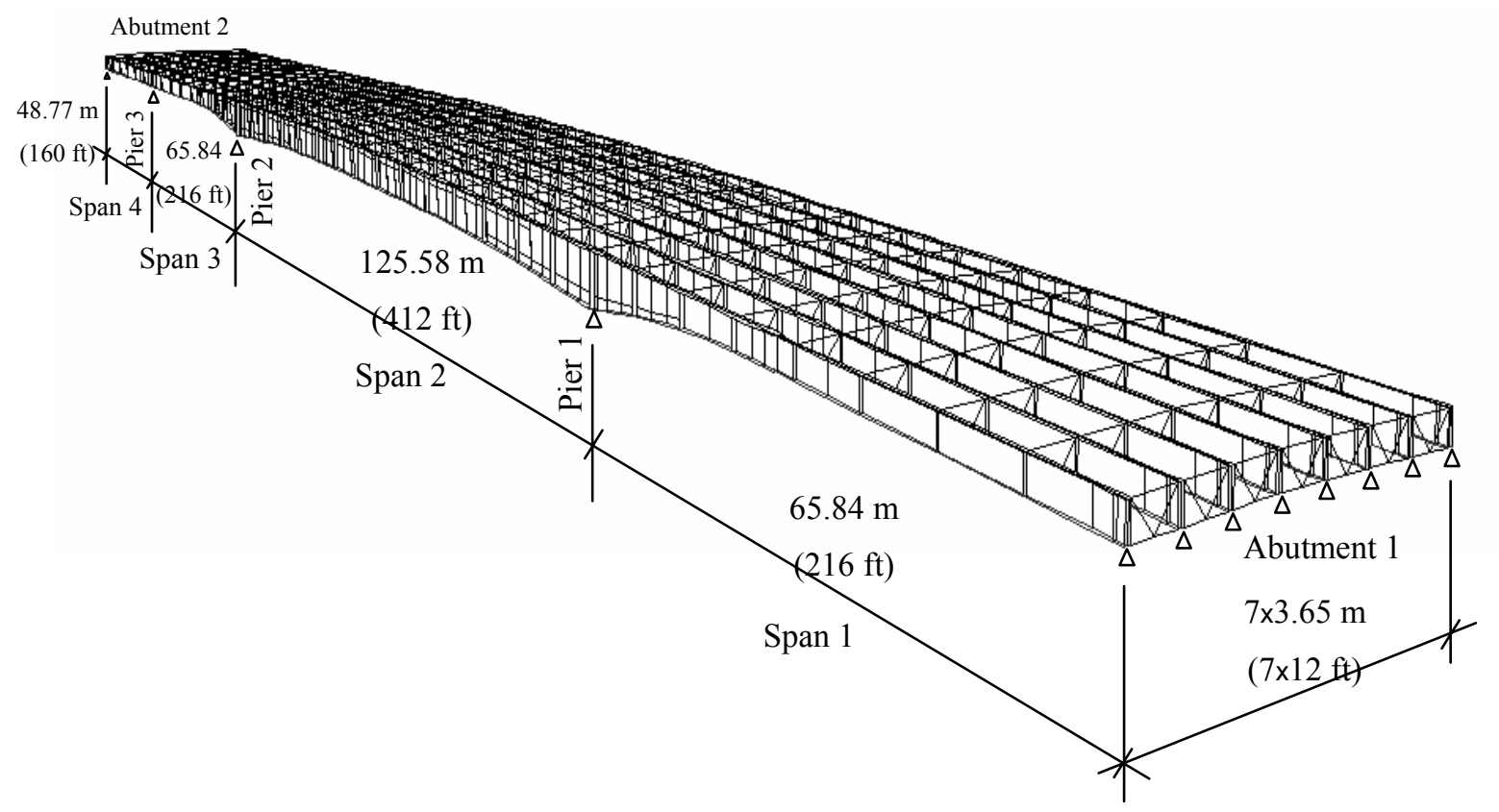

Figure 5.6 Steel Superstructure of Full Bridge Model

Figure 5.6 shows the assembly of the full bridge model including 8 steel girders as well as bracing members while the concrete deck is being removed.

\subsection{Elements properties}

\subsubsection{Shell Elements}

All steel girders as well as the concrete deck are modeled using 4 nodes iso-parametric shell elements. Appropriate thicknesses were assigned for the elements according to their locations in the model. The shell elements are formulated as three dimensional continuums following the assumptions used by Timoshenko for beam theory (the structure is the beam) and Reissner/Mindlin for the plate theory (the structure is the plate) (Bathe et al., 1983) .

4 nodded elements are selected for their outmost effectiveness in analysis of general thin and thick shells (Dvorkin and Bathe, 1984, Bathe and Dvorkin, 1985, and 1986) ', . The 4 nodded shell element shown in Figure 5.7 is generated in ADINA and is used for its high predictive capability and its preventive ability to overcome the locking problem. Locking is known in the literature as the phenomenon that makes the element too stiff in a sense that the interpolation 
functions used for that element are not able to represent zero shearing strains when they are physically negligible.

Six degrees of freedom, namely 3 displacements and 3 rotations referring to the global Cartesian coordinates, were assigned to the shell elements for the following reasons:

- In most cases the shell elements intersect in angles.

- The shell elements are couples with isoparametric beam elements used for modeling diaphragm members.

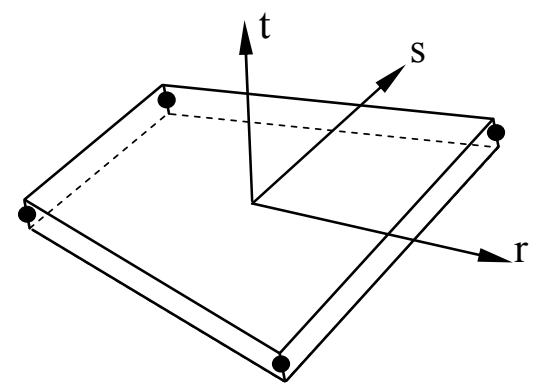

Figure 5.7 Four-Node Shell Element for Thin and Thick Shells

\subsubsection{Beam Elements}

All diaphragm members are modeled using 2 nodes Hermitian beam elements with constant cross sections and 6 degrees of freedom at each node. Figure 5.8 illustrates the geometry definition and degrees of freedom of beam elements.

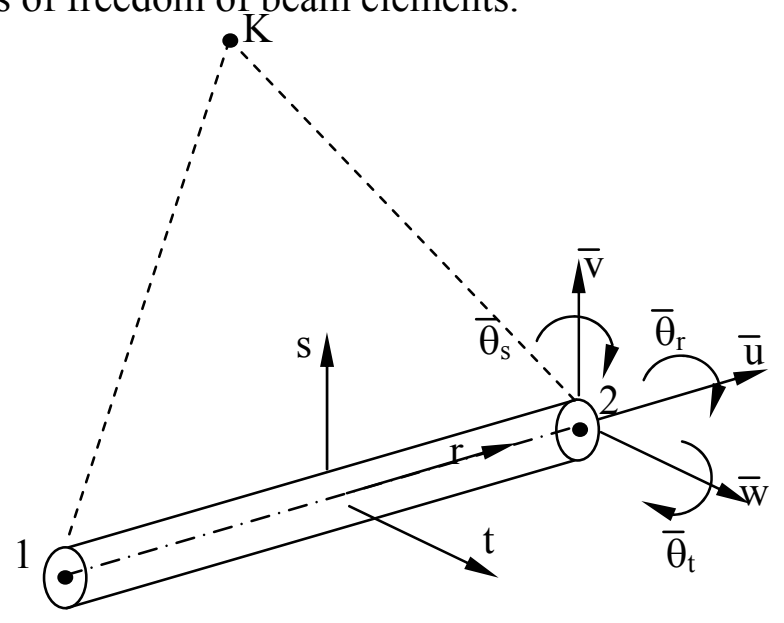

Figure 5.8 Geometry Definition of Beam Elements 
The beam elements are formulated based on the Bernoulli-Euler beam theory and corrected for shear deformation effects thus they are suitable for capturing development of straining actions including bending moments as well as axial and shearing forces. The beam behavior is described using a cross-sectional shape and a material model. Linear beam elements were assigned to the diaphragm members assuming that displacements, rotations, and strains are infinitesimally small, and elastic-isotropic material is used. The element local coordinate system $(\mathrm{r}, \mathrm{s}, \mathrm{t})$ is defined by the elements' end nodes (local nodes 1 and 2 ) and an auxiliary node $\mathrm{K}$. The node $\mathrm{K}$ is positioned appropriately with respect to the actual orientation of the principal planes of inertia of the element.

\subsection{Material modeling}

Linear Elastic-Isotropic material model was assigned for both the concrete deck as well as the steel superstructure. Two material constants are used to define the constitutive relation, namely Young's modulus (E) and Poisson's ratio (v). Elastic material model is selected for the bridge structure based on the maximum stresses identified from the calculation sheets that appeared to be within elastic ranges for the considered cases of loading. The concrete material constants were identified from material testing, while those for the steel elements were adopted from the bridge's specifications sheets. Table 5.1 lists the values of material constants assigned for the bridge model.

Table 5.1 Material Constants

\begin{tabular}{lcc}
\hline Material Constant & Concrete Material & Steel Material \\
\hline \hline Modulus of Elasticity (E) & 3.51e4 Mpa (5.1e6 PSI) & 200 Gpa (29e6 PSI) \\
Poisson's Ratio $(v)$ & 0.23 & 0.32 \\
\hline
\end{tabular}

The formulations employed for the linear elastic material constitutive model can be found in (Bathe, 1996) . 


\subsection{Boundary Conditions}

The boundary conditions and degrees of freedom at the supports are set to simulate the bridge specifications. Figure 5.9 shows the various types of the guided as well as the non-guided expansion bearings used for supporting the steel superstructure at the locations of Abutments 1 and 2 and Piers 1 and 3. Figure 5.10 shows the fixed bearings used at the location of Pier 2. Figure 5.11 illustrates the full FE model of the entire bridge with the boundary conditions assigned to the supports. The nodal points at the location of supports were assigned degrees of freedoms corresponding to either $\mathrm{A}, \mathrm{B}$, or $\mathrm{C}$ that simulate the bearing behavior. Category $\mathrm{A}$ allows displacements in $\mathrm{x}$ and $\mathrm{y}$ directions only. Category $\mathrm{B}$ allows displacements in $\mathrm{x}$ direction, while $\mathrm{C}$ provides total fixation. All categories (A, B, and $\mathrm{C}$ ) allow free rotations in all directions.

The concrete deck and top flanges of the steel girders are tied at the shell elements nodes to simulate a perfect bond between those two. This procedure is selected based of analysis of the composite action between the concrete deck and steel girders that showed a good deck/steel composite action after 10 days of concrete pour as will be demonstrated in section 6.2. 


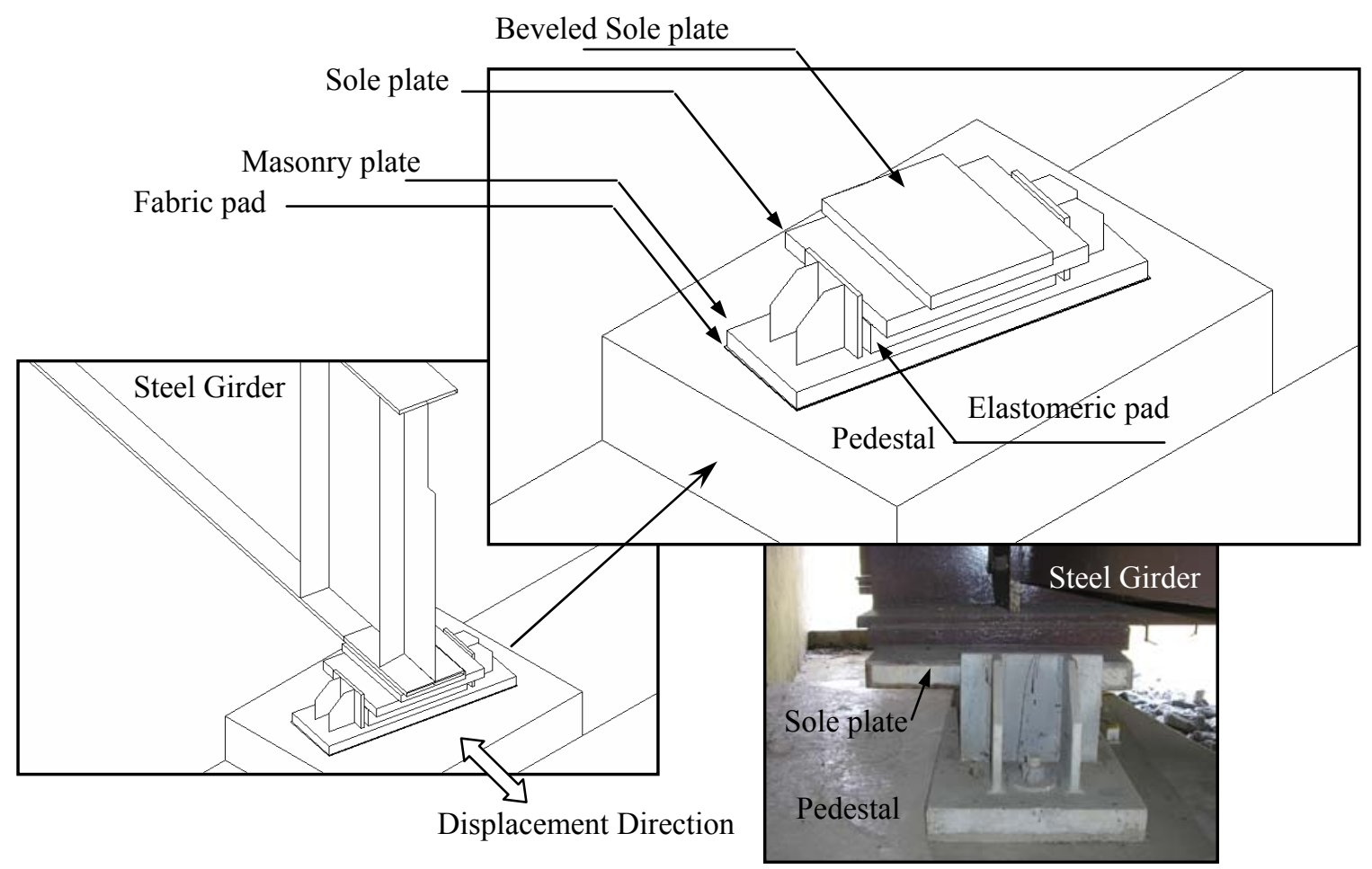

Guided Expansion Bearing on Abutments, Pier 1 and Pier 3

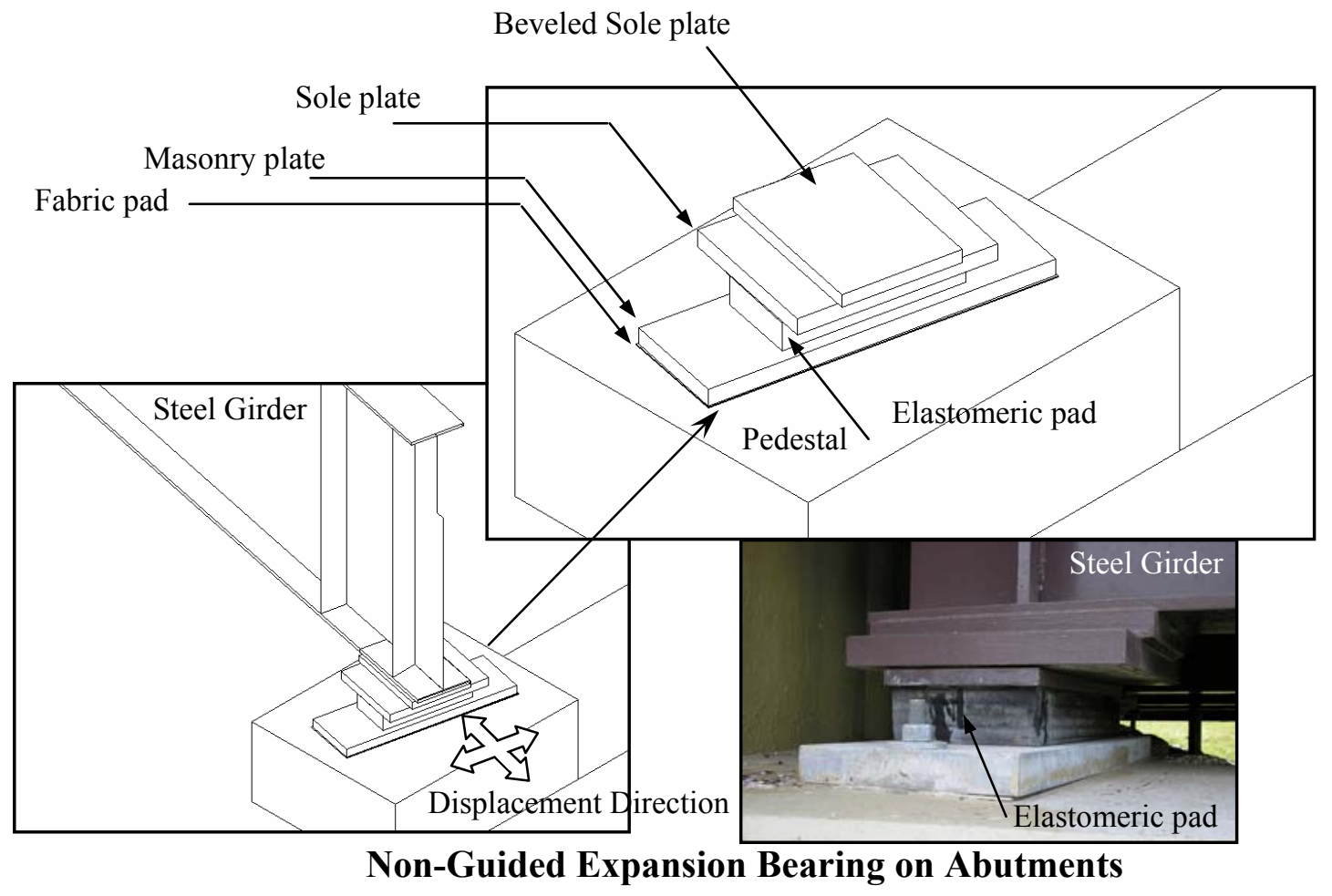

Figure 5.9 Expansion Bearings 


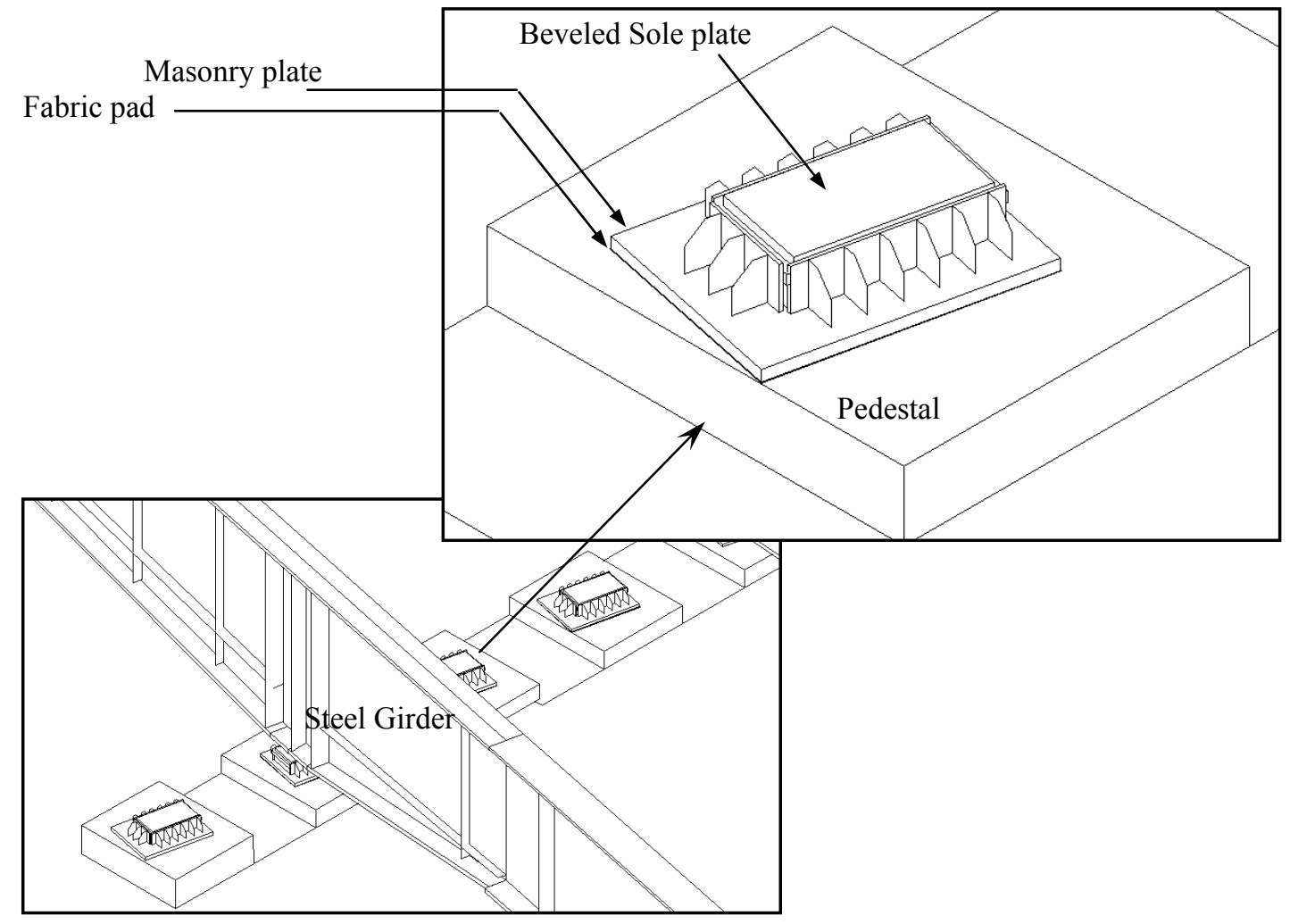

Figure 5.10 Fixed Bearings at Pier 2

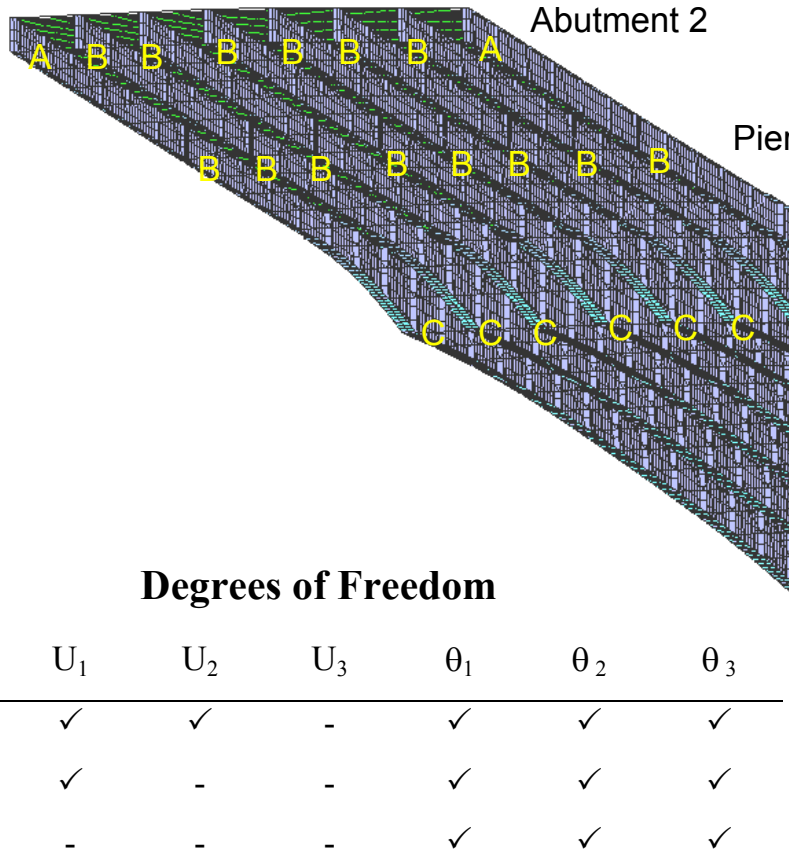

Pier 1

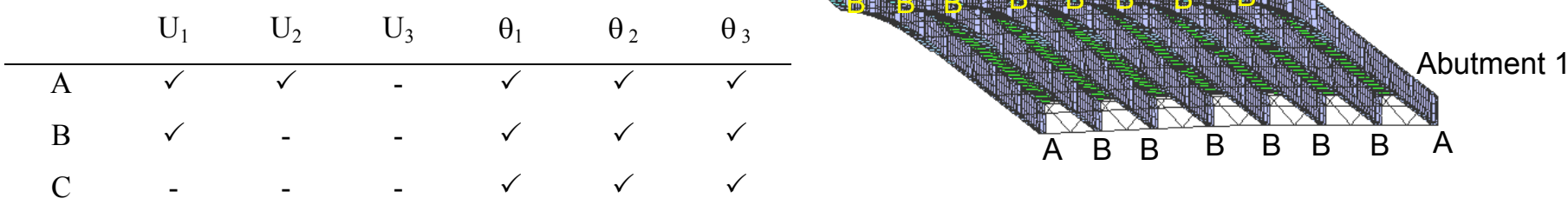

Figure 5.11 Bottom view of Full FE Model Showing Supports Degrees of Freedoms 


\subsection{Meshing}

Generating a FE Mesh of both phase 2 and the full bridge geometries start by defining three main element groups which contain elements that share common attributes. The first group contained shell elements used for meshing the steel girders, and the second group contained shell elements for meshing the concrete deck, while the third contained beam elements for meshing the diaphragm members. In each element group, the elements share common material kinematics formulations, numerical integration order, interpolation formulation and result output. Table 5.2 lists the number of nodes and elements for both models.

Table 5.2 Models Information

\begin{tabular}{lcc}
\hline Model Information & Phase II Model & Full Bridge Model \\
\hline \hline Total number of nodes & 105656 & 49025 \\
Number of Shell elements in steel girders & 96080 & 32501 \\
Number of Shell elements in conc. deck & 0 & 11827 \\
Number of Beam elements in diaphragms & 3274 & 5264 \\
\hline
\end{tabular}

\subsubsection{Meshing of Shell Elements}

The meshing algorithm is based upon the concept of subdivisions on the lines and edges in the model. For the full bridge model, a mesh density is assigned to the 3D surfaces forming both the steel girders as well as the concrete deck so that the maximum edge length (element size) along the lines of the geometry will not exceed 30 inches. This selection was based on memory and computational capacity of the used computer, while at this stage the full model was primarily used for modal analysis. The subdivisions along the edge length in this case are equally spaced and element nodes on interconnected surfaces coincide. The maximum element length on Phase 2 model is $25.4 \mathrm{~cm}$ (10 inches). Gaussian numerical integration is assigned with the order of $2 \times 2$ integration for the evaluation of the elements matrices. 2-point Gauss integration is used through the shell thickness. 


\subsubsection{Meshing of Beam Elements}

3D Beam elements are assigned to the diaphragm members with a mesh density of 4 elements per member with a length ratio of one. The largest element length is located at the top chord member and measures $81.3 \mathrm{~cm}$ ( 32 inches). The element lengths at the diagonal and lower chord members range between 40.6 to $71.1 \mathrm{~cm}$ (16 to 28 inches).

\subsection{Loading}

At stages of construction, the main loading configuration is defined by the own weight of the bridge elements, thus static response of the bridge structure is of main interest. Similar loading patterns were applied to the bridge FE models to simulate the sequence of construction. Phase 2 model is subjected to the own weight of the steel girders. This reflects the deflection profile of the girders resulting from gravity load. For this purpose the FE model is invoked to calculate the mass properties of the elements. The loading in this case is mass proportional which is defined by the gravity acceleration amounting $9.807 \mathrm{~m} / \mathrm{sec}^{2}\left(32.2 \mathrm{ft} / \mathrm{sec}^{2}\right)$. Once the own weight of the steel girder is set, the model is subjected to the own weight of the concrete deck following the sequence of concrete pour in the field. Figure 5.12 shows the loading configuration that simulates the concrete deck weight as applied on the FE model.

The distributed weight of the concrete deck (W) is calculated based on the unit weight of concrete material $\left(\mathrm{w}_{\mathrm{c}}\right)$ amounting $\left(145 \mathrm{lb} / \mathrm{ft}^{3}\right)$. W measures $33.78 \mathrm{KPa}\left(4.9 \mathrm{lb} / \mathrm{in}^{2}\right)$ at locations along the steel beam having a top flange width of 16 inches, and $18.06 \mathrm{KPa}\left(2.62 \mathrm{lb} / \mathrm{in}^{2}\right)$ where the top flange width is $30 \mathrm{in}$. 


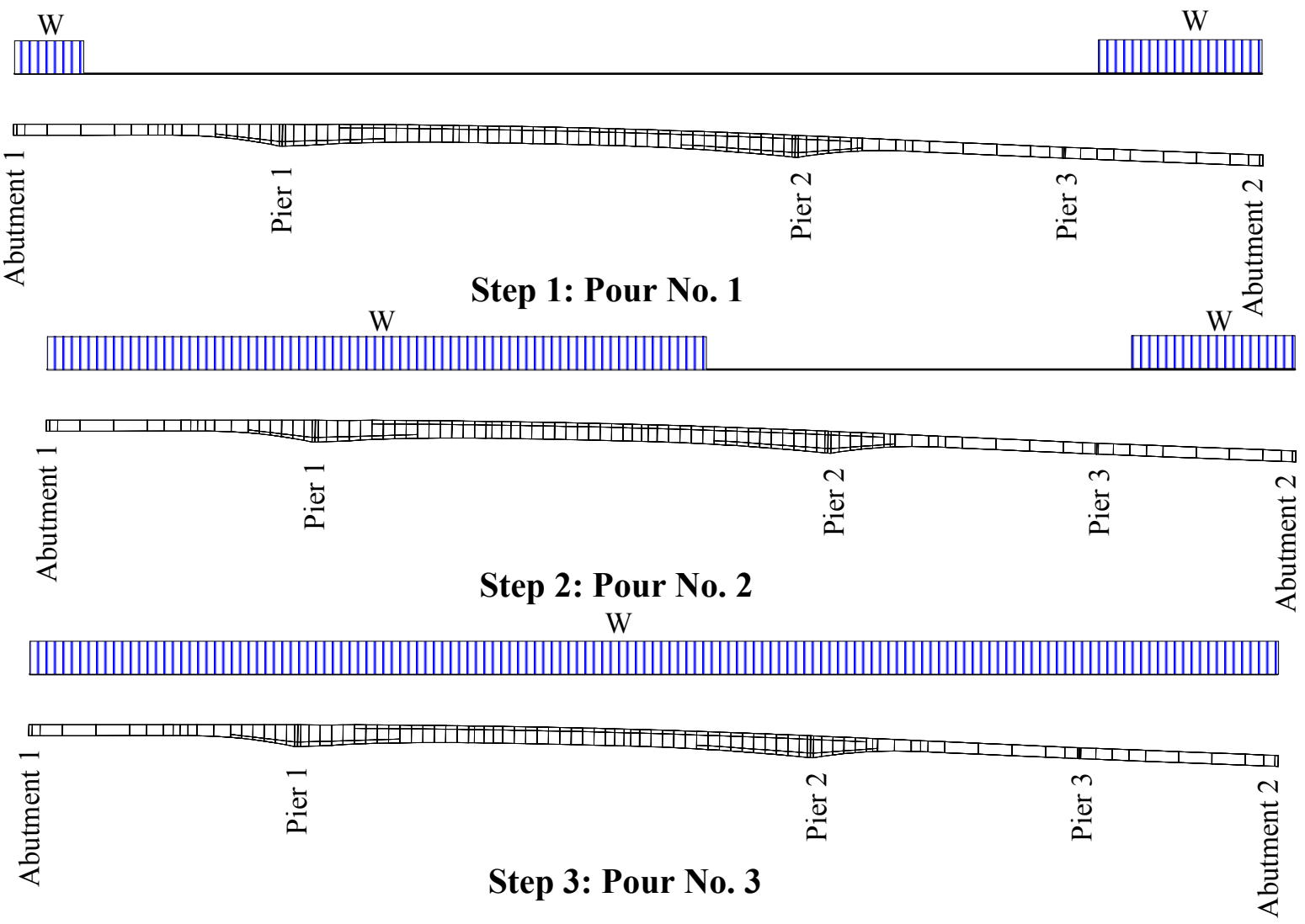

Figure 5.12 Loading of Concrete Deck Weight on FEM

\subsection{Model Validation}

The Star City Bridge notes a remarkable advantage in terms of modeling, which is expressed in the absence of residual stresses at this stage, since the bridge is just being under construction. Therefore a validated model would record the signature of the structure at the first stage of operation, which could be altered during the service life of the bridge. The model response is validated through two different methods. The first method involves a comparison of the 3DFE model response to its dead load with that theoretically calculated from the design sheets and specification drawings. This is carried out by comparing the maximum and minimum displacements in both the theoretical calculations and those resulting from the FE model due to the weight of the concrete deck after the sequence of concrete pours. The second method of validation consists of comparing the strain measurements recorded from the instrumentation system with those produced by the FE model due to matching loading sequences. The following section documents the validation of the FE models following the aforementioned methods. 


\subsubsection{Validation through Theoretically Calculated Displacements}

Figure 5.13 illustrates both the original and deformed mesh after subjecting the model to the concrete weight following the sequence of pours. The maximum downward deflection from the FE model is found to be (-11.42 in) at Span No.2, while the maximum upward deflection measured (+2.735 in) at Span No. 3.

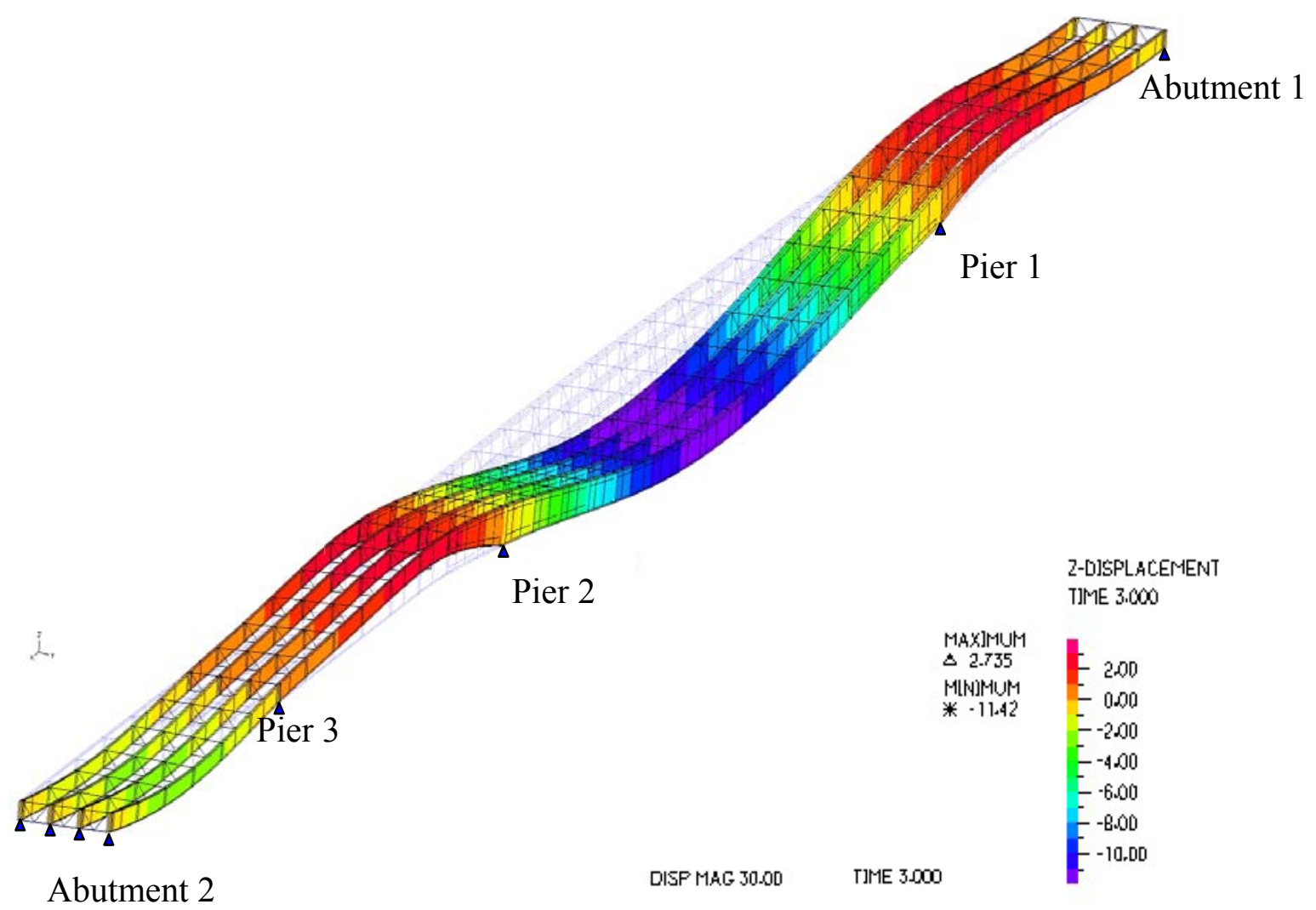

Figure 5.13 Deformation of Steel Girders due to Placement of Concrete Deck

The maximum and minimum displacements of the steel girders due to the placement of the concrete deck were theoretically calculated and identified from the specification drawing sheets of the bridge. Table 5.3 shows a comparison with the theoretically calculated displacement values and those produced from the FE model of Phase 2. A very close match could be drawn from the comparison of the displacement values, indicating that the model response agrees with theoretically calculated predictions considering gravity loads. 
Table 5.3 Comparison of FEM and Theoretical Girder Displacements

\begin{tabular}{lcc}
\hline $\begin{array}{c}\text { Displacement } \\
\text { (in) }\end{array}$ & FEM & $\begin{array}{c}\text { Theoretical Design } \\
\text { Calculations }\end{array}$ \\
\hline \hline Maximum (upward) & 2.739 & 2.16 \\
Minimum (downward) & -11.49 & -10.24 \\
\hline
\end{tabular}

\subsubsection{Validation through Strain Measurements}

Strain measurements recorded through the instrumentation system placed on the Star City Bridge are used to validate the response of the 3DFE models developed in this study. The dead load of the concrete deck is used as the loading configuration as stresses resulting from gravity loading represent substantial stress levels that are permanently locked into the structure. The dead weight of the concrete material is found to be very suitable loading configuration for verifying the FE models for another reason. The effect of the dead weight occurs instantaneously at the time of concrete placement, thus no other parameters alter the strain response of the structure. Directly recorded data in this case can be easily used with little or no doubts of long term effects such as temperature and moisture variations, creep, and stress relief due to relaxation...etc.

Figure 5.14 to Figure 5.16 illustrate a comparison between measured strains on the steel girders and those produced by the FE model. The measured strains are presented in a time history format as the instrumentation system allows data collection continuously and provides records of the data from all sensors simultaneously every 20 minutes. The FE results are interpreted as a step value since dead load application is instantaneous and time factor is not a dimension in the FE model. 


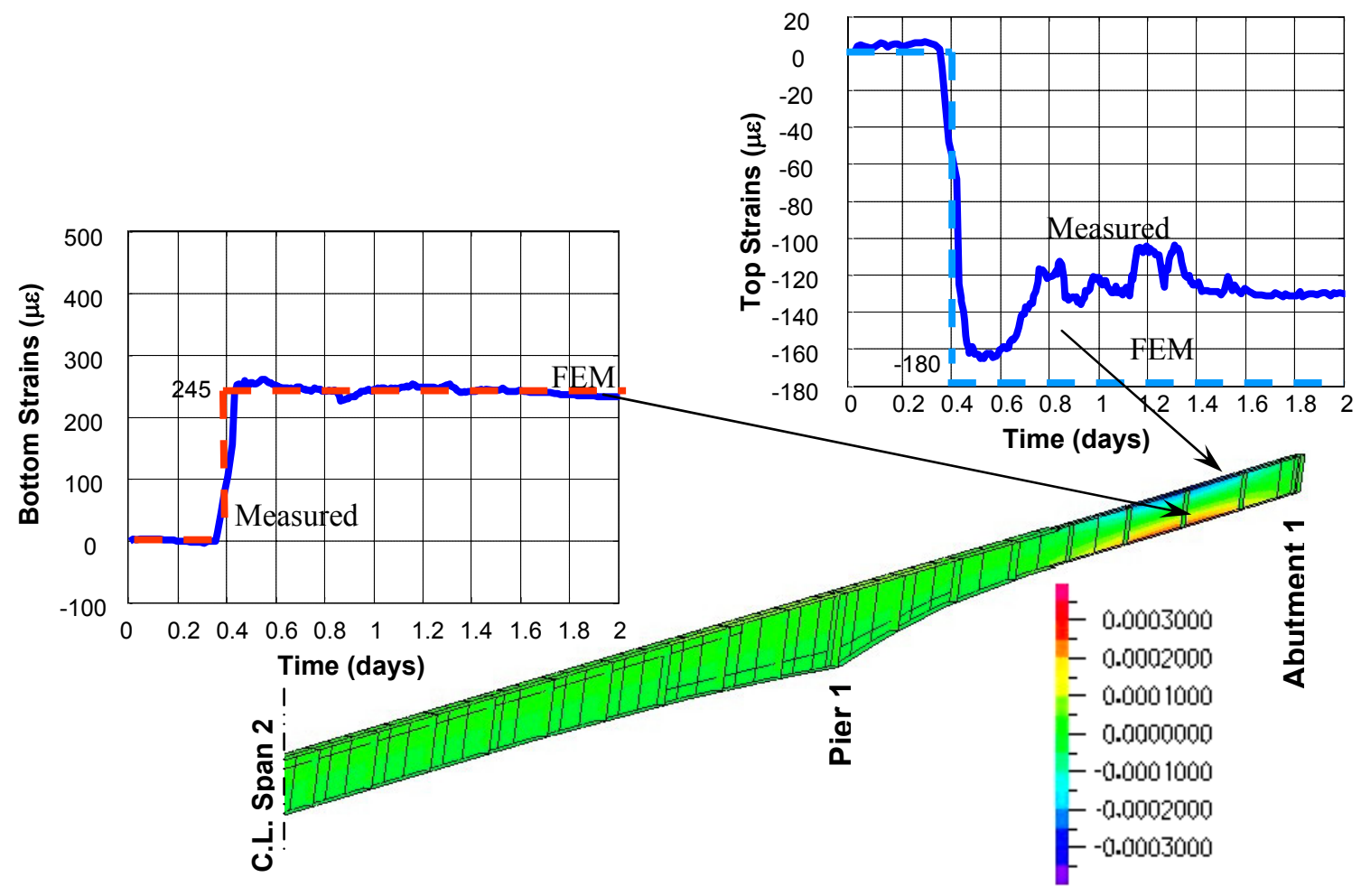

Figure 5.14 Comparison of Strains in Steel girders at Span 1 (Pour No. 1)

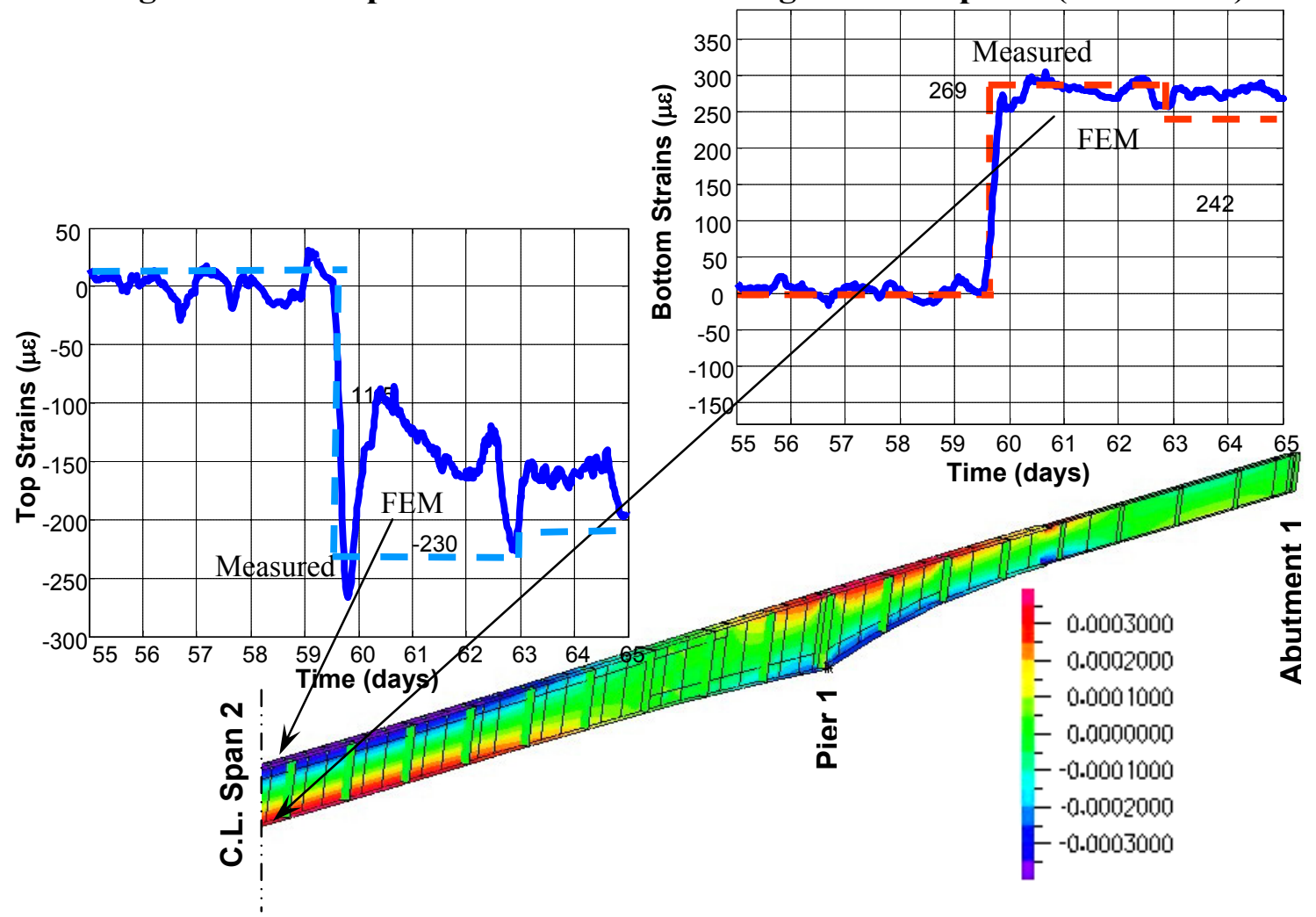

Figure 5.15 Comparison of Strains in Steel Girders at Span 2 (Pour No. 2) 


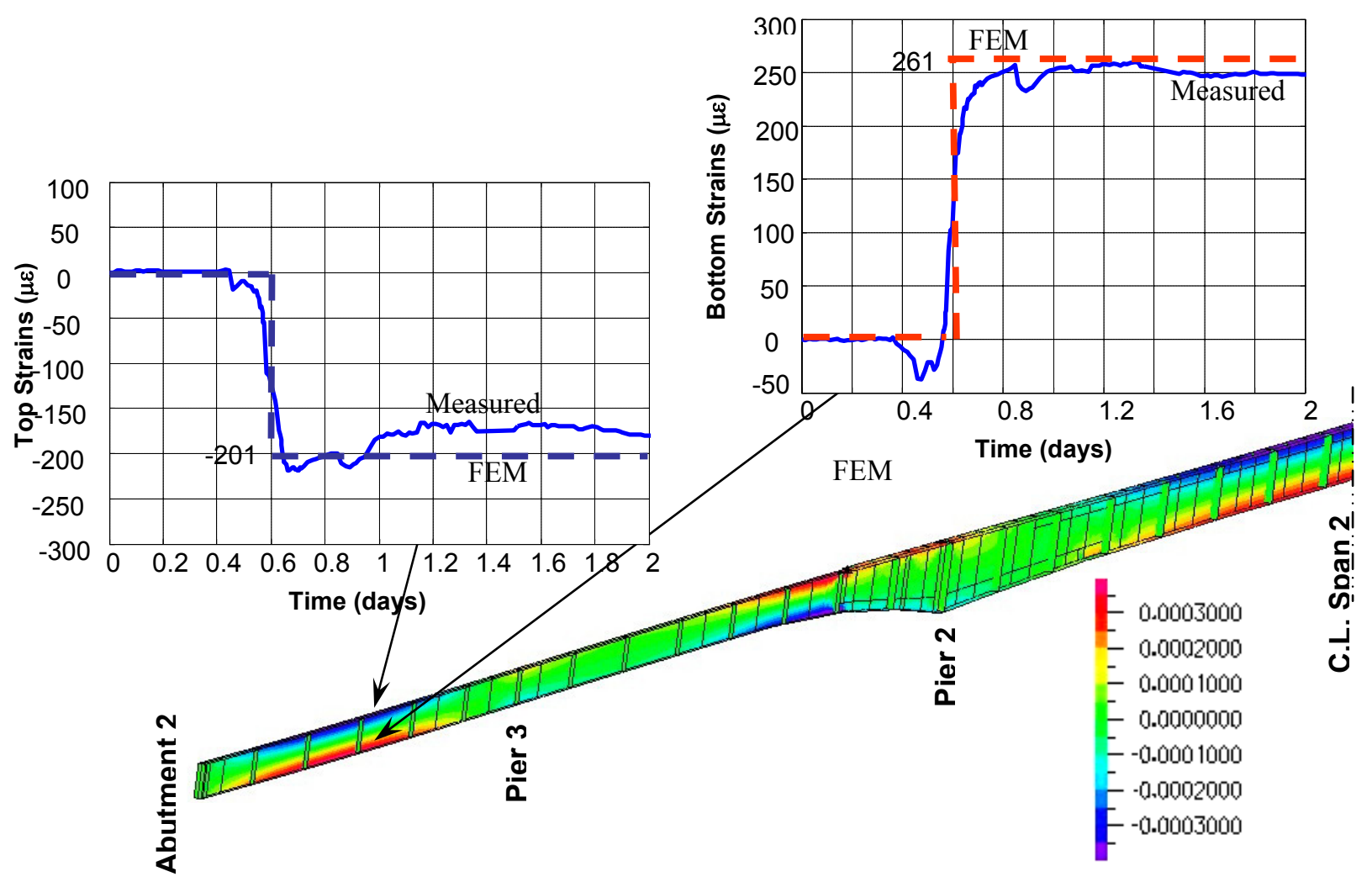

Figure 5.16 Comparison of Strains in Steel Girders at Span 4 (Pour No. 1)

The comparison of strain measurements and those produced by the FE models show a fairly good match. The location of strain measurements along the steel girders were selected for the purpose of comparison in a fashion that would produce maximum values for the respective loading sequence. i.e. strains of Span 1 are compared corresponding to Pour 1, strains of Span 2 are compared corresponding to Pour 2 , ...etc. The variation of strain measurements (that can be noticed from the time history) is related to the response of steel girders to temperature variations along the day. However when comparing the strain values induced due to dead weight application, a very close agreement between those measured and those produced from the FE models can be observed.

\subsection{Evaluation of Mesh Quality}

After the FE mesh is generated and the solution is obtained, it is important to evaluate the mesh size in terms of whether the used one has been fine enough. Two measures can be used to give an indication of the mesh quality. The first can be achieved by plotting bands of quantities that are the derivatives of the primary element variables. As an example, a band plot of pressures or 
effective stresses can be used. Considering that the stresses are continuous in the exact solution, the pressure band will be reasonably continuous if the used mesh is fine enough (Sussman and Bathe, 1986). Breaks in pressure bands indicate severity of the stress discontinuities and implies mesh refinement. This method is more useful when there are limited discontinuities in the geometry and material properties which makes the exact solution continuous. The second measures for mesh evaluation is based on jumps in results between adjacent elements at adjoin nodes. The mesh would be considered coarse if the maximum difference between results across the same node is too large.

Trials of three mesh sizes were attempted in the Star City Bridge model. The Full model was limited by the computational capacity due to the large size of the model, thus shell elements were assigned a maximum size of 30 inches. As stated before, the intent of this model was at this stage is for modal analysis. Phase 2 model was assigned a mesh size of 20 inches and a second mesh was generated to have a maximum size of 10 inches. The results of those two trials were compared to identify the impact of reducing the mesh size on the solution or whether an improvement could be obtained.

The displacements resulting from both models were compared. Maximum and minimum vertical displacement of the first model are 2.735 and -11.42 inches respectively. Those for the second model with finer mesh amounted 2.739 and -11.49 inches respectively. The displacement values indicate that the response of the entire model and displacement magnitudes did not vary by reducing the mesh size.

Analysis of strain differences across the nodes was conducted for both models. The coarser model indicated a difference range of 22 to $90 \mu \varepsilon$, while the refined model indicated a difference range of 25 to $50 \mu \varepsilon$. Larger strain differences were also identified in limited connections on both models. As a conclusion, an improvement in the strain values could be reached by using the results of the refined mesh. 


\section{CHAPTER 6}

\section{MONITORING AND ANALYSIS OF CONCRETE DECK CRACKS}

\subsection{Introduction}

Analysis is conducted on the data records for the purpose of identifying the behavior of critical bridge members and showcasing trends that could explain causes of certain phenomena such as early age cracks in the concrete deck and their effects on the overall bridge structural integrity. Analysis of strain records also aim at comparing measurements of girder strains resulting from placing the concrete deck with those predicted in theoretical numerical methods. This study is also directed towards identifying the effectiveness of design procedures such as thermal stresses in statically indeterminate bridges with complicated geometries. The instrumentation system and collected data is used to identify new crack detection techniques in the concrete deck system. Such techniques are needed for bridge health monitoring purposes especially when stay in place (SIP) forms are used in deck construction and visual inspection can not be carried out without removal of those forms. Strain measurements are also used to establish a fundamental study to place in evidence certain doubtful structural behavior of bridge elements such as steel/concrete composite action in long-term deck performance.

\subsection{Analysis of Steel/Concrete Composite Action}

The composite action between steel and concrete refers to the interaction between those two diverse materials combined in a structural system. The first record of this composite action was sited through publication of test results measuring the strength of filler joist floors (Scott, 1925). This research program was initiated by the structural steel firm of Redpath Brown Company in 1918 aiming at providing data to design filler joist floors. This experimental investigation wasn't completed until 1923 where analysis of the data showed the increased strength that accompanies the composite action. Composite systems 
attract the attention of designers especially in large structures such as bridge decks. The commonly used composite system in bridge decks consists of solid web steel beams supporting a concrete slab. In those systems, the composite action is attempted by means of suitable shear connectors that introduce a bonding mechanism between structural steel members and the concrete slab. This structural configuration follows the early design proposed by (Caughey and Scott, 1929) that was a further development of the previous study by Scott in 1925. In this investigation, the authors introduced the design of a concrete floor resting on the top flange of a steel beam and pointed out the need of a simple mechanical device that would insure the connection between the beam and the slab. Nowadays, the most commonly used shear connector in conventional bridge decks consist of shear studs.

The advantages achieved by establishing a good steel/concrete composite action can be summarized as follows:

- A reduced steel cross section to sustain a particular load.

- Increased section capacity to support an ultimate static load.

- A reduced construction depth that will result in embankment savings and reduction in total project costs.

- A reduction in total weight, resulting in a reduction in supporting elements sections including seats, columns, pedestals, etc.

A large amount of theoretical, experimental and constructional work was carried out on composite sections over the last 5 decades. In real life implementations, the complexity in the analysis comes mainly from the concrete material properties that are time-dependent. For example, the strain developed in a concrete section at any instant is composed of a mixture of elastic and plastic components that are affected not only by the loading configuration, but also by the environmental conditions. In this study, the steel/concrete composite action is addressed in a different method based on analysis of long-term recorded measurements in an operating bridge deck under service. The study aims at showing the soundness of the design principles and drawing attention to certain details considering environmental loading effects. 
In this section, the steel/concrete composite action is analyzed starting from early stages of construction. Time histories of strains recorded in both steel girders and concrete deck are compared to theoretical predictions of strain distributions assuming full composite action behavior. In this case the composite action principle is quantified by a match up between theoretical calculations and field measured variables. Actual concrete and steel material properties that were identified earlier through laboratory testing are applied in theoretical calculations, thus only the factual assumption of the composite action concept is likely to determine the outcome of the comparison. The theoretical calculations follow the elastic analysis of composite sections suggested by (Knowles, 1973) .

Calculations of the concrete area that constitute one of two components of the composite section require identifying the concrete slab effective width $\left(b_{e}\right)$. The effective slab width is dependant on the following factors:

- Beam structural system being continuous or simply supported.

- Loading configuration being distributed or concentrated.

- The ratio of flange thickness to beam depth.

- Ratio of beam length along points of zero moment to distance between beam webs.

For uniformly distributed loads, $2 b_{e}=\frac{L}{8}$ where $\mathrm{L}$ is the distance between points of zero moments along the beam length. In any case, the effective width should not exceed the girders spacing, thus in this case $b_{\mathrm{e}}$ is taken $144 / 2$ in

Figure 6.1 shows the theoretical strain distribution along a full composite section. 


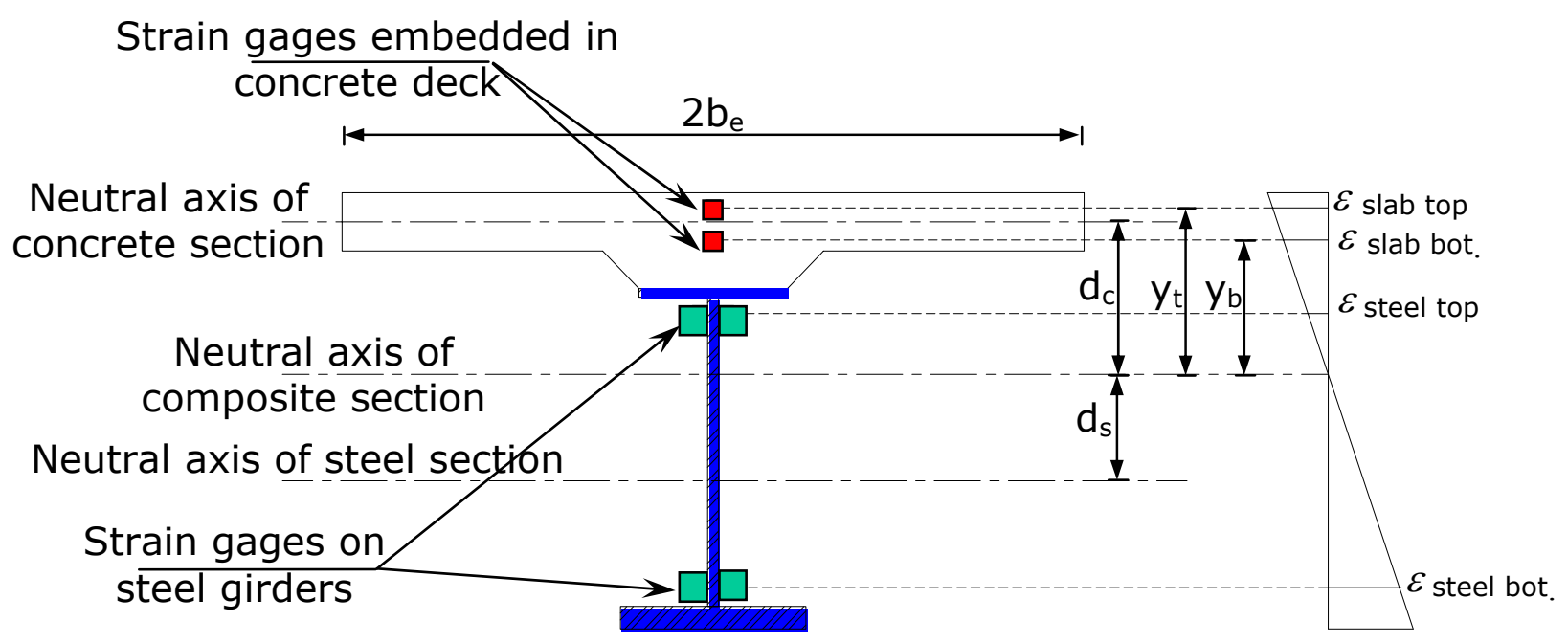

Figure 6.1 Bending Strain Distribution of Full Composite Section

The total composite area is given by:

$$
A_{t}=A_{s}+\frac{A_{c}}{m} \quad \text { Equation 6.1 }
$$

where: $\quad \mathrm{A}_{\mathrm{t}}=$ Total Composite Area

$\mathrm{A}_{\mathrm{s}}=$ Actual area of steel girder

$\mathrm{A}_{\mathrm{c}}=$ Concrete area considering the effective slab width $2 b_{e} \times d$

$\mathrm{m}=\quad$ modular ratio $\left(\frac{E_{s}}{E_{c}}\right)$, Es and Ec are modulus of Elasticity

of steel and concrete respectively.

The distance between the composite neutral axis and the slab neutral axis is given by $\left(\mathrm{d}_{\mathrm{c}}\right)$

$$
d_{c}=d_{t}\left(\frac{A_{s}}{A_{t}}\right) \quad \text { Equation } 6.2
$$

where: $\quad \mathrm{d}_{\mathrm{t}}=\quad$ distance between steel and concrete neutral axes. 
The second moment of area of composite section (It) is calculated by:

$$
I_{t}=I_{s}+\frac{I_{c}}{m}+\frac{A_{c} d_{c}^{2}}{m}+A_{s} d_{s}^{2} \quad \text { Equation 6.3 }
$$

where: $\quad \mathrm{d}_{\mathrm{s}}=$ distance between composite and steel neutral axes.

$\mathrm{I}_{\mathrm{s}} \quad=\quad$ moment of Inertia of steel section

$\mathrm{I}_{\mathrm{c}} \quad=\quad$ moment of Inertia of concrete section

Considering that the concrete slab sectional bending moment is relatively small and could be neglected (Knowles, $1973 \mathrm{sec}$. 2.6.2), the bending moment (M) acting on the section is back-calculated from the strains recorded on the steel girders from:

$$
M=\frac{\varepsilon \times I_{t} \times E_{s}}{y} \quad \text { Equation 6.4 }
$$

where: $\quad \mathrm{y}=$ distance bet. composite neutral axis and bottom strain gage

$\varepsilon=$ bending component of strains at bottom strain gage

The strains in the concrete section at the locations of the top and bottom embedment strain gages are calculated from:

$$
\begin{array}{ll}
\varepsilon_{\text {top }}=\frac{M}{E_{c} m I_{t}} \times y_{t} & \text { Equation 6.5 } \\
\varepsilon_{b o t}=\frac{M}{E_{c} m I_{t}} \times y_{b} & \text { Equation 6.6 }
\end{array}
$$

where; $\quad \mathrm{y}_{\mathrm{t}}, \mathrm{y}_{\mathrm{b}}=\quad$ distance between composite neutral axis and locations of top and bottom concrete embedment strain gages.

Analysis of concrete/steel composite action is performed since pouring the concrete deck, therefore no life load is acting on the bridge. However, ambient temperature variation during the day exerts substantial amount of loading on the superstructure that is enough to produce noticeable bending and strain magnitudes. 
Figure 6.2 and Figure 6.3 illustrate a comparison of theoretically calculated strains and their corresponding measured ones along girder No. 6 and No. 7 at early stages of concrete pouring in Span No. 4. Strain data are compared in arrays of 24 hour periods in order to capture maximum temperature variations throughout the day. The strain magnitudes are normalized at the start of each array in order to minimize the effects of other variables that provide long term strain components such as curing shrinkage, initial setting strains, variation in moisture content, creep, etc... Comparing the theoretical and measured strain time histories indicate that a large discrepancy occurs at early ages. The results tend to get a better match after a period of 10 to 11 days from concrete pouring as illustrated in Figure 6.3. This conclusion is supported by the fact that concrete material will take a time period of about 7 days to gain initial strength. Thus, with normal curing procedures, the time duration to achieve composite action will be 10 days in this particular bridge section.

This analysis highlights the importance of the timing factor in phased concreting. As concrete slabs and bridge decks are commonly placed in bays rather than in a single large pours, phased pouring can be used to achieve composite action in critical location by carefully choosing the sequence of pouring. This strategy will only be effective in the condition of taking the time factor into consideration. In order to further illustrate this remark, the ratio between measured strains and theoretical predictions were calculated and plotted in a time history format as illustrated in Figure 6.4. 


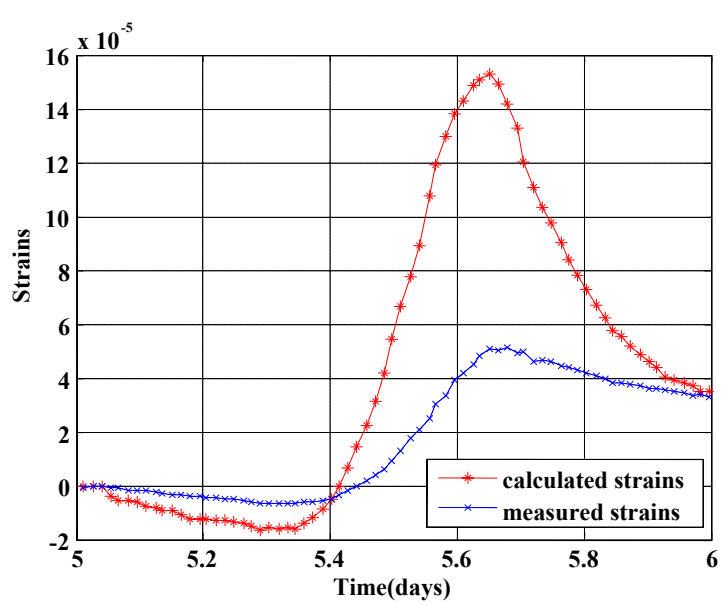

Top strains Girder 6

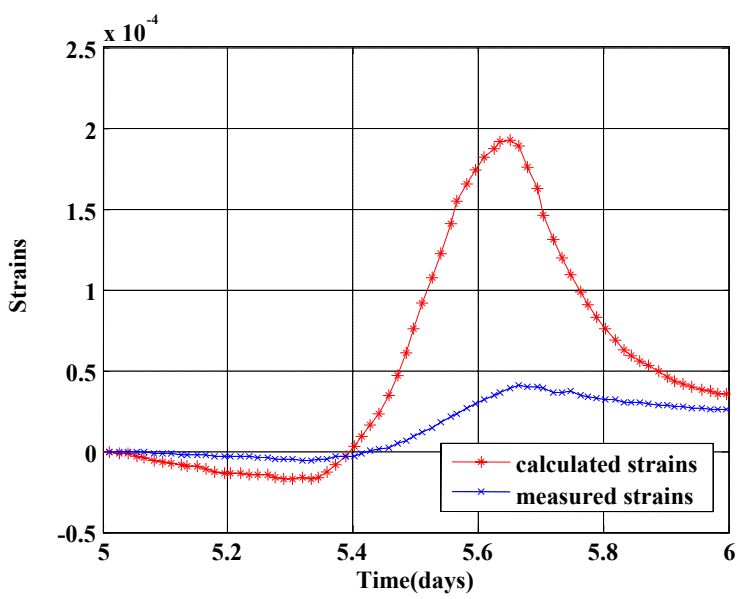

Top strains Girder 7

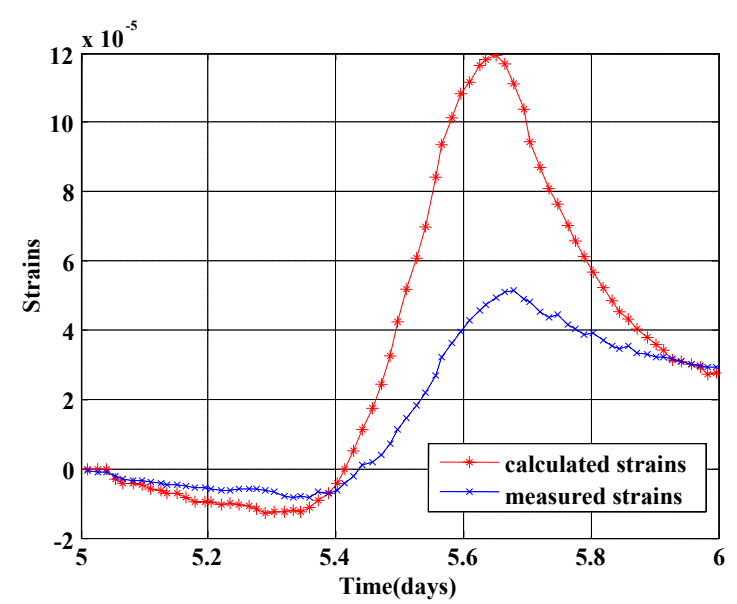

Bottom strains Girder 6

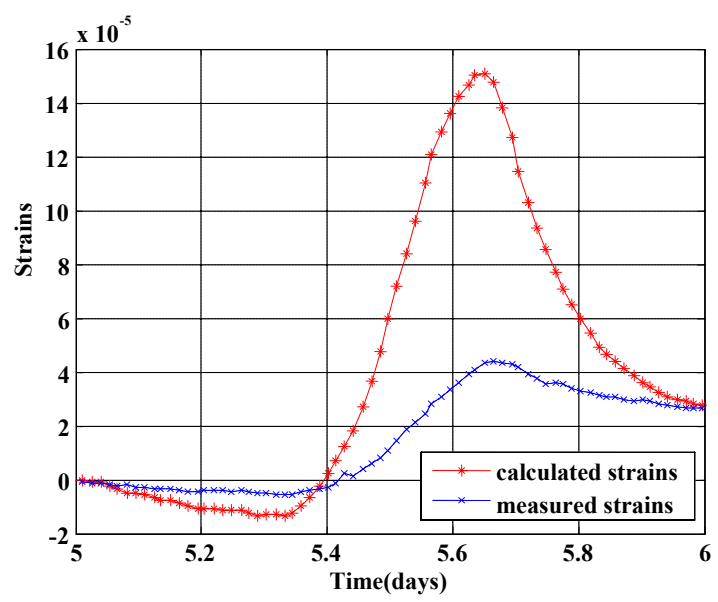

Bottom strains Girder 7

Figure 6.2 Comparison of Concrete Strain Magnitudes at Day 5

This time history shows that a ratio of one between theoretical calculations of concrete strains and those measured are obtained after day 10 and remain within this range till 90 days after placing concrete. The Steel/concrete composite action is evaluated from this comparison to an average of $85 \%$ during the period between 10 days and 90 days after pouring. 


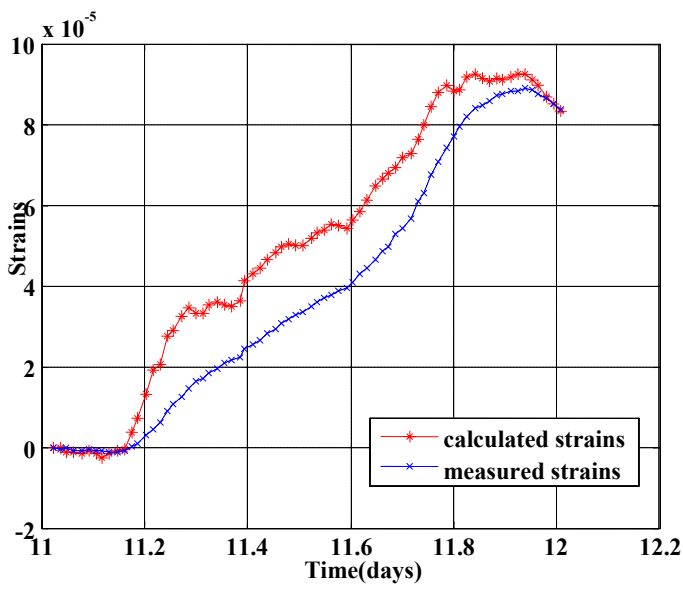

Top strains Girder 6

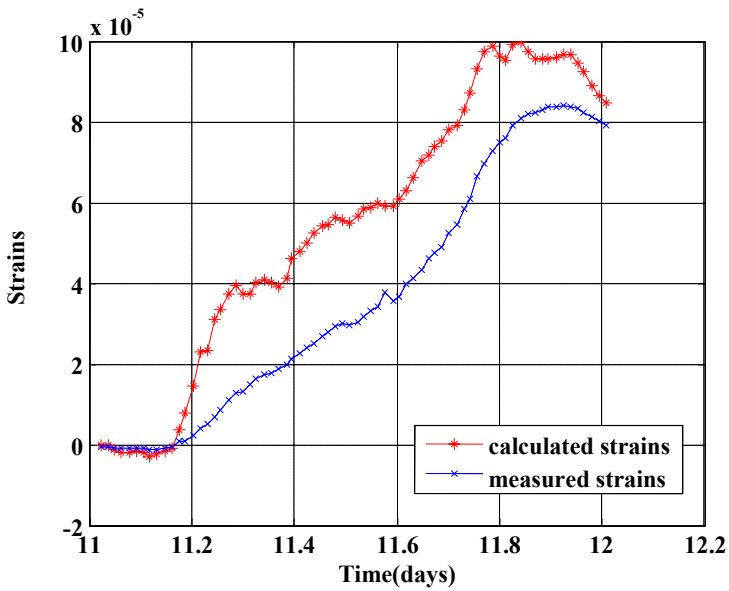

Top strains Girder 7

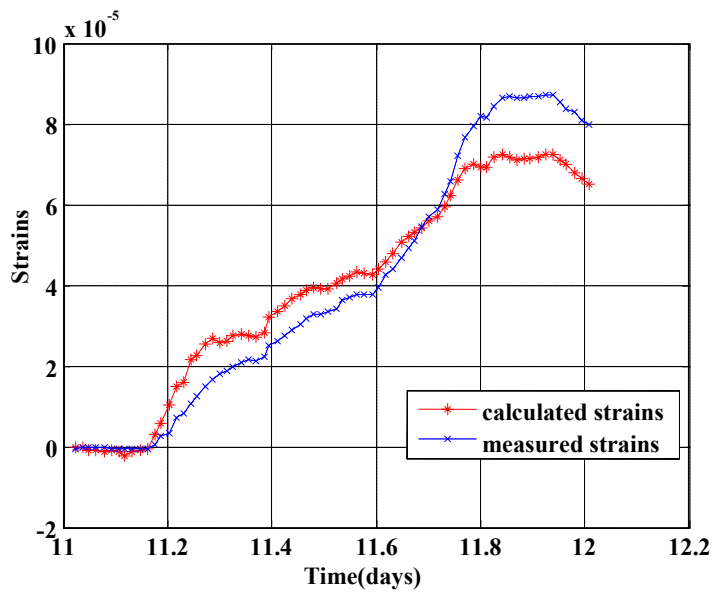

Bottom strains Girder 6

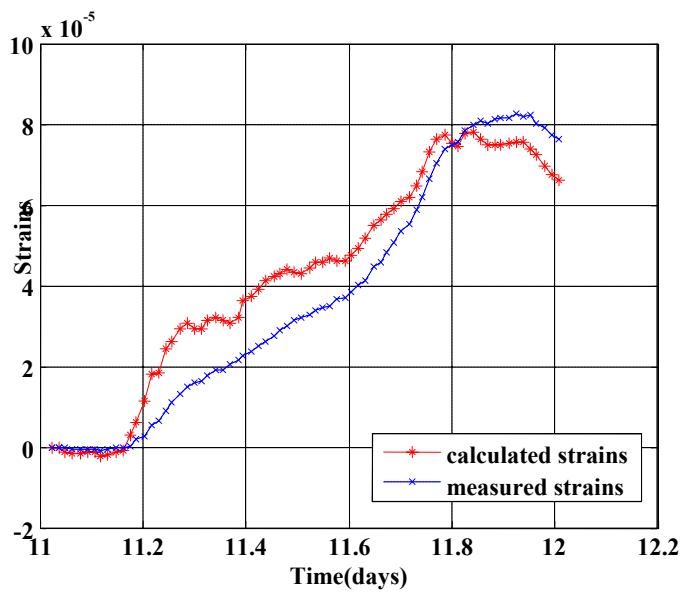

Bottom strains Girder 7

Figure 6.3 Comparison of Concrete Strain Magnitudes at Day 11 


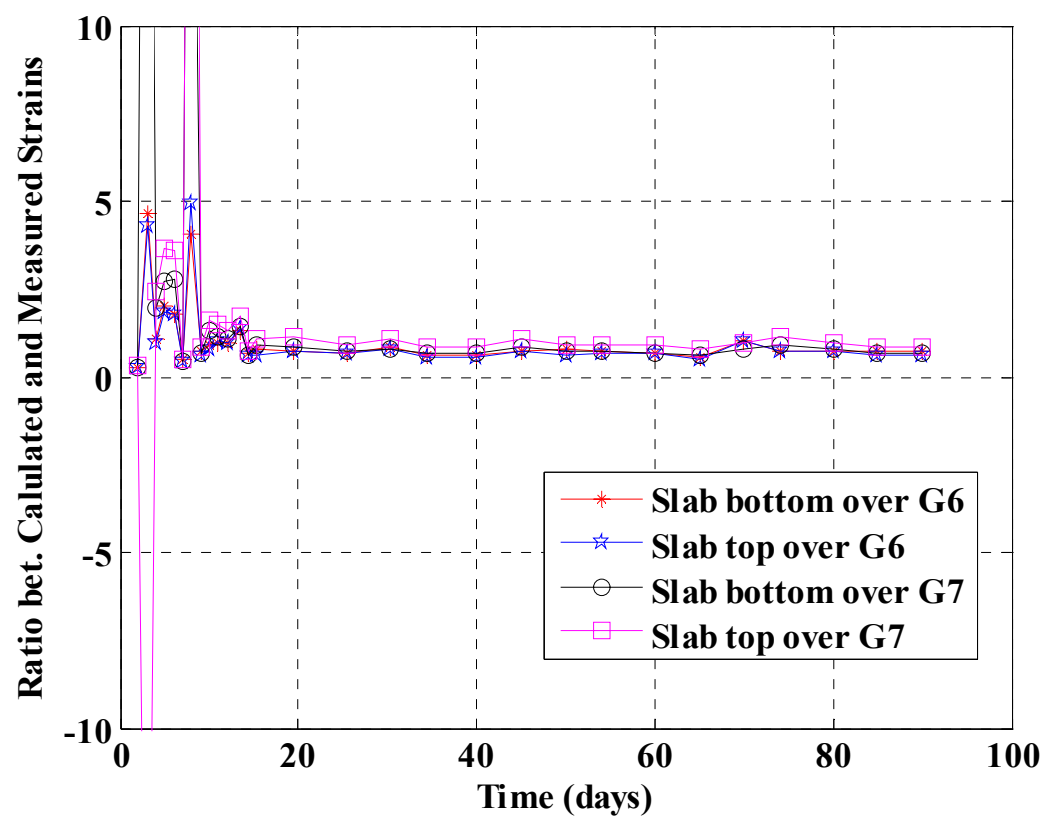

Figure 6.4 Ratio of Theoretical Concrete Strains to Measured Data

\subsection{Instrumentation Based Crack Detection and Monitoring Techniques}

The literature indicates that numerous reinforced concrete bridge decks develop early age transverse cracks, even before they are subjected to any traffic loads (French et al., 1999, Cusson and Repette, 2000) . Field investigations indicate that delamination and cracking of the latex modified concrete (LMC) mix and microsilica concrete (MSC) mix overlays have been observed nationwide. Field inspections cited that the LMC and MSC mixes currently used for overlays have a potential to develop $100 \%$ surface cracking (Babaei and Hawkins, 1990). In an attempt to reduce the formation of such cracks, a number of states increased deck thicknesses, specified a minimum cover of 2.5-inches above the top mat reinforcement, and used high performance concrete mixes that produced higher strength. Such solutions did not reduce the intensity of the problem. The exact causes of early age cracking of reinforced concrete bridge decks are still not fully understood, however previous investigations debated that the occurrence of such cracks and delaminations where due to plastic shrinkage and driven from the response to temperature 
and moisture changes. Others argued that cracks were a result of construction conditions or quality, type and frequency of traffic. Although the reasons for cracking could be subject to debate, their detrimental effects are well known. Cracks ease the ingress of moisture, oxygen and chloride ions into the depth of reinforcing steel, which in turn increases the corrosion rate and causes a reduction in service life.

Current WVDOH design practice for reinforced concrete bridge decks in new construction is to use the AASHTO LRFD empirical deck design where a $61 / 2$ inch deck with a 2 inch LMC overlay system consist the deck slab. The LMC layer in this case is expected to contribute to the structural capacity of the deck slab, therefore its composite integration with the deck system is crucial. This integration of the substrate reinforced concrete layer and the overlay will only be adequate if cracks in the concrete deck are eliminated. The first step towards understanding the cracking phenomenon of bridge decks is to identify useful techniques for monitoring the initiation and development of such cracks. Once achieved, it will be possible to analyze the factors that contribute to the cracking problem.

An instrumentation based method for monitoring the initiation and growth of cracks in concrete bridge decks has been developed and was successfully deployed to identify and monitor early age cracks in Star City Bridge. The approach is based on monitoring histories of strains in both steel reinforcement and the surrounding concrete at one particular location. As this section is subjected to diurnal environmental changes, the concrete and steel components would exhibit changes in strain values accordingly as shown in Figure 6.5. If the section under investigation is intact, both steel reinforcements and the surrounding concrete medium would show the same strain changes as illustrated in Figure 6.6. Comparison of strain responses in concrete and rebars would indicate the formation of cracks and monitoring this relation can indicate crack growth. Figure 6.7 shows application of this technique to identify crack formation is Span 1 where cracks initiated after approximately 125 days from concrete placement. The effectiveness of such a technique for crack detection is realized especially that removal of stay in place forms (if used) is not required. 

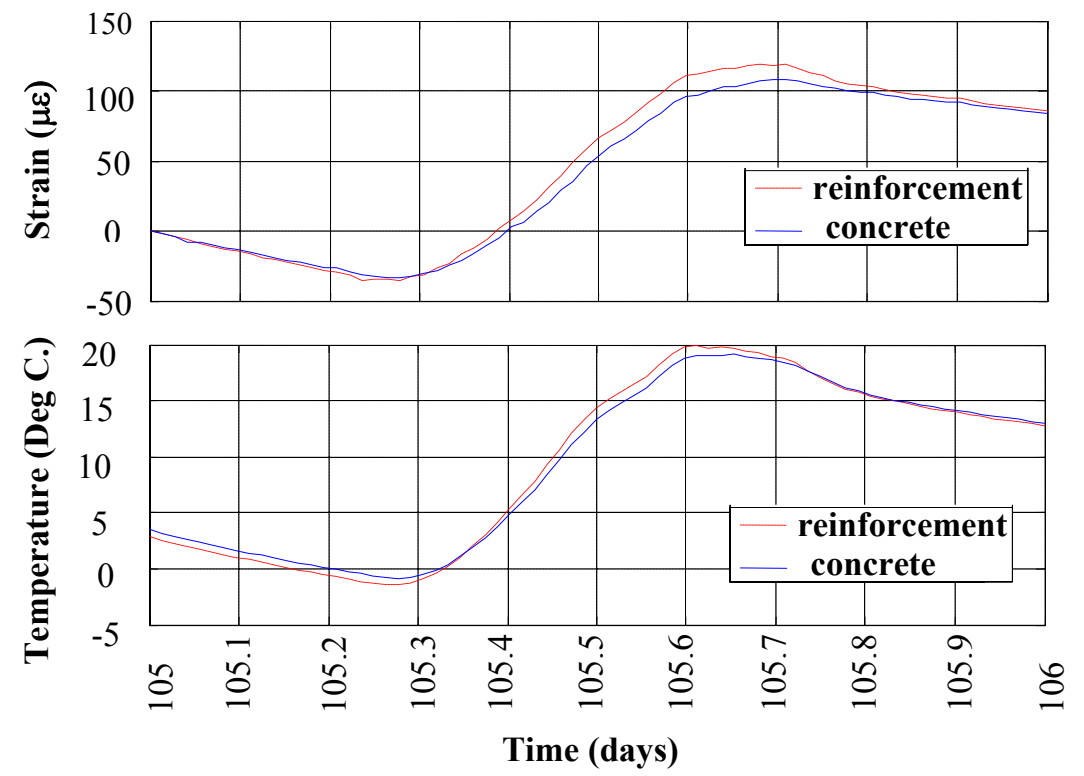

Figure 6.5 Strain Variations in rebar and concrete in Span 2 over Girder 6 Strain gages embedded in

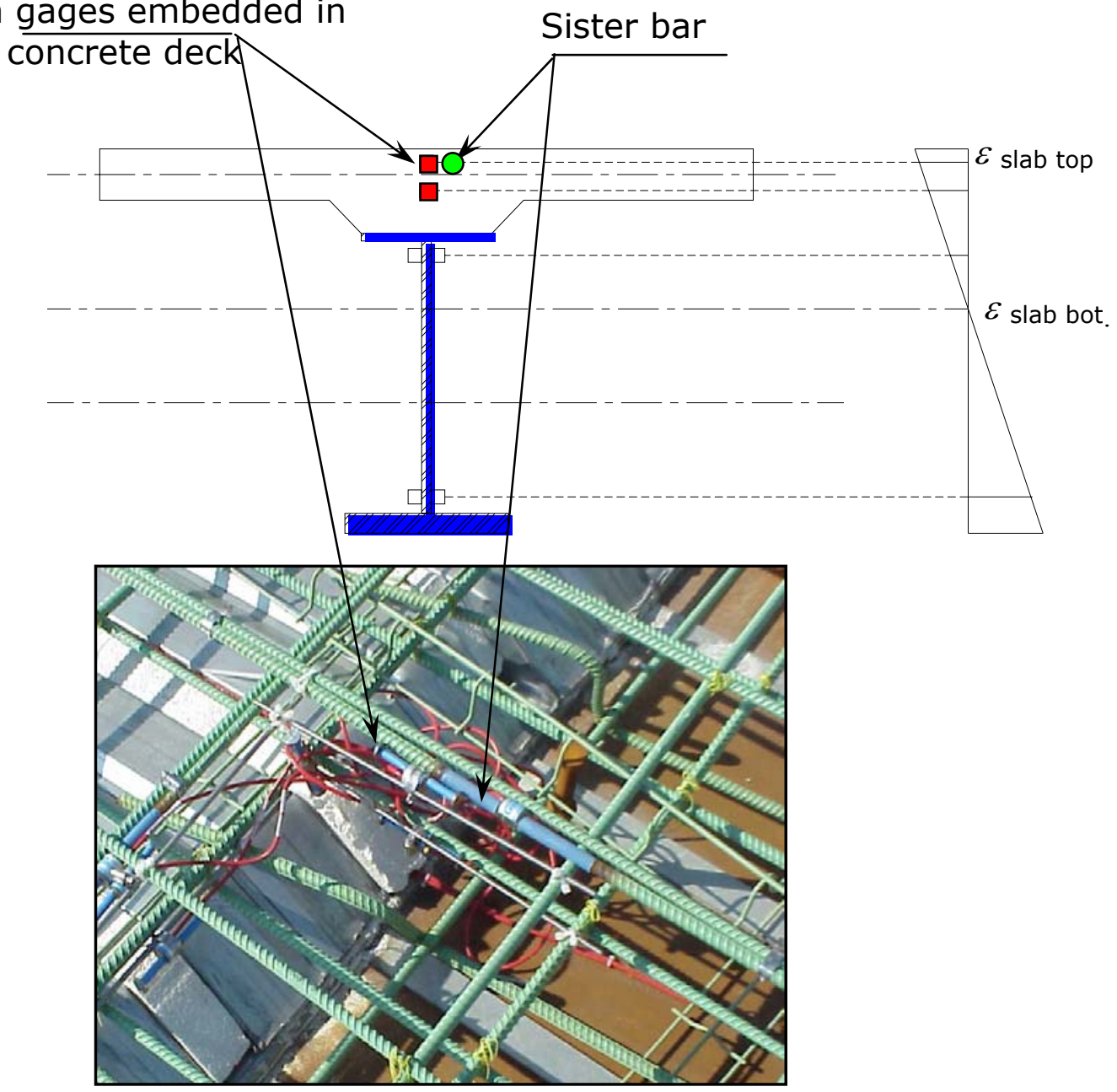

Figure 6.6 Instrumentation used for Crack Detection in Concrete Deck 
Since the response to temperature variation is our focus, data were reduced in a detailed process in order to isolate the effect of long term variables that add strain components in the concrete material such as shrinkage and creep. Strain profile histories collected from the embedment strain gages and sister bars (cumulative total strains) are reduced to segments of 24 hours in span where a full cycle of daily temperature variation occurs. Each segment has a reference datum that corresponds to the strain values at the start of the segment. The effect of shrinkage, creep and differential moisture content through the slab thickness opposed to their effect on steel rebars are minimal compared to the effect of temperature variation in small time intervals such as 24 hours and can be neglected in the analysis. Reduction of data into segments also offers a good solution to overcome the uncertainty in total strain values that could be a result of inevitable disturbance of the sensors while placing concrete. The output of this procedure is a normalized strain time history that as a result of a change in deck temperature, from which maximum strain values in concrete and steel rebars can be extracted and compared as illustrated in Figure 6.7. A zero difference in maximum strain magnitudes indicates an intact reinforced concrete section, while a deviation in this trend will indicate initiation of cracks.

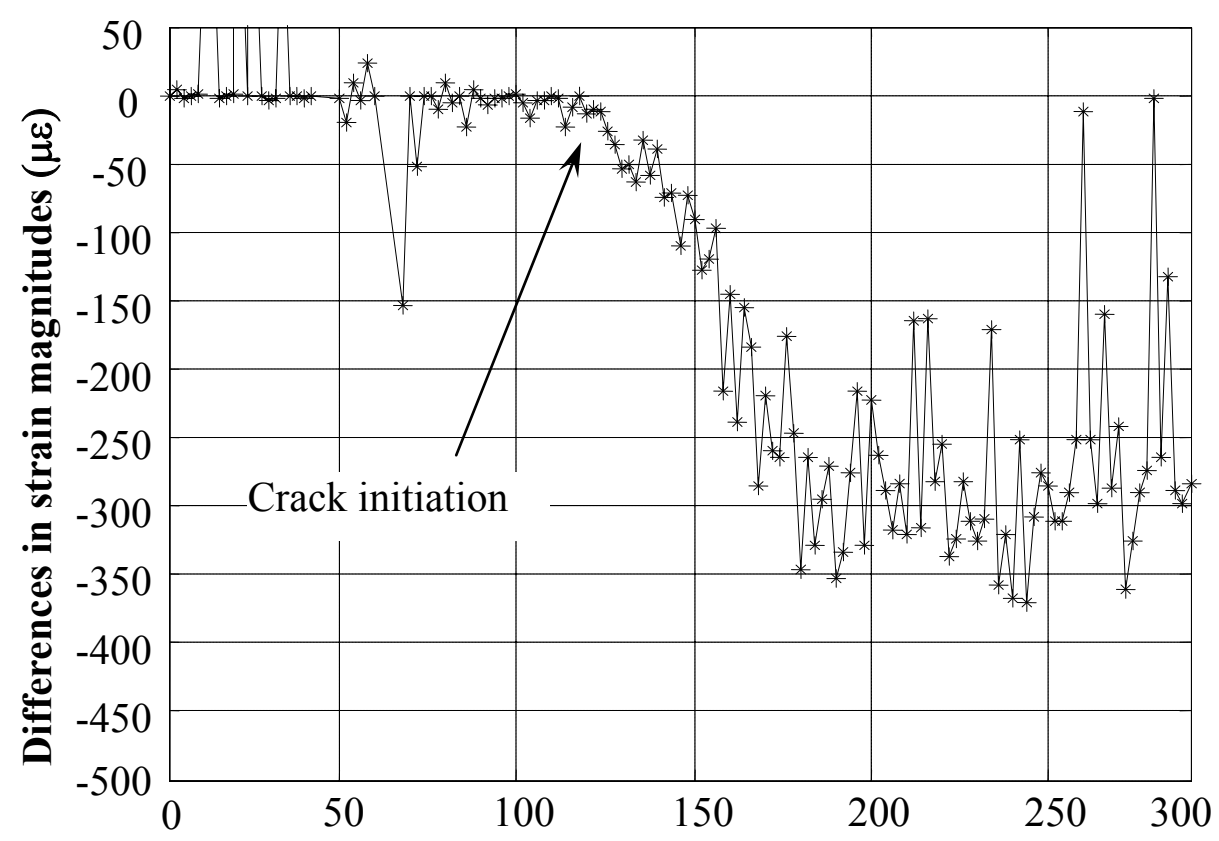

Figure 6.7 Crack Initiation and Growth on Span No. 1 over Girder 6 
Another technique for crack detection is established based on calculating the correlation coefficient between the concrete and reinforcing steel strain time histories. This technique is used to compute a quantitative value that indicates how good the two strain histories match. Assuming that strains in concrete and rebars are independent random variables $\mathrm{X}$ and Y respectively, their correlation coefficient is defined by:

$$
\rho_{X, Y}=\frac{\operatorname{COV}(X, Y)}{\sigma_{X} \sigma_{Y}} \quad \text { Equation 6.7 }
$$

Where: $\quad \rho_{\mathrm{X}, \mathrm{Y}} \quad=\quad$ Correlation Coefficient

$$
\operatorname{COV}(\mathrm{X}, \mathrm{Y})=\text { Covariance of } \mathrm{X} \text { and } \mathrm{Y}
$$$$
\sigma_{\mathrm{X}} \quad=\quad \text { Standard deviation of } \mathrm{X}
$$$$
\sigma_{\mathrm{Y}} \quad=\quad \text { Standard deviation of } \mathrm{Y}
$$

$$
\operatorname{COV}(X, Y)=E\left[\left(X-\mu_{X}\right)\left(Y-\mu_{Y}\right)\right] \quad \text { Equation } 6.8
$$

$\begin{array}{lll}\mathrm{E} & = & \text { mathematical expectation } \\ \mu_{\mathrm{X}} & = & \mathrm{E}_{\mathrm{X}} \\ \mu_{\mathrm{Y}} & = & \mathrm{E}_{\mathrm{Y}}\end{array}$

The correlation coefficient is a number with outmost values of 1 on the positive sign or -1 on the negative sign.

$$
-1 \leq \rho_{X, Y} \leq 1 \quad \text { Equation } 6.9
$$

The extreme values of $\rho_{\mathrm{X}, \mathrm{Y}}$ are achieved when $\mathrm{X}$ and $\mathrm{Y}$ are linearly related (Leon-Garcia, 1994) . The two strain values are said to be uncorrelated if $\rho_{\mathrm{X}, \mathrm{Y}}=0$. This would indicated existence of a crack in this particular section. If $\rho_{\mathrm{X}, \mathrm{Y}}=1$, the two strain signals are related linearly and the concrete section is intact. 
The correlation coefficient is calculated for segments of strain time histories in concrete and steel rebars in 24 hours periods (72 discrete values for each segment). Each segment is normalized in order to minimize long term induced effects in concrete material such as shrinkage and creep. For each segment a correlation coefficient is calculated and analyzed versus time. Figure 6.8 illustrates an example of applying this technique at the location of Pier No. 2.

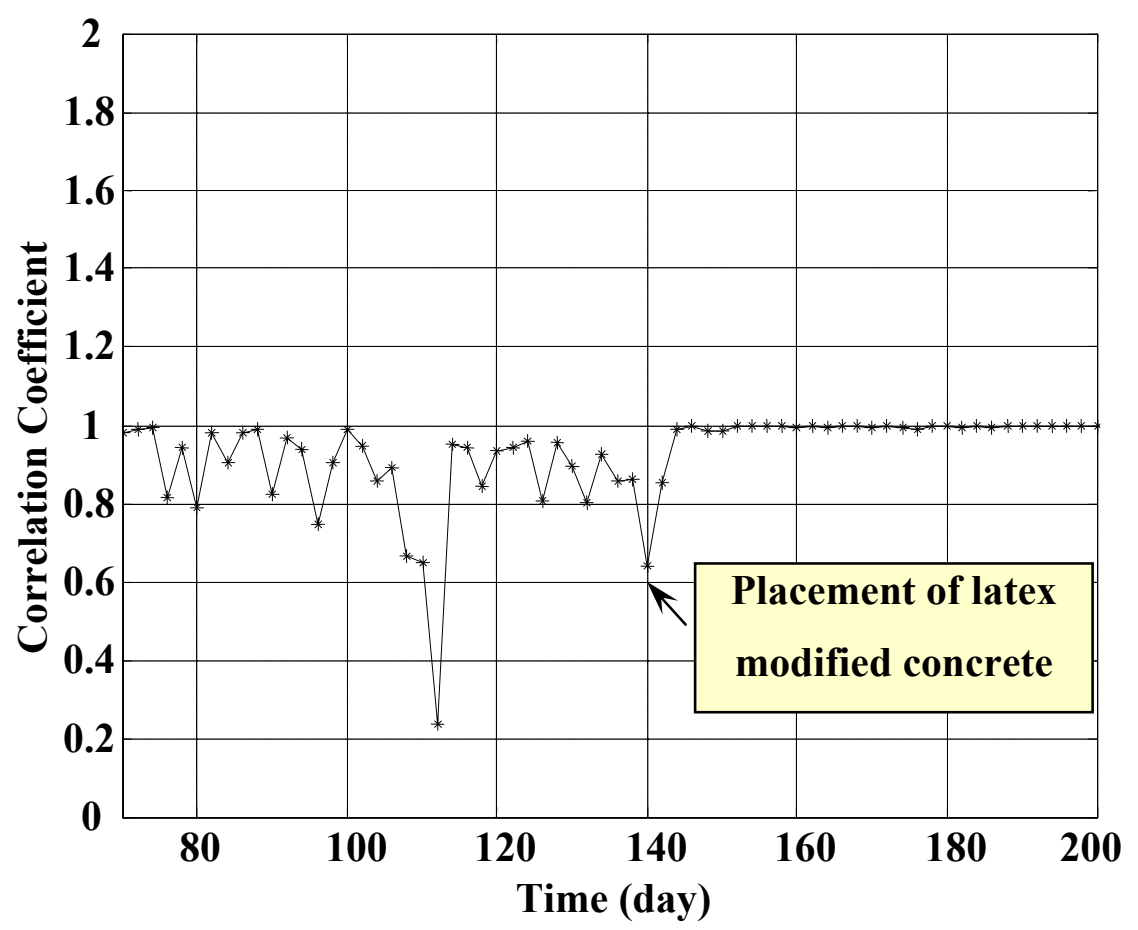

Figure 6.8 Correlation Coefficient bet. Concrete and Rebar Strains at Pier 2

The time history indicates fluctuation of the Correlation coefficient below the value of one, showing existence of a concrete crack. Once the latex modified concrete layer is placed on the deck the crack is sealed, showing a sustained value of one thereafter. This technique is further validated by plotting the difference in strain magnitude of concrete and reinforcing bars at the same location as shown in Figure 6.9. The time history shows a very small difference in those strain magnitudes after 140 days as expected from analyzing Figure 6.8. The location of the crack at Pier 2 is also justifiable since values of maximum bending negative moments are found at the top fibers of concrete deck at this location. 


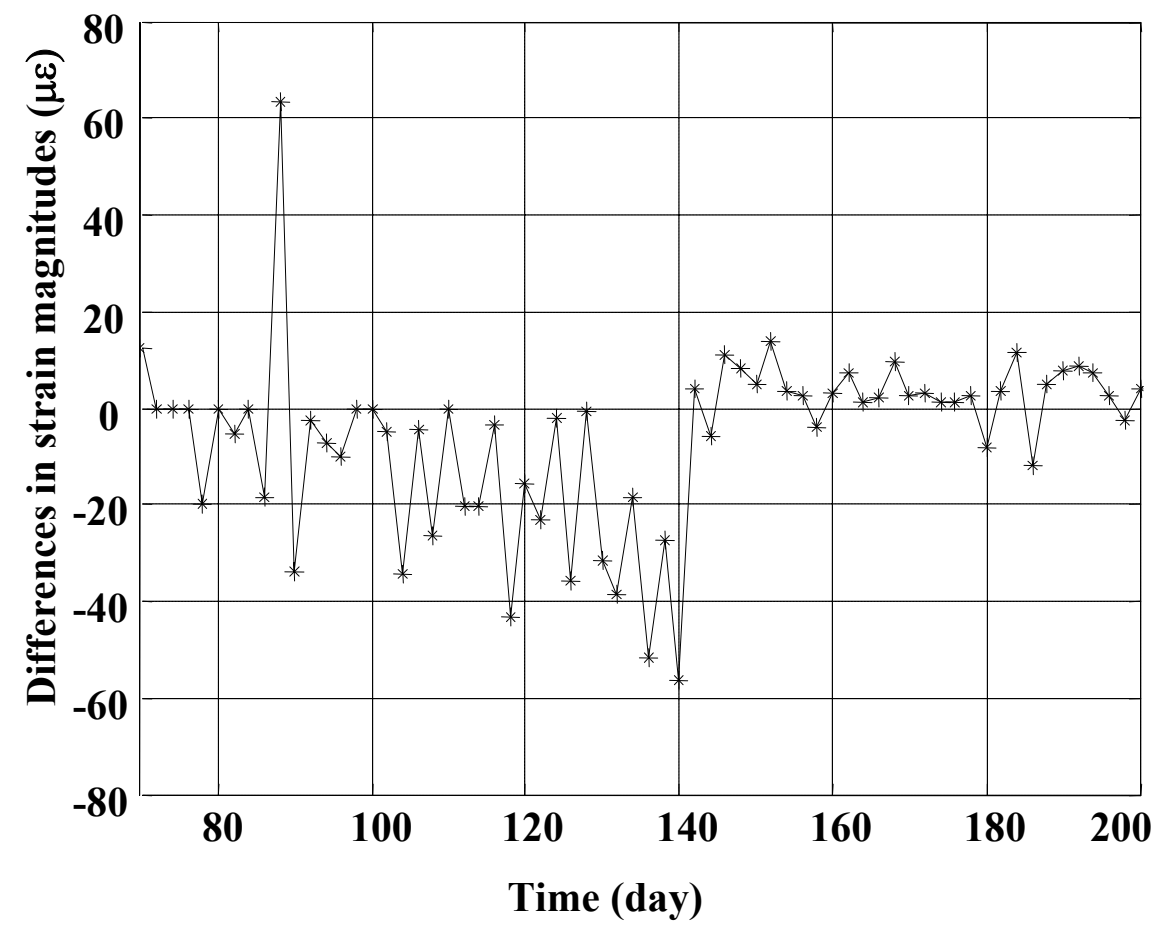

Figure 6.9 Difference in Concrete and Rebar Strain values at Top of Pier 2

\subsection{Theoretical evaluation of slip strains}

One question might be asked regarding the concept of comparing strain values in concrete and steel reinforcement to detect cracks. Why is this difference not indicating a slip strain in the deck system? There are two main sources of slips between steel and concrete. The first component is slip between the steel reinforcement and surrounding concrete, once stresses at a particular section are high. The second component is a slip strain between the concrete deck and the steel girders. In order to maintain equilibrium in the analysis of a composite section, the two slip components have to be accounted for.

Evaluation of slip strain between steel and concrete is conducted based on theoretical analysis by (Nie et al., 2004). In their study, the authors derived a close form solution to evaluate shear slip strain between steel and concrete for a simply supported beam subjected to a concentrated load at the mid-span. The same solution is adopted in this 
study and modified to suit a general case where a continuous beam with variable inertia is subjected to thermal loads. The analysis for this case is based on treating continuous beams as segments of simply supported beams tied at the location of zero strains.

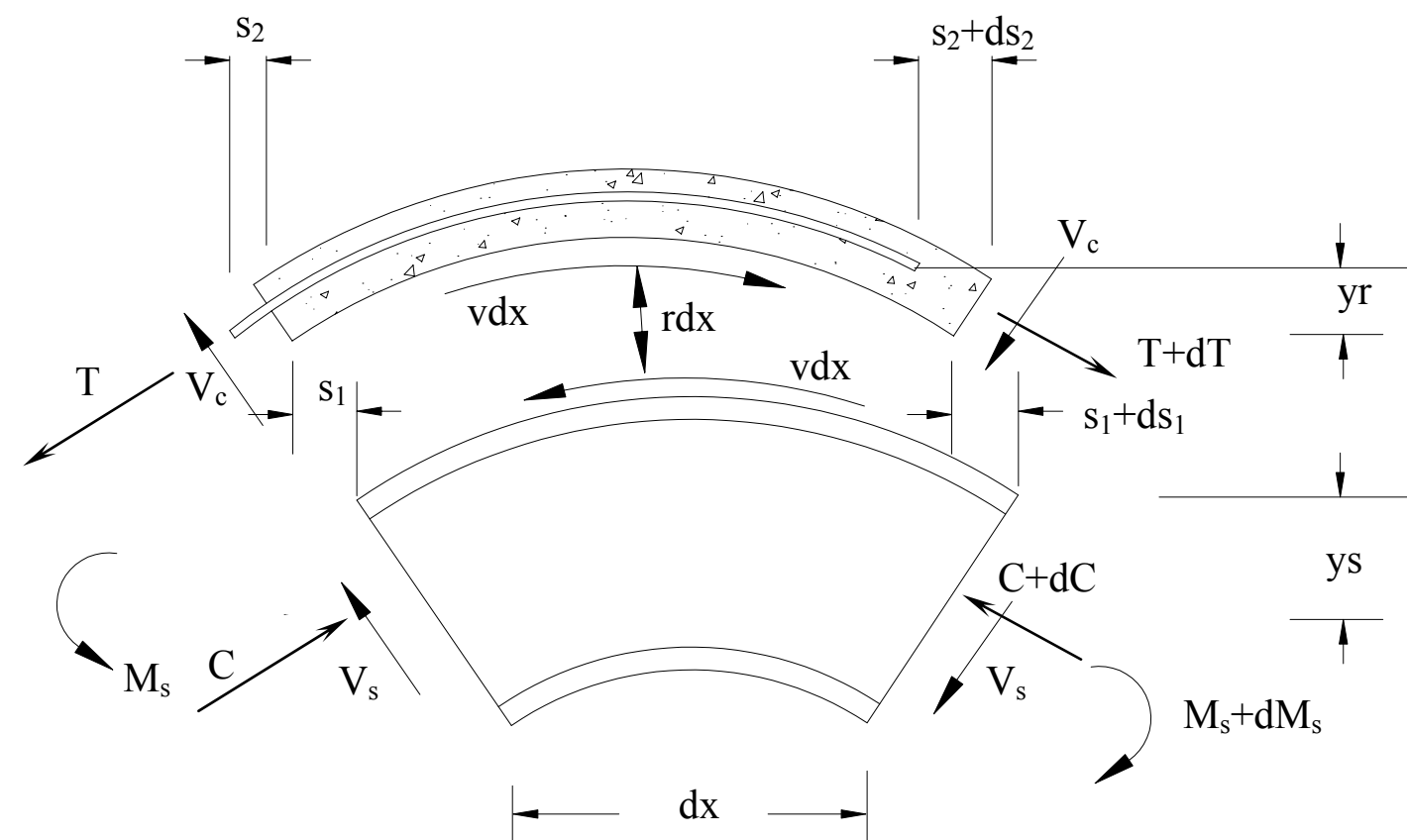

Figure 6.10 Free Body Force Diagram of a Deck Segment (Nie et al., 2004).

The shear-slip stiffness of stud connectors $\left(\mathrm{k}_{1}\right)$ is evaluated by (Nie and Cai, 2003):

$$
k_{1}=0.66 N_{s} P_{\max } \quad \text { Equation 6.10 }
$$

where $\quad \mathrm{N}_{\mathrm{s}}=$ number of shear studs per row,

$$
\mathrm{P}_{\max }=\text { design shear resistance of studs }
$$

The (Eurocode 4. 1994) gives the shear resistance of studs as:

$$
P_{\max }=k_{t} 0.8 f_{u}\left(\pi d_{s}^{2} / 4\right) \leq k_{t} 0.29 d_{s}^{2} \sqrt{f_{c k} E_{c m}} \quad \text { Equation 6.11 }
$$

where $\quad \mathrm{f}_{\mathrm{u}}=\quad$ ultimate tensile strength of stud

$\mathrm{d}_{\mathrm{s}}=$ diameter of stud 


$$
\begin{array}{ll}
\mathrm{f}_{\mathrm{ck}}= & \text { characteristic compressive strength of concrete cylinder } \\
\mathrm{E}_{\mathrm{cm}}= & \text { Modulus of Elasticity of concrete material } \\
\mathrm{k}_{\mathrm{t}}= & \text { stud reduction factor affected by profile sheeting }
\end{array}
$$

$$
k_{t}=\frac{0.7}{\sqrt{N_{s}}} \frac{b_{o}}{h_{p}}\left(\frac{h_{d}}{h_{p}}-1\right) \leq 1.0 \quad \text { Equation 6.12 }
$$

where $\quad b_{0}=$ width of deck rib

$\mathrm{h}_{\mathrm{p}}=$ height of deck rib

$\mathrm{h}_{\mathrm{d}} \quad=\quad$ shear stud height after welding.

The bond-slip stiffness $\left(\mathrm{k}_{2}\right)$ of dented reinforcement in the slab is given by (Nie et al., 2004) to be:

$$
k_{2}=5.2 p d_{r} N_{r} \sqrt{f_{c}}
$$

\section{Equation 6.13}

Where $\quad \mathrm{d}_{\mathrm{r}}=$ diameter of reinforcement bar $(\mathrm{mm})$

$\mathrm{N}_{\mathrm{r}}=$ number of reinforcement

$\mathrm{p}=$ distance between studs

The total horizontal shear slip between steel and concrete can be written as:

$$
p v=K s
$$

\section{Equation 6.14}

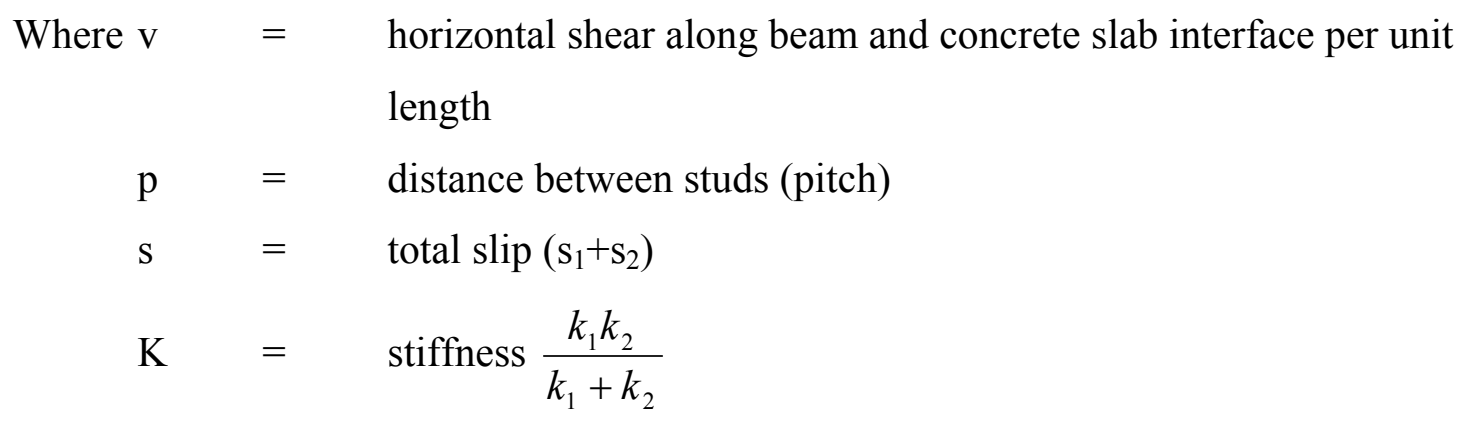


Figure (6.10) shows a deformed segment in the bridge deck of infinitesimal length $\mathrm{dx}$ where:

$$
\begin{array}{lll}
\mathrm{V}_{\mathrm{c}} & = & \text { vertical shear in concrete } \\
\mathrm{Vs} & = & \text { vertical shear in steel section } \\
\mathrm{C} & = & \text { compression force applied on steel section } \\
\mathrm{T} & = & \text { tensile force applied on steel reinforcement } \\
\mathrm{dMs} & = & \text { moment increment of steel section } \\
\mathrm{r} & = & \text { vertical force per unit length at concrete/steel interface } \\
\mathrm{ds}_{1} & = & \text { incremental slip at slab/girder interface } \\
\mathrm{ds}_{2}= & \text { incremental slip at reinforcement/concrete interface }
\end{array}
$$

The longitudinal equilibrium of the reinforcement in the segment shown in Figure (6.10) gives:

$$
\frac{d T}{d x}=-v
$$

Moment equilibrium of the segment considering concrete section and steel girder respectively gives:

$$
\begin{aligned}
& V_{c} d x+\frac{1}{2} r d x^{2}=v y_{r} d x \\
& d M_{s}+V_{s} d x=v y_{s} d x+\frac{1}{2} r d x^{2}
\end{aligned}
$$

Substituting with the value of $v=\frac{K s}{p}$,

$$
d K s=\frac{K s}{p} y_{s} \times d x+\frac{1}{2} r d x^{2}-V_{s} d x
$$

Substituting with the value of $\frac{1}{2} r d x^{2}=\frac{K s}{p} y_{r} d x-V_{c} d x$ 


$$
\therefore d M_{s}=\frac{K s}{p} y_{s} d x+\frac{K s}{p} y_{r} d x-V_{c} d x-V_{s} d x
$$

Equation 6.19

This equation can be reduced as:

$$
\begin{aligned}
& d M_{s}=K s \frac{d x}{p}\left(y_{s}+y_{r}\right)-d x\left(V_{c}+V_{s}\right) \\
& \frac{d M_{s}}{d x}=\frac{K s}{p}\left(y_{s}+y_{r}\right)-\left(V_{c}+V_{s}\right)
\end{aligned}
$$

Equation 6.21

Since curvature of the composite section $(\varphi)$ is expressed as:

$$
\begin{aligned}
& \varphi=\frac{M_{s}}{E I_{s}} \\
& \therefore \frac{d \varphi}{d x}=\frac{d M_{s}}{d x E I_{s}}=\frac{\left[\frac{K s\left(y_{s}+y_{r}\right)}{p}-\left(V_{c}+V_{s}\right)\right]}{E I_{s}}
\end{aligned}
$$

Equation 6.23

The longitudinal strain at the concrete/steel girder interface is expressed as:

$$
\varepsilon_{c b}=\frac{C}{E A_{r}}-\varphi y_{r}+\varepsilon_{s 2} \text { Equation 6.24, and } \varepsilon_{s t}=\varphi y_{s}-\frac{T}{E A_{s}} \text { Equation 6.25 }
$$

where $\varepsilon_{\mathrm{cb}}$ and $\varepsilon_{\mathrm{st}}$ are strains at the concrete and steel interfaces respectively.

The relative total slip strain between steel reinforcement and steel girder $\left(\varepsilon_{\mathrm{s}}\right)$ is evaluated as:

$$
\varepsilon_{s}=\varepsilon_{s t}-\varepsilon_{c b}+\varepsilon_{s 2}
$$

\section{Equation 6.26}

by substitution: $\varepsilon_{s}=\varphi y_{s}-\frac{T}{E A_{s}}-\frac{C}{E A_{r}}+\varphi y_{r}$, considering equilibrium, $\mathrm{T}=\mathrm{C}$ 


$$
\therefore \varepsilon_{s}=\varphi y_{s}-\frac{T}{E A_{s}}-\frac{T}{E A_{r}}+\varphi y_{r}
$$

differentiating with respect to $\mathrm{x}, \frac{d \varepsilon_{s}}{d x}=\frac{d_{s}^{2}}{d x^{2}}$

$$
\frac{d \varepsilon_{s}}{d x}=\frac{d \varphi}{d x} y_{s}-\frac{d T}{d x} \times \frac{1}{E A_{s}}-\frac{d T}{d x} \times \frac{1}{E A_{r}}+\frac{d \varphi}{d x} y_{r}
$$

Equation 6.28

substituting with value of $\frac{d \varphi}{d x}$ :

$\frac{d \varepsilon_{s}}{d x}=\frac{\left[\frac{K s}{p}\left(y_{s}+y_{r}\right)-\left(V_{c}+V_{s}\right)\right]}{E I_{s}}\left(y_{s}+y_{r}\right)+\frac{K s}{p E}\left[\frac{1}{A_{s}}+\frac{1}{A_{r}}\right]$

Equation 6.29

for simplicity, assume: $\quad y_{o}=y_{s}+y_{r}$

$$
\frac{1}{A_{o}}=\frac{1}{A_{r}}+\frac{1}{A_{s}}
$$

Equation 30

Equation 6.31

By substitution:

$$
\frac{d^{2} s}{d x^{2}}=\frac{K}{p E}\left[\frac{y_{o}^{2}}{I_{s}}+\frac{1}{A_{o}}\right] s-\left[\frac{y_{o}}{E I_{s}}\right]\left(V_{c}+V_{s}\right)
$$

Equation 6.32

Placing the variables as: $\quad P=\left(V_{c}+V_{s}\right)$

Equation 6.33

$$
\begin{aligned}
& \alpha^{2}=\frac{K}{p E}\left[\frac{y_{o}^{2}}{I_{s}}+\frac{1}{A_{o}}\right] \\
& \beta=\frac{y_{o}}{E I_{s}}
\end{aligned}
$$

$$
\therefore \frac{d^{2} s}{d x^{2}}=\alpha^{2} s-\beta P
$$


This is a non-homogeneous second order linear differential equation, which can be solved using the root method as follows:

The complete solution is: $s(x)=s_{h}(x)+s_{p}(x)$, where $\mathrm{s}_{\mathrm{h}}(\mathrm{x})$ and $\mathrm{s}_{\mathrm{p}}(\mathrm{x})$ are the complimentary and the particular solutions respectively.

\section{The complimentary solution:}

The characteristic equation is: $\quad r^{2}+2 a r+b=0$

Where

$$
\begin{aligned}
& 2 \mathrm{a}=0 \\
& \mathrm{~b}=-\alpha^{2}
\end{aligned}
$$

The roots of the characteristic equation are:

$$
r_{1,2}=-a \pm \sqrt{a^{2}-b}
$$

By substitution, $\quad r_{1,2}= \pm \sqrt{\alpha^{2}}= \pm \alpha$

Since $\alpha^{2}>$ b, the two roots are real and different, and the complimentary solution takes the form:

$$
\begin{aligned}
s & =C_{1} e^{r 1 x}+C_{2} e^{r 2 x} \\
\therefore s_{h} & =C_{1} e^{\alpha x}+C_{2} e^{-\alpha x}
\end{aligned}
$$

Where $\mathrm{C}_{1}$ and $\mathrm{C}_{2}$ are constants, to be determined from the boundary conditions.

\section{The particular solution:}

Since the forcing function is a constant $(\beta \mathrm{P})$, then the particular solution takes the form:

$$
\begin{gathered}
s_{p}=B(\text { constant }) \\
\therefore s_{p}^{\prime}=0 \\
s_{p}^{\prime \prime}=0
\end{gathered}
$$

By substitution in the original differential equation: 


$$
\begin{gathered}
0-\alpha^{2} B=-\beta P \\
\therefore B=\frac{\beta P}{\alpha^{2}}
\end{gathered}
$$

The solution of the differential equation becomes:

$$
s=C_{1} e^{\alpha x}+C_{2} e^{-\alpha x}+\frac{\beta P}{\alpha^{2}}
$$

$\mathrm{C} 1$ and $\mathrm{C} 2$ are determined by applying boundary conditions:

$$
\begin{array}{lll}
\mathrm{s}=0 & \text { when } & \mathrm{x}=0, \text { since moment at location of hinge (support) }=0 \\
\mathrm{~s}^{\prime}=0 & \text { when } & \mathrm{x}=\mathrm{L}, \text { where } \mathrm{L} \text { is location of maximum strains (zero slope) }
\end{array}
$$

By substitution,

$$
\begin{gathered}
0=C_{1}+C_{2}+\frac{\beta P}{\alpha^{2}} \\
s^{\prime}=C_{1} \alpha e^{\alpha x}-C_{2} \alpha e^{-\alpha x} \\
0=C_{1} \alpha e^{\alpha L}-C_{2} \alpha e^{-\alpha L} \\
\therefore C_{1}=C_{2} e^{-2 \alpha L}
\end{gathered}
$$

Solving for $\mathrm{C}_{2}$ :

$$
\begin{gathered}
C_{2} e^{-2 \alpha L}+C_{2}=-\frac{\beta P}{\alpha^{2}} \\
C_{2}=-\frac{\beta P}{\alpha^{2}\left(1+e^{-2 \alpha L}\right)}
\end{gathered}
$$

Solving for $\mathrm{C}_{1}$ : $\quad C_{1}=-\frac{\beta P}{\alpha^{2}}+\frac{\beta P}{\alpha^{2}\left(1+e^{-2 \alpha L}\right)}$

Substituting with values of $\mathrm{C} 1$ and $\mathrm{C} 2$ in the relation of total slip:

$$
s=\left[-\frac{\beta P}{\alpha^{2}}+\frac{\beta P}{\alpha^{2}\left(1+e^{-2 \alpha L}\right)}\right] e^{\alpha x}-\frac{\beta P}{\alpha^{2}\left(1+e^{-2 \alpha L}\right)} e^{-\alpha x}+\frac{\beta P}{\alpha^{2}}
$$


Taking common factors:

$$
\begin{gathered}
s=\frac{\beta P}{\alpha^{2}\left(1+e^{-2 \alpha L}\right)}\left[-e^{\alpha x}\left(1+e^{-2 \alpha L}\right)+e^{\alpha x}-e^{-\alpha x}+\left(1+e^{-2 \alpha L}\right)\right] \\
s=\frac{\beta P}{\alpha^{2}\left(1+e^{-2 \alpha L}\right)}\left[\left(1+e^{-2 \alpha L}\right)\left(-e^{\alpha x}+1\right)+e^{\alpha x}-e^{-\alpha x}\right]
\end{gathered}
$$

Multiplying both the nominator and denominator by $e^{2 \alpha L}$ :

$$
\begin{aligned}
& s=\frac{\beta P}{\alpha^{2}\left(e^{2 \alpha L}+1\right)}\left[\left(e^{2 \alpha L}+1\right)\left(1-e^{\alpha x}\right)+e^{\alpha x+2 \alpha L}-e^{-\alpha x+2 \alpha L}\right] \\
& s=\frac{\beta P}{\alpha^{2}\left(e^{2 \alpha L}+1\right)}\left[\left(e^{2 \alpha L}+1\right) e^{-\alpha x}\left(e^{\alpha x}-e^{2 \alpha x}\right)+e^{2 \alpha L}\left(e^{\alpha x}-e^{-\alpha x}\right)\right] \\
& s=\frac{\beta P}{\alpha^{2}\left(e^{2 \alpha L}+1\right)}\left[\left(e^{2 \alpha L}+1\right) e^{-\alpha x}\left(e^{\alpha x}-e^{2 \alpha x}\right)+e^{2 \alpha L} e^{-\alpha x}\left(e^{2 \alpha x}-1\right)\right] \\
& s=\frac{\beta P}{\alpha^{2}\left(e^{2 \alpha L}+1\right)} e^{-\alpha x}\left[\left(e^{2 \alpha L}+1\right)\left(e^{\alpha x}-e^{2 \alpha x}\right)+e^{2 \alpha L}\left(e^{2 \alpha x}-1\right)\right] \\
& s=\frac{\beta P}{\alpha^{2}\left(e^{2 \alpha L}+1\right)} e^{-\alpha \alpha}\left[e^{2 \alpha L} e^{\alpha x}-e^{2 \alpha L} e^{2 \alpha x}+e^{\alpha x}-e^{2 \alpha x}+e^{2 \alpha L} e^{2 \alpha x}-e^{2 \alpha L}\right] \\
& s=\frac{\beta P}{\alpha^{2}\left(e^{2 \alpha L}+1\right)} e^{-\alpha \alpha}\left[e^{2 \alpha L} e^{\alpha x}+e^{\alpha x}-e^{2 \alpha x}-e^{2 \alpha L}\right] \\
& \therefore s=\frac{\beta P}{\alpha^{2}\left(e^{2 \alpha L}+1\right)}\left[e^{2 \alpha L}+1-e^{\alpha x}-e^{2 \alpha L} e^{-\alpha x}\right]
\end{aligned}
$$

In order to obtain the slip strain, take derivative of the slip relation with respect to $\mathrm{x}$ :

$$
\begin{gathered}
\varepsilon_{s}=\frac{d s}{d x} \\
\therefore \varepsilon_{s}=\frac{\beta P}{\alpha^{2}\left(e^{2 \alpha L}+1\right)}\left[-\alpha e^{\alpha x}+\alpha e^{2 \alpha L} e^{-\alpha x}\right] \\
\therefore \varepsilon_{s}=\frac{\beta P}{\alpha\left(e^{2 \alpha L}+1\right)} e^{-\alpha x}\left[e^{2 \alpha L}-e^{2 \alpha x}\right]
\end{gathered}
$$

Equation 6.39

Equation 6.39 evaluates the total slip strain in a composite section at any location along the bridge length. For a particular bridge deck, the variables that need to be quantified to 
solve the equation are the length (L) which refers to the location of maximum strain values along the bridge, and the shear stresses $(\mathrm{P})$ at the location of the composite section under investigation. In our case, the response of the deck is evaluated according to the long-term slow response, thus the loading configuration is mainly related to temperature variations. The theoretical derivation shows that the slip strain depends on the amount of flexure the section is subjected to. Due to the arrangement of degrees of freedom in the bridge seats, it is clear that uniform temperature change will subject the bridge to expansion and contraction, while temperature gradient would provide curling and bending stresses.

Quantifying (L) and (P) for the Star City Bridge is a tedious task if attempted using traditional theoretical calculation due to complexity of the three dimensional degrees of freedom, beams with variable inertia, and the case of loading which consists of temperature induced stresses. Therefore, the finite element model described in Chapter 5 is used to collect quantitative values of $(\mathrm{L})$ and $(\mathrm{P})$. In order to calculate the maximum slip strain, a thorough analysis of temperature loading on bridge decks was conducted as indicated in the following section.

\subsubsection{Identification of Thermal Loading Configurations on WV Bridge decks}

Bridges are structures that are exposed to the atmosphere, thus subjected to an exchange of heat energy between their surfaces and the surrounding environment. Because of the massive nature of bridges, stresses due to thermal actions (which occur in restrained structural elements) directly impact their design procedures. Seasonal and diurnal variations in the mean bridge temperature will result in the expansion or contraction of an unrestrained bridge superstructure. In an attempt to permit unrestricted movement of the bridge, directional guides are laid out in the superstructure bearings. However, the actual thermal action experienced in bridges is far from being uniform. The climatic conditions including shade air temperature, solar radiation, and wind velocity cause a non-linear temperature profile within the structural elements. 
When designing for potential thermal effects, detailed thermal loading information is required especially in nations with climatic diversities such as in the United States. Moreover, bridge designers have to take into consideration extreme thermal loading conditions that are likely to occur within the service life of the structure that may span over 50 years in most cases. In order to verify the effect of thermal loading on West Virginia bridge decks, thermal loading schemes representative of typical WV climate shall be needed. AASHTO Standard Specifications for Highway Bridges provides only general information about temperature range for Moderate and Cold Climate conditions (AASHTO 2002):

Table 6.1 Temperature Ranges for Bridge Design According to AASHTO

$\begin{array}{lll} & \underline{\text { Rise }} & \underline{\text { Fall }} \\ \text { Moderate Climate } & 30^{\circ} \mathrm{F} & 40^{\circ} \mathrm{F} \\ \text { Cold Climate } & 35^{\circ} \mathrm{F} & 45^{\circ} \mathrm{F}\end{array}$

No definitions are provided, and no references for differential temperatures or deck gradients are indicated. Therefore temperature measurements from the instrumentation system placed in the bridge superstructure along with data from the weather station are used to identify the range of temperature variations and provide an array of temperature profiles to be used in design of bridge superstructures. This analysis includes temperature records for a period of two years. Table 6.2 summarizes the maximum positive temperature gradient identified from the temperature records along the bridge superstructure. The positive gradient indicates that the top fibers of the concrete deck measure warmer temperatures relative to the bottom fibers in the steel girders. In contrast, Table 6.3 summarizes the maximum negative temperature gradient in the bridge superstructure. Negative gradients indicate warmer temperature in the bottom fibers of the steel girders than top fibers of the concrete deck. The dates where maximum positive and negative gradients are identified are 538 days and 364 days after placing the first concrete pour respectively. The maximum average temperature gradient is calculated from table 6.2 to be $12.03 \mathrm{deg}$. $\mathrm{C}$, while the maximum average negative gradient is calculated from table 6.3 to be $-10.65 \mathrm{deg}$. C. 
Table 6.2 Maximum Positive Temperature Gradient in Bridge Superstructure

\begin{tabular}{cccc}
\hline Location & Top Temp. (deg. C) & Bottom Temp. (deg. C) & Gradient \\
\hline \hline mid-span 4 & 38.55 & 27.77 & 10.78 \\
pier 3 & 38.39 & 27.51 & 10.88 \\
mid-span 3 & 39.83 & 26.61 & 13.22 \\
pier 2 & 34.75 & 23.56 & 11.19 \\
mid-span 2 & 36.47 & 22.96 & 13.51 \\
pier 1 & 35.64 & 23.5 & 12.14 \\
mid-span 1 & 38.55 & 26.02 & 12.53 \\
\hline
\end{tabular}

Table 6.3 Maximum Negative Temperature Gradient in Bridge Superstructure

\begin{tabular}{cccc}
\hline Location & Top Temp. $($ deg. $C)$ & Bottom Temp. (deg. $C)$ & Gradient \\
\hline \hline mid-span 4 & -8.28 & 2.89 & -11.16 \\
pier 3 & -7.8 & 3.57 & -11.38 \\
mid-span 3 & -7.86 & 2.71 & -10.58 \\
pier 2 & -7.43 & 2.46 & -9.88 \\
mid-span 2 & -7.07 & 3.33 & -10.41 \\
pier 1 & -7.34 & 3.44 & -10.78 \\
mid-span 1 & -8.22 & 2.15 & -10.37 \\
\hline
\end{tabular}

\subsubsection{Calculations of Maximum Slip Strains is Concrete Bridge Deck}

The values of maximum positive and negative temperature gradients identified from monitoring the Star City Bridge data records for 2 years were used to apply temperature loading on the FEM presented within Chapter 5. Corresponding ambient temperature for each case was extracted from data records of the weather station and input into the program. Figure 6.11 and Figure 6.12 illustrate the superstructure deformation and corresponding temperature gradients for each case. 


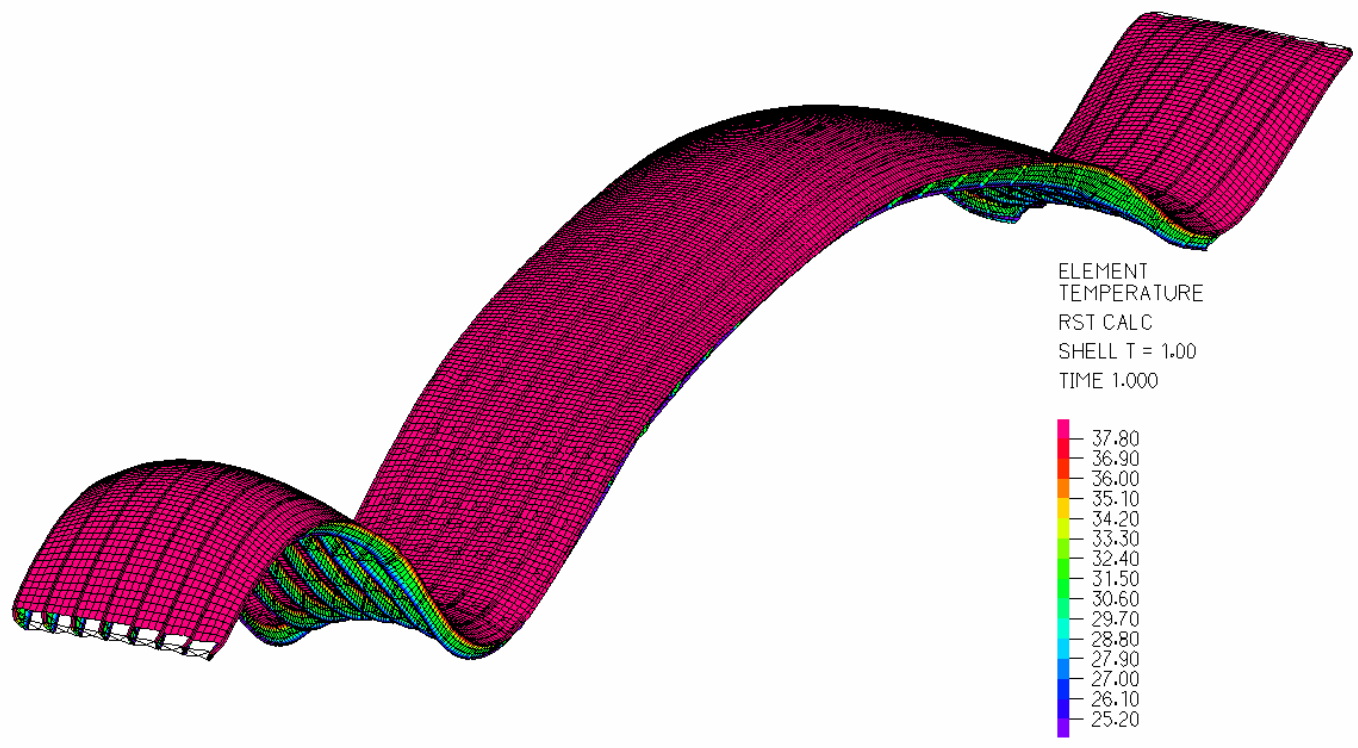

Figure 6.11 Superstructure Deformation Due to Maximum Positive Temperature Gradient

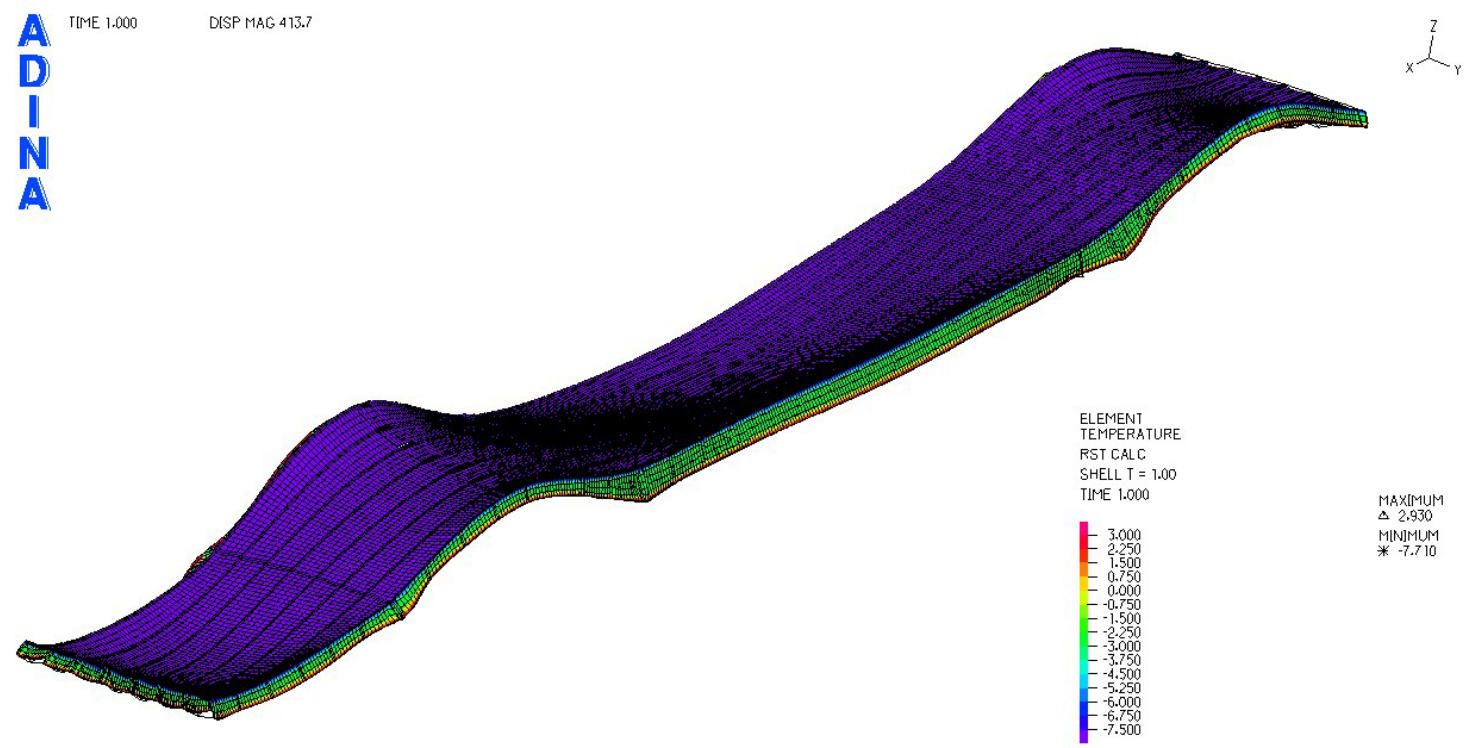

Figure 6.12 Superstructure Deformation Due to Maximum Negative Temperature Gradient

Table 6.4 summarizes calculations of total slip strains for both maximum positive and negative temperature gradients across the bridge superstructure. 
Table 6.4 Calculation of total slip strains at span No. 1

Variable

Positive Temp. Gradient

Negative Temp. Gradient

\begin{tabular}{lcc}
\hline $\mathrm{L}$ & 1377 (in) & 1296 (in) \\
$\mathrm{x}$ (location of measurement) & $518.4(\mathrm{in})$ & $518.4(\mathrm{in})$ \\
$\mathrm{k} 1$ & $7.003 \times 10^{5}$ & $7.003 \times 10^{5}$ \\
$\mathrm{k} 2$ & $8.131 \times 10^{6}$ & $8.131 \times 10^{6}$ \\
$\mathrm{k}$ & $6.447 \times 10^{5}$ & $6.447 \times 10^{5}$ \\
$\mathrm{y}_{\mathrm{o}}$ & 48.9 & 48.9 \\
$\mathrm{~A}_{\mathrm{o}}$ & 2.101 & 2.101 \\
$\mathrm{P}$ & $5034.1(\mathrm{lb})$ & $5350.3(\mathrm{lb})$ \\
$\alpha$ & 0.00608 & 0.00608 \\
$\beta$ & $2.24 \mathrm{e}-11$ & $2.24 \mathrm{e}-11$ \\
$\varepsilon_{s}$ & $0.79 \mu \varepsilon$ & $0.84 \mu \varepsilon$ \\
\hline
\end{tabular}

The slip strain resulting from maximum temperature gradients is amounts 0.79 and 0.84 micro-strain for positive and negative maximum temperature gradients respectively. It is clear that the slip strain values are relatively small compared to the calculated difference between strain in concrete and steel rebars. Therefore taking the total slip strain into consideration while adopting the described method for crack detection will not alter the outcome results.

\subsection{Analysis of Cracks Initiation through Frequency Spectrum Analysis of Bridge Superstructure}

Studying the dynamic properties of the bridge superstructure reveals important mechanisms that control the structure's response to dynamic loading. In this section dynamic properties of the bridge superstructure including natural frequencies and mode shapes are investigated through analysis of the FE models.

A multi-degree of freedom (DOF) system of the order $\mathrm{N}$ requires $(\mathrm{N})$ number of coordinates and $(\mathrm{N})$ number of simultaneous equations of motion to describe its dynamic 
properties. The N-DOF system has $\mathrm{N}$ natural frequencies, and for each of the natural frequencies corresponds normal mode shapes that describe the displacement configuration in the normal state of vibration. The mathematical terms of the natural frequencies and mode shapes are known as eigenvalues and eigenvectors. These quantities are established from solving the systems' equations of motion. The equations of motion describe the structure behavior in the state of free undamped vibrations.

The natural vibration modes depend only on the systems' mass and stiffness and the way they are distributed. When excited at one of those natural modes, all nodes in the system undergo simple harmonic motion that passes through their equilibrium position simultaneously. The magnitude of displacements is specified by the initial conditions the system is given prior to the free vibration mode (Thomson and Dahleh, 1993) .

When a multi-DOF system is excited under a forced harmonic vibration and the excitation frequency coincides with one of the natural frequencies, a condition of resonance occurs. This state produces large displacement amplitudes that are theoretically infinite; however they are practically controlled by the amount of damping in the system. The solution of a Multi-DOF system is expressed in mathematical formulation as following:

The equation of motion of the free vibration response of the system is expressed as:

$$
[M]\{\ddot{x}\}+[K]\{x\}=\{0\} \quad \text { Equation 6.40 }
$$

Where $[\mathrm{M}] \quad$ is the systems' mass matrix

$\mathrm{x} \quad$ is the displacement

$[\mathrm{K}] \quad$ is the systems' stiffness matrix

Setting the initial conditions as: $\{x(0)\}=\left\{x_{0}\right\}$ and $\{\dot{x}(0)\}=\left\{\dot{x}_{0}\right\}$ at time $\mathrm{t}=0$;

The solution of the second order differential equation (Eq. 6.40) is assumed to be:

$$
\{x\}=\{\phi\}\left(A_{1} \operatorname{Sin} \omega t+A_{2} \operatorname{Cos} \omega t\right)
$$

\section{Equation 6.41}


Where $\{\phi\} \quad=\quad(\mathrm{nx} 1)$ vector of displacement amplitudes

$\begin{array}{lll}\mathrm{A}_{1}, \text { and } \mathrm{A}_{2} & \text { are } & \text { Constants } \\ \omega & = & \text { natural frequency } \\ \mathrm{t} & = & \text { time }\end{array}$

By substituting eq. 6.41 into eq. 6.40 and solving for the equation of motion, the solution takes the form:

$$
\begin{array}{ll}
-\omega^{2}[M]\{\phi\}+[K]\{\phi\}=\{0\} & \text { Equation 6.42 } \\
\therefore\left(-\omega^{2}[M]+[K]\right)\{\phi\}=\{0\} & \text { Equation 6.43 }
\end{array}
$$

since $\{\phi\}$ can not be zero, then the determinate in Eq. 6.43 has to be zero:

$$
\operatorname{det}\left(-\omega^{2}[M]+[K]\right)=\{0\} \quad \text { Equation } 6.44
$$

Eq. 6.44, is the characteristic equation of the system from which the natural frequencies $\omega$ is determined. By substituting the roots of eq. $6.44\left(\omega_{1}^{2}, \omega_{2}^{2}, \omega_{3}^{2}, \ldots, \omega_{n}^{2}\right)$ into eq. 6.43, the mode shapes $\{\phi\}$ are calculated. The natural frequencies $\omega_{i}^{2}$ are called eigenvalues, while the corresponding mode shapes $\{\phi\}_{i}$ are called eigenvectors. It is noticed that the mode shapes are not unique, thus they do not provide a unique magnitude of the displacement. However the mode shapes determine the shape of nodal displacements relative to each other. In other words, the eigenvectors describe the relative displacements of all system coordinates when the structure is excited at the corresponding eigenvalue.

Figure 6.13 and Figure 6.14 illustrate the first 10 modes of vibrations of Phase 2 of Star City Bridge steel superstructure. Information about the first 10 modes including natural frequencies and modal participation factors are listed in Table 6.5. The modal participation factor indicates the amount of structural mass interpreted in a \%age format that contributes to the displacement in the direction of any of the three Cartesian coordinates. The first natural frequencies of the steel superstructure are calculated to be within a range of 0.206 to $1.408 \mathrm{~Hz}$. Analyzing the modes of vibrations and their 
corresponding modal participation factors reveal important information about the structure response to environmental loading conditions such as wind loading and its overall stability factors. The mode shapes as illustrated, indicate that the first 10 modes mainly consist of displacements in the $\mathrm{Y}$ direction (bridge width) normal to the traffic direction; except for mode shapes No. 6 and No. 7 that indicate torsional modes of vibration. 


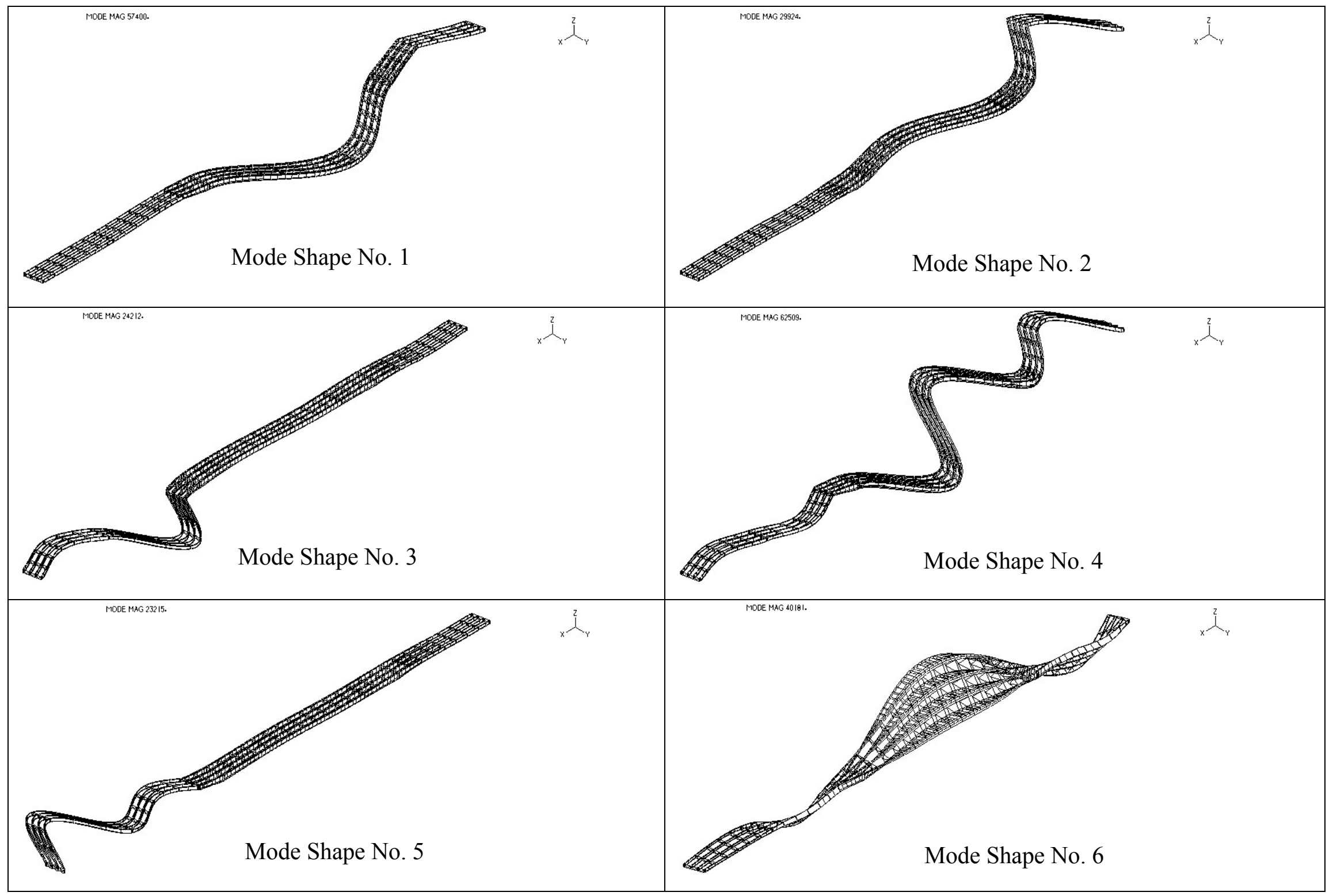

Figure 13 Mode Shapes No. 1 to No. 6 of Steel Superstructure of Phase II 


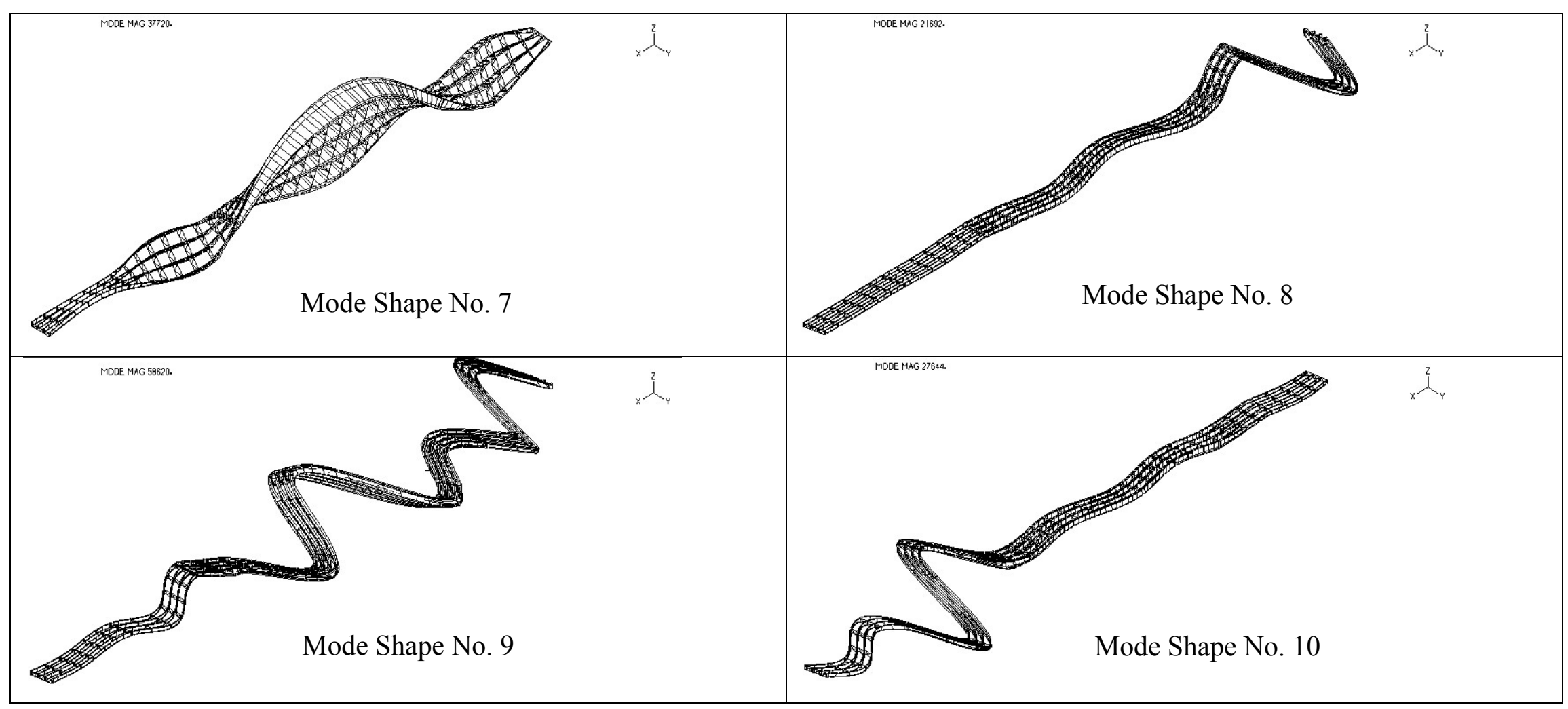

Figure 6.14 Mode Shapes No. 7 to No. 10 of Steel Superstructure of Phase II 


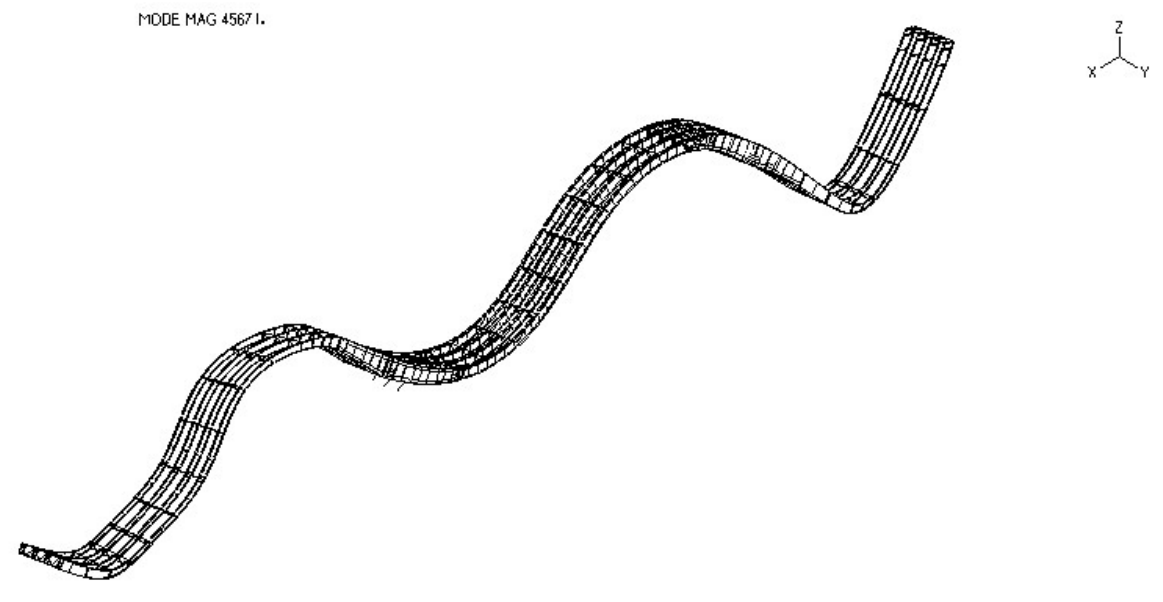

Figure 6.15 Mode Shape No. 14 of Steel Superstructure of Phase II

Further analysis of the mode shapes show that the first mode shape to incorporate vibration in the $\mathrm{Z}$ direction correspond to the $14^{\text {th }}$ natural frequency that amounts 2.081 Hz. Figure 6.15 shows the modal displacements of this particular mode. The rest of the mode shapes are combinations of those modal displacements.

Table 6.5 FE Modal Analysis of Steel Superstructure of Phase II

\begin{tabular}{|c|c|c|c|c|}
\hline Mode & Frequency & Mass (X) & Mass (Y) & Mass (Z) \\
\hline & $H z$ & \%age & \% age & \% age \\
\hline 1 & 0.206 & 0.00002 & 32.14113 & 0.00075 \\
\hline 2 & 0.437 & 0.00001 & 13.82602 & 0.00026 \\
\hline 3 & 0.516 & 0.00001 & 4.58889 & 0.00006 \\
\hline 4 & 0.601 & 0.00054 & 1.48408 & 0.00934 \\
\hline 5 & 0.660 & 0.00002 & 9.01582 & 0.00024 \\
\hline 6 & 0.799 & 0.75421 & 0.02172 & 15.81645 \\
\hline 7 & 0.801 & 0.38676 & 0.07959 & 7.72798 \\
\hline 8 & 1.002 & 0.00001 & 0.73276 & 0.00091 \\
\hline 9 & 1.143 & 0.00011 & 7.34 & 0.00177 \\
\hline 10 & 1.408 & 0.00019 & 1.38771 & 0.00084 \\
\hline
\end{tabular}


As indicated in Table 6.5, the modal participation factor also confirms this observation. It is clear that a significant amount of mass contribute to the displacements in the $\mathrm{Y}$ direction opposed to those in the $\mathrm{X}$ or $\mathrm{Z}$ directions. For example in the first mode, $32.1 \%$ of the mass contribute to the displacement in $\mathrm{Y}$ direction, and only $0.00002 \%$ and $0.00075 \%$ contribute to the displacements in $\mathrm{X}$ and $\mathrm{Z}$ directions respectively. The natural frequencies of any structure depend only on the mass and stiffness of that structure. Since the mass does not change in any of the mode shapes, it is concluded that the structural stiffness of the steel superstructure in Phase II compels the displacement modes to become easier in the direction of the bridge width (the week axis) opposed to any other direction for the largest number of first frequencies. This conclusion can explain the need to add upper chord members in the steel bracing system while construction was underway. During construction of Phase I (half the bridge), It was noticed that the steel girders once placed, lacked stability and warped in the direction of the bridge width in winter time. This problem caused halting of all construction actions, and caused long delays, where the bridge system was being evaluated. Upper chord members were added to the steel diaphragm system, and the whole structure was braced to the old bridge (still holding traffic at that time). This measure was taken in order to strengthen the stiffness of the steel superstructure in the $\mathrm{Y}$ direction, thus securing the stability of the bridge at this stage. Placing the concrete deck afterwards and completion of bridge construction added a substantial amount of mass to the system and stiffness in the lateral direction, thus changing the natural frequencies and mode shapes as illustrated in Figure 6.16, Figure 6.17 and Table 6.6. 


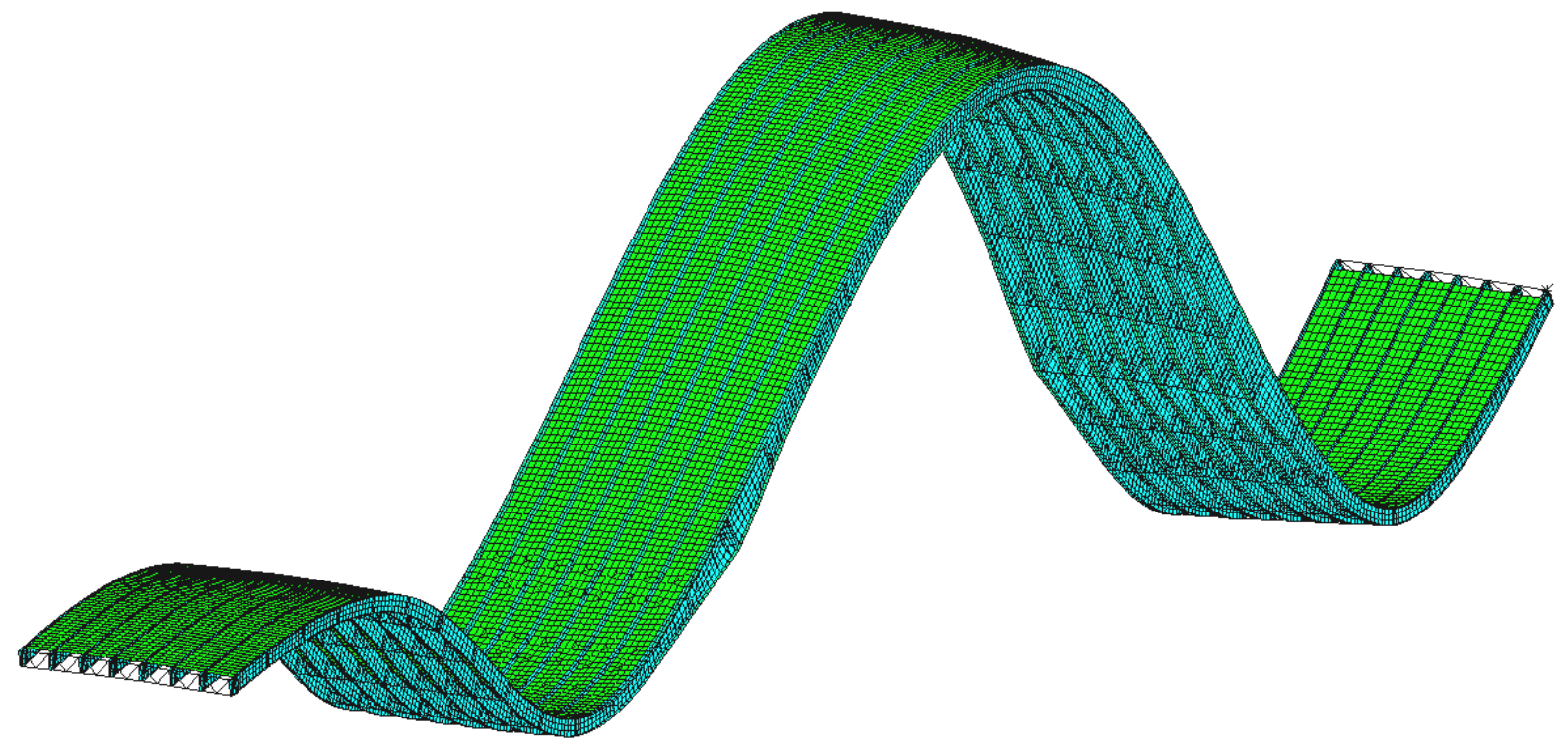

Figure 6.16 Mode Shape Corresponding to $1^{\text {st }}$ Natural Frequency of Full Bridge Superstructure

Table 6.6 FE Modal Analysis of Full Bridge Superstructure

\begin{tabular}{|c|c|c|c|c|}
\hline Mode & Frequency & Mass (X) & Mass (Y) & Mass (Z) \\
\hline & $H z$ & $\%$ age & $\%$ age & $\%$ age \\
\hline 1 & 0.730 & 1.59379 & 0.0036 & 15.02315 \\
\hline 2 & 0.923 & 0.00374 & 4.61366 & 0.01067 \\
\hline 3 & 1.634 & 2.73269 & 0.42901 & 2.55604 \\
\hline 4 & 1.821 & 0.01789 & 20.73979 & 0.07018 \\
\hline 5 & 2.024 & 0.25595 & 0.32023 & 16.20785 \\
\hline 7 & 2.173 & 0.00011 & 5.25225 & 0.07903 \\
\hline 8 & 2.286 & 0.02904 & 31.2977 & 0.74896 \\
\hline 9 & 2.594 & 2.80401 & 0.38847 & 22.10587 \\
\hline 10 & 2.974 & 0.00559 & 8.00496 & 0.12133 \\
\hline & 3.167 & 0.18832 & 0.07867 & 6.44959 \\
\hline
\end{tabular}

The modal participation factor for the full bridge shows that for the first natural frequency $15 \%$ of the mass contribute to the nodal displacements in the $\mathrm{Z}$ direction, 
while $1.59 \%$ and $0.0036 \%$ contribute to the nodal displacements in the $\mathrm{X}$ and $\mathrm{Y}$ directions respectively. This indicates that at the fundamental frequency, the mode of vibration would shift from being in the lateral direction in the case of the steel superstructure only, to being in the vertical direction in the case of the full bridge. The subsequent mode shapes consist of torsional and combinations of torsion and displacement modes. The stiffness of the bridge superstructure is mainly designed to carry vertical loads, therefore there are no significant concerns about the first vertical displacement mode. However, the torsional vibration modes tend to spread the girders apart, which could explain formation of longitudinal cracks in the bridge deck.

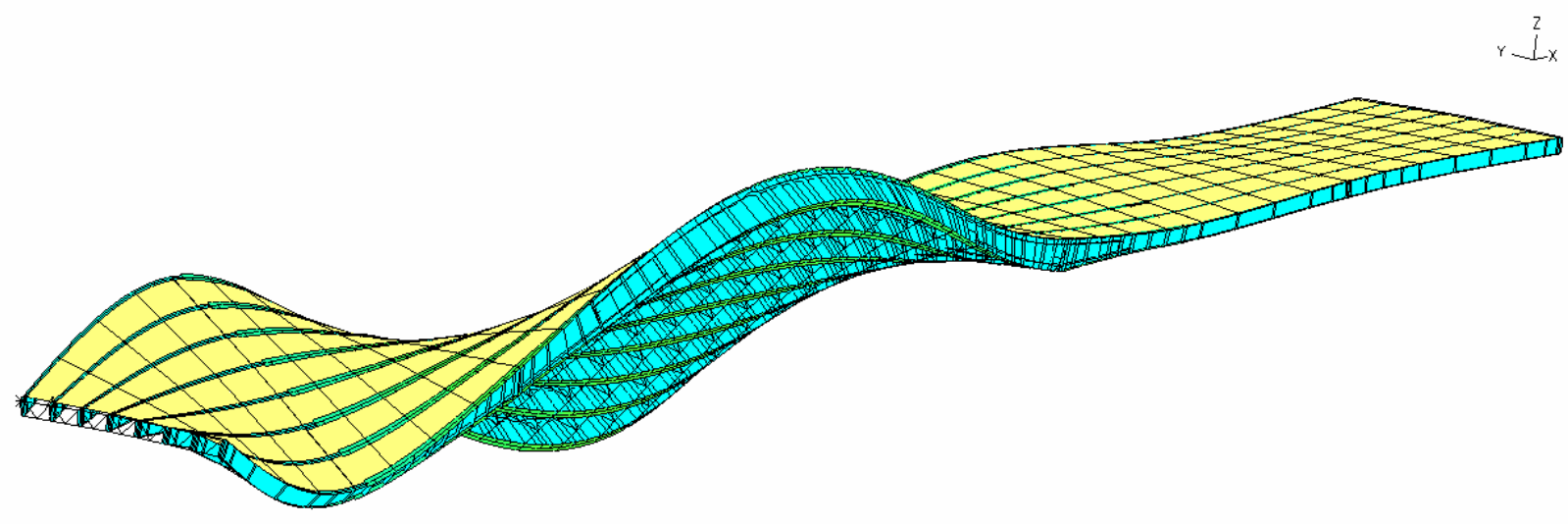

Figure 6.17 Mode Shape Corresponding to $2^{\text {nd }}$ Natural Frequency of Full Bridge

Superstructure

\subsection{Structural Health of the Bridge Superstructure after Deck Cracks}

\subsubsection{Concrete Deck}

The instrumentation embedded in the concrete deck shows different patterns of stresses according to their various locations. Histories of long-term stresses in the concrete material are calculated from the three dimensional strain histories, and in many cases reveal occurrence of transverse cracks by reaching the concrete modulus of rupture. Long-term stresses are temperature induced and occur due to the restraints from 
expansion and contraction in the bridge superstructure. Temperature induced Stresses in concrete deck are calculated by:

$$
\left[\begin{array}{c}
\sigma_{x x} \\
\sigma_{y y} \\
\sigma_{z z} \\
\sigma_{y z} \\
\sigma_{z x} \\
\sigma_{x y}
\end{array}\right]=\frac{E}{(1+v)(1-2 v)}\left[\begin{array}{cccccc}
1-v & v & v & 0 & 0 & 0 \\
v & 1-v & v & 0 & 0 & 0 \\
v & v & 1-v & 0 & 0 & 0 \\
0 & 0 & 0 & 1-2 v & 0 & 0 \\
0 & 0 & 0 & 0 & 1-2 v & 0 \\
0 & 0 & 0 & 0 & 0 & 1-2 v
\end{array}\right]\left[\begin{array}{c}
\varepsilon_{x x}-\alpha_{c} t \\
\varepsilon_{y y}-\alpha_{c} t \\
\varepsilon_{z z}-\alpha_{c} t \\
\varepsilon_{y z} \\
\varepsilon_{z x} \\
\varepsilon_{x y}
\end{array}\right] \text { Equat. 6.45 }
$$

where: $\sigma_{\mathrm{xx}}, \sigma_{\mathrm{yy}}, \sigma_{\mathrm{zz}}=$ normal stresses in the $\mathrm{x}, \mathrm{y}$, and $\mathrm{z}$ directions respectively

$$
\begin{array}{lll}
\sigma_{\mathrm{yz}}, \sigma_{\mathrm{zx}}, \sigma_{\mathrm{xy}} & = & \text { shear stresses } \\
\varepsilon_{\mathrm{xx}}, \varepsilon_{\mathrm{yy}}, \varepsilon_{\mathrm{zz}} & = & \text { normal strains in the } \mathrm{x}, \mathrm{y}, \text { and } \mathrm{z} \text { directions respectively } \\
\varepsilon_{\mathrm{yz}}, \varepsilon_{\mathrm{zx}}, \varepsilon_{\mathrm{xy}} & = & \text { shear strains } \\
\mathrm{E} & = & \text { Modulus of Elasticity of concrete } \\
v & = & \text { Poisson's Ratio of Concrete material } \\
\alpha_{t} & = & \text { Coefficient of thermal expansion of Concrete material } \\
\mathrm{t} & = & \text { temperature variation }
\end{array}
$$

Trends of stress time histories in the concrete deck in most locations seem to have reached a steady state to date. Stresses in the longitudinal (traffic direction) and transverse directions are calculated and as stresses approach the concrete modulus of rupture a crack is anticipated. Transverse cracks are visible from the top surface of the concrete deck and appear to have a frequency of 3 to $4 \mathrm{ft}$. Transverse cracks tend to be more frequent at the middle third of the bridge length. Figure 6.18 and Figure 6.19 illustrate a sample comparison between concrete stresses in span 4 . The plots clearly indicate that the stresses in the transverse direction are double those in the traffic direction, hence a longitudinal crack is more likely anticipated. 


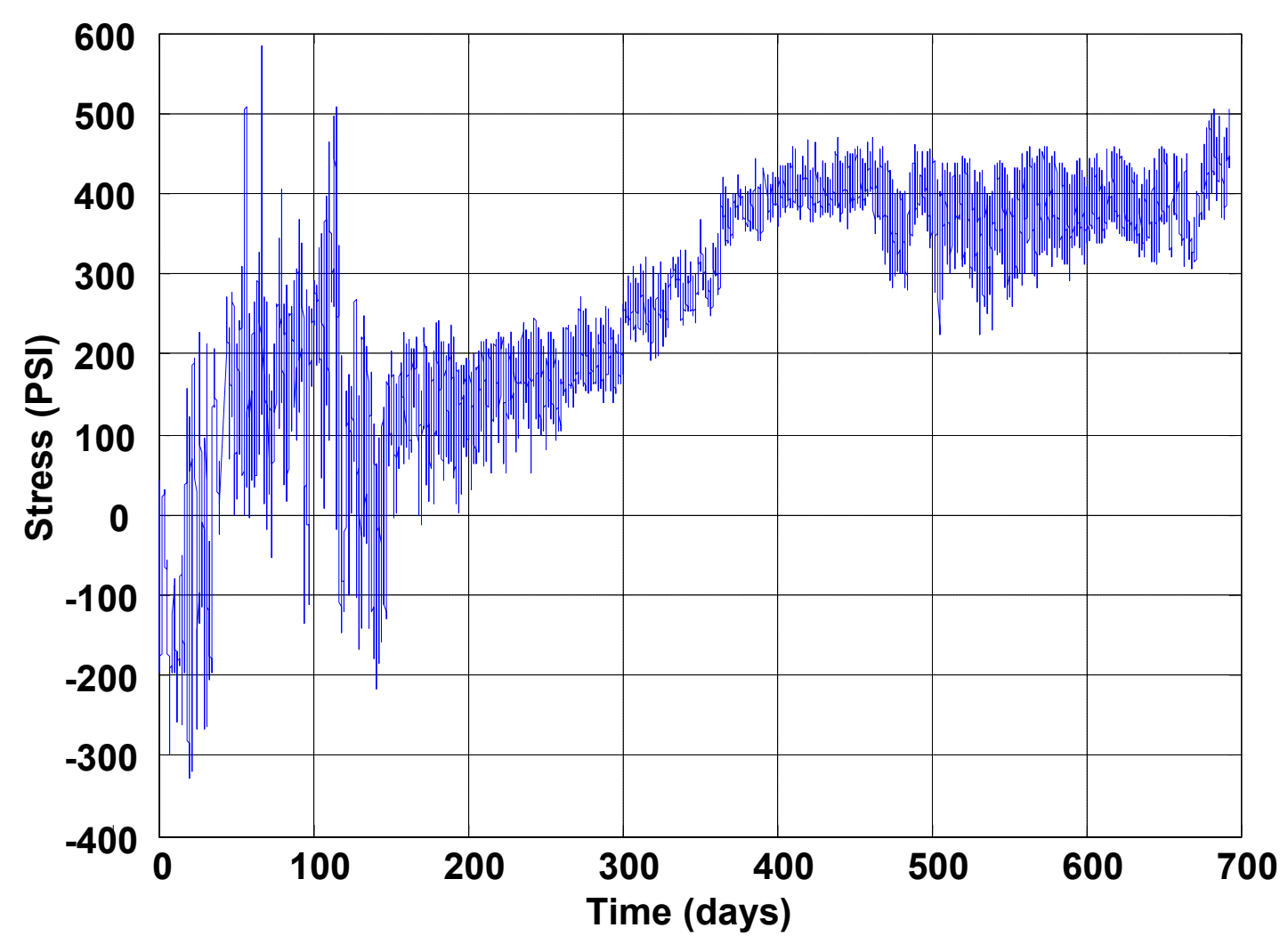

Figure 6.18 Stresses in Concrete Perp. to Traffic on Top of Mid-span 4, Girder 6

Stresses in the steel reinforcement are also calculated at critical locations of phase 2 (identified from the design calculation sheets). Stresses in the steel reinforcements appear to be in normal range and do not reflect any alarming signs. In general, the stresses in the top steel reinforcement in the transverse direction are higher compared to those in the longitudinal direction at locations between supports as can be illustrated from Figure 6.20 . 


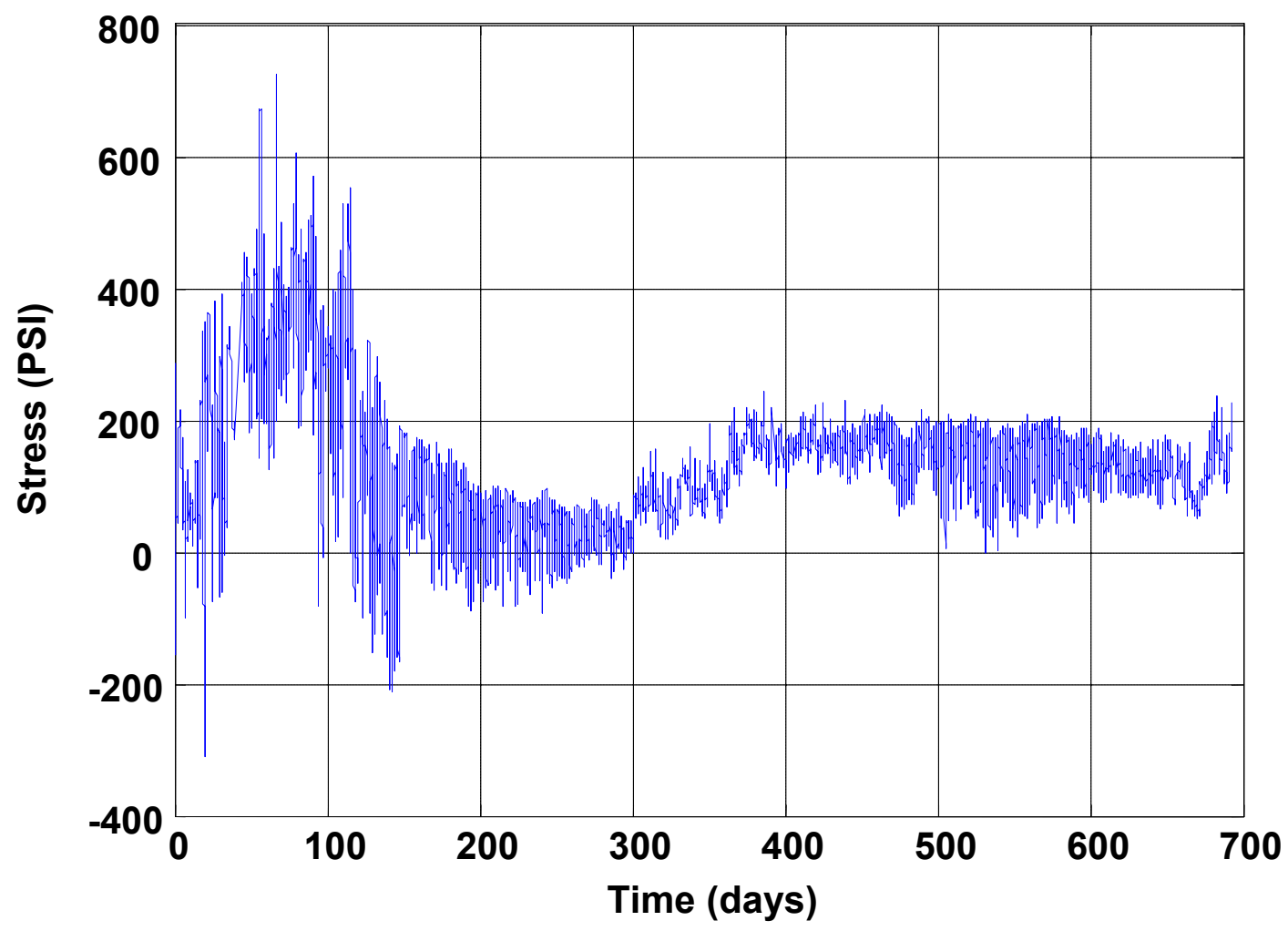

Figure 6.19 Stress in Traffic Direction on Top of Mid-span 4, Girder 6

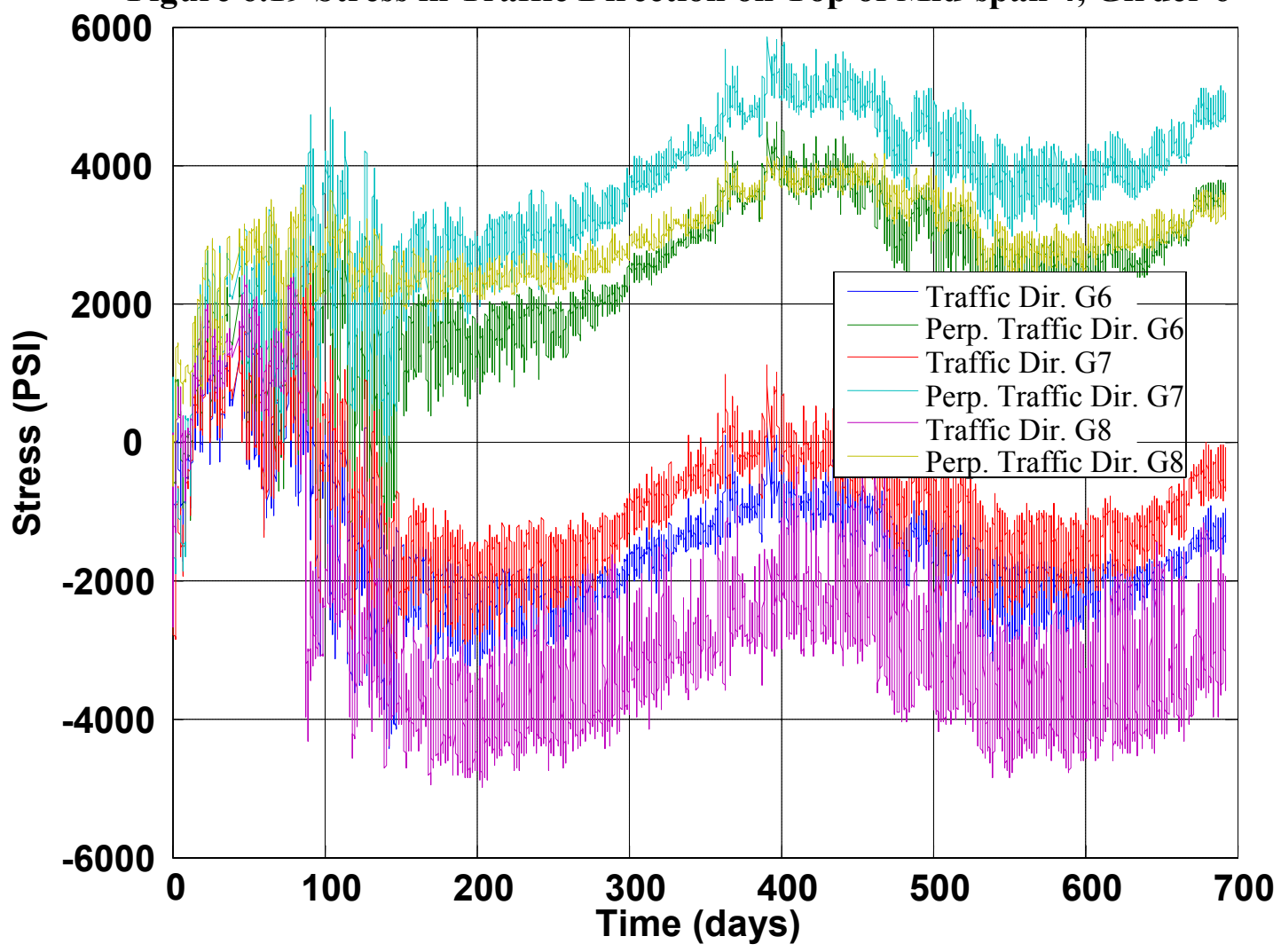

Figure 6.20 Stresses in Steel Reinforcement at Mid-Span 4 


\section{CHAPTER 7}

\section{CONCLUSIONS}

\subsection{Conclusions}

This study focuses on monitoring the health of an empirically designed bridge deck superstructure through detection and analysis of deck cracks using embedded sensory systems. The study also identifies the contribution of temperature-induced stresses in initiating premature cracking in bridge concrete decks. The work in this study includes development of a remote sensory system for long term monitoring of bridge elements and detailed 3DFE models of the bridge following actual sequences of construction. The study includes development and implementation of an innovative methodology for crack detection in reinforced concrete bridge decks, and theoretical evaluation of the total slip strain at bridge deck components. Analysis of temperature data records, offers an insight into thermal loading configurations on bridge decks including positive and negative temperature gradients. Based on 2 years of continuous monitoring of the bridge deck response, Analytical studies through finite element modeling and theoretical analysis, the following conclusions can be withdrawn:

1. A remote sensory system for long term monitoring of bridge structures is designed and successfully installed during the second phase of construction of the Star City Bridge in Morgantown, WV. The system consist of an array of sensors (more than 750 sensors) and data acquisition units that continuously record measurements such as the tri-axial state of stress and strains in concrete deck, strains and bending moments as well as shearing stresses and inclinations of the steel girders, forces at the diaphragm members, expansion and contraction of bridge ends, strains and stresses in rebars, along with temperature profiles along the deck. 
2. The instrumentation system installed on the Star City Bridge proved to be successful for securing data that can be helpful to remotely evaluate the long-term bridge deck performance. Such a system can be used to provide more accurate, more frequent and reliable data than the regular bridge visual inspection programs adopted by state highway agencies.

3. Analysis of continuous temperature records revealed that bridge decks are subjected to severe positive and negative temperature gradients along with global temperature increase and decrease. AASHTO Standard Specifications for Highway Bridges provides only general information about temperature range for Moderate and Cold Climate conditions. Current bridge design specifications do not give any guidelines for designing bridge decks to withstand temperature gradients, therefore it is recommended to consider the following temperature gradients in designing bridge superstructures. The Star City Bride experienced maximum positive and negative temperature gradients amounting $12.04 \mathrm{deg}$. C and -10.64 deg. C respectively. Average global temperature variation between winter and summer amounted $40.73 \mathrm{deg}$. C while maximum daily temperature variation in winter days measured $16.5 \mathrm{deg} C$, and that in summer day measured 14.05 deg. C.

4. The state of concrete/steel composite action is studied where measurements show that a good composite action is established after 10 days of pouring concrete. The study is based of comparing theoretically predicted temperature induced strains and those measured at locations of maximum stresses along the bridge length.

5. An innovative method for crack detection in concrete bridge decks is illustrated. The method is based on monitoring the effect of cracks on the difference in strains between steel reinforcements and surrounding concrete material. The technique features the following properties:

- Instrumentation based utilizing embedded sensors. 
- Provide continuous monitoring of initiation and growth of cracks in a time history format.

- Does not require removal of stay in place forms, therefore can be used to detect hidden cracks.

- Does not require placing sensors at the exact location of the crack since that location is not identified prior to the crack initiation.

- Isolate effects of long-term variables such as creep, and shrinkage.

6. Detailed 3DFE models are developed to describe the behavior of the bridge during the sequence of construction and after completion. The full model consists of 8 steel girders with variable inertia supporting deck slabs and connected by diaphragm members. The models responses are validated through comparison with strain measurements and with theoretically calculated deflections.

7. Theoretical analysis and 3DFE modeling results were successfully combined to originate a method to estimate the total slip strain in steel/concrete composite deck systems tied with regular traditional headed studs $\phi(7 / 8)$ ". The performed analysis used maximum positive and negative temperature gradients across the deck and showed that total slip strain was less than one microstrain in both cases.

8. An investigation of the reasons for development of longitudinal cracks in this empirically designed bridge deck is conducted through frequency spectrum analysis of bridge superstructure. The Finite element models were used for this study, where it was demonstrated that lateral stiffness of bridge superstructure was responsible for a mode of lateral warping during construction phase. Mode shapes of vibrations demonstrated a possible explanation of development of longitudinal cracks.

9. Time histories of stresses developed in various bridge members showed that the current state of the bridge is within safety limits and no signs of alarming natures were recorded to date in the steel superstructure as result of concrete deck cracks. 


\subsection{Proposed Future Work}

- The new method for crack detection was demonstrated to be effective in detecting hidden cracks in the concrete deck and indicate time of initiation and development of a particular crack. A future development is to correlate the method to the crack width. This will require precise measurement of the crack width and a mathematical correlation between that and the output factor.

- Little is provided in the literature and design methods about the effect of moisture variation on bridge superstructure. The reason could be that temperature variation is thought to be the predominant factor. The weather station at the Star City Bridge site provide information about all environmental factors and along with the response data from the instrumentation system, it would be interesting to isolate the effects of such unconventional parameters.

- Analysis of the dynamic properties of the Star City Bridge gives an insight into possible reasons for longitudinal cracks developed in the concrete deck. The finite element model can be used for further analysis where parametric study can be conducted to show the effect of different bracing systems with different lateral stiffness on the dynamic properties of the superstructure.

- The engineering community was always interested to work with better and stronger building material. In the area of bridge decks, high performance concrete is introduced and was implemented on many bridges throughout the nation. However, this did not solve the problem of premature bridge deck cracks. The concept of designing light weight flexible decks with higher strength capacity concrete material does not seem to serve the purpose of eliminating cracks, and the reasons are intuitive. Flexible decks with long spans will entertain high levels of vibrations and large deflection magnitudes that a brittle material as concrete will not be able to resist. Therefore cracks will definitely occur. There is a need to explore new solutions by using more flexible concrete material, rather than high strength concrete. 


\section{REFERENCES}

1. AASHTO M31, (1996). "Standard Specifications for Deformed and Plain Billet-Steel Bars for Concrete Reinforcement", Standard Specifications for Transportation Matrials and Methods of Sampling and Testing, American Association of State Highway and Transportation Officials, Washington, D.C.

2. AASHTO, (1996). "Standard Specifications for Highway Bridges $16^{\text {th }}$ Edition", American Association of State Highway and Transportation Officials, Washington, D.C.

3. AASHTO-LRFD, (1998). "Bridge Design Specifications", American Association State Highway and Transportation Officials, Washington, D.C.

4. AASHTO LRFD Bridge Design Specifications 3rd Edition (2004), American Association of State Highway and Transportation Officials, Washington D.C., ISBN 1-56051-250-4, P Code: LRFDUS-3.

5. Aktan A.E., Helmicki A.J., and Hunt V.J., (1996). "Issues Related to Intelligent Bridge Monitoring", Building an International Community of Structural Engineers, Proceeding of Structures Congress XIV, Chicago Ill., ASCE.

6. Aktan A.E., Tsikos C.J., Catbas F.N., Grimmelsman K., and Barrish R., (1999) "Challenges and Opportunities in Bridge Health Monitoring", Structural Health Monitoring 2000, Stanford University, Palo Alto, California, pp. 461-473.

7. Aktan A.E., Catbas F.N., Grimmelsman K.A., and Tsikos C.J., (2000). "Health Monitoring of Large Infrastructure Systems for Management", ASCE, Journal of Engineering Mechanics, v126. No. 7. 
8. American Association of State Highway and Transportation Officials (AASHTO), (1994). "Manual for Condition Evaluation of Bridges", Second Edition, AASHTO, 444 North Capitol Street, N.W., Suite 249, Washington DC, 20001.

9. American Society of Civil Engineers, (2005)."Report Card for America's Infrastructure" www.asce.org/reportcard

10. ASTM (1999). "Standard Test Method for Compressive Strength of Cylindrical Concrete Specimens", ASTM Standards Vol. 04.02.

11. ASTM, (2002), "Standard Practice for Making and Curing Concrete Test Specimens in the Laboratory", ASTM Standards Vol. 04.02.

12. ASTM-E-1318, (2002). "Standard Specification for Highway Weigh-in-Motion (WIM) Systems with User Requirements and Test Methods", American Society for Testing and Materials.

13. Autodesk Inc., (2004). “AutoCAD software V2004.0.0”, Autodesk Inc., San Raphael, Ca., USA.

14. Babaei K., and Hawkins N.M., (1990). "Performance of Bridge Deck Concrete Overlays", Extending the life of Bridges, STP 1100, ASTM, Philadelphia, Penn, pp. 95-108.

15. Bathe K.J., Dvorkin E., and Ho L.W., (1983). "Our Discrete-Kirchhoff and Isoparametric Shell Elements-an assessment", J. Computers and Structures, Vol. 16, pp.89-98.

16. Bathe K.J., and Dvorkin E. (1985). “A Four-Node Plate Bending Element Based on Mindlin/Reinssner Plate Theory and a Mixed Interpolation", Int. J. Numerical Methods in Engineering, Vol. 21, pp. 367-383. 
17. Bathe K.J. and Dvorkin E., (1986). “A Formulation of General Shell Elements - The Use of Mixed Interpolation of Tensorial Components", Int. J. Numerical Methods in Engineering, Vol. 22, pp. 697-722.

18. Bathe K.J., (1996). "Finite Element Procedures", Prentice Hall, Englewood Cliffs, NJ, Sec. 6.6.1.

19. Bathe K.J. /ADINA R\&D. Inc., (2004). “Automatic Dynamic Incremental Nonlinear Analysis Theory and Modeling Guide", Report ARD 04-7.

20. Byfors J., (1980). "Plain Concrete in Early Ages", Swedish Cement and Concrete Research Institute, Fo.3, No. 80, Stockholm, Sweden.

21. BridgeSight Software, (1999). "Reinforced Concrete Slab Design Using the Empirical Method”, Publication No. BSS09011999-1, BridgeSight Software ${ }^{\mathrm{TM}}$, Rescue, Ca 95672.

22. Carino N.J., and Lew H.S., (1982). "Re-examination of the relation between splitting tensile and compressive strength of normal weight concrete", ACI J. Proc. 79(3), pp. 214-219.

23. Carino N.J., and Tank R.C. (1992). "Maturity Functions for Concrete Made with Various Cements and Admixtures", ACI Materials Journal 89(2), pp. 188-196.

24. Catbas F.N., Ciloglu S.K., Grimmelsman K., Pan Q., Pervizpour M., and Aktan A.E., (1999). "Limitations in the Structural Identification of Long-Span Bridges", Drexel University Infrastructure and Transportation Safety Institute, Philadelphia, Pa 19104. 
25. Catbas F.N., Shah M., Burkett J., and Basharat A., (2004). "Challenges in Structural Health Monitoring", $4^{\text {th }}$ International Workshop on Structural Control, New York, NY.

26. Caughey R.A., and Scott W.B., (1929). "A Practical Method for Design of I-Beams Haunched in Concrete”, Engineering Journal, Vol. 7, No. 8, pp. 275-293.

27. Cioara T.G., and Alampalli S., (2000) "Extracting Reliable Modal Parameters for Monitoring Large Structures", European COST F3 Conference on System Identification and Structural Health Monitoring, Madrid, Spain, 333-340.

28. Chase S. B., (2003).”Long Term Bridge Monitoring to Support Bridge Technology Innovations", $19^{\text {th }}$ US-Japan Bridge Engineering Workshop, PWRI Tsukuba, Japan.

29. Connor R.J., Santosuosso, B., (2002). "Field Measurement and Controlled Load Testing on the Lehigh River Bridge", Advanced Technology for Large Structural Systems, Report 02-07.

30. Cope R.G., and Clark L.A., (1984). “Concrete Slabs Analysis and Design”, Elsevier.

31. CRD-C39-81, (1981). "Test Method for Coefficient of Linear Thermal Expansion", US Army Corps of Engineers, http://www.wes.army.mil/SL/MTC/handbook/crd_c39.pdf

32. Cunha A., Caetano E., and Delgado R., (2001). "Dynamic Tests on a Large CableStayed Bridge, an Efficient Approach", Journal of Bridge Engineering, ASCE, 6(1), 54-62.

33. Cusson D., and Repette W.L., (2000). "Early Age Cracking in Reinforced Concrete Bridge Barrier Walls", ACI Materials Journal, Vol. 97, No. 4, pp. 438-446. 
34. Dvorkin E., and Bathe K.J., (1984). "A Continuum Mechanics Based Four-Node Shell Element for General Nonlinear Analysis", Engineering Computations, Vol. 1, pp. 77-88.

35. Edward Czepiel, (1995). "Bridge Management Systems Literature Review and Research", ITI technical report no. 11, Northwestern University BIRL Industrial Research Laboratory.

http://www.iti.northwestern.edu/publications/technical_reports/tr11.html

36. European Committee for Standardization (ECS), (1994). "Eurocode 4: design of Composite Steel and Concrete Structures", Brussels.

37. Fang K.I., (1985). “Behavior of Ontario-Type Bridge Deck on Steel Girders.” PH.D. dissertation, University of Texas, Austin, TX.

38. Fang I. K., Worley J., Burns N. H., and Klingner R. E., (1990). "Behavior of Isotropic R/C Bridge Decks on Steel Girders", Journal of Structural Engineering, ASCE, 116(3): 659-678.

39. Fang M., and Kim D., (2001). "Long-Term Structural Response Monitoring of Two Highway Bridges - Phase I: Instrumentation", Report No. FHWA/CA/SD-2001/18, California Department of Transportation, Sacramento, Ca.

40. Farrar C.R., Baker W.E., Bell T.M., Cone K.M., Darling T.W, Duffey T.A., Eklund A., and Migliori A., (1994) "Dynamic Characterization and Damage Detection in the I-40 Bridge over the Rio Grand", Los Alamos National Laboratory report LA12767-MS.

41. Farrar C.R., and Doebling S.W., (1999). "Vibration-Based Structural Damage Identification", Philosophical Transactions: Mathematical, Physical and Engineering Sciences, Royal Society, London, UK. 
42. FHWA, Federal Highway Administration, (1991). “Bridge Inspector's Training Manual/90”, Washington D.C..

43. Fisher J.W., (1984). "Fatigue and Fracture in Steel Bridges”, John Wiley \& Sons, Inc., New York.

44. French C., Eppers L., Le Q., and Hajjar J.F., (1999). "Transverse Cracking in Concrete Bridge Decks", Transportation Research Record, Various Bridge Design Issues, Bridges, Other Structures, Hydraulics and Hydrology, Transportation Research Board, National Research Council, National Academy Press, 1688:21-29.

45. Friswell M.I., and Penny J.T., (1997) "Is Damage Location Using Vibration Measurements Practical?” ,Structural Damage Assessment Using Advanced Signal Processing Procedures, Proceedings of DAMAS 1997, University of Sheffield, UK, pp. 351-362.

46. Fujino F., and Abe M., (2003). "Structural Monitoring in Civil Infrastructures Research Activities of the Bridge and structure Laboratory of the University of Tokyo", Proceeding of the First International Conference on Structural Health Monitoring and Intelligent Infrastructure, Tokyo, Japan, pp. 39-50.

47. Garner N.J., and Poon S.M., (1976). "Time and Temperature Effects on Tensile, Bond and Compressive Strength", ACI J. Proc. 73(7), pp. 405-409.

48. Geokon, (1996). "Installation Manual, Models VCE-4200/4202/4210 Vibrating Wire Strain Gages”, Doc Rev G 11/00, Geokon Inc., Lebanon, NH 03766.

49. Geokon, (1998). “Installation Manual, Model VSM-4000 Vibrating Wire Strain Gage”, Doc Rev H, 4/98, Geokon Inc., Lebanon, NH. 
50. Geokon, (2000). "Installation Manual, Models VCE-4200/4202/4210 Vibrating Wire Strain Gages”, Doc Rev G, 11/00, Geokon Inc., Lebanon, NH.

51. Geokon, (2000a). "Installation Manual, Models 4911A/4911 VW Rebar Strain Meters", Doc Rev F, 03/00, Geokon Inc., Lebanon, NH.

52. Geokon, (2003). "Instruction Manual, Model 8020 (Micro-10) Multi-Channel Datalogger", Doc Rev J, 2/2003, Geokon Inc., Lebanon, NH.

53. Garibaldi L., Marchesiello S., and Gorman D.J. (1999) "Bridge Dynamics Misinterpretations due to Low Spatial Resolution and Closeness of Frequencies", Damage Assessment of Structures, Proceedings of the International Conference on Damage Assessment of Structures (DAMAS 99), Dublin, Ireland, pp. 411-422.

54. Hays C.O., Lybas J.M., and Guevara J.O., (1989). "Test of Punching Shear Strength of Lightly Reinforced Orthotropic Bridge Decks", University of Florida, Gainesville, FL.

55. Hewitt B.E., and Batchelor B.deV, (1975). "Punching Shear Strength of Restrained Slabs", Journal of the Structural Division, ASCE Vol. 101, No. St. 9 Proc. Paper 1154 B, pp. 1837-1853.

56. Holowka M., Dorton R.A., and Csagoly P.F., (1980). "Punching Shear Strength of Restrained Circular Slabs". Ministry of Transportation and Communication, Downsview, Ontario, Canada.

57. Harik I.E., Hu J.D., Smith S.W., Ren W.X., Zhao T., Campbell J.E., and Graves R.C., (2005). "Baseline Modeling of the Mayville Cable-Stayed Bridge over the Ohio River", Report No. KTC-05-10/FRT104-00IF, Kentucky Transportation Cabinet, Frankfort, Kentucky 40662. 
58. Inaudi D., Casanova N., Kronenberg P., and Vurpillot S., (1997). "Railway Bridge Monitoring during Construction and Sliding", SPIE Conference on Smart Structures and Materials, San Diego, USA.

59. Johnson E.A., Lam H.F., Katafigiotis L., and Beck J., (2000). “A Benchmark Problem for Structural Health Monitoring and Damage Detection", Proceeding of the $14^{\text {th }}$ ASCE Engineering Mechanics Conference, Austin, Texas.

60. Knowles P.R., (1973). “Composite Steel and Concrete Construction”, ISBN 0-47049580-4, John Wiley \& Sons, NY, Butterworth \& Co. Ltd, London.

61. Lau C.K., Mak P.N., Wong K.Y., Chan,W.Y.K., and Man K.L.D., (1999) "Structural Health Monitoring of Three Cable-Supported Bridges in Hong Kong”, Structural Health Monitoring 2000, Stanford University, Palo Alto, California, pp. 450-460.

62. Leon-Garcia A., (1994). "Probability and Random Process for Electrical Engineering”, Addison-Wesley Inc., $2^{\text {nd }}$ ed., ISBN 0-201-50037-X, Section 4.7

63. Lenett M.S., Hunt V.J., Helmicki A.J., and Aktan A.E., (2001).”Instrumentation, Testing and Monitoring of a Newly Constructed Reinforced Concrete Deck-on-Steel Girder Bridge - Phase III”, Report No. UC-CII 01/1, Cincinnati Infrastructure Institute, University of Cincinnati, Ohio.

64. Lew H.S. and Richard T.W., (1978). "Mechanical Properties of Concrete at Early Ages”, ACI J. Proc., 75(10), pp. 533-542.

65. Li J.Z., Su M.B., and Fan L.C., (2002). "Natural Frequency of Railway Girder Bridges under Vehicle Loads", Journal of Bridge Engineering, ASCE, 8(4), 199015 203. 
66. Lipkus S. E., (1993). "NCHRP project 12-28(2)A: bridge management system software", Computing and building engineering: proceedings of the Fifth International Conference (V-ICCCBE), Anaheim, California.

67. Loren L.T., (2003). “Continuous GPS: Pilot Applications-Phase II", final Report F2001-OR-05, FHWA/CA/IR-2003/05, California Department of Transportation, Sacramento, Ca.

68. Masri S.F., Sheng L.H., Caffrey J.P., Nigbor R.L., Wahbeh M., and Abdel-Ghaffar A. (2004), “Application of a Web-Enabled real-time Structural Health Monitoring System for Civil Infrastructure Systems", Smart Materials and Structures, No. 13, pp. 1269-1283.

69. Meng X., Roberts G., Dodson A., Andreotti M., Cosser E., and Meo M., (2004). "Development of a Prototype Remote Structural Health Monitoring System (RSHMS)", $1^{\text {st }}$ FIG International Symposium on Engineering Surveys for Construction Works and Structural Engineering, Nottingham, UK.

70. Moore M.E., Phares B.M., Graybeal B.A., Rolander D.D., and Washer G.A., (2001). "Reliability of Visual Inspection of Highway Bridges", Federal Highway Administration, FHWA-RD-01-020, Washington, DC, June, 2001.

71. Nagayama T., Abe M., Fujino Y., and Ikeda K., (2005). "Structural Identification of Non-proportional Damped Systems and its Applications to a Full Scale Suspension Bridge”, Journal of Structural engineering, ASCE, Vol. 131, No. 10, pp. 1536-1545.

72. Nassif H., Gucunski N., Abu-amra T., Gindy M., and Balic M., (2002). “Analytical Modeling and Instrumentation Planning of The Doremus Avenue Bridge”, Final Report FHWA-NJ-2002-008, New Jersey Department of Transportation, Trenton, NJ. 
73. Nawy E.G., (1997). "Concrete Construction Engineering Handbook", CRC Press, NY, ISBN 0-8493-2666-4, pp.19-16,19-18.

74. Nie J., Fan J., and Cai C., (2004). "Stiffness and Deflection of Steel-Concrete Composite Beams under Negative Bending”, ASCE J. Structural Engineering, Vol. 130, Issue 11, pp. 1842-1851.

75. Nie J., and Cai C., (2003). "Steel-concrete Composite Beams Considering Shear Slip Effects”, ASCE J. Structural Engineering, Vol. 129, No. 4, pp. 495-506.

76. Ockleston A.J., (1955). "Load Tests on a three Story Reinforced Concrete Building in Johannesburg", The Structural Engineer, Vol. 33, pp. 304-322.

77. Park R., (1964). “Ultimate Strength of Rectangular Concrete Slabs under ShortTerm Uniform Loading with Edges Restrained against Lateral Movement", Proceeding of the Institute of Civil Engineering, Vol. 28, pp. 125-150.

78. Prine D.W., and Fish P.E., (1996). "Remote Global Monitoring of the Michigan Street Bridge, Sturgeon Bay, Wisconsin", Infrastructure Technology Institute, Northwestern University, technical report No. 19.

79. PureTechnologies Ltd., "SoundPrint Acoustic Monitoring, Bronx-Whitestone Bridge", (http://www.soundprint.com/pdf/case_study_bronx.pdf last accessed October, 2005).

80. Ren W., Harik I., Blandford G., Lenett M., and Baseheart T., (2004). "Roebling Suspension Bridge. II: Ambient Testing anf Live Load Response", Journal of Bridge Engineering, ASCE, pp. 119-126. 
81. Rizkalla S., Benmokrane B., and Tadros G., (2000) "Structural Health Monitoring Bridges with Fibre Optic Sensors", European COST F3 Conference on System Identification and Structural Health Monitoring, Madrid, Spain, pp. 501-510.

82. Rohrmann R.G., Baessler M., Said S., Schmid W., and Ruecker W.F., (1999) "Structural Causes of Temperature Affected Modal Data of Civil Structures Obtained by Long Time Monitoring", Proceedings of the XVII International Modal Analysis Conference, Kissimmee, Florida, pp. 1-6.

83. Scherer W. T., and Glagola D. M., (1993). "Overview of Markovian models for bridge management systems", proceedings of two parallel conferences: Infrastructure planning and management, June 21-23, Denver, Colorado.

84. Scott, W.B, (1925). "The strength of Steel Joists Embedded in Concrete", Struct. Engr, No. 26, pp. 201-219.

85. Shoukry S.N., Riad M.Y., and William G.W., (2003). "West Virginia Smart Road: Early Age Behavior of Doweled Concrete Pavements", Proceedings of the International Conference on Highway Pavement Data, Analysis and Mechanistic Design Application, Columbus, Ohio.

86. Shoukry S.N., Riad M.Y., and William G.W., (2004). "Field testing of Shokbars", Draft final report, West Virginia Department of Transportation, Division of Highways, Report No. RP\#170.

87. Shoukry S.N., William G.W., and Riad M.Y., (2005). "Early Age Cracks in Concrete Bridge Decks", Draft final report, West Virginia Department of Transportation, Division of Highways, Report No. T646-76-4.56.

88. Sohn H., Farrar C.R., Hunter N.F., and Worden K., (2001) "Structural Health Monitoring Using Statistical Pattern Recognition Techniques", ASME Journal of 
Dynamic Systems, Measurement and Control: Special Issue on Identification of Mechanical Systems, Vol. 123, No. 4, pp. 706-711.

89. Sohn H., Farrar C., Hemez F., Shunk D., Stinemates D., and Nadler B., (2003). “ $A$ Review of Structural Health Monitoring Literature: 1996-2001", Los Alamos National Laboratory, Report No. LA-13976-MS.

90. Sozen M.A., and Siess C.P., (1963). “Investigation of Multiple-Panel Reinforced Concrete Floor Slabs, Design Methods - Their Evolution and Comparison", Proceedings of the American Concrete Institute, No. 60, pp. 999-1020.

91. Sumitro S., Matsui, Y., Kono M., Okamoto T., and Fujii K., (2001). “Long Span Bridge Health Monitoring System in Japan", Proceeding of SPIE the International Society for Optical Engineering, vol. 4337 pp 517-524.

92. Sussman T., and Bathe K.J., (1986). "Studies of Finite Element Procedures - Stress Band Plots and the Evaluation of Finite Element Meshes", Engineering Computations, Vol. 3, No. 3, pp. 178-191.

93. Thompson P. D., (1993). "Pontis bridge management system", Proceedings, Pacific Rim TransTech Conference, July 25-28, Washington State Convention Center, Seattle, Washington, USA, ed. W. P. Carr, 500-506, vol. 2. New York, NY: American Society of Civil Engineers.

94. Thomson W.T., and Dahleh M.D., (1993). "Theory of Vibration with Applications", $5^{\text {th }}$ ed., Prentice-Hall Inc., NJ 07458, ISBN 0-13-65106-X.

95. Thompson P. D., (1993). "Pontis: the maturing of bridge management systems in the USA", Bridge management 2: inspection, maintenance assessment and repair, ed. J. E. Harding, G. A. R. Parke, and M. J. Ryall, 971-978. London: T. Telford. 
96. Thomson P., Marulanda J.C., Marulanda J.A., and Caicedo J., (2001). "Real Time Health Monitoring of Civil Infrastructure Systems in Colombia”, proceeding SPIE the International Society for Optical Engineering, vol. 4337 pp 113-121.

97. Vierk R.K., (1979). "Vibration Analysis", $2^{\text {nd }}$ Ed., Harper Collins Publishers Inc., NY. ISBN 0-7002-2525-0.

98. Vurpillot S., Casanova N., Inaudi D., and Kronenberg P., (1997). “Bridge spatial displacement monitoring with 100 fiber optic deformation sensors", SPIE $5^{\text {th }}$ annual meeting on smart structures and materials, vol. 3043, pp. 51-57, San Diego, USA.

99. William G.W., Shoukry S.N., and Riad M.Y., (2005). "Thermal Stresses in Steel Girder Bridges with Integral Abutments", Journal of Bridge Structures, Vol 1, Issue 2, pp.103-119.

100. Wipf T.J., Phares B.M., Greimann L.F., and Wood D., (2003). "Monitoring and Evaluation of a Plate Girder Bridge", Proceeding of the 2003 Mid-Continent Transportation Research Symposium, Ames, Iowa.

101. Xia Y., Fujino Y., Abe M., Murakoshi J., (2005). "Short-term and Long-term Health Monitoring Experience of a Short Highway Bridge: Case Study”, Bridge Structures, Vol. 1, No.1, pp. 43-53. 


\section{Appendix A1}

\section{TESTING OF CONCRETE MATERIAL}

\section{A1.1 Compression Strength Tests results}

Table A1-1 Compression strength of Pour No. 1

\begin{tabular}{|l|c|c|c|c|c|c|c|}
\hline \multirow{2}{*}{ Age } & \multicolumn{2}{|c|}{ Specimen No. 1 } & \multicolumn{2}{c|}{ Specimen No. 2 } & \multicolumn{2}{c|}{ Specimen No. 3 } & Average \\
\cline { 2 - 7 } & $\begin{array}{c}\text { Load } \\
(l b s)\end{array}$ & $\begin{array}{c}\text { Stress } \\
(P S I)\end{array}$ & $\begin{array}{c}\text { Load } \\
(l b s)\end{array}$ & $\begin{array}{c}\text { Stress } \\
(P S I)\end{array}$ & $\begin{array}{c}\text { Load } \\
(l b s)\end{array}$ & $\begin{array}{c}\text { Stress } \\
(P S I)\end{array}$ & $\begin{array}{c}\text { Stress } \\
(P S I)\end{array}$ \\
\hline Day 1 & 52000 & 1839 & 51000 & 1804 & 48000 & 1698 & 1780 \\
Day 3 & 110000 & 3890 & 106000 & 3749 & 101000 & 3572 & 3737 \\
Day 7 & 145000 & 5128 & 140000 & 4951 & 135000 & 4775 & 4951 \\
Day 14 & 150000 & 5305 & 172000 & 6083 & 148000 & 5234 & 5541 \\
Day 28 & 167500 & 5924 & 174500 & 6172 & 160000 & 5659 & 5918 \\
Day 60 & 193000 & 6825 & 197500 & 6985 & - & - & 6905 \\
\hline
\end{tabular}

Table A1-2 Compression strength of Pour No. 2

\begin{tabular}{|l|c|c|c|c|c|}
\hline \multirow{2}{*}{ Age } & \multicolumn{2}{|c|}{ Specimen No. 1 } & \multicolumn{2}{c|}{ Specimen No. 2 } & Average \\
\cline { 2 - 5 } & $\begin{array}{c}\text { Load } \\
(l b s)\end{array}$ & $\begin{array}{c}\text { Stress } \\
(P S I)\end{array}$ & $\begin{array}{c}\text { Load } \\
(l b s)\end{array}$ & $\begin{array}{c}\text { Stress } \\
(P S I)\end{array}$ & $\begin{array}{c}\text { Stress } \\
(P S I)\end{array}$ \\
\hline \hline Day 1 & 61500 & 2175 & 62000 & 2192 & 2184 \\
Day 3 & 97500 & 3448 & 77500 & 2741 & 3094 \\
Day 7 & 134500 & 4757 & 121500 & 4297 & 4527 \\
Day 14 & 151000 & 5340 & 130500 & 4615 & 4978 \\
Day 21 & 145000 & 5128 & 140000 & 4951 & 5040 \\
Day 60 & 144500 & 5110 & 147000 & 5199 & 5154 \\
\hline
\end{tabular}

Table A1-3 Compression strength of Pour No. 3

\begin{tabular}{|l|c|c|c|c|c|}
\hline \multirow{2}{*}{ Age } & \multicolumn{2}{|c|}{ Specimen No. 1 } & \multicolumn{2}{c|}{ Specimen No. 2 } & Average \\
\cline { 2 - 5 } & $\begin{array}{c}\text { Load } \\
(l b s)\end{array}$ & $\begin{array}{c}\text { Stress } \\
(P S I)\end{array}$ & $\begin{array}{c}\text { Load } \\
(l b s)\end{array}$ & $\begin{array}{c}\text { Stress } \\
(P S I)\end{array}$ & $\begin{array}{c}\text { Stress } \\
(P S I)\end{array}$ \\
\hline Day 1 & 61000 & 2157 & 84500 & 2988 & 2573 \\
Day 3 & 116500 & 4120 & 126500 & 4474 & 4297 \\
Day 7 & 127000 & 4491 & 123000 & 4350 & 4421 \\
Day 14 & 131000 & 4633 & 158000 & 5588 & 5110 \\
Day 21 & 132500 & 4686 & 136000 & 4810 & 4748 \\
\hline
\end{tabular}




\section{A1.2 Tensile Strength Tests Results}

Table A1-4 Tensile Strength of Pour No. 1

\begin{tabular}{|l|c|c|c|c|c|c|c|}
\hline \multirow{2}{*}{ Age } & \multicolumn{2}{|c|}{ Specimen No. 1 } & \multicolumn{2}{c|}{ Specimen No. 2 } & \multicolumn{2}{c|}{ Specimen No. 3 } & Average \\
\cline { 2 - 7 } & $\begin{array}{c}\text { Load } \\
(l b s)\end{array}$ & $\begin{array}{c}\text { Stress } \\
(P S I)\end{array}$ & $\begin{array}{c}\text { Load } \\
(l b s)\end{array}$ & $\begin{array}{c}\text { Stress } \\
(P S I)\end{array}$ & $\begin{array}{c}\text { Load } \\
(l b s)\end{array}$ & $\begin{array}{c}\text { Stress } \\
(P S I)\end{array}$ & $\begin{array}{c}\text { Stress } \\
(P S I)\end{array}$ \\
\hline Day 1 & 10100 & 201 & 12000 & 239 & 13000 & 259 & 233 \\
Day 3 & 25000 & 497 & 22000 & 438 & 21000 & 418 & 451 \\
Day 7 & 27000 & 537 & 22000 & 438 & 28000 & 557 & 511 \\
Day 14 & 23600 & 470 & 26500 & 527 & 26000 & 517 & 505 \\
Day 28 & 29600 & 589 & 29000 & 577 & 25500 & 507 & 558 \\
Day 60 & 25900 & 515 & 23500 & 467 & - & - & 491 \\
\hline
\end{tabular}

Table A1-5 Tensile Strength of Pour No. 2

\begin{tabular}{|l|c|c|c|c|c|}
\hline \multirow{2}{*}{ Age } & \multicolumn{2}{|c|}{ Specimen No. 1 } & \multicolumn{2}{c|}{ Specimen No. 2 } & Average \\
\cline { 2 - 5 } & $\begin{array}{c}\text { Load } \\
(l b s)\end{array}$ & $\begin{array}{c}\text { Stress } \\
(P S I)\end{array}$ & $\begin{array}{c}\text { Load } \\
(l b s)\end{array}$ & $\begin{array}{c}\text { Stress } \\
(P S I)\end{array}$ & $\begin{array}{c}\text { Stress } \\
(P S I)\end{array}$ \\
\hline Day 1 & 16600 & 330 & 14600 & 290 & 310 \\
Day 3 & 19600 & 389 & 228 & 453 & 421 \\
Day 7 & 23100 & 459 & 24600 & 489 & 474 \\
Day 14 & 25000 & 497 & 26500 & 527 & 512 \\
Day 21 & 25000 & 497 & 25100 & 499 & 498 \\
Day 60 & 32900 & 654 & 29400 & 584 & 619 \\
\hline
\end{tabular}

Table A1-6 Tensile Strength of Pour No. 3

\begin{tabular}{|l|c|c|c|c|c|}
\hline \multirow{2}{*}{ Age } & \multicolumn{2}{|c|}{ Specimen No. 1 } & \multicolumn{2}{c|}{ Specimen No. 2 } & Average \\
\cline { 2 - 5 } & $\begin{array}{c}\text { Load } \\
(l b s)\end{array}$ & $\begin{array}{c}\text { Stress } \\
(P S I)\end{array}$ & $\begin{array}{c}\text { Load } \\
(l b s)\end{array}$ & $\begin{array}{c}\text { Stress } \\
(P S I)\end{array}$ & $\begin{array}{c}\text { Stress } \\
(P S I)\end{array}$ \\
\hline Day 1 & 13700 & 272 & 11400 & 226 & 249 \\
Day 3 & 15400 & 306 & 17200 & 342 & 324 \\
Day 7 & 22000 & 437 & - & - & 437 \\
\hline
\end{tabular}




\section{A1.3 Modulus of Elasticity \& Poisson's Ratio Tests Results}

Table A1-7 Modulus of Elasticity of Pour No. 1 at Day 1

\begin{tabular}{|c|c|c|c|c|c|c|c|c|c|}
\hline & $\begin{array}{l}\text { Load } \\
\text { (lbs) } \\
\end{array}$ & $\begin{array}{c}\text { Vertical } \\
\text { Strain } \\
(\mu \varepsilon) \\
\end{array}$ & $\begin{array}{c}\text { Horizontal } \\
\text { Strain } \\
(\mu \varepsilon) \\
\end{array}$ & $\begin{array}{c}\text { Temp } \\
\left({ }^{\circ} \mathrm{C}\right) \\
\end{array}$ & $\begin{array}{c}\text { Stresses } \\
(P S I) \\
\end{array}$ & $\begin{array}{c}\text { Differential } \\
\text { Vertical } \\
\text { Strain }(\mu \varepsilon) \\
\end{array}$ & $\begin{array}{l}\text { Differential } \\
\text { Horizontal } \\
\text { Strain }(\mu \varepsilon) \\
\end{array}$ & $\begin{array}{c}\text { Stress/Strain } \\
(P S I) \\
\end{array}$ & $\begin{array}{c}\text { Hor/Vert. } \\
\text { Strain } \\
\text { ratio } \\
\end{array}$ \\
\hline \multirow{12}{*}{ 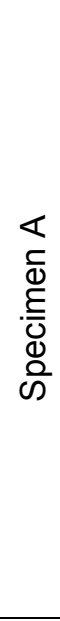 } & 0 & 2207.14 & 2773.01 & 21.9 & 0 & 0.0 & 0 & - & - \\
\hline & 1010 & 2197.01 & 2775.26 & 21.7 & 35.721 & -10.1 & 2.25 & 3526305 & 0.222 \\
\hline & 2000 & 2185.59 & 2777.78 & 21.7 & 70.735 & -21.5 & 4.77 & 3066035 & 0.220 \\
\hline & 2990 & 2174.79 & 2779.64 & 21.6 & 105.749 & -32.3 & 6.63 & 3242048 & 0.172 \\
\hline & 3990 & 2163.57 & 2782.02 & 21.5 & 141.117 & -43.6 & 9.01 & 3152210 & 0.212 \\
\hline & 5010 & 2152.46 & 2783.69 & 21.5 & 177.192 & -54.7 & 10.68 & 3247088 & 0.150 \\
\hline & 6000 & 2141.14 & 2786.16 & 21.5 & 212.206 & -66.0 & 13.15 & 3093120 & 0.218 \\
\hline & 5490 & 2145.39 & 2784.91 & 21.4 & 194.169 & -61.8 & 11.9 & 4244135 & 0.294 \\
\hline & 4520 & 2154.94 & 2783.29 & 21.4 & 159.862 & -52.2 & 10.28 & 3592331 & 0.169 \\
\hline & 3530 & 2165.3 & 2781.22 & 21.4 & 124.848 & -41.8 & 8.21 & 3379741 & 0.199 \\
\hline & 2520 & 2175.52 & 2779.81 & 21.3 & 89.1268 & -31.6 & 6.8 & 3495252 & 0.137 \\
\hline & 1540 & 2187.11 & 2777.52 & 21.3 & 54.466 & -20.0 & 4.51 & 2990547 & 0.197 \\
\hline \multirow{12}{*}{$\begin{array}{l}\infty \\
\frac{c}{\Phi} \\
. \frac{E}{0} \\
\Phi \\
\stackrel{0}{0}\end{array}$} & 0 & 2658.01 & 2667.85 & 21.2 & 0 & 0 & 0 & - & - \\
\hline & 1010 & 2648.66 & 2669.87 & 21.1 & 35.721 & -9.35 & 2.02 & 3820478 & 0.216 \\
\hline & 2010 & 2638.21 & 2672.41 & 21 & 71.089 & -19.8 & 4.56 & 3384478 & 0.243 \\
\hline & 3000 & 2628.3 & 2674.35 & 21 & 106.103 & -29.71 & 6.5 & 3533211 & 0.195 \\
\hline & 4000 & 2617.52 & 2676.62 & 21 & 141.471 & -40.49 & 8.77 & 3280872 & 0.210 \\
\hline & 5030 & 2606.25 & 2678.52 & 20.9 & 177.9 & -51.76 & 10.67 & 3232372 & 0.168 \\
\hline & 6010 & 2596.02 & 2680.76 & 21 & 212.560 & -61.99 & 12.91 & 3388117 & 0.218 \\
\hline & 5500 & 2600.75 & 2679.45 & 21 & 194.522 & -57.26 & 11.6 & 3813441 & 0.276 \\
\hline & 4500 & 2609.45 & 2678.06 & 20.9 & 159.155 & -48.56 & 10.21 & 4065264 & 0.159 \\
\hline & 3510 & 2619.94 & 2675.62 & 20.9 & 124.141 & -38.07 & 7.77 & 3337857 & 0.232 \\
\hline & 2520 & 2629.85 & 2674.13 & 20.9 & 89.126 & -28.16 & 6.28 & 3533211 & 0.150 \\
\hline & 1520 & 2640.76 & 2671.58 & 20.9 & 53.759 & -17.25 & 3.73 & 3241778 & 0.233 \\
\hline
\end{tabular}


Table A1-8 Modulus of Elasticity of Pour No. 1 at Day 2

\begin{tabular}{|c|c|c|c|c|c|c|c|c|c|}
\hline & $\begin{array}{l}\text { Load } \\
\text { (lbs) } \\
\end{array}$ & $\begin{array}{c}\text { Vertical } \\
\text { Strain } \\
(\mu \varepsilon) \\
\end{array}$ & $\begin{array}{c}\text { Horizontal } \\
\text { Strain } \\
(\mu \varepsilon) \\
\end{array}$ & $\begin{array}{c}\text { Temp } \\
\left({ }^{\circ} \mathrm{C}\right) \\
\end{array}$ & $\begin{array}{c}\text { Stresses } \\
(P S I) \\
\end{array}$ & $\begin{array}{c}\text { Differential } \\
\text { Vertical } \\
\text { Strain }(\mu \varepsilon) \\
\end{array}$ & $\begin{array}{l}\text { Differential } \\
\text { Horizontal } \\
\text { Strain }(\mu \varepsilon) \\
\end{array}$ & $\begin{array}{c}\text { Stress/Strain } \\
(P S I) \\
\end{array}$ & $\begin{array}{c}\text { Hor/Vert. } \\
\text { Strain } \\
\text { ratio } \\
\end{array}$ \\
\hline \multirow{19}{*}{ 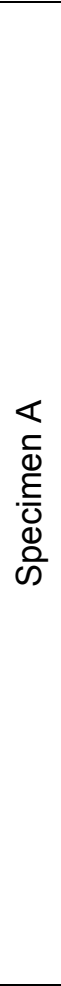 } & 0 & 2565.3 & 2538.5 & 21.2 & 0 & 0 & 0 & - & - \\
\hline & 700 & 2560 & 2539.5 & 21.2 & -24.787 & -5.3 & 1 & 4676917 & 0.188 \\
\hline & 1281 & 2555.8 & 2540.6 & 21 & -45.332 & -9.5 & 2.1 & 4891602 & 0.261 \\
\hline & 1748 & 2552.9 & 2541.6 & 20.9 & -61.857 & -12.4 & 3.1 & 5698313 & 0.344 \\
\hline & 2247 & 2550.2 & 2542.6 & 20.9 & -79.499 & -15.1 & 4.1 & 6533951 & 0.370 \\
\hline & 3037 & 2544.7 & 2544.4 & 20.8 & -107.413 & -20.6 & 5.9 & 5075279 & 0.327 \\
\hline & 3750 & 2539.9 & 2545.7 & 20.7 & -132.647 & -25.4 & 7.2 & 5257143 & 0.270 \\
\hline & 4463 & 2535.4 & 2547.2 & 20.6 & -157.882 & -29.9 & 8.7 & 5607619 & 0.333 \\
\hline & 5227 & 2530.8 & 2548.7 & 20.5 & -184.903 & -34.5 & 10.2 & 5874083 & 0.326 \\
\hline & 5739 & 2528.5 & 2549.4 & 20.4 & -202.991 & -36.8 & 10.9 & 7864475 & 0.304 \\
\hline & 5973 & 2526.5 & 2550.3 & 20.3 & -211.253 & -38.8 & 11.8 & 4131277 & 0.45 \\
\hline & 5436 & 2529.9 & 2549.5 & 20.2 & -192.272 & -35.4 & 11 & 5582806 & 0.235 \\
\hline & 4716 & 2534.3 & 2548.5 & 20.2 & -166.814 & -31 & 10 & 5785818 & 0.227 \\
\hline & 3908 & 2538.4 & 2547.5 & 20.2 & -138.23 & -26.9 & 9 & 6971700 & 0.243 \\
\hline & 3144 & 2544.6 & 2546.2 & 20.1 & -111.21 & -20.7 & 7.7 & 4358191 & 0.209 \\
\hline & 2456 & 2549.5 & 2545.1 & 20 & -86.868 & -15.8 & 6.6 & 4967558 & 0.224 \\
\hline & 1824 & 2554.4 & 2544 & 20 & -64.537 & -10.9 & 5.5 & 4557393 & 0.224 \\
\hline & 1357 & 2558.5 & 2543.3 & 20 & -48.012 & -6.8 & 4.8 & 4030514 & 0.170 \\
\hline & 675 & 2562.1 & 2542.8 & 19.9 & -23.894 & -3.2 & 4.3 & 6699368 & 0.138 \\
\hline \multirow{14}{*}{$\begin{array}{l}\infty \\
\frac{1}{\Phi} \\
\frac{E}{0} \\
\Phi \\
\text { ஸे }\end{array}$} & 0 & 2051.2 & 2179.5 & 21.4 & 0 & 0 & 0 & - & - \\
\hline & 549 & 2045.3 & 2180.4 & 21.3 & -19.428 & -5.9 & -0.9 & 3292910 & 0.153 \\
\hline & 1900 & 2036.2 & 2182.1 & 21.3 & -67.217 & -15 & -2.6 & 5251519 & 0.186 \\
\hline & 3169 & 2027.3 & 2183.8 & 21.3 & -112.103 & -23.9 & -4.3 & 5043344 & 0.191 \\
\hline & 4217 & 2018.3 & 2185.3 & 21.3 & -149.173 & -32.9 & -5.8 & 4118871 & 0.166 \\
\hline & 5007 & 2012.6 & 2187 & 21.3 & -177.087 & -38.6 & -7.5 & 4897199 & 0.298 \\
\hline & 5960 & 2006.6 & 2188.2 & 21.3 & -210.807 & -44.6 & -8.7 & 5620025 & 0.2 \\
\hline & 4602 & 2016.4 & 2186.7 & 21.3 & -162.795 & -34.8 & -7.2 & 4899197 & 0.153 \\
\hline & 3441 & 2023.9 & 2185.6 & 21.3 & -121.705 & -27.3 & -6.1 & 5478594 & 0.146 \\
\hline & 2430 & 2032.3 & 2184.6 & 21.3 & -85.975 & -18.9 & -5.1 & 4253567 & 0.119 \\
\hline & 1344 & 2038.4 & 2183.8 & 21.3 & -47.565 & -12.8 & -4.3 & 6296673 & 0.131 \\
\hline & 549 & 2044 & 2183.2 & 21.3 & -19.428 & -7.2 & -3.7 & 5024526 & 0.107 \\
\hline & 0 & 2049.6 & 2182.6 & 21.3 & 0 & -1.6 & -3.1 & 3469315 & 0.107 \\
\hline & 0 & 2051.2 & 2179.5 & 21.4 & 0 & 0 & 0 & - & - \\
\hline
\end{tabular}


Table A1-9 Modulus of Elasticity of Pour No. 1 at Day 3

\begin{tabular}{|c|c|c|c|c|c|c|c|c|c|}
\hline & $\begin{array}{l}\text { Load } \\
\text { (Ibs) } \\
\end{array}$ & $\begin{array}{c}\text { Vertical } \\
\text { Strain } \\
(\mu \varepsilon) \\
\end{array}$ & $\begin{array}{c}\text { Horizontal } \\
\text { Strain } \\
(\mu \varepsilon) \\
\end{array}$ & $\begin{array}{c}\text { Temp } \\
\left({ }^{\circ} \mathrm{C}\right) \\
\end{array}$ & $\begin{array}{c}\text { Stresses } \\
(P S I) \\
\end{array}$ & $\begin{array}{c}\text { Differential } \\
\text { Vertical } \\
\text { Strain }(\mu \varepsilon) \\
\end{array}$ & $\begin{array}{c}\text { Differential } \\
\text { Horizontal } \\
\text { Strain }(\mu \varepsilon) \\
\end{array}$ & $\begin{array}{c}\text { Stress/Strain } \\
(P S I) \\
\end{array}$ & $\begin{array}{c}\text { Hor/Vert. } \\
\text { Strain } \\
\text { ratio } \\
\end{array}$ \\
\hline \multirow{17}{*}{ 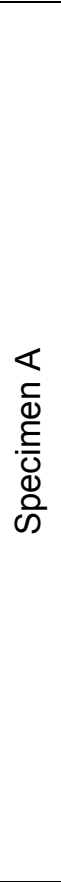 } & 0 & 2553.7 & 2525.5 & 21.8 & 0 & 0 & 0 & - & - \\
\hline & 902 & 2549.3 & 2526 & 21.8 & -31.933 & -4.4 & 0.5 & 7257648 & 0.113 \\
\hline & 1534 & 2545.8 & 2526.7 & 21.8 & -54.264 & -7.9 & 1.2 & 6380350 & 0.2 \\
\hline & 2304 & 2541.6 & 2527.8 & 21.6 & -81.509 & -12.1 & 2.3 & 6486689 & 0.261 \\
\hline & 2992 & 2537.5 & 2528.9 & 21.6 & -105.85 & -16.2 & 3.4 & 5936838 & 0.268 \\
\hline & 3801 & 2532.6 & 2530 & 21.5 & -134.434 & -21.1 & 4.5 & 5833463 & 0.224 \\
\hline & 4666 & 2526 & 2532.4 & 21.4 & -165.028 & -27.7 & 6.9 & 4635421 & 0.363 \\
\hline & 5411 & 2520.3 & 2534.3 & 21.3 & -191.379 & -33.4 & 8.8 & 4622956 & 0.333 \\
\hline & 6074 & 2513.9 & 2536.1 & 21.2 & -214.826 & -39.8 & 10.6 & 3663717 & 0.281 \\
\hline & 5423 & 2516.5 & 2535.6 & 21.1 & -191.825 & -37.2 & 10.1 & 8846601 & 0.192 \\
\hline & 4356 & 2523.3 & 2534.4 & 21 & -154.085 & -30.4 & 8.9 & 5549966 & 0.176 \\
\hline & 3832 & 2529.2 & 2533 & 20.9 & -135.551 & -24.5 & 7.5 & 3141511 & 0.237 \\
\hline & 3093 & 2534.6 & 2532.1 & 20.9 & -109.423 & -19.1 & 6.6 & 4838432 & 0.166 \\
\hline & 2197 & 2541.8 & 2530.5 & 20.8 & -77.712 & -11.9 & 5 & 4404214 & 0.222 \\
\hline & 1370 & 2546.5 & 2529.8 & 20.7 & -48.458 & -7.2 & 4.3 & 6224235 & 0.148 \\
\hline & 631 & 2550.2 & 2529.2 & 20.6 & -22.331 & -3.5 & 3.7 & 7061496 & 0.162 \\
\hline & 31 & 2554.5 & 2528.8 & 20.6 & -1.116 & 0.8 & 3.3 & 4933643 & 0.093 \\
\hline \multirow{14}{*}{ 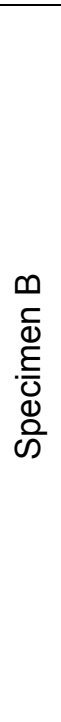 } & 0 & 2044.9 & 2161.1 & 21.7 & 0 & 0 & 0 & - & - \\
\hline & 763 & 2037.9 & 2165.8 & 21.6 & -27.020 & -7 & 4.7 & 3860112 & 0.671 \\
\hline & 1559 & 2033.1 & 2166.6 & 21.5 & -55.158 & -11.8 & 5.5 & 5861947 & 0.166 \\
\hline & 2462 & 2027.2 & 2167.3 & 21.4 & -87.091 & -17.7 & 6.2 & 5412484 & 0.118 \\
\hline & 3441 & 2019.3 & 2168.7 & 21.4 & -121.705 & -25.6 & 7.6 & 4381443 & 0.177 \\
\hline & 4375 & 2012.4 & 2169.8 & 21.3 & -154.755 & -32.5 & 8.7 & 4789886 & 0.159 \\
\hline & 5240 & 2005.5 & 2171.2 & 21.2 & -185.349 & -39.4 & 10.1 & 4433881 & 0.202 \\
\hline & 6244 & 1997.6 & 2172.5 & 21.1 & -220.856 & -47.3 & 11.4 & 4494513 & 0.164 \\
\hline & 5183 & 2004 & 2171.8 & 21 & -183.339 & -40.9 & 10.7 & 5861947 & 0.109 \\
\hline & 4243 & 2011.5 & 2170.5 & 20.9 & -150.066 & -33.4 & 9.4 & 4436470 & 0.173 \\
\hline & 3314 & 2019.8 & 2169.4 & 20.9 & -117.239 & -25.1 & 8.3 & 3955048 & 0.132 \\
\hline & 1913 & 2026.9 & 2168.5 & 20.8 & -67.663 & -18 & 7.4 & 6982440 & 0.126 \\
\hline & 833 & 2033.9 & 2167.9 & 20.8 & -29.477 & -11 & 6.8 & 5455199 & 0.085 \\
\hline & 31 & 2041.5 & 2167.1 & 20.7 & -1.116 & -3.4 & 6 & 3731665 & 0.105 \\
\hline
\end{tabular}


Table A1-10 Modulus of Elasticity of Pour No. 1 at Day 7

\begin{tabular}{|c|c|c|c|c|c|c|c|c|c|}
\hline & $\begin{array}{l}\text { Load } \\
\text { (lbs) } \\
\end{array}$ & $\begin{array}{c}\text { Vertical } \\
\text { Strain } \\
(\mu \varepsilon) \\
\end{array}$ & $\begin{array}{c}\text { Horizontal } \\
\text { Strain } \\
(\mu \varepsilon) \\
\end{array}$ & $\begin{array}{c}\text { Temp } \\
\left({ }^{\circ} \mathrm{C}\right) \\
\end{array}$ & $\begin{array}{c}\text { Stresses } \\
(P S I) \\
\end{array}$ & $\begin{array}{c}\text { Differential } \\
\text { Vertical } \\
\text { Strain }(\mu \varepsilon) \\
\end{array}$ & $\begin{array}{l}\text { Differential } \\
\text { Horizontal } \\
\text { Strain }(\mu \varepsilon) \\
\end{array}$ & $\begin{array}{c}\text { Stress/Strain } \\
(P S I) \\
\end{array}$ & $\begin{array}{c}\text { Hor/Vert } \\
\text { Strain } \\
\text { ratio } \\
\end{array}$ \\
\hline \multirow{16}{*}{ 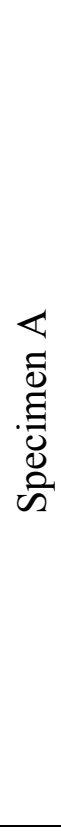 } & 0 & 2562.2 & 2524.83 & 20 & 0.000 & 0 & 0 & - & - \\
\hline & 518 & 2559.8 & 2526.7 & 19.7 & -18.312 & -2.4 & 1.2 & 7629835 & 0.500 \\
\hline & 1515 & 2555.1 & 2528.1 & 19.7 & -53.595 & -7.1 & 2.6 & 7507093 & 0.298 \\
\hline & 2191 & 2550.7 & 2529.7 & 19.7 & -77.489 & -11.5 & 4.2 & 5430548 & 0.364 \\
\hline & 2955 & 2545.5 & 2531.2 & 19.7 & -104.510 & -16.7 & 5.7 & 5196304 & 0.288 \\
\hline & 3757 & 2539.2 & 2533.2 & 19.7 & -132.871 & -23 & 7.7 & 4501692 & 0.317 \\
\hline & 4382 & 2532.7 & 2534.8 & 19.3 & -154.979 & -29.5 & 9.3 & 3401217 & 0.246 \\
\hline & 4950 & 2525.2 & 2537.2 & 19.3 & -175.077 & -37 & 11.7 & 2679747 & 0.320 \\
\hline & 6282 & 2517.4 & 2539.6 & 19.3 & -222.196 & -44.8 & 14.1 & 6040883 & 0.308 \\
\hline & 5550 & 2519.4 & 2539 & 19.2 & -196.291 & -42.8 & 13.5 & 12952111 & 0.300 \\
\hline & 4521 & 2526.1 & 2537 & 19.2 & -159.892 & -36.1 & 11.5 & 5432821 & 0.299 \\
\hline & 3738 & 2534.3 & 2534.5 & 19.2 & -132.201 & -27.9 & 9 & 3376917 & 0.305 \\
\hline & 2759 & 2542.6 & 2532.4 & 19.2 & -97.588 & -19.6 & 6.9 & 4170289 & 0.253 \\
\hline & 1787 & 2551.9 & 2530.3 & 19.2 & -63.197 & -10.3 & 4.8 & 3697859 & 0.226 \\
\hline & 644 & 2558.2 & 2528.8 & 19.2 & -22.778 & -4 & 3.3 & 6415797 & 0.238 \\
\hline & 38 & 2562.4 & 2527.5 & 19 & -1.340 & 0.2 & 2 & 5104280 & 0.310 \\
\hline \multirow{13}{*}{ 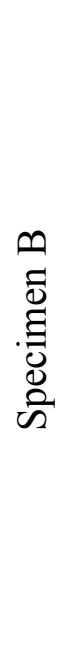 } & 0 & 2058.5 & 2162.6 & 20.5 & 0.000 & 0 & 0 & - & - \\
\hline & 821 & 2052.9 & 2163.4 & 20.3 & -29.031 & -5.6 & 0.8 & 5184035 & 0.143 \\
\hline & 1938 & 2046.9 & 2164.4 & 20.1 & -68.557 & -11.6 & 1.8 & 6587712 & 0.167 \\
\hline & 3492 & 2038 & 2166 & 20 & -123.492 & -20.5 & 3.4 & 6172451 & 0.180 \\
\hline & 4666 & 2031.3 & 2167.4 & 19.9 & -165.028 & -27.2 & 4.8 & 6199415 & 0.209 \\
\hline & 5544 & 2025.5 & 2168.4 & 19.8 & -196.068 & -33 & 5.8 & 5351794 & 0.172 \\
\hline & 6491 & 2020.2 & 2169.9 & 19.7 & -229.565 & -38.3 & 7.3 & 6320158 & 0.283 \\
\hline & 5304 & 2026.5 & 2168.7 & 19.6 & -187.582 & -32 & 6.1 & 6663921 & 0.190 \\
\hline & 4155 & 2033 & 2168 & 19.5 & -146.939 & -25.5 & 5.4 & 6252743 & 0.108 \\
\hline & 2810 & 2041.3 & 2166.8 & 19.4 & -99.374 & -17.2 & 4.2 & 5730784 & 0.145 \\
\hline & 1560 & 2047.8 & 2166.1 & 19.4 & -55.158 & -10.7 & 3.5 & 6802435 & 0.108 \\
\hline & 701 & 2053.3 & 2165.4 & 19.4 & -24.788 & -5.2 & 2.8 & 5521903 & 0.127 \\
\hline & 0 & 2058.1 & 2164.9 & 19.3 & 0.000 & -0.4 & 2.3 & 5164096 & 0.104 \\
\hline
\end{tabular}


Table A1-11 Modulus of Elasticity of Pour No. 1 at Day 14

\begin{tabular}{|c|c|c|c|c|c|c|c|c|c|}
\hline & $\begin{array}{l}\text { Load } \\
\text { (lbs) }\end{array}$ & $\begin{array}{l}\text { Vertical } \\
\text { Strain } \\
(\mu \varepsilon)\end{array}$ & $\begin{array}{c}\text { Horizontal } \\
\text { Strain } \\
(\mu \varepsilon)\end{array}$ & $\begin{array}{c}\text { Temp } \\
\left({ }^{\circ} \mathrm{C}\right) \\
\end{array}$ & $\begin{array}{c}\text { Stresses } \\
(P S I)\end{array}$ & $\begin{array}{l}\text { Differential } \\
\text { Vertical } \\
\text { Strain }(\mu \varepsilon)\end{array}$ & $\begin{array}{c}\text { Differential } \\
\text { Horizontal } \\
\text { Strain }(\mu \varepsilon)\end{array}$ & $\begin{array}{c}\text { Stress/Strain } \\
(P S I) \\
\end{array}$ & $\begin{array}{c}\text { Hor/Vert } \\
\text { Strain } \\
\text { ratio } \\
\end{array}$ \\
\hline \multirow{21}{*}{ 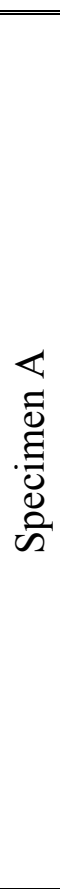 } & $\overline{0}$ & 252567.8 & 2528.1 & 21.2 & 0.000 & $\overline{0}$ & $\overline{0}$ & $\overline{-1}$ & $\overline{-1}$ \\
\hline & 750 & 2565 & 2528.9 & 21.1 & -26.526 & -2.8 & 0.8 & 9473517 & 0.286 \\
\hline & 1410 & 2561.28 & 2529.8 & 21 & -49.869 & -6.5 & 1.7 & 6274931 & 0.242 \\
\hline & 2170 & 2557.67 & 2530.7 & 20.8 & -76.748 & -10.1 & 2.6 & 7445852 & 0.249 \\
\hline & 3020 & 2552.8 & 2532.2 & 20.8 & -106.811 & -15 & 4.1 & 6173024 & 0.308 \\
\hline & 4300 & 2546.75 & 2534.3 & 20.8 & -152.082 & -21.1 & 6.2 & 7482773 & 0.347 \\
\hline & 5470 & 2540.3 & 2536.3 & 20.7 & -193.462 & -27.5 & 8.2 & 6415554 & 0.310 \\
\hline & 6390 & 2535.4 & 2537.4 & 20.6 & -226.000 & -32.4 & 9.3 & 6640484 & 0.224 \\
\hline & 7250 & 2531 & 2539.5 & 20.5 & -256.417 & -36.8 & 11.4 & 6912796 & 0.477 \\
\hline & 8280 & 2525.1 & 2540.9 & 20.5 & -292.845 & -42.7 & 12.8 & 6174378 & 0.237 \\
\hline & 9140 & 2519.84 & 2542.7 & 20.4 & -323.262 & -48 & 14.6 & 5782567 & 0.342 \\
\hline & 9940 & 2515.6 & 2543.8 & 20.3 & -351.556 & -52.2 & 15.7 & 6673169 & 0.259 \\
\hline & 9170 & 2519.3 & 2543.1 & 20.3 & -324.323 & -48.5 & 15 & 7360325 & 0.189 \\
\hline & 8060 & 2525.8 & 2540.9 & 20.3 & -285.064 & -42 & 12.8 & 6039731 & 0.338 \\
\hline & 7020 & 2531.4 & 2539.8 & 20.2 & -248.282 & -36.4 & 11.7 & 6568305 & 0.196 \\
\hline & 5970 & 2537.5 & 2537.7 & 20.2 & -211.146 & -30.3 & 9.6 & 6087899 & 0.344 \\
\hline & 4950 & 2542.9 & 2536.3 & 20.2 & -175.071 & -24.9 & 8.2 & 6680584 & 0.259 \\
\hline & 3980 & 2548.7 & 2534.6 & 20.1 & -140.764 & -19.1 & 6.5 & 5914959 & 0.293 \\
\hline & 2890 & 2554.4 & 2533.4 & 20.1 & -102.213 & -13.4 & 5.3 & 6763315 & 0.211 \\
\hline & 1390 & 2562.8 & 2531.1 & 20.1 & -49.161 & -5 & 3 & 6315678 & 0.274 \\
\hline & 20 & 2570.2 & 2530 & 20 & -0.707 & 2.4 & 1.9 & 6547822 & 0.149 \\
\hline \multirow{20}{*}{ 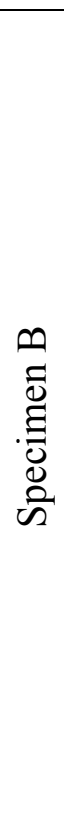 } & 0 & 2069.8 & 2168.6 & 21.7 & 0.000 & 0 & 0 & - & - \\
\hline & 970 & 2061.5 & 2169.65 & 21.6 & -34.307 & -8.3 & 1.05 & 4133345 & 0.127 \\
\hline & 1980 & 2053.2 & 2171.3 & 21.5 & -70.028 & -16.6 & 2.7 & 4303792 & 0.199 \\
\hline & 2830 & 2045.4 & 2172.5 & 21.4 & -100.091 & -24.4 & 3.9 & 3854183 & 0.154 \\
\hline & 3960 & 2035.9 & 2174.5 & 21.3 & -140.056 & -33.9 & 5.9 & 4206906 & 0.211 \\
\hline & 5050 & 2027.2 & 2175.9 & 21.3 & -178.607 & -42.6 & 7.3 & 4431138 & 0.161 \\
\hline & 6010 & 2018.8 & 2178 & 21.2 & -212.560 & -51 & 9.4 & 4042034 & 0.250 \\
\hline & 7050 & 2010.4 & 2179.6 & 21.2 & -249.343 & -59.4 & 11 & 4378870 & 0.190 \\
\hline & 8330 & 1999.3 & 2182.3 & 21.1 & -294.614 & -70.5 & 13.7 & 4078448 & 0.243 \\
\hline & 9100 & 1992.9 & 2183.6 & 21.1 & -321.847 & -76.9 & 15 & 4255188 & 0.203 \\
\hline & 10040 & 1984.7 & 2185.5 & 21.1 & -355.093 & -85.1 & 16.9 & 4054357 & 0.232 \\
\hline & 9380 & 1989.8 & 2184.1 & 21 & -331.750 & -80 & 15.5 & 4577009 & 0.275 \\
\hline & 8050 & 2000.2 & 2182 & 21 & -284.711 & -69.6 & 13.4 & 4522997 & 0.202 \\
\hline & 6920 & 2009.8 & 2179.8 & 21 & -244.745 & -60 & 11.2 & 4163084 & 0.229 \\
\hline & 5520 & 2021.2 & 2177.7 & 21 & -195.230 & -48.6 & 9.1 & 4343413 & 0.184 \\
\hline & 4030 & 2034.2 & 2175.1 & 20.9 & -142.532 & -35.6 & 6.5 & 4053693 & 0.200 \\
\hline & 3110 & 2041.9 & 2173.7 & 20.9 & -109.994 & -27.9 & 5.1 & 4225763 & 0.182 \\
\hline & 2120 & 2050.6 & 2172 & 20.9 & -74.980 & -19.2 & 3.4 & 4024611 & 0.195 \\
\hline & 1070 & 2059.4 & 2170.9 & 20.8 & -37.844 & -10.4 & 2.3 & 4220021 & 0.125 \\
\hline & 0 & 2068.5 & 2169.2 & 20.8 & 0.000 & -1.3 & 0.6 & 4158631 & 0.187 \\
\hline
\end{tabular}


Table A1-12 Modulus of Elasticity of Pour No. 1 at Day 21

\begin{tabular}{|c|c|c|c|c|c|c|c|c|c|}
\hline & $\begin{array}{l}\text { Load } \\
\text { (lbs) } \\
\end{array}$ & $\begin{array}{c}\text { Vertical } \\
\text { Strain } \\
(\mu \varepsilon)\end{array}$ & $\begin{array}{c}\text { Horizontal } \\
\text { Strain } \\
(\mu \varepsilon)\end{array}$ & $\begin{array}{c}\text { Temp } \\
\left({ }^{\circ} \mathrm{C}\right) \\
\end{array}$ & $\begin{array}{c}\text { Stresses } \\
(P S I) \\
\end{array}$ & $\begin{array}{c}\text { Differential } \\
\text { Vertical } \\
\text { Strain }(\mu \varepsilon) \\
\end{array}$ & $\begin{array}{l}\text { Differential } \\
\text { Horizontal } \\
\text { Strain }(\mu \varepsilon) \\
\end{array}$ & $\begin{array}{c}\text { Stress/Strain } \\
(P S I) \\
\end{array}$ & $\begin{array}{c}\text { Hor/Vert. } \\
\text { Strain } \\
\text { ratio } \\
\end{array}$ \\
\hline \multirow{20}{*}{ 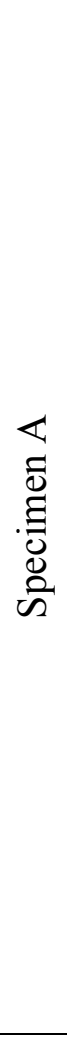 } & 0 & 2591.9 & 2550.7 & 18.6 & 0.000 & 0 & 0 & - & - \\
\hline & 860 & 2587.7 & 2551.6 & 18.5 & -30.416 & -4.2 & 0.9 & 7241977 & 0.214 \\
\hline & 2030 & 2582.6 & 2553.41 & 18.5 & -71.797 & -9.3 & 2.71 & 8113788 & 0.355 \\
\hline & 3060 & 2577.6 & 2554.6 & 18.5 & -108.225 & -14.3 & 3.9 & 7285766 & 0.238 \\
\hline & 4360 & 2570.8 & 2556.9 & 18.4 & -154.204 & -21.1 & 6.2 & 6761490 & 0.338 \\
\hline & 5550 & 2565.2 & 2558.5 & 18.4 & -196.291 & -26.7 & 7.8 & 7515656 & 0.286 \\
\hline & 6310 & 2560.9 & 2560.04 & 18.4 & -223.171 & -31 & 9.34 & 6251052 & 0.358 \\
\hline & 7650 & 2554.5 & 2561.88 & 18.3 & -270.564 & -37.4 & 11.18 & 7405132 & 0.288 \\
\hline & 8570 & 2549.46 & 2563.8 & 18.3 & -303.102 & -42.44 & 13.1 & 6456026 & 0.381 \\
\hline & 9450 & 2544.7 & 2564.95 & 18.3 & -334.226 & -47.2 & 14.25 & 6538584 & 0.242 \\
\hline & 11080 & 2535.1 & 2568.3 & 18.3 & -391.875 & -56.8 & 17.6 & 6005157 & 0.349 \\
\hline & 10800 & 2536.15 & 2567.4 & 18.2 & -381.972 & -55.75 & 16.7 & 9431412 & 0.857 \\
\hline & 9550 & 2542.8 & 2565.8 & 18.2 & -337.762 & -49.1 & 15.1 & 6648082 & 0.241 \\
\hline & 8200 & 2550.27 & 2563.3 & 18.2 & -290.016 & -41.63 & 12.6 & 6391770 & 0.335 \\
\hline & 6860 & 2557.03 & 2561.47 & 18.2 & -242.623 & -34.87 & 10.77 & 7010776 & 0.271 \\
\hline & 5060 & 2566.67 & 2558.27 & 18.2 & -178.961 & -25.23 & 7.57 & 6603945 & 0.332 \\
\hline & 3670 & 2573.3 & 2556.58 & 18.2 & -129.800 & -18.6 & 5.88 & 7414968 & 0.255 \\
\hline & 1910 & 2582.69 & 2553.87 & 18.1 & -67.553 & -9.21 & 3.17 & 6629107 & 0.289 \\
\hline & 620 & 2589.13 & 2552.38 & 18.1 & -21.928 & -2.77 & 1.68 & 7084543 & 0.231 \\
\hline & 0 & 2591.3 & 2551.56 & 18.1 & 0.000 & -0.6 & 0.86 & 10105084 & 0.378 \\
\hline \multirow{17}{*}{ 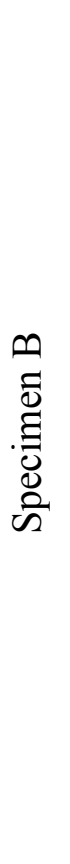 } & 0 & 2093.5 & 2194.2 & 19.4 & 0.000 & 0 & 0 & - & - \\
\hline & 880 & 2087.05 & 2195.04 & 19.4 & -31.124 & -6.45 & 0.84 & 4825374 & 0.130 \\
\hline & 2010 & 2078.07 & 2197.09 & 19.4 & -71.089 & -15.43 & 2.89 & 4450513 & 0.228 \\
\hline & 3720 & 2064.7 & 2199.21 & 19.3 & -131.568 & -28.8 & 5.01 & 4523480 & 0.159 \\
\hline & 5080 & 2053.53 & 2201.79 & 19.4 & 79.668 & -39.97 & 7.59 & 4306195 & 0.231 \\
\hline & 6690 & 2040.69 & 2204.35 & 19.3 & -236.611 & -52.81 & 10.15 & 4434747 & 0.199 \\
\hline & 8170 & 2028.34 & 2207.43 & 19.3 & -288.955 & -65.16 & 13.23 & 4238408 & 0.249 \\
\hline & 9740 & 2015 & 2209.86 & 19.3 & -344.482 & -78.5 & 15.66 & 4162477 & 0.182 \\
\hline & 9020 & 2021.6 & 2209.18 & 19.3 & -319.018 & -71.9 & 14.98 & 3858305 & 0.103 \\
\hline & 8230 & 2028 & 2207.57 & 19.2 & -291.077 & -65.5 & 13.37 & 4365712 & 0.252 \\
\hline & 7200 & 2038 & 2206.04 & 19.2 & -254.648 & -55.5 & 11.84 & 3642883 & 0.153 \\
\hline & 6100 & 2047.34 & 2203.61 & 19.2 & -215.744 & -46.16 & 9.41 & 4165372 & 0.260 \\
\hline & 4190 & 2058.22 & 2200.51 & 19.1 & -148.191 & -35.28 & 6.31 & 6208868 & 0.285 \\
\hline & 3570 & 2067 & 2199.53 & 19.1 & -126.263 & -26.5 & 5.33 & 2497498 & 0.112 \\
\hline & 2300 & 2079 & 2197.88 & 19.1 & -81.346 & -14.5 & 3.68 & 3743092 & 0.138 \\
\hline & 750 & 2088.6 & 2195.3 & 19 & -26.526 & -4.9 & 1.1 & 5710425 & 0.269 \\
\hline & 0 & 2092.7 & 2194.8 & 19 & 0.000 & -0.8 & 0.6 & 6469719 & 0.122 \\
\hline
\end{tabular}


Table A1-13 Modulus of Elasticity of Pour No. 1 at Day 28

\begin{tabular}{|c|c|c|c|c|c|c|c|c|c|}
\hline & $\begin{array}{l}\text { Load } \\
\text { (lbs) } \\
\end{array}$ & $\begin{array}{c}\text { Vertical } \\
\text { Strain } \\
(\mu \varepsilon) \\
\end{array}$ & $\begin{array}{c}\text { Horizontal } \\
\text { Strain } \\
(\mu \varepsilon) \\
\end{array}$ & $\begin{array}{c}\text { Temp } \\
\left({ }^{\circ} \mathrm{C}\right) \\
\end{array}$ & $\begin{array}{c}\text { Stresses } \\
(P S I) \\
\end{array}$ & $\begin{array}{c}\text { Differential } \\
\text { Vertical } \\
\text { Strain }(\mu \varepsilon) \\
\end{array}$ & $\begin{array}{l}\text { Differential } \\
\text { Horizontal } \\
\text { Strain }(\mu \varepsilon) \\
\end{array}$ & $\begin{array}{c}\text { Stress/Strain } \\
(P S I) \\
\end{array}$ & $\begin{array}{c}\text { Hor/Vert. } \\
\text { Strain } \\
\text { ratio } \\
\end{array}$ \\
\hline \multirow{16}{*}{ 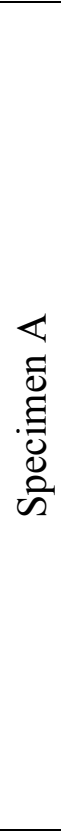 } & 0 & 2595.48 & 2559.32 & 19.6 & 0.000 & 0 & 0 & - & - \\
\hline & 1000 & 2591.12 & 2560.17 & 19.5 & -35.368 & -4.36 & 0.85 & 8111880 & 0.195 \\
\hline & 2000 & 2586.06 & 2561.9 & 19.4 & -70.736 & -9.42 & 2.58 & 6989683 & 0.342 \\
\hline & 2990 & 2581.6 & 2563.12 & 19.4 & -105.750 & -13.88 & 3.8 & 7850699 & 0.274 \\
\hline & 4280 & 2575.45 & 2565.26 & 19.4 & -151.374 & -20.03 & 5.94 & 7418611 & 0.348 \\
\hline & 5800 & 2568.9 & 2567.49 & 19.3 & -205.133 & -26.58 & 8.17 & 8207488 & 0.340 \\
\hline & 7040 & 2562.4 & 2570.04 & 19.2 & -248.989 & -33.08 & 10.72 & 6747087 & 0.392 \\
\hline & 8550 & 2555.37 & 2572.31 & 19.1 & -302.395 & -40.11 & 12.99 & 7596781 & 0.323 \\
\hline & 10030 & 2547.5 & 2575.28 & 19.1 & -354.739 & -47.98 & 15.96 & 6651123 & 0.377 \\
\hline & 9370 & 2551.2 & 2574.12 & 19 & -331.396 & -44.28 & 14.8 & 6308850 & 0.314 \\
\hline & 8270 & 2556.67 & 2572.73 & 19 & -292.492 & -38.81 & 13.41 & 7112354 & 0.254 \\
\hline & 7470 & 2561.47 & 2571.29 & 18.9 & -264.197 & -34.01 & 11.97 & 5894633 & 0.300 \\
\hline & 5750 & 2570.09 & 2569.5 & 18.8 & -203.365 & -25.39 & 10.18 & 7057147 & 0.208 \\
\hline & 3850 & 2580.2 & 2565.7 & 18.8 & -136.166 & -15.28 & 6.38 & 6646767 & 0.376 \\
\hline & 1320 & 2592.02 & 2562.67 & 18.7 & -46.685 & -3.46 & 3.35 & 7570264 & 0.256 \\
\hline & 0 & 2599 & 2561.14 & 18.7 & 0.000 & 3.52 & 1.82 & 6688466 & 0.219 \\
\hline \multirow{15}{*}{ 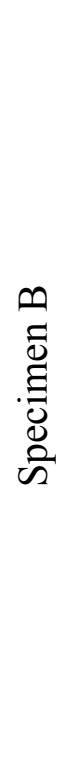 } & 0 & 2104.7 & 2211.9 & 19.7 & 0.000 & 0 & 0 & - & - \\
\hline & 1130 & 2095.8 & 2211.9 & 19.5 & -39.966 & -8.9 & 0 & 4490518 & 0.000 \\
\hline & 2700 & 2083.16 & 2214.4 & 19.4 & -95.493 & -21.54 & 2.5 & 4392994 & 0.198 \\
\hline & 4180 & 2071.4 & 2216.4 & 19.4 & -147.837 & -33.3 & 4.5 & 4451049 & 0.170 \\
\hline & 5850 & 2057.8 & 2219.6 & 19.3 & -206.902 & -46.9 & 7.7 & 4342957 & 0.235 \\
\hline & 7350 & 2045.5 & 2221.67 & 19.2 & -259.953 & -59.2 & 9.77 & 4313146 & 0.168 \\
\hline & 9140 & 2030.78 & 2225.13 & 19.1 & -323.262 & -73.92 & 13.23 & 4300839 & 0.235 \\
\hline & 10130 & 2022.57 & 2226.79 & 19 & -358.276 & -82.13 & 14.89 & 4264813 & 0.202 \\
\hline & 8840 & 2031.7 & 2225.01 & 19 & -312.651 & -73 & 13.11 & 4997202 & 0.195 \\
\hline & 6980 & 2046.68 & 2221.66 & 18.9 & -246.867 & -58.02 & 9.76 & 4391462 & 0.224 \\
\hline & 5080 & 2061.68 & 2218.9 & 18.8 & -179.668 & -43.02 & 7 & 4479921 & 0.184 \\
\hline & 3580 & 2074.53 & 2216.3 & 18.8 & -126.617 & -30.17 & 4.4 & 4128536 & 0.202 \\
\hline & 2110 & 2086.6 & 2214.46 & 18.7 & -74.626 & -18.1 & 2.56 & 4307428 & 0.152 \\
\hline & 810 & 2097.54 & 2212.42 & 18.6 & -28.648 & -7.16 & 0.52 & 4202754 & 0.186 \\
\hline & 0 & 2103.4 & 2211.9 & 18.6 & 0.000 & -1.3 & 0 & 4888723 & 0.089 \\
\hline
\end{tabular}


Table A1-14 Modulus of Elasticity of Pour No. 1 at Day 60

\begin{tabular}{|c|c|c|c|c|c|c|c|c|c|}
\hline & $\begin{array}{l}\text { Load } \\
\text { (lbs) } \\
\end{array}$ & $\begin{array}{c}\text { Vertical } \\
\text { Strain } \\
(\mu \varepsilon) \\
\end{array}$ & $\begin{array}{c}\text { Horizontal } \\
\text { Strain } \\
(\mu \varepsilon) \\
\end{array}$ & $\begin{array}{c}\text { Temp } \\
\left({ }^{\circ} \mathrm{C}\right) \\
\end{array}$ & $\begin{array}{c}\text { Stresses } \\
(P S I) \\
\end{array}$ & $\begin{array}{c}\text { Differential } \\
\text { Vertical } \\
\text { Strain }(\mu \varepsilon) \\
\end{array}$ & $\begin{array}{l}\text { Differential } \\
\text { Horizontal } \\
\text { Strain }(\mu \varepsilon) \\
\end{array}$ & $\begin{array}{c}\text { Stress/Strain } \\
(P S I) \\
\end{array}$ & $\begin{array}{c}\text { Hor/Vert. } \\
\text { Strain } \\
\text { ratio } \\
\end{array}$ \\
\hline \multirow{14}{*}{ 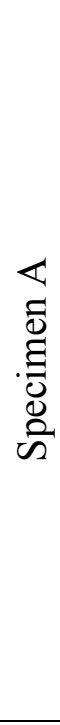 } & 0 & 2203.43 & 2233.7 & 21.1 & 0.000 & 0 & 0 & - & - \\
\hline & 1000 & 2198.23 & 2234.68 & 21.1 & -35.368 & -5.2 & 0.72 & 4706386 & 0.095 \\
\hline & 2000 & 2191.92 & 2236.02 & 21.1 & -70.736 & -11.5 & 2.59 & 4030284 & 0.217 \\
\hline & 3000 & 2186.39 & 2237 & 21.1 & -106.103 & -17 & 3.73 & 4318412 & 0.139 \\
\hline & 4000 & 2179.99 & 2238.83 & 21.1 & -141.471 & -23.4 & 5.73 & 3769012 & 0.215 \\
\hline & 5010 & 2174.01 & 2240.44 & 21.1 & -177.192 & -29.4 & 6.41 & 3925520 & 0.073 \\
\hline & 6000 & 2168.03 & 2241.63 & 21.1 & -212.206 & -35.4 & 8.82 & 3699560 & 0.252 \\
\hline & 5500 & 2170.3 & 2241.17 & 21.1 & -194.522 & -33.1 & 7.77 & 4728315 & 0.281 \\
\hline & 4510 & 2176.07 & 2239.2 & 21.2 & -159.508 & -27.4 & 6.55 & 4382626 & 0.151 \\
\hline & 3510 & 2181.68 & 2237.76 & 21.2 & -124.141 & -21.8 & 4.63 & 3877532 & 0.213 \\
\hline & 2500 & 2186.9 & 2236.64 & 21.2 & -88.419 & -16.5 & 3.19 & 4493267 & 0.181 \\
\hline & 1520 & 2193 & 2234.94 & 21.2 & -53.759 & -10.4 & 1.41 & 3964999 & 0.200 \\
\hline & 530 & 2198.54 & 2234.11 & 21.2 & -18.745 & -4.9 & 0.39 & 4300303 & 0.127 \\
\hline & 0 & 2201.77 & 2233.3 & 21.1 & 0.000 & -1.7 & -0.68 & 4299296 & 0.245 \\
\hline \multirow{14}{*}{ 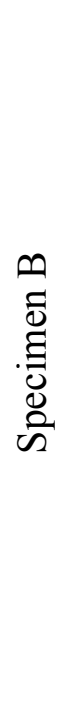 } & 0 & 1637.86 & 1834.29 & 21.1 & 0.000 & 0 & 0 & - & - \\
\hline & 1010 & 1630.27 & 1835.01 & 21.1 & -35.721 & -7.59 & 0.72 & 4706386 & 0.095 \\
\hline & 1990 & 1621.67 & 1836.88 & 21.1 & -70.382 & -16.19 & 2.59 & 4030284 & 0.217 \\
\hline & 2990 & 1613.48 & 1838.02 & 21.1 & -105.749 & -24.38 & 3.73 & 4318412 & 0.139 \\
\hline & 3980 & 1604.19 & 1840.02 & 21.1 & -140.763 & -33.67 & 5.73 & 3769012 & 0.215 \\
\hline & 5010 & 1594.91 & 1840.7 & 21.1 & -177.192 & -42.95 & 6.41 & 3925520 & 0.073 \\
\hline & 6010 & 1585.35 & 1843.11 & 21.1 & -212.560 & -52.51 & 8.82 & 3699560 & 0.252 \\
\hline & 5510 & 1589.09 & 1842.06 & 21.1 & -194.876 & -48.77 & 7.77 & 4728315 & 0.281 \\
\hline & 4510 & 1597.16 & 1840.84 & 21.1 & -159.508 & -40.7 & 6.55 & 4382626 & 0.151 \\
\hline & 3520 & 1606.19 & 1838.92 & 21.1 & -124.494 & -31.67 & 4.63 & 3877532 & 0.213 \\
\hline & 2510 & 1614.14 & 1837.48 & 21.1 & -88.773 & -23.72 & 3.19 & 4493267 & 0.181 \\
\hline & 1510 & 1623.06 & 1835.7 & 21.1 & -53.405 & -14.8 & 1.41 & 3964999 & 0.200 \\
\hline & 530 & 1631.12 & 1834.68 & 21.1 & -18.745 & -6.74 & 0.39 & 4300303 & 0.127 \\
\hline & 0 & 1635.48 & 1833.61 & 21.1 & 0.000 & -2.38 & -0.68 & 4299296 & 0.245 \\
\hline
\end{tabular}


Table A1-15 Modulus of Elasticity of Pour No. 2 at Day 1

\begin{tabular}{|c|c|c|c|c|c|c|c|c|c|}
\hline & $\begin{array}{r}\text { Load } \\
\text { (lbs) } \\
\end{array}$ & $\begin{array}{c}\text { Vertical } \\
\text { Strain } \\
(\mu \varepsilon) \\
\end{array}$ & $\begin{array}{c}\text { Horizontal } \\
\text { Strain } \\
(\mu \varepsilon) \\
\end{array}$ & $\begin{array}{c}\text { Temp } \\
\left({ }^{\circ} \mathrm{C}\right) \\
\end{array}$ & $\begin{array}{c}\text { Stresses } \\
(P S I) \\
\end{array}$ & $\begin{array}{c}\text { Differential } \\
\text { Vertical } \\
\text { Strain }(\mu \varepsilon) \\
\end{array}$ & $\begin{array}{l}\text { Differential } \\
\text { Horizontal } \\
\text { Strain }(\mu \varepsilon) \\
\end{array}$ & $\begin{array}{c}\text { Stress/Strain } \\
(P S I) \\
\end{array}$ & $\begin{array}{c}\text { Hor/Vert } \\
\text { Strain } \\
\text { ratio } \\
\end{array}$ \\
\hline \multirow{12}{*}{ 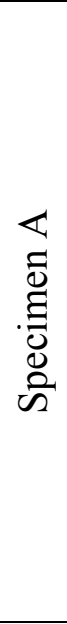 } & 0 & 2184.47 & 2533.71 & 22.5 & 0.000 & 0 & 0 & - & - \\
\hline & 980 & 2176.88 & 2535.75 & 22.3 & -34.660 & -7.6 & 2.04 & 4566593 & 0.269 \\
\hline & 1990 & 2168.15 & 2537.26 & 22.3 & -70.382 & -16.3 & 3.55 & 4091807 & 0.173 \\
\hline & 3050 & 2159.29 & 2539.02 & 22.3 & -107.872 & -25.2 & 5.31 & 4231361 & 0.199 \\
\hline & 3980 & 2150.79 & 2540.99 & 22.2 & -140.764 & -33.7 & 7.28 & 3869653 & 0.232 \\
\hline & 5000 & 2142.24 & 2542.2 & 22.2 & -176.839 & -42.2 & 8.49 & 4219316 & 0.142 \\
\hline & 4500 & 2145.64 & 2542.06 & 22.2 & -159.155 & -38.8 & 8.35 & 5201146 & 0.041 \\
\hline & 3530 & 2153.24 & 2540.29 & 22.2 & -124.848 & -31.2 & 6.58 & 4514048 & 0.233 \\
\hline & 2520 & 2161.08 & 2538.93 & 22.2 & -89.127 & -23.4 & 5.22 & 4556310 & 0.173 \\
\hline & 1520 & 2169.93 & 2536.68 & 22.1 & -53.759 & -14.5 & 2.97 & 3996361 & 0.254 \\
\hline & 510 & 2178.08 & 2535.41 & 22.1 & -18.038 & -6.4 & 1.7 & 4383003 & 0.156 \\
\hline & 0 & 2182.78 & 2534.19 & 22.1 & 0.000 & -1.7 & 0.48 & 3837782 & 0.260 \\
\hline \multirow{12}{*}{ 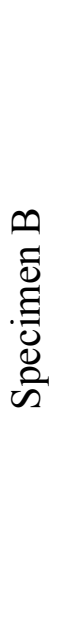 } & 0 & 2266.58 & 2348.91 & 21.5 & 0.000 & 0 & 0 & - & - \\
\hline & 1000 & 2255.28 & 2350.02 & 21.4 & -35.368 & -11.3 & 1.11 & 3129893 & 0.098 \\
\hline & 1980 & 2242.13 & 2352.73 & 21.4 & -70.028 & -24.45 & 3.82 & 2635775 & 0.206 \\
\hline & 2990 & 2228.32 & 2355.1 & 21.4 & -105.750 & -38.26 & 6.19 & 2586638 & 0.172 \\
\hline & 3990 & 2214.81 & 2357.78 & 21.4 & -141.118 & -51.77 & 8.87 & 2617897 & 0.198 \\
\hline & 5000 & 2200.6 & 2360.21 & 21.4 & -176.839 & -65.98 & 11.3 & 2513826 & 0.171 \\
\hline & 4510 & 2204.92 & 2359.62 & 21.3 & -159.509 & -61.66 & 10.71 & 4011625 & 0.137 \\
\hline & 3520 & 2217.17 & 2356.63 & 21.3 & -124.495 & -49.41 & 7.72 & 2858295 & 0.244 \\
\hline & 2520 & 2229.53 & 2354.23 & 21.3 & -89.127 & -37.05 & 5.32 & 2861472 & 0.194 \\
\hline & 1510 & 2243 & 2351.79 & 21.3 & -53.405 & -23.58 & 2.88 & 2651928 & 0.181 \\
\hline & 520 & 2255.78 & 2349.75 & 21.3 & -18.313 & -10.8 & 0.84 & 2739759 & 0.160 \\
\hline & 0 & 2262.93 & 2348.03 & 21.3 & 0.000 & -3.65 & -0.88 & 2572203 & 0.241 \\
\hline
\end{tabular}


Table A1-16 Modulus of Elasticity of Pour No. 2 at Day 2

\begin{tabular}{|c|c|c|c|c|c|c|c|c|c|}
\hline & $\begin{array}{l}\text { Load } \\
\text { (lbs) }\end{array}$ & $\begin{array}{c}\text { Vertical } \\
\text { Strain } \\
(\mu \varepsilon)\end{array}$ & $\begin{array}{c}\text { Horizontal } \\
\text { Strain } \\
(\mu \varepsilon)\end{array}$ & $\begin{array}{l}\text { Temp } \\
\left({ }^{\circ} \mathrm{C}\right) \\
\end{array}$ & $\begin{array}{c}\text { Stresses } \\
(P S I) \\
\end{array}$ & $\begin{array}{c}\text { Differential } \\
\text { Vertical } \\
\text { Strain }(\mu \varepsilon)\end{array}$ & $\begin{array}{l}\text { Differential } \\
\text { Horizontal } \\
\text { Strain }(\mu \varepsilon) \\
\end{array}$ & $\begin{array}{c}\text { Stress/Strain } \\
(P S I)\end{array}$ & $\begin{array}{c}\text { Hor/Vert. } \\
\text { Strain } \\
\text { ratio }\end{array}$ \\
\hline \multirow{14}{*}{ 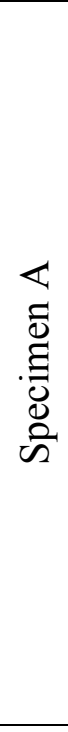 } & 0 & 2192.87 & 2534.11 & 21 & 0.000 & 0 & 0 & - & - \\
\hline & 1000 & 2185.39 & 2535.6 & 21 & -35.368 & -7.5 & 1.49 & 4728315 & 0.199 \\
\hline & 1990 & 2176.9 & 2537.62 & 20.9 & -70.382 & -16 & 3.51 & 4124160 & 0.238 \\
\hline & 3010 & 2169.32 & 2539.13 & 20.9 & -106.457 & -23.5 & 5.02 & 4759255 & 0.199 \\
\hline & 3990 & 2161.54 & 2541.26 & 20.8 & -141.118 & -31.3 & 7.15 & 4455069 & 0.274 \\
\hline & 4990 & 2154.61 & 2542.66 & 20.8 & -176.485 & -38.3 & 8.55 & 5103578 & 0.202 \\
\hline & 6000 & 2146.67 & 2544.71 & 20.8 & -212.207 & -46.2 & 10.6 & 4498926 & 0.258 \\
\hline & 5480 & 2150.65 & 2543.85 & 20.7 & -193.816 & -42.2 & 9.74 & 4620918 & 0.216 \\
\hline & 4500 & 2157.33 & 2542.44 & 20.7 & -159.155 & -35.5 & 8.33 & 5188688 & 0.211 \\
\hline & 3510 & 2165.11 & 2540.92 & 20.7 & -124.141 & -27.8 & 6.81 & 4500529 & 0.195 \\
\hline & 2510 & 2172.63 & 2539.76 & 20.6 & -88.773 & -20.2 & 5.65 & 4703164 & 0.154 \\
\hline & 1500 & 2181.36 & 2537.92 & 20.6 & -53.052 & -11.5 & 3.81 & 4091807 & 0.211 \\
\hline & 520 & 2189.65 & 2536.87 & 20.6 & -18.391 & -3.2 & 2.76 & 4180994 & 0.127 \\
\hline & 0 & 2194.64 & 2535.81 & 20.6 & 0.000 & 1.8 & 1.7 & 3685622 & 0.212 \\
\hline \multirow{14}{*}{ 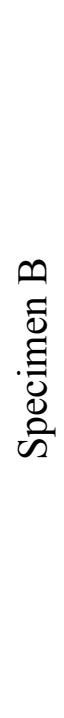 } & 0 & 2288.73 & 2354.78 & 21.1 & 0.000 & 0 & 0 & - & - \\
\hline & 990 & 2278.87 & 2356.15 & 21.1 & -35.014 & -9.86 & 1.37 & 3551127 & 0.139 \\
\hline & 1990 & 2268.75 & 2358.44 & 21 & -70.382 & -19.98 & 3.66 & 3494841 & 0.226 \\
\hline & 2980 & 2259.05 & 2360.18 & 20.9 & -105.396 & -29.68 & 5.4 & 3609703 & 0.179 \\
\hline & 3980 & 2248.62 & 2362.58 & 20.9 & -140.764 & -40.11 & 7.8 & 3390968 & 0.230 \\
\hline & 5020 & 2238.06 & 2364.78 & 20.8 & -177.546 & -50.67 & 10 & 3483192 & 0.208 \\
\hline & 6000 & 2227.61 & 2367.17 & 20.7 & -212.207 & -61.12 & 12.39 & 3316788 & 0.229 \\
\hline & 5510 & 2231.84 & 2365.9 & 20.7 & -194.877 & -56.89 & 11.12 & 4096979 & 0.300 \\
\hline & 4500 & 2241.21 & 2364.39 & 20.7 & -159.155 & -47.52 & 9.61 & 3812324 & 0.161 \\
\hline & 3520 & 2251.81 & 2362.08 & 20.6 & -124.495 & -36.92 & 7.3 & 3269853 & 0.218 \\
\hline & 2510 & 2261.76 & 2360.34 & 20.6 & -88.773 & -26.97 & 5.56 & 3590098 & 0.175 \\
\hline & 1520 & 2272.35 & 2358.08 & 20.5 & -53.759 & -16.38 & 3.3 & 3306338 & 0.213 \\
\hline & 510 & 2282.18 & 2356.81 & 20.5 & -18.038 & -6.55 & 2.03 & 3633924 & 0.129 \\
\hline & 0 & 2287.84 & 2355.57 & 20.4 & 0.000 & -0.89 & 0.79 & 3186851 & 0.219 \\
\hline
\end{tabular}


Table A1-17 Modulus of Elasticity of Pour No. 2 at Day 3

\begin{tabular}{|c|c|c|c|c|c|c|c|c|c|}
\hline & $\begin{array}{l}\text { Load } \\
\text { (lbs) }\end{array}$ & $\begin{array}{c}\text { Vertical } \\
\text { Strain } \\
(\mu \varepsilon)\end{array}$ & $\begin{array}{c}\text { Horizontal } \\
\text { Strain } \\
(\mu \varepsilon)\end{array}$ & $\begin{array}{l}\text { Temp } \\
\left({ }^{\circ} \mathrm{C}\right) \\
\end{array}$ & $\begin{array}{c}\text { Stresses } \\
(P S I) \\
\end{array}$ & $\begin{array}{c}\text { Differential } \\
\text { Vertical } \\
\text { Strain }(\mu \varepsilon)\end{array}$ & $\begin{array}{l}\text { Differential } \\
\text { Horizontal } \\
\text { Strain }(\mu \varepsilon) \\
\end{array}$ & $\begin{array}{c}\text { Stress/Strain } \\
(P S I)\end{array}$ & $\begin{array}{c}\text { Hor/Vert. } \\
\text { Strain } \\
\text { ratio }\end{array}$ \\
\hline \multirow{14}{*}{ 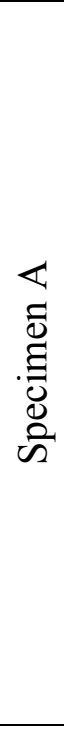 } & 0 & 2189.58 & 2528.64 & 20.8 & 0.000 & 0 & 0 & - & - \\
\hline & 1000 & 2182.3 & 2529.7 & 20.7 & -35.368 & -7.3 & 1.06 & 4858214 & 0.146 \\
\hline & 1980 & 2174.42 & 2531.61 & 20.7 & -70.028 & -15.2 & 2.97 & 4398533 & 0.242 \\
\hline & 2990 & 2166.82 & 2533.01 & 20.6 & -105.750 & -22.8 & 4.37 & 4700194 & 0.184 \\
\hline & 4010 & 2158.97 & 2534.96 & 20.6 & -141.825 & -30.6 & 6.32 & 4595561 & 0.248 \\
\hline & 5010 & 2152.02 & 2536.28 & 20.6 & -177.193 & -37.6 & 7.64 & 5088891 & 0.190 \\
\hline & 6020 & 2144.59 & 2538.09 & 20.5 & -212.914 & -45 & 9.45 & 4807735 & 0.244 \\
\hline & 5520 & 2148.41 & 2537.32 & 20.5 & -195.230 & -41.2 & 8.68 & 4629293 & 0.202 \\
\hline & 4500 & 2155.22 & 2536.36 & 20.4 & -159.155 & -34.4 & 7.72 & 5297379 & 0.141 \\
\hline & 3540 & 2162.86 & 2534.74 & 20.4 & -125.202 & -26.7 & 6.1 & 4444121 & 0.212 \\
\hline & 2540 & 2170.1 & 2534.08 & 20.4 & -89.834 & -19.5 & 5.44 & 4885055 & 0.091 \\
\hline & 1510 & 2178.76 & 2532.42 & 20.3 & -53.405 & -10.8 & 3.78 & 4206562 & 0.192 \\
\hline & 510 & 2186.4 & 2531.1 & 20.3 & -18.038 & -3.2 & 2.46 & 4629293 & 0.173 \\
\hline & 0 & 2190.79 & 2530.38 & 20.3 & 0.000 & 1.2 & 1.74 & 4108787 & 0.164 \\
\hline \multirow{14}{*}{ 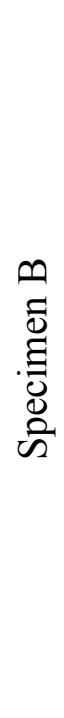 } & 0 & 2289.58 & 2353.07 & 20.8 & 0.000 & 0 & 0 & - & - \\
\hline & 1000 & 2279.76 & 2354.88 & 20.7 & -35.368 & -9.82 & 1.81 & 3601608 & 0.184 \\
\hline & 1990 & 2270.34 & 2356.92 & 20.7 & -70.382 & -19.24 & 3.85 & 3716998 & 0.217 \\
\hline & 3010 & 2261.64 & 2358.37 & 20.7 & -106.457 & -27.94 & 5.3 & 4146569 & 0.167 \\
\hline & 3990 & 2252.4 & 2360.51 & 20.6 & -141.118 & -37.18 & 7.44 & 3751130 & 0.232 \\
\hline & 4990 & 2242.88 & 2362.36 & 20.6 & -176.485 & -46.7 & 9.29 & 3715105 & 0.194 \\
\hline & 5990 & 2232.31 & 2364.72 & 20.5 & -211.853 & -57.27 & 11.65 & 3346054 & 0.223 \\
\hline & 5480 & 2236.75 & 2363.46 & 20.5 & -193.816 & -52.83 & 10.39 & 4062517 & 0.284 \\
\hline & 4490 & 2245.44 & 2362.03 & 20.5 & -158.801 & -44.14 & 8.96 & 4029242 & 0.165 \\
\hline & 3490 & 2255.48 & 2359.76 & 20.4 & -123.434 & -34.1 & 6.69 & 3522689 & 0.226 \\
\hline & 2530 & 2263.8 & 2358.38 & 20.4 & -89.481 & -25.78 & 5.31 & 4080899 & 0.166 \\
\hline & 1520 & 2273.69 & 2355.87 & 20.4 & -53.759 & -15.89 & 2.8 & 3611878 & 0.254 \\
\hline & 500 & 2283.34 & 2354.68 & 20.4 & -17.684 & -6.24 & 1.61 & 3738358 & 0.123 \\
\hline & 0 & 2289.23 & 2353.61 & 20.3 & 0.000 & -0.35 & 0.54 & 3002360 & 0.182 \\
\hline
\end{tabular}


Table A1-18 Modulus of Elasticity of Pour No. 2 at Day 7

\begin{tabular}{|c|c|c|c|c|c|c|c|c|c|}
\hline & $\begin{array}{l}\text { Load } \\
\text { (lbs) }\end{array}$ & $\begin{array}{c}\text { Vertical } \\
\text { Strain } \\
(\mu \varepsilon)\end{array}$ & $\begin{array}{c}\text { Horizontal } \\
\text { Strain } \\
(\mu \varepsilon)\end{array}$ & $\begin{array}{l}\text { Temp } \\
\left({ }^{\circ} \mathrm{C}\right) \\
\end{array}$ & $\begin{array}{c}\text { Stresses } \\
(P S I) \\
\end{array}$ & $\begin{array}{c}\text { Differential } \\
\text { Vertical } \\
\text { Strain }(\mu \varepsilon)\end{array}$ & $\begin{array}{l}\text { Differential } \\
\text { Horizontal } \\
\text { Strain }(\mu \varepsilon) \\
\end{array}$ & $\begin{array}{c}\text { Stress/Strain } \\
(P S I)\end{array}$ & $\begin{array}{c}\text { Hor/Vert. } \\
\text { Strain } \\
\text { ratio }\end{array}$ \\
\hline \multirow{14}{*}{ 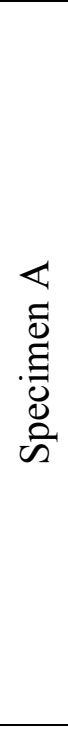 } & 0 & 2194.09 & 2529.05 & 20.2 & 0.000 & 0 & 0 & - & - \\
\hline & 980 & 2187.81 & 2530.32 & 20.1 & -34.660 & -6.3 & 1.27 & 5519178 & 0.202 \\
\hline & 2000 & 2181.14 & 2532.46 & 20.1 & -70.736 & -13 & 3.41 & 5408568 & 0.321 \\
\hline & 2980 & 2175.41 & 2533.71 & 20 & -105.396 & -18.7 & 4.66 & 6048942 & 0.218 \\
\hline & 4060 & 2168.7 & 2535.97 & 20 & -143.593 & -25.4 & 6.92 & 5692581 & 0.337 \\
\hline & 5030 & 2163.42 & 2537.15 & 20 & -177.900 & -30.7 & 8.1 & 6497493 & 0.223 \\
\hline & 6000 & 2157.54 & 2539.02 & 19.9 & -212.207 & -36.6 & 9.97 & 5834483 & 0.318 \\
\hline & 5510 & 2160.79 & 2538.11 & 19.9 & -194.877 & -33.3 & 9.06 & 5332375 & 0.280 \\
\hline & 4490 & 2166.81 & 2537.37 & 19.9 & -158.801 & -27.3 & 8.32 & 5992550 & 0.123 \\
\hline & 3520 & 2173.54 & 2535.83 & 19.8 & -124.495 & -20.6 & 6.78 & 5097587 & 0.229 \\
\hline & 2530 & 2179.7 & 2534.83 & 19.8 & -89.481 & -14.4 & 5.78 & 5684110 & 0.162 \\
\hline & 1510 & 2186.68 & 2533.12 & 19.7 & -53.405 & -7.4 & 4.07 & 5168360 & 0.245 \\
\hline & 530 & 2192.81 & 2531.86 & 19.7 & -18.745 & -1.3 & 2.81 & 5654232 & 0.206 \\
\hline & 0 & 2196.67 & 2531.05 & 19.7 & 0.000 & 2.6 & 2 & 4856200 & 0.210 \\
\hline \multirow{14}{*}{ 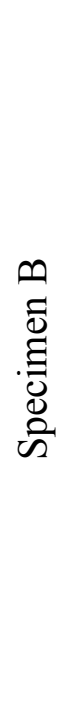 } & 0 & 2303.12 & 2359.69 & 20.5 & 0.000 & 0 & 0 & - & - \\
\hline & 1010 & 2293.62 & 2361.19 & 20.4 & -35.721 & -9.5 & 1.5 & 3760155 & 0.158 \\
\hline & 2000 & 2283.25 & 2363.3 & 20.4 & -70.736 & -19.87 & 3.61 & 3376482 & 0.203 \\
\hline & 2980 & 2265.37 & 2365.57 & 20.4 & -105.396 & -37.75 & 5.88 & 1938503 & 0.127 \\
\hline & 3990 & 2262.04 & 2367.33 & 20.3 & -141.118 & -41.08 & 7.64 & 10727169 & 0.529 \\
\hline & 5000 & 2251.61 & 2369.44 & 20.2 & -176.839 & -51.51 & 9.75 & 3424878 & 0.202 \\
\hline & 6000 & 2240.83 & 2371.52 & 20.2 & -212.207 & -62.29 & 11.83 & 3280872 & 0.193 \\
\hline & 5460 & 2245.75 & 2370.12 & 20.1 & -193.108 & -57.37 & 10.43 & 3881831 & 0.285 \\
\hline & 4480 & 2254.77 & 2368.79 & 20 & -158.448 & -48.35 & 9.1 & 3842621 & 0.147 \\
\hline & 3520 & 2264.63 & 2366.49 & 20 & -124.495 & -38.49 & 6.8 & 3443518 & 0.233 \\
\hline & 2520 & 2275.28 & 2364.41 & 19.9 & -89.127 & -27.84 & 4.72 & 3320920 & 0.195 \\
\hline & 1520 & 2285.5 & 2362.45 & 19.9 & -53.759 & -17.62 & 2.76 & 3460645 & 0.192 \\
\hline & 530 & 2296.24 & 2360.1 & 19.8 & -18.745 & -6.88 & 0.41 & 3260160 & 0.219 \\
\hline & 0 & 2301.29 & 2359.83 & 19.7 & 0.000 & -1.83 & 0.14 & 3711868 & 0.053 \\
\hline
\end{tabular}


Table A1-19 Modulus of Elasticity of Pour No. 2 at Day 14

\begin{tabular}{|c|c|c|c|c|c|c|c|c|c|}
\hline & $\begin{array}{l}\text { Load } \\
\text { (lbs) }\end{array}$ & $\begin{array}{c}\text { Vertical } \\
\text { Strain } \\
(\mu \varepsilon)\end{array}$ & $\begin{array}{c}\text { Horizontal } \\
\text { Strain } \\
(\mu \varepsilon)\end{array}$ & $\begin{array}{l}\text { Temp } \\
\left({ }^{\circ} \mathrm{C}\right) \\
\end{array}$ & $\begin{array}{c}\text { Stresses } \\
(P S I) \\
\end{array}$ & $\begin{array}{c}\text { Differential } \\
\text { Vertical } \\
\text { Strain }(\mu \varepsilon)\end{array}$ & $\begin{array}{l}\text { Differential } \\
\text { Horizontal } \\
\text { Strain }(\mu \varepsilon) \\
\end{array}$ & $\begin{array}{c}\text { Stress/Strain } \\
(P S I)\end{array}$ & $\begin{array}{c}\text { Hor/Vert. } \\
\text { Strain } \\
\text { ratio }\end{array}$ \\
\hline \multirow{14}{*}{ 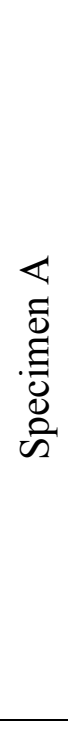 } & 0 & 2207.52 & 2538.8 & 21.2 & 0.000 & 0 & 0 & - & - \\
\hline & 1020 & 2201.39 & 2540.11 & 21.2 & -36.075 & -6.1 & 1.31 & 5885016 & 0.214 \\
\hline & 2040 & 2194.54 & 2542.12 & 21.1 & -72.150 & -13 & 3.32 & 5266445 & 0.293 \\
\hline & 3030 & 2188.35 & 2543.59 & 21.1 & -107.164 & -19.2 & 4.79 & 5656562 & 0.237 \\
\hline & 4040 & 2181.78 & 2545.26 & 21.1 & -142.885 & -25.7 & 6.46 & 5437058 & 0.254 \\
\hline & 5030 & 2176.02 & 2546.47 & 21.1 & -177.900 & -31.5 & 7.67 & 6078840 & 0.210 \\
\hline & 6020 & 2169.59 & 2548.29 & 21.1 & -212.914 & -37.9 & 9.49 & 5445430 & 0.283 \\
\hline & 5490 & 2172.79 & 2547.41 & 21.1 & -194.169 & -34.7 & 8.61 & 5857791 & 0.275 \\
\hline & 4500 & 2178.68 & 2546.34 & 21 & -159.155 & -28.8 & 7.54 & 5944672 & 0.182 \\
\hline & 3520 & 2184.99 & 2544.6 & 21 & -124.494 & -22.5 & 5.8 & 5492938 & 0.276 \\
\hline & 2510 & 2191.04 & 2543.48 & 21 & -88.773 & -16.5 & 4.68 & 5904376 & 0.185 \\
\hline & 1530 & 2198.01 & 2541.59 & 21 & -54.113 & -9.5 & 2.79 & 4972803 & 0.271 \\
\hline & 540 & 2204.64 & 2540.02 & 20.9 & -19.099 & -2.9 & 1.22 & 5281164 & 0.237 \\
\hline & 0 & 2207.94 & 2539.72 & 20.9 & 0.000 & 0.4 & 0.92 & 5787457 & 0.091 \\
\hline \multirow{14}{*}{ 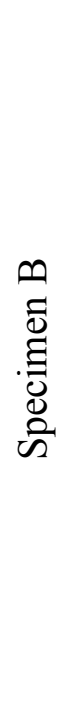 } & 0 & 2315.08 & 2368.15 & 21.2 & 0.000 & 0 & 0 & - & - \\
\hline & 1010 & 2308.46 & 2369.63 & 21.1 & -35.721 & -6.62 & 1.48 & 5395993 & 0.224 \\
\hline & 2010 & 2300.45 & 2371.68 & 21.1 & -71.089 & -14.63 & 3.53 & 4415455 & 0.256 \\
\hline & 3000 & 2291.68 & 2373.53 & 21.1 & -106.103 & -23.4 & 5.38 & 3992488 & 0.211 \\
\hline & 4000 & 2283.04 & 2375.47 & 21 & -141.471 & -32.04 & 7.32 & 4093495 & 0.225 \\
\hline & 5010 & 2273.73 & 2377.7 & 21 & -177.192 & -41.35 & 9.55 & 3836893 & 0.240 \\
\hline & 6020 & 2264.8 & 2379.36 & 20.9 & -212.914 & -50.28 & 11.21 & 4000165 & 0.186 \\
\hline & 5500 & 2267.95 & 2379.04 & 20.9 & -194.522 & -47.13 & 10.89 & 5838493 & 0.102 \\
\hline & 4510 & 2277.27 & 2376.76 & 20.9 & -159.508 & -37.81 & 8.61 & 3756880 & 0.245 \\
\hline & 3520 & 2285.48 & 2375.13 & 20.8 & -124.494 & -29.6 & 6.98 & 4264813 & 0.199 \\
\hline & 2510 & 2295.05 & 2372.95 & 20.8 & -88.773 & -20.03 & 4.8 & 3732651 & 0.228 \\
\hline & 1530 & 2303.32 & 2371.75 & 20.8 & -54.113 & -11.76 & 3.6 & 4191105 & 0.145 \\
\hline & 510 & 2312.48 & 2369.5 & 20.8 & -18.038 & -2.6 & 1.35 & 3938335 & 0.246 \\
\hline & 0 & 2315.98 & 2369.16 & 20.8 & 0.000 & 0.9 & 1.01 & 5153593 & 0.097 \\
\hline
\end{tabular}


Table A1-20 Modulus of Elasticity of Pour No. 2 at Day 21

\begin{tabular}{|c|c|c|c|c|c|c|c|c|c|}
\hline & $\begin{array}{l}\text { Load } \\
\text { (lbs) }\end{array}$ & $\begin{array}{c}\text { Vertical } \\
\text { Strain } \\
(\mu \varepsilon)\end{array}$ & $\begin{array}{c}\text { Horizontal } \\
\text { Strain } \\
(\mu \varepsilon)\end{array}$ & $\begin{array}{l}\text { Temp } \\
\left({ }^{\circ} \mathrm{C}\right) \\
\end{array}$ & $\begin{array}{c}\text { Stresses } \\
(P S I) \\
\end{array}$ & $\begin{array}{c}\text { Differential } \\
\text { Vertical } \\
\text { Strain }(\mu \varepsilon)\end{array}$ & $\begin{array}{l}\text { Differential } \\
\text { Horizontal } \\
\text { Strain }(\mu \varepsilon) \\
\end{array}$ & $\begin{array}{c}\text { Stress/Strain } \\
(P S I)\end{array}$ & $\begin{array}{c}\text { Hor/Vert. } \\
\text { Strain } \\
\text { ratio }\end{array}$ \\
\hline \multirow{14}{*}{ 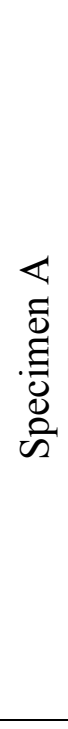 } & 0 & 2224.6 & 2553.92 & 20.4 & 0.000 & 0 & 0 & - & - \\
\hline & 1010 & 2218.12 & 2554.82 & 20.2 & -35.721 & -6.5 & 0.9 & 5512573 & 0.139 \\
\hline & 2020 & 2210.92 & 2556.44 & 20.2 & -71.443 & -13.7 & 2.52 & 4961316 & 0.225 \\
\hline & 3020 & 2204.76 & 2557.59 & 20.1 & -106.810 & -19.8 & 3.67 & 5741525 & 0.187 \\
\hline & 4010 & 2198.34 & 2559.32 & 20.1 & -141.824 & -26.3 & 5.4 & 5453912 & 0.269 \\
\hline & 5040 & 2192.09 & 2560.62 & 20.1 & -178.253 & -32.5 & 6.7 & 5828613 & 0.208 \\
\hline & 6050 & 2185.59 & 2562.3 & 20.1 & -213.975 & -39 & 8.38 & 5495611 & 0.258 \\
\hline & 5510 & 2188.71 & 2561.46 & 20 & -194.876 & -35.9 & 7.54 & 6121349 & 0.269 \\
\hline & 4540 & 2194.02 & 2560.48 & 20 & -160.569 & -30.6 & 6.56 & 6460784 & 0.185 \\
\hline & 3550 & 2200.22 & 2558.9 & 20 & -125.555 & -24.4 & 4.98 & 5647438 & 0.255 \\
\hline & 2510 & 2206.42 & 2558.01 & 20 & -88.773 & -18.2 & 4.09 & 5932662 & 0.144 \\
\hline & 1540 & 2213.12 & 2556.38 & 20 & -54.466 & -11.5 & 2.46 & 5120412 & 0.243 \\
\hline & 540 & 2219.35 & 2555.19 & 19.9 & -19.099 & -5.3 & 1.27 & 5677014 & 0.191 \\
\hline & 0 & 2223.01 & 2554.27 & 19.9 & 0.000 & -1.6 & 0.35 & 5218199 & 0.251 \\
\hline \multirow{14}{*}{ 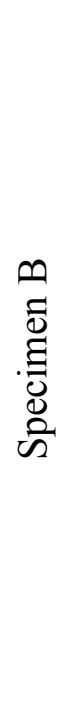 } & 0 & 2333.1 & 2382.98 & 20.5 & 0.000 & 0 & 0 & - & - \\
\hline & 1030 & 2325.06 & 2384.49 & 20.5 & -36.429 & -8.04 & 1.51 & 4530949 & 0.188 \\
\hline & 2010 & 2315.83 & 2386.77 & 20.4 & -71.089 & -17.27 & 3.79 & 3755194 & 0.247 \\
\hline & 3010 & 2307.09 & 2388.64 & 20.4 & -106.457 & -26.01 & 5.66 & 4046658 & 0.214 \\
\hline & 4030 & 2297.25 & 2391.01 & 20.4 & -142.532 & -35.85 & 8.03 & 3666174 & 0.241 \\
\hline & 5030 & 2288.36 & 2392.69 & 20.4 & -177.900 & -44.74 & 9.71 & 3978380 & 0.189 \\
\hline & 6060 & 2278.62 & 2395.01 & 20.4 & -214.329 & -54.48 & 12.03 & 3740126 & 0.238 \\
\hline & 5490 & 2283.25 & 2393.79 & 20.3 & -194.169 & -49.85 & 10.81 & 4354135 & 0.263 \\
\hline & 4520 & 2290.25 & 2392.11 & 20.3 & -159.862 & -42.85 & 9.13 & 4900966 & 0.240 \\
\hline & 3510 & 2299.6 & 2389.74 & 20.3 & -124.141 & -33.5 & 6.76 & 3820478 & 0.253 \\
\hline & 2510 & 2308.51 & 2388.25 & 20.3 & -88.773 & -24.59 & 5.27 & 3969449 & 0.167 \\
\hline & 1510 & 2318.59 & 2386.08 & 20.3 & -53.405 & -14.51 & 3.1 & 3508710 & 0.215 \\
\hline & 510 & 2384.16 & 2327.8 & 20.3 & -18.038 & 51.06 & -55.18 & 539389.9 & 0.889 \\
\hline & 0 & 2382.91 & 2332.91 & 20.2 & 0.000 & 49.81 & -50.07 & $-1.40 E+07$ & 4.088 \\
\hline
\end{tabular}


Table A1-21 Modulus of Elasticity of Pour No. 2 at Day 28

\begin{tabular}{|c|c|c|c|c|c|c|c|c|c|}
\hline & $\begin{array}{l}\text { Load } \\
\text { (lbs) }\end{array}$ & $\begin{array}{c}\text { Vertical } \\
\text { Strain } \\
(\mu \varepsilon)\end{array}$ & $\begin{array}{c}\text { Horizontal } \\
\text { Strain } \\
(\mu \varepsilon)\end{array}$ & $\begin{array}{l}\text { Temp } \\
\left({ }^{\circ} \mathrm{C}\right) \\
\end{array}$ & $\begin{array}{c}\text { Stresses } \\
(P S I) \\
\end{array}$ & $\begin{array}{c}\text { Differential } \\
\text { Vertical } \\
\text { Strain }(\mu \varepsilon)\end{array}$ & $\begin{array}{l}\text { Differential } \\
\text { Horizontal } \\
\text { Strain }(\mu \varepsilon) \\
\end{array}$ & $\begin{array}{c}\text { Stress/Strain } \\
(P S I)\end{array}$ & $\begin{array}{c}\text { Hor/Vert. } \\
\text { Strain } \\
\text { ratio }\end{array}$ \\
\hline \multirow{14}{*}{ 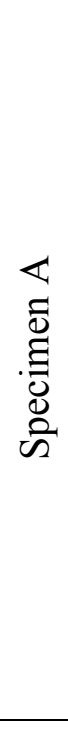 } & 0 & 2233.88 & 2573.57 & 19.6 & 0.000 & 0 & 0 & - & - \\
\hline & 1020 & 2229.9 & 2575.8 & 19.3 & -36.075 & -4 & 2.23 & 9064108 & 0.560 \\
\hline & 2020 & 2223.59 & 2578.07 & 19.2 & -71.443 & -10.3 & 4.5 & 5605039 & 0.360 \\
\hline & 3010 & 2218.21 & 2579.48 & 19.2 & -106.457 & -15.7 & 5.91 & 6508200 & 0.262 \\
\hline & 4030 & 2211.34 & 2581.73 & 19.2 & -142.532 & -22.5 & 8.16 & 5251114 & 0.328 \\
\hline & 5000 & 2207.51 & 2583.84 & 19.4 & -176.839 & -26.4 & 10.27 & 8957379 & 0.551 \\
\hline & 6030 & 2200.8 & 2585.51 & 19.4 & -213.267 & -33.1 & 11.94 & 5429036 & 0.249 \\
\hline & 5530 & 2204.02 & 2584.76 & 19.4 & -195.583 & -29.9 & 11.19 & 5491894 & 0.233 \\
\hline & 4510 & 2209.76 & 2583.67 & 19.4 & -159.508 & -24.1 & 10.1 & 6284869 & 0.190 \\
\hline & 3500 & 2216.35 & 2582.02 & 19.4 & -123.787 & -17.5 & 8.45 & 5420557 & 0.250 \\
\hline & 2520 & 2222.38 & 2580.58 & 19.4 & -89.127 & -11.5 & 7.01 & 5748000 & 0.239 \\
\hline & 1520 & 2229.38 & 2578.68 & 19.4 & -53.759 & -4.5 & 5.11 & 5052542 & 0.271 \\
\hline & 530 & 2235.41 & 2577.4 & 19.5 & -18.745 & 1.5 & 3.83 & 5806653 & 0.212 \\
\hline & 0 & 2239.17 & 2576.4 & 19.5 & 0.000 & 5.3 & 2.83 & 4985354 & 0.266 \\
\hline \multirow{14}{*}{ 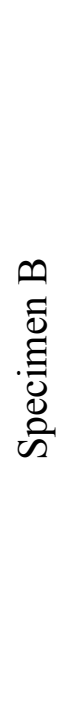 } & 0 & 2344.71 & 2397.06 & 21.5 & 0.000 & 0 & 0 & - & - \\
\hline & 1010 & 2341.24 & 2400.33 & 20.7 & -35.721 & -3.47 & 3.27 & 10294373 & 0.942 \\
\hline & 2020 & 2333.45 & 2404.45 & 20.6 & -71.443 & -11.26 & 7.39 & 4585555 & 0.529 \\
\hline & 3040 & 2328.68 & 2406.12 & 20 & -107.518 & -16.03 & 9.06 & 7562925 & 0.350 \\
\hline & 4050 & 2320.22 & 2408.41 & 19.9 & -143.240 & -24.49 & 11.35 & 4222396 & 0.271 \\
\hline & 5050 & 2312.34 & 2410.01 & 19.9 & -178.607 & -32.37 & 12.95 & 4488299 & 0.203 \\
\hline & 6020 & 2304.08 & 2412.29 & 19.9 & -212.914 & -40.63 & 15.23 & 4153361 & 0.276 \\
\hline & 5520 & 2307.98 & 2410.8 & 19.9 & -195.230 & -36.73 & 13.74 & 4534333 & 0.382 \\
\hline & 4510 & 2314.66 & 2409.54 & 19.9 & -159.509 & -30.05 & 12.48 & 5347526 & 0.189 \\
\hline & 3540 & 2323.22 & 2407.28 & 19.9 & -125.202 & -21.49 & 10.22 & 4007799 & 0.264 \\
\hline & 2530 & 2330.89 & 2406.11 & 19.9 & -89.481 & -13.82 & 9.05 & 4657298 & 0.153 \\
\hline & 1520 & 2339.02 & 2403.74 & 19.9 & -53.759 & -5.69 & 6.68 & 4393785 & 0.292 \\
\hline & 530 & 2346.68 & 2402.29 & 20 & -18.745 & 1.97 & 5.23 & 4571034 & 0.189 \\
\hline & 0 & 2351.04 & 2401.22 & 20 & 0.000 & 6.33 & 4.16 & 4299296 & 0.245 \\
\hline
\end{tabular}


Table A1-22 Modulus of Elasticity of Pour No. 3 at Day 1

\begin{tabular}{|c|c|c|c|c|c|c|c|c|c|}
\hline & $\begin{array}{l}\text { Load } \\
\text { (lbs) }\end{array}$ & $\begin{array}{c}\text { Vertical } \\
\text { Strain } \\
(\mu \varepsilon)\end{array}$ & $\begin{array}{c}\text { Horizontal } \\
\text { Strain } \\
(\mu \varepsilon)\end{array}$ & $\begin{array}{l}\text { Temp } \\
\left({ }^{\circ} \mathrm{C}\right) \\
\end{array}$ & $\begin{array}{c}\text { Stresses } \\
(P S I)\end{array}$ & $\begin{array}{c}\text { Differential } \\
\text { Vertical } \\
\text { Strain }(\mu \varepsilon)\end{array}$ & $\begin{array}{l}\text { Differential } \\
\text { Horizontal } \\
\text { Strain }(\mu \varepsilon)\end{array}$ & $\begin{array}{c}\text { Stress/Strain } \\
(P S I)\end{array}$ & $\begin{array}{c}\text { Hor/Vert. } \\
\text { Strain } \\
\text { ratio }\end{array}$ \\
\hline \multirow{13}{*}{ 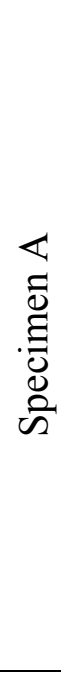 } & 0 & 2207.14 & 2773.01 & 21.9 & 0.000 & 0 & 0 & - & - \\
\hline & 1010 & 2197.01 & 2775.26 & 21.7 & -35.721 & -10.1 & 2.25 & 3526305 & 0.222 \\
\hline & 2000 & 2185.59 & 2777.78 & 21.7 & -70.736 & -21.5 & 4.77 & 3066035 & 0.221 \\
\hline & 2990 & 2174.79 & 2779.64 & 21.6 & -105.750 & -32.3 & 6.63 & 3242048 & 0.172 \\
\hline & 3990 & 2163.57 & 2782.02 & 21.5 & -141.118 & -43.6 & 9.01 & 3152210 & 0.212 \\
\hline & 5010 & 2152.46 & 2783.69 & 21.5 & -177.193 & -54.7 & 10.68 & 3247088 & 0.150 \\
\hline & 6000 & 2141.14 & 2786.16 & 21.5 & -212.207 & -66 & 13.15 & 3093120 & 0.218 \\
\hline & 5490 & 2145.39 & 2784.91 & 21.4 & -194.169 & -61.8 & 11.9 & 4244135 & 0.294 \\
\hline & 4520 & 2154.94 & 2783.29 & 21.4 & -159.862 & -52.2 & 10.28 & 3592331 & 0.170 \\
\hline & 3530 & 2165.3 & 2781.22 & 21.4 & -124.848 & -41.8 & 8.21 & 3379741 & 0.200 \\
\hline & 2520 & 2175.52 & 2779.81 & 21.3 & -89.127 & -31.6 & 6.8 & 3495252 & 0.138 \\
\hline & 1540 & 2187.11 & 2777.52 & 21.3 & -54.466 & -20 & 4.51 & 2990547 & 0.198 \\
\hline & 0 & 2207.14 & 2773.01 & 21.9 & 0.000 & 0 & 0 & - & - \\
\hline \multirow{13}{*}{ 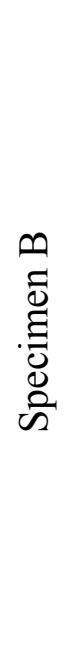 } & 0 & 2658.01 & 2667.85 & 21.2 & 0.000 & 0 & 0 & - & - \\
\hline & 1010 & 2648.66 & 2669.87 & 21.1 & -35.721 & -9.35 & 2.02 & 3820478 & 0.216 \\
\hline & 2010 & 2638.21 & 2672.41 & 21 & -71.089 & -19.8 & 4.56 & 3384478 & 0.243 \\
\hline & 3000 & 2628.3 & 2674.35 & 21 & -106.103 & -29.71 & 6.5 & 3533211 & 0.196 \\
\hline & 4000 & 2617.52 & 2676.62 & 21 & -141.471 & -40.49 & 8.77 & 3280872 & 0.211 \\
\hline & 5030 & 2606.25 & 2678.52 & 20.9 & -177.900 & -51.76 & 10.67 & 3232372 & 0.169 \\
\hline & 6010 & 2596.02 & 2680.76 & 21 & -212.560 & -61.99 & 12.91 & 3388117 & 0.219 \\
\hline & 5500 & 2600.75 & 2679.45 & 21 & -194.523 & -57.26 & 11.6 & 3813441 & 0.277 \\
\hline & 4500 & 2609.45 & 2678.06 & 20.9 & -159.155 & -48.56 & 10.21 & 4065264 & 0.160 \\
\hline & 3510 & 2619.94 & 2675.62 & 20.9 & -124.141 & -38.07 & 7.77 & 3337857 & 0.233 \\
\hline & 2520 & 2629.85 & 2674.13 & 20.9 & -89.127 & -28.16 & 6.28 & 3533211 & 0.150 \\
\hline & 1520 & 2640.76 & 2671.58 & 20.9 & -53.759 & -17.25 & 3.73 & 3241778 & 0.234 \\
\hline & 0 & 2658.01 & 2667.85 & 21.2 & 0.000 & 0 & 0 & - & - \\
\hline
\end{tabular}


Table A1-23 Modulus of Elasticity of Pour No. 3 at Day 2

\begin{tabular}{|c|c|c|c|c|c|c|c|c|c|}
\hline & $\begin{array}{l}\text { Load } \\
\text { (lbs) }\end{array}$ & $\begin{array}{c}\text { Vertical } \\
\text { Strain } \\
(\mu \varepsilon)\end{array}$ & $\begin{array}{c}\text { Horizontal } \\
\text { Strain } \\
(\mu \varepsilon)\end{array}$ & $\begin{array}{l}\text { Temp } \\
\left({ }^{\circ} \mathrm{C}\right) \\
\end{array}$ & $\begin{array}{c}\text { Stresses } \\
(P S I) \\
\end{array}$ & $\begin{array}{c}\text { Differential } \\
\text { Vertical } \\
\text { Strain }(\mu \varepsilon)\end{array}$ & $\begin{array}{l}\text { Differential } \\
\text { Horizontal } \\
\text { Strain }(\mu \varepsilon) \\
\end{array}$ & $\begin{array}{c}\text { Stress/Strain } \\
(P S I)\end{array}$ & $\begin{array}{c}\text { Hor/Vert. } \\
\text { Strain } \\
\text { ratio }\end{array}$ \\
\hline \multirow{14}{*}{ 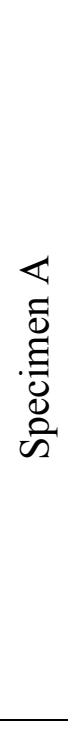 } & 0 & 2244.6 & 2785.71 & 20.2 & 0.000 & 0 & 0 & - & - \\
\hline & 1000 & 2236.21 & 2787.46 & 20.2 & -35.367 & -8.4 & 1.75 & 4215470 & 0.209 \\
\hline & 1990 & 2226.76 & 2789.8 & 20.2 & -70.382 & -17.8 & 4.09 & 3705198 & 0.248 \\
\hline & 3000 & 2218.24 & 2791.44 & 20.1 & -106.103 & -26.4 & 5.73 & 4192661 & 0.192 \\
\hline & 4000 & 2209.16 & 2793.57 & 20.1 & -141.471 & -35.4 & 7.86 & 3895132 & 0.235 \\
\hline & 4990 & 2200.68 & 2794.96 & 20.1 & -176.485 & -43.9 & 9.25 & 4129023 & 0.164 \\
\hline & 6010 & 2191.54 & 2797.21 & 20 & -212.560 & -53.1 & 11.5 & 3946953 & 0.246 \\
\hline & 5490 & 2195.54 & 2796.18 & 20 & -194.169 & -49.1 & 10.47 & 4597813 & 0.258 \\
\hline & 4520 & 2203.73 & 2795.02 & 20 & -159.862 & -40.9 & 9.31 & 4188860 & 0.142 \\
\hline & 3520 & 2212.87 & 2792.89 & 20 & -124.494 & -31.7 & 7.18 & 3869562 & 0.233 \\
\hline & 2530 & 2221.5 & 2791.85 & 19.9 & -89.481 & -23.1 & 6.14 & 4057256 & 0.121 \\
\hline & 1530 & 2231.06 & 2789.61 & 19.9 & -54.113 & -13.5 & 3.9 & 3699560 & 0.234 \\
\hline & 500 & 2240.67 & 2788.22 & 19.9 & -17.684 & -3.9 & 2.51 & 3790721 & 0.145 \\
\hline & 0 & 2246.12 & 2787.47 & 19.8 & 0.000 & 1.5 & 1.76 & 3244752 & 0.138 \\
\hline \multirow{14}{*}{ 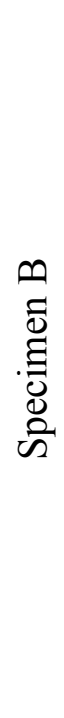 } & 0 & 2687.54 & 2672.94 & 19 & 0.000 & 0 & 0 & - & - \\
\hline & 1060 & 2677.26 & 2673.74 & 19.1 & -37.490 & -10.28 & 0.8 & 3646874 & 0.078 \\
\hline & 2010 & 2668.29 & 2675.79 & 19.2 & -71.089 & -19.25 & 2.85 & 3745753 & 0.229 \\
\hline & 3010 & 2659.19 & 2677.47 & 19.1 & -106.457 & -28.35 & 4.53 & 3886571 & 0.185 \\
\hline & 4050 & 2649.64 & 2679.69 & 19.1 & -143.239 & -37.9 & 6.75 & 3851571 & 0.232 \\
\hline & 5030 & 2640.64 & 2681.25 & 19.1 & -177.900 & -46.9 & 8.31 & 3851160 & 0.173 \\
\hline & 6050 & 2631.34 & 2683.56 & 19 & -213.975 & -56.2 & 10.62 & 3879048 & 0.248 \\
\hline & 5480 & 2635.73 & 2682.11 & 19 & -193.815 & -51.81 & 9.17 & 4592174 & 0.330 \\
\hline & 4530 & 2643.75 & 2680.75 & 19 & -160.216 & -43.79 & 7.81 & 4189452 & 0.170 \\
\hline & 3530 & 2652.81 & 2678.41 & 18.9 & -124.848 & -34.73 & 5.47 & 3903730 & 0.258 \\
\hline & 2520 & 2661.31 & 2677.11 & 18.9 & -89.127 & -26.23 & 4.17 & 4202526 & 0.153 \\
\hline & 1540 & 2670.96 & 2674.95 & 18.9 & -54.466 & -16.58 & 2.01 & 3591755 & 0.224 \\
\hline & 520 & 2679.91 & 2673.51 & 18.9 & -18.391 & -7.63 & 0.57 & 4030743 & 0.161 \\
\hline & 0 & 2685.11 & 2672.4 & 18.8 & 0.000 & -2.43 & -0.54 & 3536780 & 0.213 \\
\hline
\end{tabular}


Table A1-24 Modulus of Elasticity of Pour No. 3 at Day 3

\begin{tabular}{|c|c|c|c|c|c|c|c|c|c|}
\hline & $\begin{array}{l}\text { Load } \\
\text { (lbs) }\end{array}$ & $\begin{array}{c}\text { Vertical } \\
\text { Strain } \\
(\mu \varepsilon)\end{array}$ & $\begin{array}{c}\text { Horizontal } \\
\text { Strain } \\
(\mu \varepsilon)\end{array}$ & $\begin{array}{l}\text { Temp } \\
\left({ }^{\circ} \mathrm{C}\right) \\
\end{array}$ & $\begin{array}{c}\text { Stresses } \\
(P S I) \\
\end{array}$ & $\begin{array}{c}\text { Differential } \\
\text { Vertical } \\
\text { Strain }(\mu \varepsilon)\end{array}$ & $\begin{array}{l}\text { Differential } \\
\text { Horizontal } \\
\text { Strain }(\mu \varepsilon) \\
\end{array}$ & $\begin{array}{c}\text { Stress/Strain } \\
(P S I)\end{array}$ & $\begin{array}{c}\text { Hor/Vert. } \\
\text { Strain } \\
\text { ratio }\end{array}$ \\
\hline \multirow{14}{*}{ 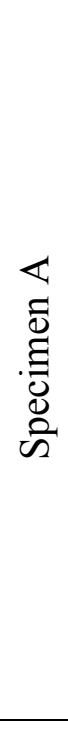 } & 0 & 2244.98 & 2783.5 & 20.3 & 0.000 & 0 & 0 & - & - \\
\hline & 1010 & 2236.81 & 2784.64 & 20.1 & -35.721 & -8.2 & 1.14 & 4372273 & 0.140 \\
\hline & 1990 & 2227.52 & 2788.28 & 20 & -70.382 & -17.5 & 4.78 & 3730941 & 0.392 \\
\hline & 3010 & 2219.8 & 2789.91 & 19.9 & -106.457 & -25.2 & 6.41 & 4672947 & 0.211 \\
\hline & 4000 & 2210.54 & 2792.27 & 19.9 & -141.471 & -34.4 & 8.77 & 3781222 & 0.255 \\
\hline & 5010 & 2202.02 & 2793.96 & 19.9 & -177.192 & -43 & 10.46 & 4192661 & 0.198 \\
\hline & 5990 & 2192.54 & 2796.2 & 19.8 & -211.853 & -52.4 & 12.7 & 3656164 & 0.236 \\
\hline & 5490 & 2196.53 & 2795.21 & 19.8 & -194.169 & -48.4 & 11.71 & 4432055 & 0.248 \\
\hline & 4510 & 2204.86 & 2794.1 & 19.8 & -159.508 & -40.1 & 10.6 & 4160917 & 0.133 \\
\hline & 3530 & 2214.3 & 2792.04 & 19.8 & -124.848 & -30.7 & 8.54 & 3671657 & 0.218 \\
\hline & 2520 & 2223.02 & 2790.72 & 19.7 & -89.127 & -22 & 7.22 & 4096499 & 0.151 \\
\hline & 1520 & 2232.84 & 2788.56 & 19.7 & -53.759 & -12.1 & 5.06 & 3601608 & 0.220 \\
\hline & 530 & 2241.97 & 2787.15 & 19.7 & -18.745 & -3 & 3.65 & 3835062 & 0.154 \\
\hline & 0 & 2247.67 & 2786.08 & 19.7 & 0.000 & 2.7 & 2.58 & 3288584 & 0.188 \\
\hline \multirow{14}{*}{ 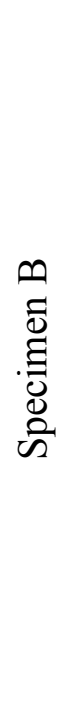 } & 0 & 2684.81 & 2668.14 & 19 & 0.000 & 0 & 0 & - & - \\
\hline & 1010 & 2675.74 & 2669.64 & 19.5 & -35.721 & -9.07 & 1.5 & 3938420 & 0.165 \\
\hline & 2000 & 2667.75 & 2671.43 & 19.5 & -70.736 & -17.06 & 3.29 & 4382242 & 0.224 \\
\hline & 3010 & 2658.98 & 2673.77 & 19.4 & -106.457 & -25.83 & 5.63 & 4073144 & 0.267 \\
\hline & 4010 & 2651 & 2675.32 & 19.4 & -141.824 & -33.81 & 7.18 & 4432055 & 0.194 \\
\hline & 5010 & 2642.44 & 2677.55 & 19.4 & -177.192 & -42.37 & 9.41 & 4131752 & 0.261 \\
\hline & 6050 & 2633.68 & 2679.07 & 19.4 & -213.975 & -51.13 & 10.93 & 4198916 & 0.174 \\
\hline & 5490 & 2637.53 & 2678.48 & 19.4 & -194.169 & -47.28 & 10.34 & 5144407 & 0.153 \\
\hline & 4490 & 2646.06 & 2676.44 & 19.4 & -158.801 & -38.75 & 8.3 & 4146283 & 0.239 \\
\hline & 3500 & 2654.06 & 2675.05 & 19.4 & -123.787 & -30.75 & 6.91 & 4376765 & 0.174 \\
\hline & 2530 & 2662.61 & 2673.07 & 19.3 & -89.481 & -22.2 & 4.93 & 4012487 & 0.232 \\
\hline & 1520 & 2671.01 & 2671.62 & 19.3 & -53.759 & -13.8 & 3.48 & 4252556 & 0.173 \\
\hline & 530 & 2679.93 & 2669.75 & 19.3 & -18.745 & -4.88 & 1.61 & 3925349 & 0.210 \\
\hline & 0 & 2683.98 & 2669.27 & 19.2 & 0.000 & -0.83 & 1.13 & 4628378 & 0.119 \\
\hline
\end{tabular}


Table A1-25 Modulus of Elasticity of Pour No. 3 at Day 7

\begin{tabular}{|c|c|c|c|c|c|c|c|c|c|}
\hline & $\begin{array}{l}\text { Load } \\
\text { (lbs) }\end{array}$ & $\begin{array}{c}\text { Vertical } \\
\text { Strain } \\
(\mu \varepsilon)\end{array}$ & $\begin{array}{c}\text { Horizontal } \\
\text { Strain } \\
(\mu \varepsilon)\end{array}$ & $\begin{array}{l}\text { Temp } \\
\left({ }^{\circ} \mathrm{C}\right) \\
\end{array}$ & $\begin{array}{c}\text { Stresses } \\
(P S I) \\
\end{array}$ & $\begin{array}{c}\text { Differential } \\
\text { Vertical } \\
\text { Strain }(\mu \varepsilon)\end{array}$ & $\begin{array}{l}\text { Differential } \\
\text { Horizontal } \\
\text { Strain }(\mu \varepsilon) \\
\end{array}$ & $\begin{array}{c}\text { Stress/Strain } \\
(P S I)\end{array}$ & $\begin{array}{c}\text { Hor/Vert. } \\
\text { Strain } \\
\text { ratio }\end{array}$ \\
\hline \multirow{14}{*}{ 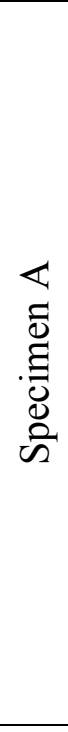 } & 0 & 2234.52 & 2778.15 & 21.7 & 0.000 & 0 & 0 & - & - \\
\hline & 1000 & 2226.01 & 2779.84 & 21.7 & -35.368 & -8.5 & 1.69 & 4156028 & 0.199 \\
\hline & 2010 & 2216.59 & 2781.38 & 21.7 & -71.089 & -17.9 & 3.23 & 3792088 & 0.163 \\
\hline & 3020 & 2208.09 & 2782.82 & 21.7 & -106.810 & -26.4 & 4.67 & 4202526 & 0.169 \\
\hline & 4010 & 2199.97 & 2784.69 & 21.8 & -141.824 & -34.6 & 6.54 & 4312083 & 0.230 \\
\hline & 5000 & 2190.45 & 2786.18 & 21.8 & -176.839 & -44.1 & 8.03 & 3677953 & 0.157 \\
\hline & 6060 & 2181.03 & 2787.78 & 21.8 & -214.328 & -53.5 & 9.63 & 3979816 & 0.170 \\
\hline & 5510 & 2185.19 & 2786.58 & 21.8 & -194.876 & -49.3 & 8.43 & 4676031 & 0.288 \\
\hline & 4520 & 2192.63 & 2785.27 & 21.8 & -159.862 & -41.9 & 7.12 & 4706199 & 0.176 \\
\hline & 3530 & 2200.89 & 2783.29 & 21.8 & -124.848 & -33.6 & 5.14 & 4238997 & 0.240 \\
\hline & 2520 & 2208.87 & 2782 & 21.8 & -89.127 & -25.7 & 3.85 & 4476375 & 0.162 \\
\hline & 1540 & 2217.76 & 2779.78 & 21.8 & -54.466 & -16.8 & 1.63 & 3898812 & 0.250 \\
\hline & 530 & 2226.29 & 2778.2 & 21.8 & -18.745 & -8.2 & 0.05 & 4187746 & 0.185 \\
\hline & 0 & 2231.15 & 2777.27 & 21.8 & 0.000 & -3.4 & -0.88 & 3856982 & 0.191 \\
\hline \multirow{14}{*}{ 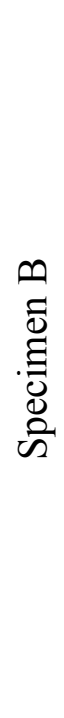 } & 0 & 2687.4 & 2665.13 & 19 & 0.000 & 0 & 0 & - & - \\
\hline & 1010 & 2679.46 & 2666.61 & 18.9 & -35.721 & -7.94 & 1.48 & 4498926 & 0.186 \\
\hline & 2000 & 2671.25 & 2668.65 & 19.3 & -70.736 & -16.15 & 3.52 & 4264813 & 0.248 \\
\hline & 3020 & 2663.21 & 2670.24 & 19.4 & -106.810 & -24.19 & 5.11 & 4486959 & 0.198 \\
\hline & 4010 & 2654.98 & 2672.17 & 19.3 & -141.824 & -32.42 & 7.04 & 4254449 & 0.235 \\
\hline & 5020 & 2647.18 & 2673.67 & 19.2 & -177.546 & -40.22 & 8.54 & 4579676 & 0.192 \\
\hline & 6020 & 2639.14 & 2675.45 & 19.5 & -212.914 & -48.26 & 10.32 & 4398979 & 0.221 \\
\hline & 5510 & 2642.37 & 2675.02 & 19.6 & -194.876 & -45.03 & 9.89 & 5584389 & 0.133 \\
\hline & 4500 & 2650.06 & 2672.9 & 19.9 & -159.155 & -37.34 & 7.77 & 4645185 & 0.276 \\
\hline & 3510 & 2657.46 & 2671.43 & 20 & -124.141 & -29.94 & 6.3 & 4731637 & 0.199 \\
\hline & 2510 & 2665.57 & 2669.34 & 20.1 & -88.773 & -21.83 & 4.21 & 4361010 & 0.258 \\
\hline & 1540 & 2673.23 & 2668.01 & 20 & -54.466 & -14.17 & 2.88 & 4478689 & 0.174 \\
\hline & 510 & 2682.02 & 2665.78 & 20.2 & -18.038 & -5.38 & 0.65 & 4144349 & 0.254 \\
\hline & 0 & 2685.68 & 2665.26 & 20.3 & 0.000 & -1.72 & 0.13 & 4928299 & 0.142 \\
\hline
\end{tabular}


Table A1-26 Modulus of Elasticity of Pour No. 3 at Day 14

\begin{tabular}{|c|c|c|c|c|c|c|c|c|c|}
\hline & $\begin{array}{l}\text { Load } \\
\text { (lbs) }\end{array}$ & $\begin{array}{c}\text { Vertical } \\
\text { Strain } \\
(\mu \varepsilon)\end{array}$ & $\begin{array}{c}\text { Horizontal } \\
\text { Strain } \\
(\mu \varepsilon)\end{array}$ & $\begin{array}{l}\text { Temp } \\
\left({ }^{\circ} \mathrm{C}\right) \\
\end{array}$ & $\begin{array}{c}\text { Stresses } \\
(P S I) \\
\end{array}$ & $\begin{array}{c}\text { Differential } \\
\text { Vertical } \\
\text { Strain }(\mu \varepsilon)\end{array}$ & $\begin{array}{l}\text { Differential } \\
\text { Horizontal } \\
\text { Strain }(\mu \varepsilon) \\
\end{array}$ & $\begin{array}{c}\text { Stress/Strain } \\
(P S I)\end{array}$ & $\begin{array}{c}\text { Hor/Vert. } \\
\text { Strain } \\
\text { ratio }\end{array}$ \\
\hline \multirow{14}{*}{ 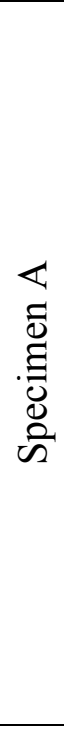 } & 0 & 2261.32 & 2785.72 & 20.6 & 0.000 & 0 & 0 & - & - \\
\hline & 1020 & 2253.47 & 2787.3 & 20.5 & -36.075 & 7.9 & 1.58 & 4595561 & 0.201 \\
\hline & 2000 & 2246.48 & 2789.17 & 20.4 & -70.736 & 14.8 & 3.45 & 4958575 & 0.268 \\
\hline & 3020 & 2240.79 & 2790.44 & 20.4 & -106.810 & 20.5 & 4.72 & 6340097 & 0.223 \\
\hline & 3990 & 2233.55 & 2792.43 & 20.3 & -141.117 & 27.8 & 6.71 & 4738503 & 0.275 \\
\hline & 5010 & 2226.86 & 2793.72 & 20.2 & -177.192 & 34.5 & 8 & 5392399 & 0.193 \\
\hline & 6000 & 2219.42 & 2795.47 & 20.2 & -212.206 & 41.9 & 9.75 & 4706199 & 0.235 \\
\hline & 5500 & 2223.49 & 2794.56 & 20.2 & -194.522 & 37.8 & 8.84 & 4344938 & 0.224 \\
\hline & 4500 & 2230.08 & 2793.57 & 20.1 & -159.155 & 31.2 & 7.85 & 5366888 & 0.150 \\
\hline & 3520 & 2237.56 & 2791.87 & 20.1 & -124.494 & 23.8 & 6.15 & 4633749 & 0.227 \\
\hline & 2520 & 2244.36 & 2790.86 & 20.1 & -89.127 & 17 & 5.14 & 5201146 & 0.149 \\
\hline & 1540 & 2252.02 & 2789.12 & 20 & -54.466 & 9.3 & 3.4 & 4524862 & 0.227 \\
\hline & 510 & 2259.3 & 2788.14 & 20 & -18.038 & 2 & 2.42 & 5003960 & 0.135 \\
\hline & 0 & 2264.11 & 2787.23 & 19.9 & 0.000 & -2.8 & 1.51 & 3750016 & 0.189 \\
\hline \multirow{14}{*}{ 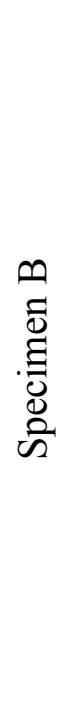 } & 0 & 2703.28 & 2678.21 & 16.1 & 0.000 & 0 & 0 & - & - \\
\hline & 980 & 2695.39 & 2679.49 & 16.6 & -34.660 & 7.89 & 1.28 & 4392958 & 0.162 \\
\hline & 2040 & 2687.62 & 2681.37 & 17.7 & -72.150 & 15.66 & 3.16 & 4824950 & 0.242 \\
\hline & 3000 & 2680.85 & 2682.81 & 18.4 & -106.103 & 22.43 & 4.6 & 5015226 & 0.213 \\
\hline & 4000 & 2673.2 & 2684.61 & 18.5 & -141.471 & 30.08 & 6.4 & 4623241 & 0.235 \\
\hline & 5000 & 2666.14 & 2686.02 & 18.6 & -176.839 & 37.14 & 7.81 & 5009603 & 0.200 \\
\hline & 6080 & 2657.85 & 2688.12 & 19 & -215.036 & 45.43 & 9.91 & 4607626 & 0.253 \\
\hline & 5530 & 2661.71 & 2686.92 & 19.2 & -195.583 & 41.57 & 8.71 & 5039453 & 0.311 \\
\hline & 4510 & 2668.32 & 2685.54 & 19 & -159.508 & 34.96 & 7.33 & 5457663 & 0.209 \\
\hline & 3510 & 2676.02 & 2683.57 & 19.2 & -124.141 & 27.26 & 5.36 & 4593220 & 0.256 \\
\hline & 2520 & 2682.2 & 2683.22 & 19.1 & -89.127 & 21.08 & 5.01 & 5665715 & 0.057 \\
\hline & 1520 & 2690.87 & 2680.34 & 19 & -53.759 & 12.41 & 2.13 & 4079330 & 0.332 \\
\hline & 560 & 2697.55 & 2679.02 & 19 & -19.806 & 5.73 & 0.81 & 5082797 & 0.198 \\
\hline & 0 & 2701.88 & 2677.93 & 18.8 & 0.000 & 1.4 & -0.28 & 4574126 & 0.252 \\
\hline
\end{tabular}


Table A1-27 Modulus of Elasticity of Pour No. 3 at Day 21

\begin{tabular}{|c|c|c|c|c|c|c|c|c|c|}
\hline & $\begin{array}{l}\text { Load } \\
\text { (lbs) }\end{array}$ & $\begin{array}{c}\text { Vertical } \\
\text { Strain } \\
(\mu \varepsilon)\end{array}$ & $\begin{array}{c}\text { Horizontal } \\
\text { Strain } \\
(\mu \varepsilon)\end{array}$ & $\begin{array}{l}\text { Temp } \\
\left({ }^{\circ} \mathrm{C}\right) \\
\end{array}$ & $\begin{array}{c}\text { Stresses } \\
(P S I) \\
\end{array}$ & $\begin{array}{c}\text { Differential } \\
\text { Vertical } \\
\text { Strain }(\mu \varepsilon)\end{array}$ & $\begin{array}{l}\text { Differential } \\
\text { Horizontal } \\
\text { Strain }(\mu \varepsilon) \\
\end{array}$ & $\begin{array}{c}\text { Stress/Strain } \\
(P S I)\end{array}$ & $\begin{array}{c}\text { Hor/Vert. } \\
\text { Strain } \\
\text { ratio }\end{array}$ \\
\hline \multirow{14}{*}{ 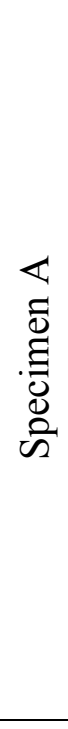 } & 0 & 2277.1 & 2795.41 & 21.6 & 0.000 & 0 & 0 & - & - \\
\hline & 1020 & 2268.63 & 2796.54 & 21.6 & -36.075 & -8.5 & 1.13 & 4259168 & 0.133 \\
\hline & 2030 & 2261.06 & 2798.42 & 21.7 & -71.797 & -16 & 3.01 & 4718821 & 0.248 \\
\hline & 3030 & 2254.43 & 2799.55 & 21.6 & -107.164 & -22.7 & 4.14 & 5334509 & 0.170 \\
\hline & 4020 & 2246.88 & 2801.36 & 21.5 & -142.178 & -30.2 & 5.95 & 4637631 & 0.240 \\
\hline & 5030 & 2240.36 & 2802.42 & 21.4 & -177.900 & -36.7 & 7.01 & 5478754 & 0.163 \\
\hline & 6040 & 2232.64 & 2804.2 & 21.6 & -213.621 & -44.5 & 8.79 & 4627134 & 0.231 \\
\hline & 5510 & 2236.48 & 2803.12 & 21.4 & -194.876 & -40.6 & 7.71 & 4881493 & 0.281 \\
\hline & 4520 & 2242.79 & 2802.3 & 21.3 & -159.862 & -34.3 & 6.89 & 5548988 & 0.130 \\
\hline & 3530 & 2250.02 & 2800.57 & 21.3 & -124.848 & -27.1 & 5.16 & 4842893 & 0.239 \\
\hline & 2520 & 2256.65 & 2799.71 & 21.3 & -89.127 & -20.4 & 4.3 & 5387854 & 0.130 \\
\hline & 1530 & 2264.23 & 2797.95 & 21.2 & -54.113 & -12.9 & 2.54 & 4619277 & 0.232 \\
\hline & 510 & 2271.58 & 2796.84 & 21.2 & -18.038 & -5.5 & 1.43 & 4908184 & 0.151 \\
\hline & 0 & 2276.34 & 2795.71 & 21.1 & 0.000 & -0.8 & 0.3 & 3789407 & 0.237 \\
\hline \multirow{14}{*}{ 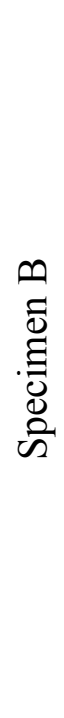 } & 0 & 2707.96 & 2696.59 & 17 & 0.000 & 0 & 0 & - & - \\
\hline & 1000 & 2701.02 & 2697.73 & 16.8 & -35.368 & -6.94 & 1.14 & 5096224 & 0.164 \\
\hline & 2030 & 2693.24 & 2699.69 & 17.4 & -71.797 & -14.72 & 3.1 & 4682369 & 0.252 \\
\hline & 3020 & 2686.08 & 2701.13 & 17.9 & -106.810 & -21.88 & 4.54 & 4890240 & 0.201 \\
\hline & 4030 & 2678.55 & 2702.71 & 18 & -142.532 & -29.41 & 6.12 & 4743888 & 0.210 \\
\hline & 5010 & 2670.87 & 2704.73 & 18.1 & -177.192 & -37.09 & 8.14 & 4513078 & 0.263 \\
\hline & 6030 & 2663.49 & 2706.13 & 18.2 & -213.267 & -44.47 & 9.54 & 4888232 & 0.190 \\
\hline & 5500 & 2666.57 & 2705.69 & 18.8 & -194.522 & -41.39 & 9.1 & 6086017 & 0.143 \\
\hline & 4520 & 2674.48 & 2703.86 & 19.1 & -159.862 & -33.48 & 7.27 & 4381851 & 0.231 \\
\hline & 3510 & 2681.26 & 2702.58 & 19.3 & -124.141 & -26.7 & 5.99 & 5268654 & 0.189 \\
\hline & 2520 & 2689.31 & 2700.61 & 19.3 & -89.127 & -18.65 & 4.02 & 4349580 & 0.245 \\
\hline & 1520 & 2696.32 & 2699.47 & 19.6 & -53.759 & -11.64 & 2.88 & 5045335 & 0.163 \\
\hline & 540 & 2704.01 & 2697.54 & 19.6 & -19.099 & -3.95 & 0.95 & 4507209 & 0.251 \\
\hline & 0 & 2707.92 & 2697.37 & 19.7 & 0.000 & -0.04 & 0.78 & 4884555 & 0.043 \\
\hline
\end{tabular}




\section{A1.4 Coefficient of Thermal Expansion Test Results}

Table A1-28 Coefficient of Thermal Expansion of Pour No. 2 after 7 Days

\begin{tabular}{|c|c|c|c|c|c|}
\hline & $\begin{array}{c}\text { Temp } \\
\left({ }^{\circ} \mathrm{C}\right) \\
\end{array}$ & $\begin{array}{c}\text { Vertical } \\
\text { Strain } \\
(\mu \varepsilon) \\
\end{array}$ & $\begin{array}{c}\text { Horizontal } \\
\text { Strain } \\
(\mu \varepsilon) \\
\end{array}$ & $\begin{array}{c}\text { Differential } \\
\text { Vertical } \\
\text { Strain }(\mu \varepsilon) \\
\end{array}$ & $\begin{array}{c}\text { Differential } \\
\text { Horizontal } \\
\text { Strain }(\mu \varepsilon) \\
\end{array}$ \\
\hline \multirow{11}{*}{ 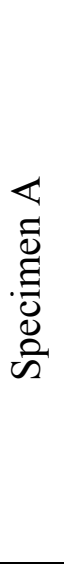 } & 20.7 & 2194.38 & 2529.01 & 0.00 & 0.00 \\
\hline & 21.1 & 2197.01 & 2528.56 & 7.51 & 4.43 \\
\hline & 21.9 & 2193.65 & 2527.04 & 13.91 & 12.67 \\
\hline & 22.5 & 2192.52 & 2525.73 & 20.10 & 18.68 \\
\hline & 23.0 & 2191.46 & 2524.46 & 25.14 & 23.51 \\
\hline & 23.6 & 2190.05 & 2522.72 & 31.05 & 29.09 \\
\hline & 24.2 & 2188.31 & 2521.08 & 36.63 & 34.77 \\
\hline & 24.9 & 2185.59 & 2518.54 & 42.45 & 40.77 \\
\hline & 26.0 & 2182.20 & 2515.34 & 52.48 & 50.99 \\
\hline & 26.8 & 2179.01 & 2512.34 & 59.05 & 57.75 \\
\hline & 27.4 & 2177.19 & 2510.84 & 64.55 & 63.57 \\
\hline \multirow{11}{*}{ 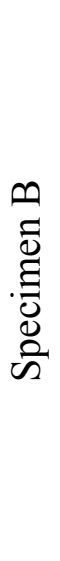 } & 20.6 & 2299.67 & 2357.53 & 0.00 & 0.00 \\
\hline & 21.4 & 2300.64 & 2357.06 & 10.73 & 9.29 \\
\hline & 22.3 & 2297.25 & 2354.87 & 18.32 & 18.08 \\
\hline & 23.0 & 2295.82 & 2353.45 & 25.43 & 25.20 \\
\hline & 23.5 & 2294.24 & 2352.04 & 29.95 & 29.89 \\
\hline & 24.2 & 2292.37 & 2350.31 & 36.62 & 36.70 \\
\hline & 24.9 & 2290.33 & 2348.38 & 43.12 & 43.31 \\
\hline & 25.8 & 2287.63 & 2345.57 & 51.40 & 51.48 \\
\hline & 27.0 & 2283.85 & 2342.26 & 62.26 & 62.81 \\
\hline & 27.9 & 2280.64 & 2339.35 & 70.03 & 70.88 \\
\hline & 28.5 & 2278.79 & 2337.75 & 75.50 & 76.60 \\
\hline
\end{tabular}


Table A1-29 Coefficient of Thermal Expansion of Pour No. 2 after 14 Days

\begin{tabular}{|c|c|c|c|c|c|}
\hline & $\begin{array}{c}\text { Temp } \\
\left({ }^{\circ} \mathrm{C}\right) \\
\end{array}$ & $\begin{array}{c}\text { Vertical } \\
\text { Strain } \\
(\mu \varepsilon) \\
\end{array}$ & $\begin{array}{c}\text { Horizontal } \\
\text { Strain } \\
(\mu \varepsilon) \\
\end{array}$ & $\begin{array}{c}\text { Differential } \\
\text { Vertical } \\
\text { Strain }(\mu \varepsilon) \\
\end{array}$ & $\begin{array}{l}\text { Differential } \\
\text { Horizontal } \\
\text { Strain }(\mu \varepsilon) \\
\end{array}$ \\
\hline \multirow{11}{*}{ 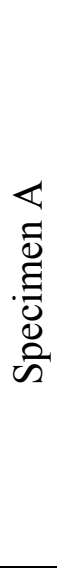 } & 20.9 & 2209.42 & 2539.92 & 0.00 & 0.00 \\
\hline & 21.4 & 2211.78 & 2539.34 & 8.46 & 5.52 \\
\hline & 21.8 & 2210.89 & 2538.52 & 12.45 & 9.58 \\
\hline & 22.7 & 2204.69 & 2535.61 & 17.23 & 17.65 \\
\hline & 23.3 & 2204.39 & 2533.99 & 24.25 & 23.35 \\
\hline & 23.6 & 2203.00 & 2532.69 & 26.52 & 25.71 \\
\hline & 24.3 & 2199.09 & 2530.79 & 31.15 & 32.35 \\
\hline & 24.7 & 2198.83 & 2529.66 & 35.77 & 36.10 \\
\hline & 25.4 & 2198.34 & 2527.33 & 43.82 & 42.31 \\
\hline & 27.4 & 2190.36 & 2520.10 & 60.24 & 59.48 \\
\hline & 28.1 & 2187.68 & 2517.34 & 66.10 & 65.26 \\
\hline \multirow{11}{*}{ 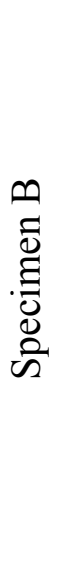 } & 20.8 & 2316.50 & 2369.33 & 0.00 & 0.00 \\
\hline & 21.4 & 2317.91 & 2368.86 & 8.73 & 6.85 \\
\hline & 22.0 & 2316.56 & 2367.18 & 14.70 & 12.49 \\
\hline & 23.0 & 2311.59 & 2364.37 & 21.93 & 21.88 \\
\hline & 23.8 & 2310.15 & 2362.52 & 30.25 & 29.79 \\
\hline & 24.1 & 2309.07 & 2361.36 & 32.83 & 32.29 \\
\hline & 24.6 & 2305.33 & 2359.19 & 35.19 & 36.22 \\
\hline & 25.0 & 2304.33 & 2358.01 & 39.07 & 39.92 \\
\hline & 26.0 & 2303.29 & 2355.54 & 50.23 & 49.65 \\
\hline & 28.9 & 2295.68 & 2348.55 & 78.00 & 78.04 \\
\hline & 29.2 & 2293.07 & 2346.00 & 79.05 & 79.15 \\
\hline
\end{tabular}


Table A1-30 Coefficient of Thermal Expansion of Pour No. 3 after 7 Days

\begin{tabular}{|c|c|c|c|c|c|}
\hline & $\begin{array}{c}\text { Temp } \\
\left({ }^{\circ} \mathrm{C}\right) \\
\end{array}$ & $\begin{array}{c}\text { Vertical } \\
\text { Strain } \\
(\mu \varepsilon) \\
\end{array}$ & $\begin{array}{c}\text { Horizontal } \\
\text { Strain } \\
(\mu \varepsilon) \\
\end{array}$ & $\begin{array}{c}\text { Differential } \\
\text { Vertical } \\
\text { Strain }(\mu \varepsilon) \\
\end{array}$ & $\begin{array}{c}\text { Differential } \\
\text { Horizontal } \\
\text { Strain }(\mu \varepsilon) \\
\end{array}$ \\
\hline \multirow{11}{*}{ 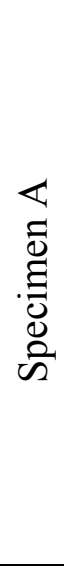 } & 21.1 & 2250.66 & - & 0.00 & - \\
\hline & 22.5 & 2252.90 & - & 63.00 & - \\
\hline & 23.4 & 2249.26 & - & 70.34 & - \\
\hline & 24.3 & 2242.00 & - & 74.06 & - \\
\hline & 25.2 & 2241.57 & - & 84.61 & - \\
\hline & 25.7 & 2238.77 & - & 87.91 & - \\
\hline & 26.0 & 2235.37 & - & 88.17 & - \\
\hline & 26.3 & 2234.82 & - & 91.28 & - \\
\hline & 27.9 & 2232.35 & - & 108.33 & - \\
\hline & 30.9 & 2220.73 & - & 133.31 & - \\
\hline & 31.7 & 2217.02 & - & 139.36 & - \\
\hline \multirow{11}{*}{ 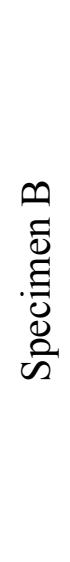 } & 20.9 & 2687.62 & 2666.34 & 0.00 & 0.00 \\
\hline & 21.8 & 2688.81 & 2665.60 & 12.17 & 10.24 \\
\hline & 22.5 & 2686.59 & 2664.03 & 18.49 & 17.21 \\
\hline & 23.1 & 2680.17 & 2660.66 & 19.39 & 21.16 \\
\hline & 24.2 & 2679.09 & 2658.55 & 31.73 & 32.47 \\
\hline & 24.3 & 2677.01 & 2657.25 & 30.87 & 32.39 \\
\hline & 24.7 & 2673.14 & 2655.66 & 31.88 & 35.68 \\
\hline & 25.4 & 2672.88 & 2654.08 & 40.16 & 42.64 \\
\hline & 26.4 & 2670.69 & 2651.00 & 50.17 & 51.76 \\
\hline & 29.0 & 2659.96 & 2641.93 & 71.16 & 74.41 \\
\hline & 29.7 & 2656.55 & 2639.48 & 76.29 & 80.50 \\
\hline
\end{tabular}


Table A1-31 Coefficient of Thermal Expansion of Pour No. 3 after 14 Days

\begin{tabular}{|c|c|c|c|c|c|}
\hline & $\begin{array}{c}\text { Temp } \\
\left({ }^{\circ} \mathrm{C}\right) \\
\end{array}$ & $\begin{array}{c}\text { Vertical } \\
\text { Strain } \\
(\mu \varepsilon) \\
\end{array}$ & $\begin{array}{c}\text { Horizontal } \\
\text { Strain } \\
(\mu \varepsilon) \\
\end{array}$ & $\begin{array}{c}\text { Differential } \\
\text { Vertical } \\
\text { Strain }(\mu \varepsilon) \\
\end{array}$ & $\begin{array}{l}\text { Differential } \\
\text { Horizontal } \\
\text { Strain }(\mu \varepsilon) \\
\end{array}$ \\
\hline \multirow{10}{*}{ 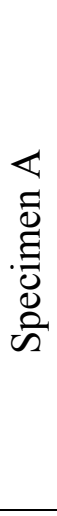 } & 20.8 & 2262.07 & 2786.29 & 0.00 & 0.00 \\
\hline & 21.1 & 2264.38 & 2785.59 & 5.97 & 2.96 \\
\hline & 21.4 & 2263.92 & 2785.07 & 9.17 & 6.10 \\
\hline & 21.9 & 2262.25 & 2783.56 & 13.60 & 10.69 \\
\hline & 22.8 & 2258.18 & 2780.55 & 20.51 & 18.66 \\
\hline & 23.3 & 2256.45 & 2778.83 & 24.88 & 23.04 \\
\hline & 24.2 & 2252.20 & 2775.03 & 31.61 & 30.22 \\
\hline & 25.2 & 2248.34 & 2771.35 & 39.95 & 38.74 \\
\hline & 26.2 & 2243.57 & 2767.37 & 47.38 & 46.96 \\
\hline & 27.0 & 2240.59 & 2764.63 & 54.16 & 53.98 \\
\hline \multirow{10}{*}{ 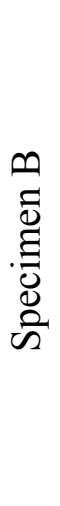 } & 20.7 & 2702.86 & 2677.94 & 0.00 & 0.00 \\
\hline & 21.8 & 2703.85 & 2676.00 & 14.41 & 11.48 \\
\hline & 22.2 & 2702.44 & 2675.05 & 17.88 & 15.41 \\
\hline & 23.4 & 2697.51 & 2671.45 & 27.59 & 26.45 \\
\hline & 24.6 & 2690.24 & 2666.62 & 34.96 & 36.26 \\
\hline & 25.4 & 2687.60 & 2664.36 & 42.08 & 43.76 \\
\hline & 26.9 & 2682.07 & 2659.71 & 54.85 & 57.41 \\
\hline & 28.1 & 2677.01 & 2655.36 & 64.43 & 67.70 \\
\hline & 29.5 & 2671.19 & 2650.72 & 75.69 & 80.14 \\
\hline & 30.0 & 2667.15 & 2647.75 & 77.75 & 83.27 \\
\hline
\end{tabular}

